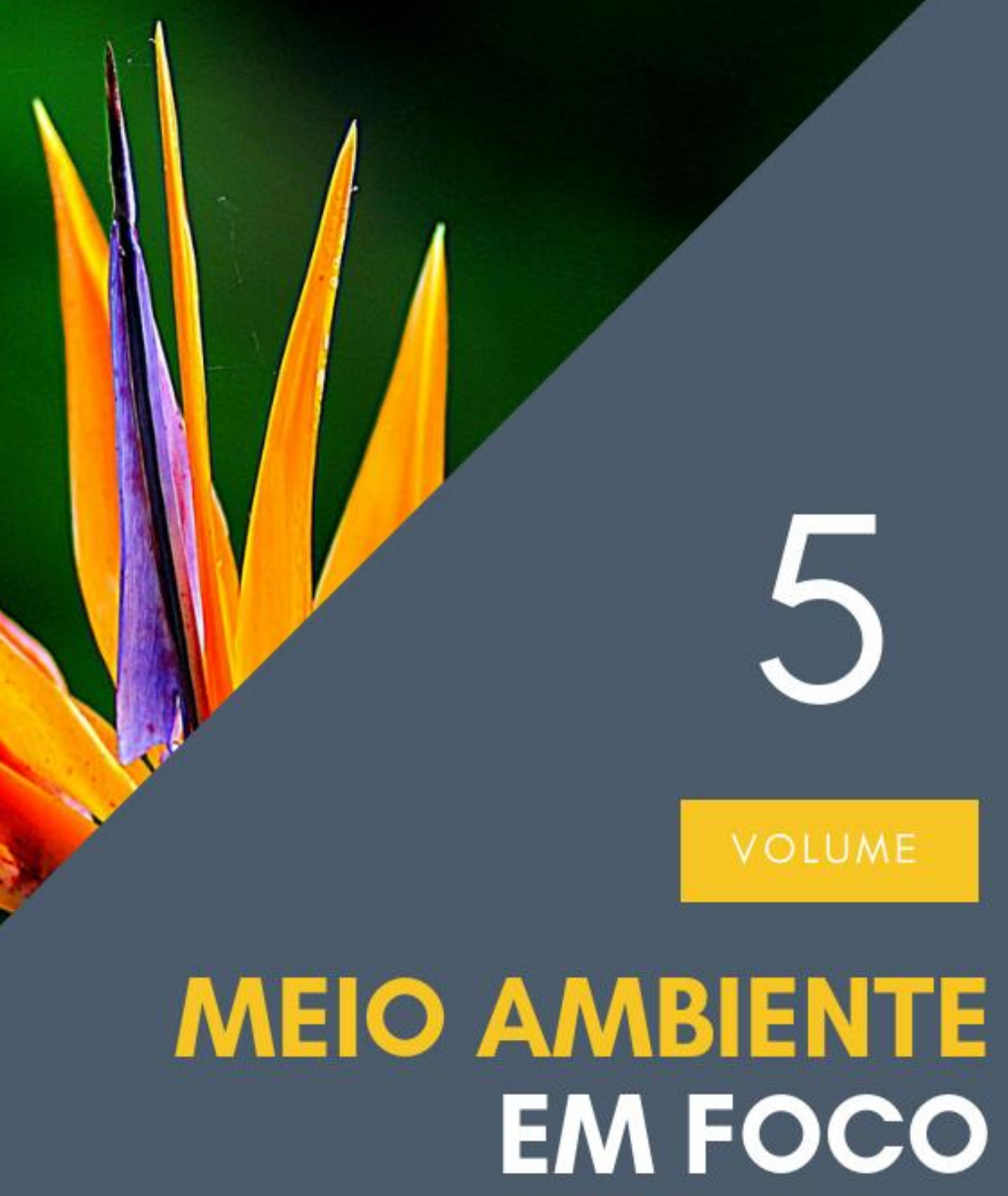

Fabiane dos Santos Toledo

(Organizadora)

Editora Poisson

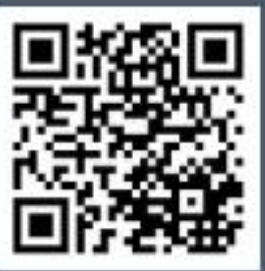


Editora Poisson

\title{
Meio Ambiente em Foco Volume 5
}

\author{
1a Edição
}

Belo Horizonte

Poisson

2019 
Editor Chefe: Dr. Darly Fernando Andrade

\section{Conselho Editorial}

Dr. Antônio Artur de Souza - Universidade Federal de Minas Gerais

Ms. Davilson Eduardo Andrade

Dr. José Eduardo Ferreira Lopes - Universidade Federal de Uberlândia

Dr. Otaviano Francisco Neves - Pontifícia Universidade Católica de Minas Gerais

Dr. Luiz Cláudio de Lima - Universidade FUMEC

Dr. Nelson Ferreira Filho - Faculdades Kennedy

Ms. Valdiney Alves de Oliveira - Universidade Federal de Uberlândia

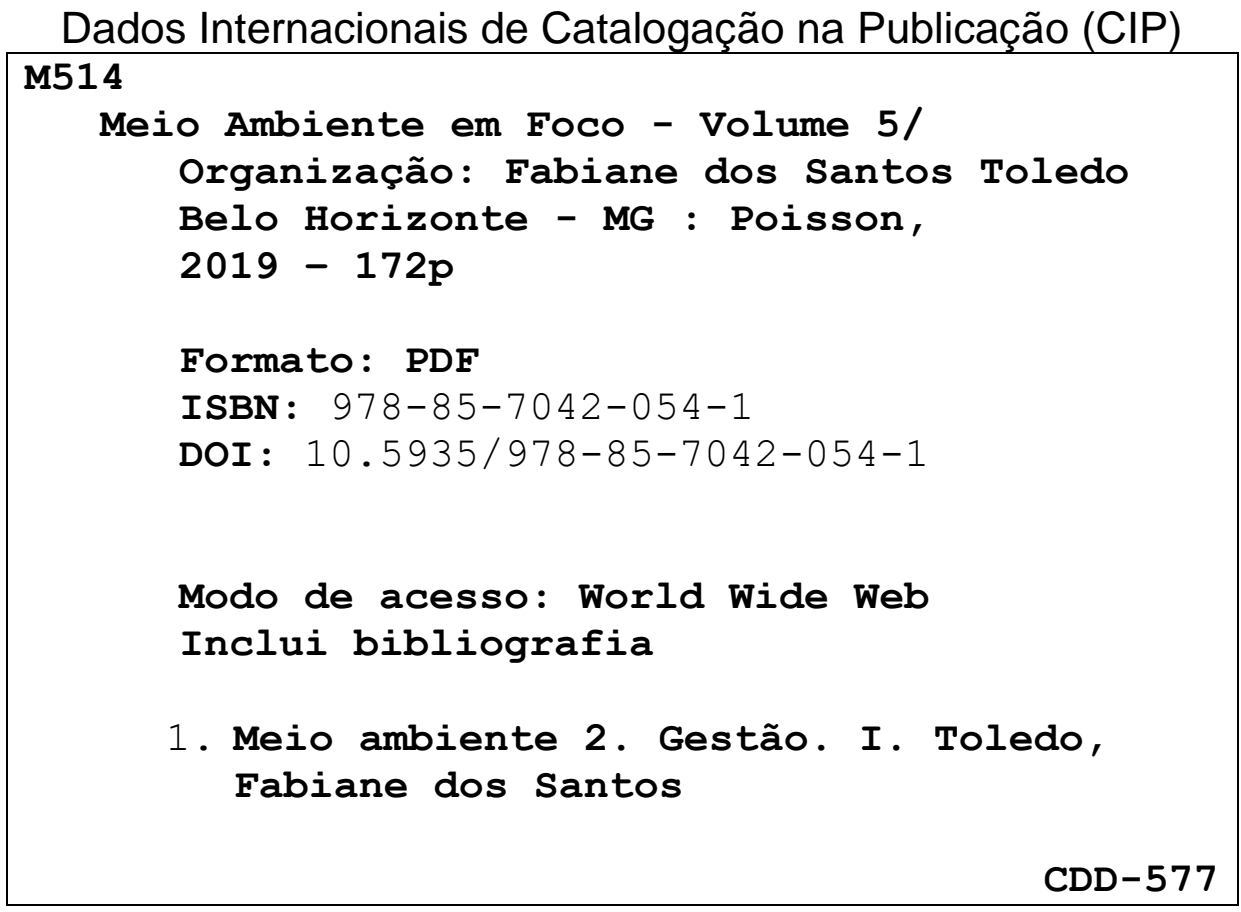

O conteúdo dos artigos e seus dados em sua forma, correção e confiabilidade são de responsabilidade exclusiva dos seus respectivos autores.

Baixe outros títulos gratuitamente em www.poisson.com.br 


\section{APRESENTAÇÃO}

Há uma exigência imperiosa em ligarmos as relações humanas com as bases da sustentabilidade para a vida em nosso planeta. Ressignificar, no sentido de atribuir o que se conhece à nossa visão sobre o meio do qual somos integrantes, é um dos caminhos para a percepção ambiental mais eficiente e ativa em prol da educação e da qualidade de vida que constitui a essência de qualquer ser vivo. Para tal, requer-se mudar as perspectivas e alterar os resultados, além das escolhas e dos comportamentos.

Formar entendimento e conectar o ser humano com o meio ambiente apazigua e restaura os valores, as escolhas e as atitudes ambientais, transformando a sociedade e a cultura além das necessidades. É com esse viés que se pode chegar à tomada de consciência e às mudanças significativas.

Ao ampliarmos os conhecimentos e levá-los adiante cumprimos com o desafio de coordenar a riqueza ambiental do país de forma mais equitativa e descentralizada, assegurando a reflexão e o debate com justiça socioambiental. Desenvolvendo, portanto, a clareza do papel de cada um nesse processo.

Alinhar ao que o caro leitor espera, surpreendê-lo e estimulá-lo a compartilhar com o maior número de pessoas, desde estudantes, profissionais, a tomadores de decisões, se propaga nas próximas páginas, recheadas de bons conteúdos, comprometimento dos autores e amplas vias de conhecimento.

Aproveite a leitura!

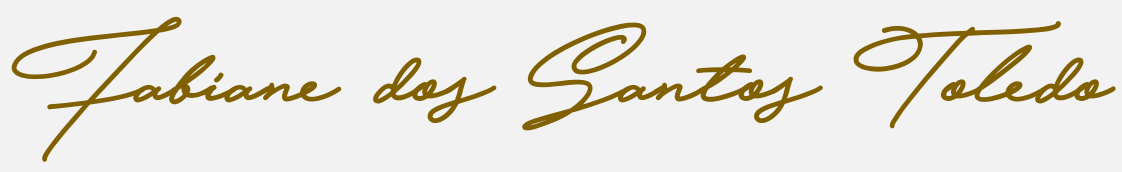




\section{SUMÁRIO}

Capítulo 1: Plantas medicinais na amazônia: Um diagnóstico da produção científica

Dayanne de Souza Carvalho, Tyfanne Verônica Leão Garcia, Janaína Paolucci Sales de Lima, Douglas Willian Nogueira de Souza, Marcos André Braz Vaz

Capítulo 2: Etnobotânica de plantas medicinais em quintais urbanos na cidade de Manaus 13

Helena Carolina Alves Barreto, Larissa Carvalho Gato, Dayanne de Souza Carvalho, Ísis Ribeiro do Nascimento, Janaína Paolucci Sales de Lima

Capítulo 3: Crescimento inicial de mudas de acacia negra (Acacia mearnsii de wild) sob omissão de micronutrientes 22

Elias de Sá Farias, Nelson Venturin, Diana Suzete Nunes da Silva, Paloma Carvalho Diniz , Katya Kavuya Jeannot, João Faustino Munguambe

Capítulo 4: Potencial fungitóxico do óleo essencial de Rosmarinus officinalis no controle do aspergillus flavus.

Lundoi Tobias Lee, Ana Paula Martinazzo, Carlos Eduardo de Souza Teodoro, Sabrinna Aires Garcia, Ronald de Oliveira Rodrigues Junior

Capítulo 5: Esporos de fungos micorrízicos arbusculares em lavouras de cafeeiros (coffea canephora L.) no estado de Rôndonia. 32

Marta de Souza da Silva, Franklin dos Santos Amaral, Ana Lucy Caproni, Gabriel Cestari Vilardi, José Rodolfo Dantas de Oliveira Granha, Ricardo Luis Louro Berbara

Capítulo 6: Fungos micorrizicos arbusculares em floresta nativa, cerrado e pastagem no município de Guajará-Mirim/RO como bioindicador de estabilidade.

Thais Ponhês dos Santos, Wesley de Paulo Morais, Ana Lucy Caproni , Ricardo Luis Louro Berbara, José Rodolfo Dantas de Oliveira Granha

Capítulo 7: Interferência da aplicação de mordentes na impressão botânica de tecidos de seda.

Carolina Bittencourt de Souza dos Santos, Doralice de Souza Luro Balan

Capítulo 8: Produção de mudas de seringueira para viveiros comerciais 60

Rafaella Gouveia Mendes, Amanda Fialho, Josef Gastl Filho, Rosenvaldo da Silva Araujo, Danylla Paula de Menezes, Pedro Henrique de Freitas Deliberto Ferreira 


\section{SUMÁRIO}

Capítulo 9: A produção agrícola-energética e seu impacto no meio ambiente ... 67 Ronaldo Alberto Pollo, Gabriel Rondina Pupo da Silveira, Lincoln Gehring Cardoso, Sérgio Campos

Capítulo 10: Potencial de uma área municipal para integração ao sistema nacional de unidades de conservação: Uma análise da legislação

Fabricio Camillo Sperandio, Felipe Hashimoto Fengler Gerson Araújo de Medeiros' Admilson Írio Ribeiro' Mauricio José Borges, Giovanna Frederici de Mello, Sabrina Pasetto, Naiara Torres dos Santos

Capítulo 11: Turismo sustentável no uso das águas termais - Barra do Garças (MT) - Brasil

Rildo Vieira de Araújo, Ana Cristina de Almeida Ribeiro, Andreza da Silva Melo, Reginaldo Brito da Costa

Capítulo 12: Disposição a pagar pela conservação de unidades de conservação: Um estudo de caso no município de Presidente Figueiredo/AM 80

Andreia Oliveira dos Santos, Elane Conceição de Oliveira

Capítulo 13: Programa bolsa verde e inclusão: A experiência das famílias agroextrativistas na Resex Médio Purus, Lábrea (AM)

Silvânia Queiroz e Silva, Elenise Faria Scherer

Capítulo 14: Observatório da educação do campo no Alto Solimões - OBECAS: da implementação aos primeiros resultados. 107

Jarliane da Silva Ferreira, Maria Auxiliadora dos Santos Coelho

Capítulo15: Educação ambiental e sustentabilidade: Oficinas de produção de materiais decorativos para a biblioteca Maria Gabriela Pacheco Pardey

Maraína Souza Medeiros, Pedro Henrique Pereira e Moreira, Rosiane Gonçalves de Lima, Patrícia Michele Ribeiro

Capítulo 16: Educação ambiental e a sustentabilidade dos recursos hídricos ... 123 Roberta Borges de Medeiros Falcão, Patrícia Freire Chagas, Cinthya Antonia Vieira Gurgel

Capítulo 17: Educador ambiental e sua formação profissional 129

Debora Regina Marochi de Oliveira, Terezinha Corrêa Lindino 


\section{SUMÁRIO}

Capítulo 18: Aspectos legais para uma Educação Ambiental: Pensando uma extensão com as escolas de Cláudio-MG.

Frederico Cordeiro Martins, Jairo Barduni Filho, Márcio Pereira

Capítulo 19: A efetivação da educação ambiental critica no ensino superior, ministrado na modalidade à distância

Leandro Costa Fávaro, Sérgio Ricardo Magalhães, Letícia Rodrigues da Fonseca

Capítulo 20: Educação ambiental na escola: Conceitos e práticas lúdicas e uso do aplicativo Plasticbank.

Gregorio Augusto Marciaga Teófilo, Juan Franc's Lima de Moura, Gesiane Oliveira da Trindade

Capítulo 21: Espaços educacionais sustentáveis

Jaqueline Fernanda Meireles, Terezinha Corrêa Lindino

Autores: 


\title{
Capítulo 1
}

\section{PLANTAS MEDICINAIS DIAGNÓSTICO DA PRODUÇÃO CIENTÍFICA}

\author{
Dayanne de Souza Carvalho \\ Tyfanne Verônica Leão Garcia \\ Janaína Paolucci Sales de Lima \\ Douglas Willian Nogueira de Souza \\ Marcos André Braz Vaz
}

Resumo: Na Amazônia, as plantas medicinais são uma das principais formas para o tratamento de diversas doenças, tendo em vista o contexto cultural, a falta de proximidade com locais onde existe atendimento médico, baixo custo em relação aos medicamentos industrializados e confiabilidade. O presente artigo tem como objetivo realizar uma análise da produção científica sobre plantas medicinais na Amazônia, utilizando a base de dados SCIELO. Foi realizado um levantamento bibliográfico, visando a obtenção de artigos científicos e de revisão. Para a análise dos dados utilizou-se a estatística descritiva, onde os dados foram tabulados, sendo feita também a plotação de gráficos. Com base nos resultados, percebeu-se que o ano de 2014 foi o que apresentou maior quantidade de publicações, sendo que a Revista Brasileira de Plantas Medicinais teve destaque por conter 13 dos 31 artigos analisados. Houve um aumento no número de publicações no período de 1997 a 2017. A maior parte destas abrange a etnobotânica e foram desenvolvidas na zona urbana. Além disso, Asteraceae e Lamiaceae foram as famílias que se destacaram e a área de estudo onde a maioria dos trabalhos foram desenvolvidos foi o estado do Amazonas. O crescimento do número de publicações se deve ao aumento da procura por plantas medicinais, em virtude, por exemplo, do fato de que a maioria da população utilize as espécies medicinais como única alternativa de recursos terapêuticos, e também da obtenção de informações para a elaboração de estudos químicos e farmacológicos. Sendo assim, este crescimento na produção científica denota grande interesse por plantas medicinais, dado que apresentam relevância nos contextos social, econômico, ambiental e cultural.

Palavras Chave: flora medicinal, saber tradicional, estatística descritiva.

${ }^{*} \mathrm{O}$ artigo foi apresentado no V Seminário Internacional em Ciências do Ambiente e Sustentabilidade na Amazônia 


\section{INTRODUÇÃO}

Planta medicinal é definida como "espécie vegetal, cultivada ou não, utilizada com propósitos terapêuticos" (BRASIL, 2014). O conhecimento do homem acerca dos benefícios das plantas origina-se simultaneamente com sua história. Surgiu conforme tentava suprir suas necessidades básicas, por meio de observações, casualidades e tentativas. Havia uma dependência do homem primitivo em relação à natureza, visando sua sobrevivência, de modo que usou especialmente as plantas medicinais para obter cura. Acredita-se que o registro escrito pelo chinês Shen Numg seja o mais antigo, onde descreve a utilização de centenas de plantas medicinais na cura de diversas enfermidades (ALMEIDA, 2011).

A etnobotânica é a ciência que analisa e estuda as informações populares que o homem tem sobre o uso das plantas (VÁSQUEZ; MENDONÇA; NODA, 2014). Os estudos etnobotânicos mostram que as pessoas influenciam a estrutura de paisagens e comunidades vegetais, a biologia de determinadas populações de plantas que denotam importância, a evolução de espécies, não somente sob negativos aspectos como regularmente são atribuídos à intervenção do homem, mas propiciando benefícios e viabilizando os recursos manejados (ALBUQUERQUE; ANDRADE, 2002).

Atualmente, cerca de $80 \%$ da população utiliza recursos da medicina popular para tratamento de alguma doença, sendo que os conhecimentos das técnicas utilizadas e o emprego são transmitidos por gerações de forma oral (FIRMO et al., 2011). Devido tais informações serem preocupantes no meio científico, pois pouco se sabe sobre a confiabilidade e segurança da maioria das plantas medicinais, evidencia-se o aumento das pesquisas relacionadas à etnobotânica.

Os saberes da Amazônia, decorrentes de pescadores, seringueiros, caboclos, garimpeiros, indígenas, madeireiros, colonos, entre outros grupos, foram consolidados em suas práticas, com destaque para a utilização de "remédios do mato" como um dos aspectos culturais bastante notáveis (SANTOS, 2000).

Na região amazônica, as plantas medicinais constituem-se como um dos principais meios para o tratamento de diversas doenças, considerando o contexto cultural, a ausência de proximidade com locais onde há atendimento médico, o baixo custo comparado ao dos medicamentos sintéticos e a confiabilidade (FLOR; BARBOSA, 2015).

Diante do exposto, este trabalho objetivou analisar a produção científica acerca de plantas medicinais na Amazônia, utilizando como base de dados a SCIELO (Scientific Eletronic Library Online), visando um levantamento sobre tais perspectivas etnobotânicas em seus avanços referentes ao número de periódicos obtidos ao longo de vinte anos, para, destarte, comparar o crescimento e/ou diminuição de publicações voltadas a esse tema.

\section{METODOLOGIA}

Para o levantameto de dados utilizou-se a pesquisa bibliográfica, conforme Gil (2002, p. 44), a qual constitui-se como aquela "desenvolvida com base em material já elaborado, constituído principalmente de livros e artigos científicos."

As fontes bibliográficas foram artigos científicos de 1997 a 2017, incluindo artigos de revisão, a partir da base de dados SCIELO no mês de abril de 2018. Utilizou-se as seguintes palavras-chave: "plantas medicinais" e "Amazônia". É importante destacar que o acesso aos artigos científicos é gratuito e os dados coletados são de domínio público.

A Scientific Eletronic Library Online (SCIELO) consiste em uma biblioteca eletrônica produzida em parceria entre a Fundação de Amparo à Pesquisa do Estado de São Paulo (FAPESP) e o Centro Latino-Americano e do Caribe de Informação em Ciências da Saúde (BIREME) (HAYASHI et al., 2008).

Criada em 1998, apresenta como característica o fato de possuir uma coleção multidisciplinar de revistas científicas nacionais de 16 países (da América Latina, Caribe, África do Sul e Europa), sendo pioneira na admissão do acesso aberto. Tem apoio do Centro Latino-Americano e do Caribe de Informação em Ciências da Saúde (BIREME) e do Conselho Nacional de Desenvolvimento Científico e Tecnológico (CNPq). Até o final de 2013, a SCIELO detinha mais de mil periódicos em sua coleção, com aproximadamente quinhentos mil artigos publicados e, em 2012, possuiu uma média diária superior a 1,5 milhões de acessos (REGO, 2014). 
Com o intuito de delimitar e nortear o trabalho, foram determinadas as seguintes variáveis com base em estudo desenvolvido por Lisboa e Rodrigues (2017): nome do periódico, ano de publicação, famílias das espécies com maior destaque, abordagem sobre etnobotânica, área de estudo, incluindo zona urbana e/ou rural.

Posteriormente, a análise dos dados de cada variável foi feita através de estatística descritiva, sendo realizada a tabulação e organização destes em uma planilha do programa Excel versão 2016, além da plotação de gráficos. A estatística descritiva "se constitui num conjunto de técnicas que objetivam descrever, analisar e interpretar os dados numéricos de uma população ou amostra" (FONSECA; MARTINS, 2006).

\section{RESULTADOS E DISCUSSÃO}

Realizada a busca no banco de dados da SCIELO foram selecionados 31 artigos pertinentes à temática estudada no período de 20 anos. Entre estes, 15 publicações concentraram-se entre os anos de 2013 e
2017, representando a maior parte $(48 \%)$ dos trabalhos analisados (Figura 1).

Nesse período, a maior quantidade de publicações (6) foi observada no ano de 2014. Também percebeu-se que houve aumento na quantidade de publicações até 2017 em relação a 1997. Isso pode ser em função da ampliação do consumo de plantas medicinais, visto que a maior parte da população encontra como única fonte de recursos terapêuticos, produtos de origem vegetal, principalmente as espécies vegetais medicinais (MESSIAS et al., 2015). Além do mais, informações obtidas de comunidades que utilizam a flora medicinal são empregadas na formulação de hipóteses em relação às propriedades terapêuticas em estudos farmacológicos e químicos das espécies, onde o conhecimento popular acerca do manejo da flora é importante no desenvolvimento de estratégias conservacionistas quanto ao uso de tais recursos (ALBUQUERQUE; HANAZAKI, 2006).

Figura 1: Trabalhos publicados sobre plantas medicinais na Amazônia no período de 1997 a 2017.

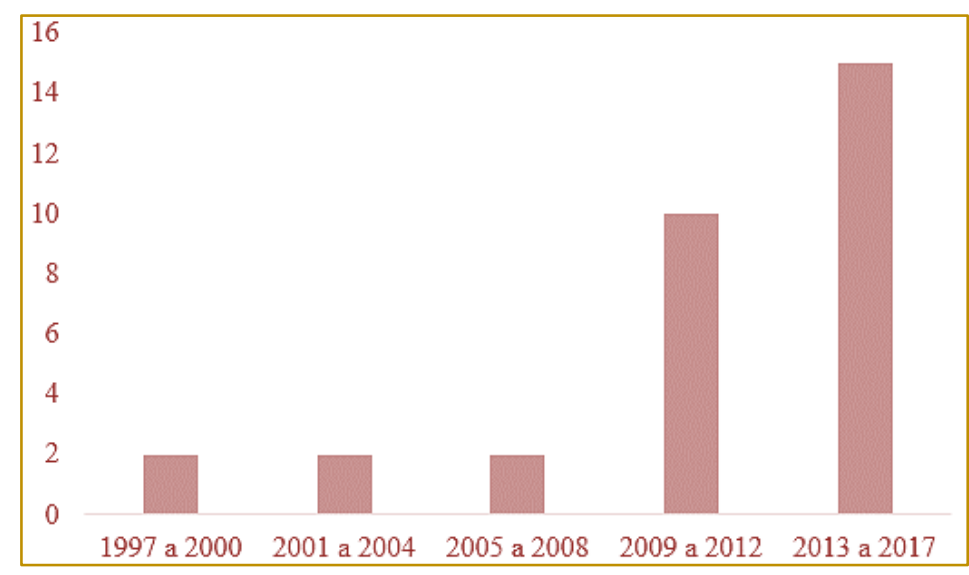

Entre os 10 periódicos que continham publicações acerca de plantas medicinais na Amazônia, a Revista Brasileira de Plantas Medicinais se destacou, com 13 publicações (42\%) (Tabela 1). O que corrobora com estudo desenvolvido por Lisboa e Rodrigues (2017), onde este periódico obteve maior quantidade de publicações.
Esta revista abrange de forma multidisciplinar as áreas: Conservação de Recursos Genéticos; Anatomia e Morfologia Vegetal; Biotecnologia; Ecofisiologia; Bioensaios; Etnofarmacologia; $\quad$ Farmacologia; Farmacognosia; Fitotecnia; Fisiologia Vegetal; Fitoterapia, Tecnologia de Alimentos e Uso de Plantas Medicinais na Medicina Veterinária; Fitoquímica e Etnobotânica. 
Tabela 1 - Periódicos das publicações analisadas no período de 20 anos.

\begin{tabular}{|c|c|c|}
\hline Nome do Periódico & Quantidade & $\%$ \\
\hline Acta Agronómica & 1 & 3 \\
\hline Acta Amazonica & 8 & 26 \\
\hline Acta Botanica Brasilica & 1 & 3 \\
\hline Anais da Academia Brasileira de Ciências & 2 & 6 \\
\hline Ciência Rural & 1 & 3 \\
\hline História, Ciências, Saúde-Manguinhos & 1 & 3 \\
\hline Horticultura Brasileira & 2 & 6 \\
\hline Mana & 1 & 3 \\
\hline Revista Brasileira de Farmacognosia & 1 & 3 \\
\hline Revista Brasileira de Plantas Medicinais & 13 & 42 \\
\hline Total & 31 & 100 \\
\hline
\end{tabular}

As famílias das espécies que obtiveram destaque nos artigos foram: Arecaceae, Euphorbiaceae, Meliaceae, Malpighiaceae, Amaranthaceae, Fabaceae, Aquifoliaceae, Poaceae, Zingiberaceae, Sterculiaceae, Myrtaceae, Crassulaceae, Caesalpiniaceae, Cucurbitaceae, Cyperaceae, Celastraceae, Verbenaceae, Malvaceae, Asphodelaceae, Apocynaceae, Araceae, Asteraceae, Lamiaceae, Bignoniaceae, Rubiaceae e Rutaceae, pertencentes à classe Magnoliopsida. Bem como Lauraceae, Annonaceae, Siparunaceae e Piperaceae, da classe Fanerógama e Liliaceae, pertencente à classe Liliopsida.

Dentre estas famílias, foi possível obeservar que duas se destacaram: Asteraceae e Lamiaceae, presentes em 5 artigos. De acordo com Moerman e Estabrook (2003), um dos motivos para tal destaque seria o fato de que estas duas famílias se encontram em quase todo o mundo. Apresentam espécies de grande adaptação, tanto em ambientes temperados como tropicais, sendo relevantes culturalmente.

Fora analisado se os trabalhos possuíam uma abordagem etnobotânica assim como quais se encontram em zonas rurais e/ou urbanas (Tabela 2). O estudo apresentou 19 artigos (61\%) abordando a etnobotânica, o que evidencia maior procura em compreender e interpretar o conhecimento, o contexto cultural, os usos e manejo tradicionais das plantas, especialmente, as medicinais (CABALLERO, 1979).

Além dos trabalhos identificados em tais zonas, foram obervadas duas publicações voltadas às terras indígenas. Percebeu-se que há mais trabalhos realizados na zona urbana, a saber, 18 publicações, cerca de $58 \%$ do total, o que demonstra que os quintais urbanos são um considerável banco de recursos genéticos de grande imprescindibilidade para a humanidade, contribuindo para a conservação da agrobiodiversidade (SIVIERO et al., 2012). Na zona urbana, também são encontrados mercados regionais e feiras, os quais trazem à tona aspectos e importância de vasto patrimônio etnobotânico (USTULIN et al., 2009). Alguns possuem caráter de revisão bibliográfica e foram categorizados como indefinidos (16\%).

Tabela 2 - Periódicos das publicações analisadas no período de 20 anos.

\begin{tabular}{|c|c|c|}
\hline Abordagem sobre etnobotânica & Quantidade & $\%$ \\
\hline Sim & 19 & 61 \\
\hline Não & 12 & 39 \\
\hline Zona urbana e/ou rural & Quantidade & $\%$ \\
\hline Indefinido & 5 & 16 \\
\hline Terra Indígena & 2 & 6 \\
\hline Zona rural & 6 & 19 \\
\hline Zona urbana & 18 & 58 \\
\hline
\end{tabular}

Em relação à área de estudo, foram encontradas pesquisas que correspondem aos estados do Acre, Amazonas, Maranhão, Mato Grosso, Pará, Rondônia e Roraima, assim como pesquisas nos seguintes países: Bolívia e Equador. Os trabalhos categorizados como indefinidos (5) não possuem área de 
estudo. O estado do Amazonas foi a área que prevaleceu, com 9 artigos.

\section{CONCLUSÕES}

O número de publicações com relação a estudos sobre plantas medicinais na região amazônica ampliou, o que denota o aumento do interesse por estas espécies vegetais, ao passo que apresentam relevância quanto aos

\section{REFERÊNCIAS}

[1] Albuquerque, U. P.; Andrade, L. H. C. Conhecimento botânico tradicional e conservação em uma área de Caatinga no estado de Pernambuco, nordeste do Brasil. Acta Botanica Brasilica, v. 16, n. 3, p. 273-285, 2002.

[2] Albuquerque, U. P.; Hanazaki, N. As pesquisas etnodirigidas na descoberta de novos fármacos de interesse médico e farmacêutico: fragilidades e perspectivas. Revista Brasileira de Farmacognosia, v. 16, p. 678-89, 2006.

[3] Almeida, M. Z. Plantas medicinais: abordagem histórico-contemporânea. In: Plantas medicinais. 3. ed. Salvador: Edufba, 2011. p. 34-66.

[4] Brasil. Ministério da Saúde. Anvisa. Resolução da Diretoria Colegiada - RDC n 26, de 13 de maio de 2014. Brasília: Anvisa, 2014. 34p.

[5] Caballero, J. La Etnobotânica. In: BARRERA, A. La Etnobotânica: tres puntos de vista y una perspectiva. Xalapa: INIREB, 1979. p. 27-30.

[6] Firmo, W. C. A; Menezes, V. J. M.; Passos, C. E. C.; Dias, C. N.; Alves, L. P. L.; Dias, I. C. L.; Neto, M. S.; Olea, R. S. G. Contexto histórico, uso popular e concepção científica sobre plantas medicinais. Caderno de Pesquisa, São Luís, v. 18, n. Especial, p. 90-95, 2011.

[7] Flor, A. S. S. O.; Barbosa, W. L. R. Sabedoria popular no uso de plantas medicinais pelos moradores do bairro do Sossego no distrito de Marudá - PA. Revista Brasileira de Plantas Medicinais, Campinas, v. 17, n. 4, p. 757-768, 2015.

[8] Fonseca, J. M.; Martins, G. A. Curso de Estatística. 6. ed. São Paulo: Atlas, 2006.

[9] Gil, A. C. Como elaborar projetos de pesquisa. 4aㅡ ed. São Paulo: Atlas, 2002.

[10] Hayashi, M. C. P. I.; Ferreira-JR, A.; Bitar, M.; Hayashi, C. R. M.; Silva, M. R. História da educação brasileira: A produção científica na biblioteca eletrônica Scielo. Educação \& Sociedade, v. 29, n. 102, p. 181-211, jan./abr. 2008. aspectos sociais, econômicos, ambientais e culturais.

A maioria dos artigos encontrados na base de dados da SCIELO aborda sobre etnobotânica, a qual possibilita verificar diferentes dimensões acerca da relação do homem com as plantas, como por exemplo, os saberes dos povos tradicionais voltados ao uso de espécies com finalidade terapêutica.

[11] Lisboa, R. S.; Rodrigues, F. M. Análise da produção científica sobre plantas medicinais. Estudos - Vida e Saúde (EVS), Goiânia, v. 44, n. 1, p. 8-14, 2017.

[12] Messias, M. C. T. B.; Menegatto, M. F.; Prado, A. C. C; Santos, B. R.; Guimarães, M. F. M. Uso popular de plantas medicinais e perfil socioeconômico dos usuários: um estudo em área urbana em Ouro Preto, MG, Brasil. Revista Brasileira de Plantas Medicinais, Campinas, v. 17, n. 1, p.76-104, 2015.

[13] Moerman, D. E.; Estabrook, G. F. Native Americans' choice of species for medicinal use is

[14] dependent on plant family: conirmation with metasigniicance analysis. Journal of Ethnopharmacology, v. 87, n. 1, p. $51-59,2003$.

[15] Rego, T. C. Produtivismo, pesquisa e comunicação científica: entre o veneno e o remédio. Educação e Pesquisa, São Paulo, v. 40, n. 2, p. 325-346, abr./jun. 2014.

[16] Santos, F. S. D. Tradições populares de uso de plantas medicinais na Amazônia. História, Ciências, Saúde - Manguinhos, v. 6, n. 1., p. 919939, 2000

[17] Siviero, A.; Delunardo, T. A.; Haverroth, M.; Oliveira, L. C.; Mendonça, A. M. S. Plantas medicinais em quintais urbanos de Rio Branco, Acre. Revista Brasileira de Plantas Medicinais, Botucatu, v. 14, n. 4, p.598-610, 2012

[18] Ustulin, M.; Figueiredo, B. B.; Tremea, C.; Pott, A.; Pott, V. J.; Bueno, N. R.; Castilho, R. O. Plantas medicinais comercializadas no Mercado Municipal de Campo Grande - MS. Revista Brasileira de Farmacognosia, v. 19, n. 3, p. 805813, 2009.

[19] Vásquez, S. P. F.; Mendonça, M. S.; Noda, S. N. Etnobotânica de plantas medicinais em comunidades ribeirinhas do município de Manacapuru, Amazonas, Brasil. Acta Amazonica, v. 44, n. 4, p. 457-472, 2014. 


\title{
Bapítulo 2
}

\section{ETNOBOTANNICA DE PLANTAS MEDICINAIS EM QUINTAIS URBANOS NA CIDADE DE MANAUS}

\author{
Helena Carolina Alves Barreto \\ Larissa Carvalho Gato \\ Dayanne de Souza Carvalho \\ Ísis Ribeiro do Nascimento
}

Janaína Paolucci Sales de Lima

Resumo: A agrobiodiversidade dos quintais urbanos na cidade de Manaus vem sendo construído, alterado e enriquecido ao longo do tempo pelas pessoas que moram na residência. Este estudo teve como objetivo analisar a estrutura dos quintais localizados no bairro Tarumã na zona Oeste de Manaus, AM. Foram realizadas entrevistas com perguntas abertas e semiestruturadas com 60 mantenedores de quintais urbanos, a escolha das residências foi realizada pelo método de amostragem sistemática. Foram identificadas uma grande riqueza de plantas medicinais em relação ao seu uso, registrando $79 \mathrm{com}$ fins medicinais, 31 para uso múltiplos e medicinal, 5 alimentar, 5 para uso medicinal e ornamental e 11 para ornamental. As espécies estão distribuídas em 51 famílias botânicas, com destaque para as espécies da família Euphorbiaceae e Lamiaceae. Quanto ao hábito de crescimento das plantas merecem destaque herbáceo (59\%) seguida de arbustivo (27\%), arbóreo com (11\%) e trepadeira com (3\%). As análises da diversidade florística foram representadapelo índice de Shannon-Wiener, a representação da proporção de indivíduos por espécies correspondendo ao índice de Pielou, o quociente de mistura de Jentsch foi utilizado para indicar quantas plantas de cada espécies são encontrada em média no povoamento. A análise de similaridade florísticas foi realizada através do índice de Jaccard. O estudo aponta que os quintais são unidades de práticas culturais urbanas que envolvem a conservação de espécies de plantas espaço e lazer.

Palavras-chave: Manaus, Agricultura urbana, Manejo. 


\section{INTRODUÇÃO}

A Amazônia é o maior bioma brasileiro em extensão, abrangendo nove Estados de três regiões e ocupando uma área de $49,29 \%$ do território nacional (IBGE, 2004). Esse bioma apresenta a maior biodiversidade do planeta, incluindo a diversidade genética, diversidade de espécies e diversidade de ecossistemas. Em relação à conservação da agrobiodiversidade, os quintais urbanos são considerados um verdadeiro banco de recursos genéticos de grande importância para a humanidade.

Semedo e Barbosa (2007) consideram os quintais urbanos como estratégias de maximização dos pequenos espaços disponíveis e reflexos dos conhecimentos agrícolas herdados das áreas de agricultura familiar e dos quintais rurais. Essas áreas têm como princípio a diversificação produtiva como forma de garantir oferta de produtos o ano todo, bem como, amenizar carências de vitaminas e sais minerais para a população mais pobre, uma vez que, seus produtos apresentam abundância desses elementos.

A Etnobotânica surge como campo interdisciplinar que compreende o estudo e a interpretação do conhecimento, significação cultural, manejo e usos tradicionais dos elementos da flora (CABALLERO, 1979).

Nesse contexto, o homem utiliza as plantas como alternativa terapêutica na perpetuação de informações valiosas, muitas vezes próprias de sua cultura. Este fator faz com que cada sociedade, ou comunidade possua seu próprio sistema de classificação, crenças e métodos populares capazes de promover a cura dos seus próprios males (MOREIRA et al., 2002).

Dos grupos de espécies botânicas utilizadas por populações sedentárias na forma de quintais caseiros na Amazônia, o de maior expressão, ou pelo menos o de maior visibilidade, é o da categoria "perene" (CLEMENT, 1999). Nesse grupo se encaixam as árvores frutíferas comestíveis que incorporam à alimentação diferentes fontes de vitaminas, de suma importância ao metabolismo fisiológico humano, podendo também oferecer sombra e lazer, além de se enquadrarem no grupo das medicinais alternativas (BRASIL, 2002; MADALENO, 2000).

No presente estudo foi realizado o levantamento etnobotânico das espécies de uso medicinal, reconhecidas e utilizadas em quintais agroflorestais urbanos localizados nos bairros da cidade de Manaus (AM).

\section{MATERIAL E MÉTODOS}

A pesquisa foi realizada na cidade de Manaus, no bairro do Tarumã limitado a leste pela Avenida Torquato Tapajós, a norte pelo igarapé do Mariano, a sul pela cabeceira do igarapé do Gigante, acompanhando o médio e baixo curso do igarapé Bolívia, todos afluentes da bacia do Tarumã-Açu, limite ocidental do bairro e da área urbana de Manaus.

Desta forma, foram selecionados dois bairros localizados no bairro do Tarumã: Parque Riachuelo I e Parque Riachuelo II. A escolha das residências foi realizada pelo método de amostragem sistemática de pontos, sendo selecionados 30 quintais agroflorestais por bairro.

Os dados foram coletados no período de outubro de 2015 a maio de 2016. A metodologia de coleta de dados primários foi feita via abordagem qualitativa utilizando técnicas de entrevista semi-estruturada, seguindo um roteiro-guia padrão e de observação direta participante (Albuquerque \& Lucena 2004.). A transmissão de informações entre gerações e as diversas curiosidades que cada indivíduo relata é parte do conhecimento adquirido com o passar dos tempos. Isto se deve ao fato de cada cultura ou civilização construir uma imagem própria de sua natureza e perceber de maneira distinta os bens e riquezas confinadas a ela, adotando assim, uma estratégia particular de uso dos recursos naturais (TOLEDO et al., 1995).

Cada entrevista foi realizada após a assinatura pelo entrevistado de um termo de consentimento aceitando participar da pesquisa e autorizando a divulgação dos resultados do estudo.

Foram pesquisados aspectos qualitativos e quantitativos da dinâmica estrutural e espacial dos quintais e socioeconômicos dos entrevistados. A entrevista aplicada considerou os aspectos levantados por Millate-Mustafa (1998) e constou de questões sobre a área do quintal e dados das espécies alimentares cultivadas como: nome comum, forma de obtenção da planta, indicação de usos da espécie, hábito de crescimento, 
propagação e formas de preparo do fitoterápico.

A identificação das espécies foi realizada por comparação das fotografias tiradas in situ, com consulta à literatura especializada.

\subsection{ANÁLISE DOS DADOS}

A variação de espécies existente entre os quintais pode ser representada e quantificada de diversas maneiras, sendo a mais comum o uso de índice de diversidade. Logo, para avaliar o comportamento nos quintais de cada bairro, foram utilizadas as fórmulas dos índices de diversidade, equabilidade, quociente de mistura e similaridade:

A diversidade de plantas dos quintais (total, por bairro e forma de vida) foi obtida através do Índice de Shannon-Wiener $\left(H^{\prime}\right.$, base logaritmo decimal) (MAGURRAN, 1988). A equabilidade de Pielou (J') corresponde a uma representação numérica da proporção de indivíduos, por espécie, na unidade amostrada (PIELOU, 1975). O valor do Quociente de Mistura de Jentsch (QM) foi obtido a partir da análise do total de indivíduos encontrados por espécie através da amostragem.As análises de similaridade florística dos quintais foram realizadas através do Índice de Jaccard (ODUM, 1988).

O objetivo do uso dos coeficientes foi comparar a flora dos bairros observados a partir de uma análise qualitativa baseada na presença ou ausência de espécies. Para a análise dos dados foi utilizado o programa Excel® versão 2007 para Windows $₫$.

\section{RESULTADOS E DISCUSSÃO}

O perfil socioeconômico dos entrevistados revelou que a maioria dos responsáveis pela condução e manejo do quintal é do gênero feminino sendo (65\%). As idades médias dos entrevistados variam entre 60 a 80 anos.

A Etnobotânica tem grande importância para as populações regionais no que toca à exploração e manejo de recursos para obtenção de remédios, alimentos e matériasprimas (FERRO, 2006). Os resultados indicam uma grande riqueza de plantas medicinais registrando 79 com fins medicinais, distribuídas em 51 famílias botânicas (Tabela 1), com destaque para as espécies da família Euphorbiaceae e Lamiaceae.

Tabela 1. Espécies de plantas cultivadas como de uso medicinal nos quintais agroflorestais urbanos cidade de Manaus - AM.

\begin{tabular}{|l|c|c|c|c|}
\hline \multirow{2}{*}{ Família/Nome Cientifico } & Nopular & Parte usada & Indicação & Preparo \\
\hline Acanthaceae & Mutuquinha & Folha & Colesterol & Chá \\
\hline Justicia pectoralis Jacq. & & Folha & Diabete, inflamação & Chá \\
\hline Justicia calycina (Nees) V.A.W. Graham & Sara tudo & & & \\
\hline Adoxaceae & Sabugueiro & Folha & Sarampo & Banho \\
\hline Sambucus nigra L. & & & & \\
\hline Amaranthaceae & Melhoral & Folha & $\begin{array}{c}\text { Bronquite/dor de } \\
\text { cabeça }\end{array}$ & Chá \\
\hline Alternanthera brasiliana (L.) O. Kun & Emenda osso & Folha & Lesões & Sumo \\
\hline Pfaffia glomerata (speag.) Peders. & Terramicina & Folha & Inflamações & Chá \\
\hline Alternathera brasiliana (L.) O. Kunt. & Caja & Folha/Fruto & Diarreia & Chá/suco \\
\hline Anacardiaceae & Caju & Folha/Fruto & Laxante/Gripe & Chá/suco \\
\hline Spondias mombin L & Manga & Folha/Fruto & Anemia & Chá/suco \\
\hline Anacardium occidentale L & & & & \\
\hline Mangifera indica L. & Graviola & Folha/Fruto & Pressão & Suco \\
\hline Annonaceae & Chicória & Folha & Dores estomacal & Chá \\
\hline Annona muricata L. & & & & \\
\hline Apiaceae & Jibóia do & Folha & Proteção & Banho \\
\hline Eryngium foetidum L. & & & & \\
\hline Araceae & Patauá & Semente & Anemia & Vinho \\
\hline Epipremnum pinnatum L. & Açai & Fruto & Anemia & Suco \\
\hline Areceae & & &
\end{tabular}


Tabela 1. Espécies de plantas cultivadas como de uso medicinal nos quintais agroflorestais urbanos cidade de Manaus - AM (continuação ...)

\begin{tabular}{|c|c|c|c|c|}
\hline Família/Nome Cientifico & $\begin{array}{l}\text { Nome } \\
\text { popular }\end{array}$ & Parte usada & Indicação & Preparo \\
\hline Oenocarpus bacaba & Bacaba & Semente & Rejuvenesce & Vinho \\
\hline Mauritia vinifera Mart & Buriti & Fruto & Anemia & Suco \\
\hline Cocos nucifera L. & Coco & Fruto & Asma & Agua \\
\hline Astrocaryum vulgare Mart. & Tucumã & Fruto/casca & Rejuvenesce & Oléo \\
\hline \multicolumn{5}{|l|}{ Asteracea } \\
\hline Baccharis trimera (Less.) DC. & Carqueja & Folha & Estomacal & Chá \\
\hline Tanacetum vulgare L. & $\begin{array}{l}\text { Catinga } \\
\text { mulata }\end{array}$ & Folha & Reumatismo & Chá \\
\hline Pluchea sagittalis (Lam) Cabrera. & Marcela & Folha & Febre & Chá \\
\hline Acmella oleracea $(\mathrm{L})$ & Jambu & Folha & Dor de cabeça & Chá \\
\hline Artemisia absinthium $L$ & Losna & Folha & Fígado & Chá \\
\hline Spilanthes acmella (L.) Murr. var. typica. & Pimenteira & Folha & Dores no corpo & Chá \\
\hline Eupatorium triplinerve Vahl. & $\begin{array}{l}\text { Japana } \\
\text { branca }\end{array}$ & Folha & Infecções & Chá/banho \\
\hline \multicolumn{5}{|l|}{ Bignoniaceae } \\
\hline Mansoa alliacea (Lam.) A. H. Gentry & Cipo alho & Folha & Dor de cabeça & Chá \\
\hline Tabebuia chrysotricha & Ipê amarelo & Casca/Folhas & Ferimento & Chá \\
\hline Tabebuia impetiginosa & Ipê rosa & Casca/Folha & Gripe & Chá \\
\hline $\begin{array}{l}\text { Tabebuia impetiginosa (Mart. ex DC.) } \\
\text { Standl }\end{array}$ & Ipê roxo & Casca/Folha & Alergia & Chá \\
\hline Bixa orellana L. & Urucu & Raiz/Semente & Expectorante & Chá \\
\hline \multicolumn{5}{|l|}{ Boraginaceae } \\
\hline $\begin{array}{l}\text { Heliotropium elongatum Hoffm Ex } \\
\text { Roem. \& Schult. }\end{array}$ & $\begin{array}{l}\text { Crista-de- } \\
\text { galo }\end{array}$ & Folha & Asma & Chá \\
\hline \multicolumn{5}{|l|}{ Brassicaceae } \\
\hline Nasturtium officinale $\mathrm{R} . \mathrm{Br}$ & Agrião & Folha & Anemia/Bronquite & Chá \\
\hline Brassica oleracea L. & $\begin{array}{l}\text { Couve de } \\
\text { corda }\end{array}$ & Folha & Anemia/ Gastrite & Suco \\
\hline \multicolumn{5}{|l|}{ Bromeliaceae } \\
\hline Ananas comosus (L.) Merr & Abacaxi & Casca/fruto & Bronquite & Suco \\
\hline \multicolumn{5}{|l|}{ Burseraceae } \\
\hline Commiphora myrrha (T. Nees) Engl. & Mirra & Folha & Inflamação & Chá \\
\hline \multicolumn{5}{|l|}{ Cactaceae } \\
\hline $\begin{array}{l}\text { Selenicereus grandiflorus (L.) Britton \& } \\
\text { Rose. }\end{array}$ & Cacto chato & Folha & Hemorragia/asma & Chá \\
\hline \multicolumn{5}{|l|}{ Caricaceae } \\
\hline Carica papaya $L$ & Mamão & Fruto & Diabete/Verrugas & Suco/latex \\
\hline \multicolumn{5}{|l|}{ Chenopodiaceae } \\
\hline Chenopodium ambrosioides L. & Mastruz & Folha & Gripe/tosse & Chá \\
\hline \multicolumn{5}{|l|}{ Chlorantaceae. } \\
\hline Melissa officinalis & Cidreira & Folha & Dor de cabeça & Chá \\
\hline \multicolumn{5}{|l|}{ Crassulaceae } \\
\hline Kalanchoe pinnata (Lam.) Pers. & Coerama & Folha & Gastrite & Chá \\
\hline Clusiaceae & & & Frutos & \\
\hline Platonia insignis Mart & Bacuri & Fruto & Anti-inflamatorio & Suco \\
\hline \multicolumn{5}{|l|}{ Cucurbitaceae } \\
\hline Cucurbita pepo L. & Abóbora & Folhas/Polpas & Prisao de ventre & Sumo \\
\hline \multicolumn{5}{|l|}{ Euphorbiaceae } \\
\hline Euphorbia tirucalli & $\begin{array}{l}\text { Cachorro } \\
\text { pelado }\end{array}$ & Talo & Verruga/Câncer & Látex \\
\hline Euphorbia tirucalli L. & $\begin{array}{l}\text { Dedo de } \\
\text { adão, aveloz }\end{array}$ & Leite & Verruga & Látex \\
\hline Manihot esculenta Crantz & Mandioca & Raiz & Calmante & Chá \\
\hline Jatropha curcas L. & Pião branco & Folha & Sinusite & Chá \\
\hline Jatropha gossypiifolia L. & Pinhão roxo & Folha & Hemorragia & Chá \\
\hline Phyllanthus niruri L. & $\begin{array}{l}\text { Quebra } \\
\text { Pedra }\end{array}$ & Folha & Diabetes & Chá \\
\hline
\end{tabular}


Tabela 1. Espécies de plantas cultivadas como de uso medicinal nos quintais agroflorestais urbanos cidade de Manaus - AM (continuação ...)

\begin{tabular}{|c|c|c|c|c|}
\hline Família/Nome Cientifico & $\begin{array}{l}\text { Nome } \\
\text { popular }\end{array}$ & Parte usada & Indicação & Preparo \\
\hline Acalypha reptans & Rabo de gato & Folha & Gastrite & Chá \\
\hline $\begin{array}{l}\text { Hevea brasiliensis (Willd. ex A. Juss.) } \\
\text { Müll. Arg. }\end{array}$ & Seringueira & Casca & Vermicida & Látex \\
\hline \multicolumn{5}{|l|}{ Fabaceae } \\
\hline Dipteryx odorata (Aubl) Willd. & Cumarú & Semente & Úlcera & Lambedor \\
\hline Phaseolus vulgaris L. & Feijão & Semente & Anemia & Alimento \\
\hline Inga edulis Mart & Ingazeiro & Folha/semente & Problemas intestinal & Chá/suco \\
\hline Bauhinia forficata Link. & Pata de vaca & Casca/folha & Colesterol & Chá \\
\hline Tamarindus indica L. & Tamarino & Folha & Pressão & Chá \\
\hline Persea americana Mill & Abacateiro & Folha & Pressão & Chá \\
\hline Ocimum canum Sims. & Alfavaca & Folha/fruto & Doenças renais & Suco \\
\hline Rosmarinus officinalis $\mathrm{L}$. & Alecrim & Folha & Dor de cabeça & Chá \\
\hline Plectranthus barbatus Andr. & Boldo & Folha & Anti-inflamatório & Chá \\
\hline Melissa officinalis $L$ & Erva Cidreira & Folha & Dor intestin & Chá \\
\hline Mentha piperita L. & Hortelã & Folha & Cólica & Chá \\
\hline Plectranthus amboinicus Lour. & $\begin{array}{l}\text { Hortelã } \\
\text { grande }\end{array}$ & Folha & Gripe & Chá \\
\hline Ocimum basilicum L. & Manjericão & Folha & $\begin{array}{l}\text { Pressão/ Dores no } \\
\text { corpo }\end{array}$ & Chá \\
\hline Coleus amboinicus Lour. & Malvarisco & Folha & Dor de cabeça & Chá \\
\hline Origanum vulgare L. & Oregano & Semente & Dores no estomago & Chá \\
\hline Mentha pulegium L. & Poejo & Folha & Dor de cabe;ca & Chá \\
\hline \multicolumn{5}{|l|}{ Leguminosae } \\
\hline Erythrina indica var. picta (L.) B. \& M. & Brasileirinha & Folha & Derrame & Chá \\
\hline \multicolumn{5}{|l|}{ Liliaceae } \\
\hline Aloe vera L. ex Webb & Babosa & Folhas & Queda de cabelo & Chá \\
\hline \multicolumn{5}{|l|}{ Llliciaceae } \\
\hline Allium fistulosum L. & Cebolinha & Folhas & Gripe & Chá \\
\hline Illicium verum Hook. f. & $\begin{array}{c}\text { Anis } \\
\text { estrelado }\end{array}$ & Folhas/Fruto & Inflamação/Tosse & Chá \\
\hline \multicolumn{5}{|l|}{ Malpighiaceae } \\
\hline Malpighia glabra L & Acerola & Fruto & Gripe & Suco \\
\hline Byrsonima spicata (Cav.) DC. & Murici & Casca & $\begin{array}{l}\text { Inflamações } \\
\text { intestinal }\end{array}$ & Chá \\
\hline \multicolumn{5}{|l|}{ Malvaceae } \\
\hline Gossypium hirsutum L. & Algodão roxo & Folhas & Inflamações & Banho \\
\hline Meliaceae & & & & Folhas \\
\hline Carapa guianensis Aubl. & Andiroba & Folha/casca & Dores de garganta & Chá \\
\hline \multicolumn{5}{|l|}{ Monimiaceae. } \\
\hline Peumus boldus Molina. & $\begin{array}{l}\text { Boldo-do- } \\
\text { chile }\end{array}$ & Folhas & Dores Intestinal & Chá \\
\hline \multicolumn{5}{|l|}{ Moraceae } \\
\hline Morus nigra L. & Amora & Folhas & Diabetes/Menopausa & Suco/Chá \\
\hline Musaceae. & & & & Fruto \\
\hline Musa paradisiaca L. & Banana & Frutos & Diarreia & Suco \\
\hline \multicolumn{5}{|l|}{ Myrtaceae } \\
\hline Psidium araça Raddi. & Araçazeiro & Folha & Diarreia & Chá \\
\hline Syzygium jambolanum (Lam.) DC. & Azeitona & Casca/fruto & Asma/Infecção & Chá \\
\hline Psidium guajava L. & Goiaba & Folha/fruto & Cólica & Chá/Suco \\
\hline $\begin{array}{l}\text { Syzygium malaccense (L.) Merr. \& L.M. } \\
\text { Perry. }\end{array}$ & Jambo & Fruto & Dor de cabeça & Suco \\
\hline Myrtus jaboticaba Vell & Jabuticaba & Fruto & Artrite & Suco \\
\hline Eugenia uniflora L. & Pitanga & Folhas & Reumatismo & Suco \\
\hline \multicolumn{5}{|l|}{ Oxalidaceae } \\
\hline Averrhoa carambola L. & Carambola & Folha/fruto & Diabete/febre/gripe & Cha/suco \\
\hline \multicolumn{5}{|l|}{ Passifloraceae } \\
\hline Passiflora edulis Sims & Maracujá & Fruto & Calmante & Suco \\
\hline Phytolacaceae & & & & \\
\hline
\end{tabular}


Tabela 1. Espécies de plantas cultivadas como de uso medicinal nos quintais agroflorestais urbanos cidade de Manaus - AM (continuação ...)

\begin{tabular}{|c|c|c|c|c|}
\hline Família/Nome Cientifico & $\begin{array}{l}\text { Nome } \\
\text { popular }\end{array}$ & Parte usada & Indicação & Preparo \\
\hline Petiveria alliacea L. & Mucura-caá & Folhas & Dor de cabeça & Chá \\
\hline \multicolumn{5}{|l|}{ Piperaceae } \\
\hline Piper umbellatum L. & Capeba & Folha & Inchaço & Sumo \\
\hline Piper callosum Ruiz \& Pav. & $\begin{array}{c}\text { Elixir } \\
\text { paregorico }\end{array}$ & Folha & $\begin{array}{c}\text { Dor de } \\
\text { estomago/Cólicas }\end{array}$ & Chá \\
\hline Piper cavalcantei Yunck. & Oléo elétrico & Folha & Infecções intestinais & Chá \\
\hline \multicolumn{5}{|l|}{ Poaceae } \\
\hline Cymbopogon citratus (DC.) Stapf. & $\begin{array}{l}\text { Capim } \\
\text { cheiroso }\end{array}$ & Folha & Dor de cabeça & Chá \\
\hline Cymbopogon densiflorus (Steud.) Stapf. & Capim santo & Folha & Calmante & Chá \\
\hline Cymbopogon nardus (L.) Rendle. & Citronela & Folha & Febre intestinal & Chá \\
\hline \multicolumn{5}{|l|}{ Portulacaceae } \\
\hline Portulaca pilosa L. & $\begin{array}{l}\text { Amor- } \\
\text { crescido }\end{array}$ & Folha & Infecção intestinal & Chá \\
\hline Portulaca grandiflora Hook. & Onze-horas & Folha & Infecção intestinal & Chá \\
\hline \multicolumn{5}{|l|}{ Rubiaceae } \\
\hline Coffea arabica L. & Café & Folha/semente & $\begin{array}{l}\text { Aumenta o } \\
\text { metabolismo }\end{array}$ & Chá \\
\hline Genipa americana L. & Jenipapo & Fruto & Anemia & Suco \\
\hline Morinda citrifolia. L. & Noni & Fruto & Câncer & Suco \\
\hline \multicolumn{5}{|l|}{ Rutaceae } \\
\hline Ruta graveolenses L. & Arruda & Folha & $\begin{array}{c}\text { Dor de } \\
\text { cabeça/Reumatismo }\end{array}$ & Chá \\
\hline $\begin{array}{l}\text { Citrus aurantium subsp. bergamia } \\
\text { (Risso) Wight \& Arn. }\end{array}$ & Bergamota & Folha /fruto & Reumatismo & Suco \\
\hline Citrus sinensis (L) Osbeck & Laranja & Folha & Calmante & Chá \\
\hline Citrus aurantiifolia (Christm.) Swingle. & Lima & Folha & Infecção intestinal & Chá \\
\hline Citrus limon (L.) Burm. f. & Limão & Folha & Gripe & Suco \\
\hline Citrus aurantifolia (Christm.) Swingle. & $\begin{array}{l}\text { Limão } \\
\text { Galego }\end{array}$ & Folha & Anti-inflamatorio & Suco \\
\hline $\begin{array}{l}\text { Citrus aurantium subsp. bergamia } \\
\text { (Risso) Wight \& Arn. }\end{array}$ & Tangerina & Folha/fruto & Gripe & Chá/Suco \\
\hline \multicolumn{5}{|l|}{ Scrophulariaceae } \\
\hline Scoparia dulcis L. & Vassourinha & Folha & Diabetes & Chá \\
\hline \multicolumn{5}{|l|}{ Solanaceae } \\
\hline Atropa belladonna L. & Beladona & Folha/ Flor & Asma & Chá \\
\hline \multicolumn{5}{|l|}{ Sapindaceae } \\
\hline Nephelium lappaceum & Rambutan & Fruto & Câncer & Suco \\
\hline \multicolumn{5}{|l|}{ Sapotaceae } \\
\hline Pouteria caimito (Ruiz \& Pav.) Radlk & Abiú & Fruto & Pneumonia & Suco \\
\hline \multicolumn{5}{|l|}{ Urticaceae } \\
\hline Cecropia peltata L. & Embauba & Casca/Folhas & Tosse & Chá \\
\hline \multicolumn{5}{|l|}{ Vitaceae } \\
\hline Cissus sicyoides L. & Insulina & Folha & Diabetes & Chá \\
\hline \multicolumn{5}{|l|}{ Zingiberaceae } \\
\hline Zingiber officinale (Willd.) Roscoe. & Mangaratáia & Caule & Catarro & Chá \\
\hline Costus spp. & Pobre velho & Raiz & Dor de cabeça & Chá \\
\hline
\end{tabular}

A riqueza de espécies medicinais cultivadas nos quintais de urbano de Manaus (Tabela 2) corrobora com a tese de estreitamento da relação entre comunidades florestais e áreas urbanas na Amazônia. Resultados semelhantes foram relatados por Silveiro e colaboradores (2012), estes resultados indicam a manutenção do fluxo de espécies da floresta para o município. 
Tabela 2. Análise da diversidade e similaridade florística entre os quintais agroflorestais urbanos no município de Manaus - AM.

\begin{tabular}{|c|c|c|c|}
\hline Índice & Denomiação & Valores & \multicolumn{2}{c|}{ Análise } \\
\hline Diversidade & Shannon-Wiener & $3,46-3,78$ & Alta diversidade de espécies. \\
\hline Equabilidade & Pielou & 0,87 & $\begin{array}{c}\text { Melhor distribuição entre o número de } \\
\text { indivíduos por espécies. }\end{array}$ \\
\hline Quociente de mistura & Jentsch & 0,66 & Maior heterogeneidade. \\
\hline Similaridade & Jaccard & 0,51 & $\begin{array}{c}\text { Alta similaridade dos quintais quanto } \\
\text { à composição florística. }\end{array}$ \\
\hline
\end{tabular}

Nos quintais urbanos de Manaus o intervalo para o índice de diversidade de ShannonWiener foi de 3,46 a 3,78 o que demonstra uma alta diversidade de espécies. O índice expressa a incerteza em prever a qual espécie pertence um determinado indivíduo retirado aleatoriamente de uma amostra (MAGURRAN, 1988).

Lima e colaboradores (2000) afirmaram que índices elevados em geral relacionam áreas relativamente bem conservadas associadas a populações com significativo conhecimento etnobotânico. O valor encontrado do índice de Pielou foi 0,87, desse modo, quanto mais proporcional o número de indivíduos entre as espécies, maior o valor de equabilidade. Conforme Arruda e Daniel (2007) relataram o índice varia de 0 a 1, quanto mais próximo de 1 , melhor a distribuição entre o número de indivíduos por espécies.

Lamprecht (1962) descreveu que o quociente de mistura de Jentesch (QM) é utilizado para indicar quantas plantas de cada espécie são encontrada em média no povoamento. Os dados analisados forneceram em média um quociente de 0,66, ou seja, existem em termos médios dois indivíduos de cada espécie, quanto maior o quociente, menor número de indivíduo por espécies, mais heterogênea será a vegetação da área em estudo (LIMA, 1994). Portanto esse valor é inferior, esses resultados indicam que a vegetação dos quintais dos bairro estudados possui uma heterogeneidade maior.

Quanto ao índice de similaridade de Jaccard, para os dois bairros estudados, optou-se pela análise de agrupamento, descrevendo a similaridade entre duas unidades estudadas, o valor menor foi 0,51 indicando uma alta similaridade dos quintais quanto a composição florística. Mota (2007) descreve que $\mathrm{o}$ índice de similaridade de Jaccard raramente atinge valores acima de $60 \%$ e deve ser superior a $25 \%$ para que duas formações florestais sejam consideradas similares.

Figura 1. Distribuição das espécies vegetais dos quintais agroflorestais urbanos de Manaus em categorias de uso.

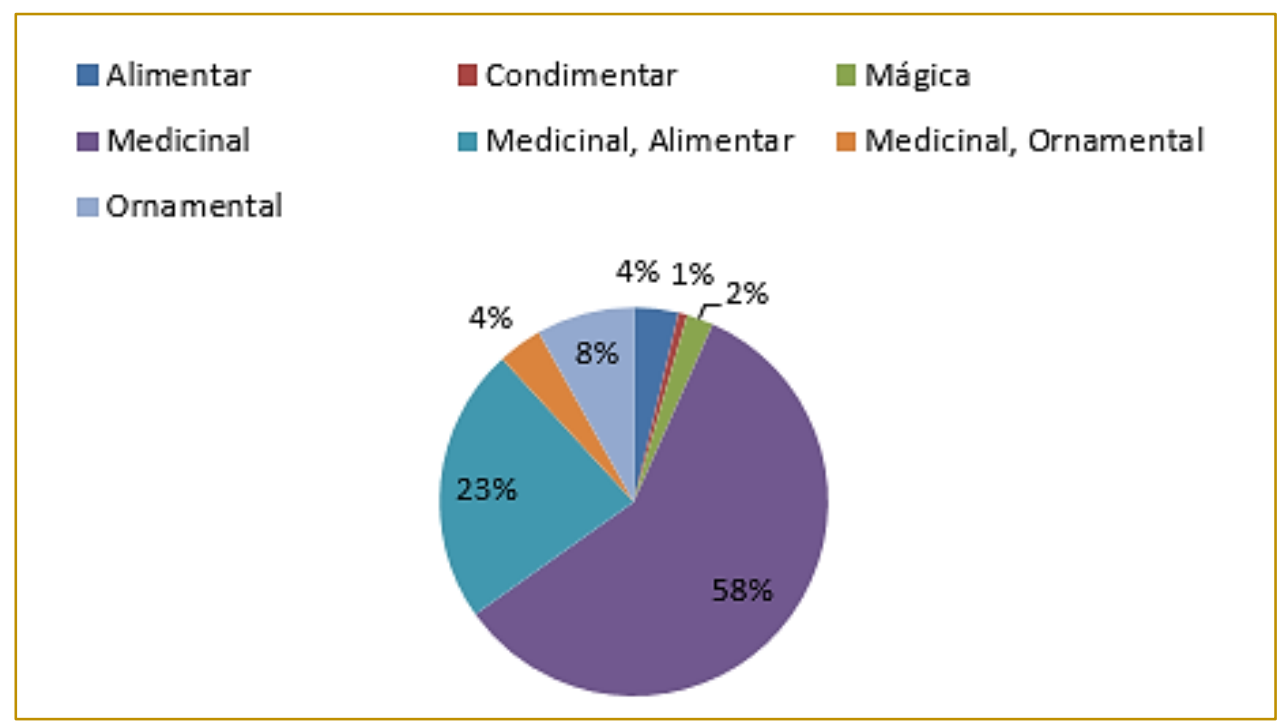


Quanto ao tipo de crescimento das plantas cultivadas pelos moradores, destacam-se 0 tipo herbáceo (43\%) e arbustivo (26\%). Durante a pesquisa verificou-se que os entrevistados têm o hábito de cultivar as plantas medicinais em canteiros suspensos e em vasos separados, devido disponibilidade de espaço para formação do quintal (Figura 2). De acordo com Semedo e Barbosa (2007) os quintais urbanos são caracterizados por possuírem estratégias de maximização dos pequenos espaços disponíveis refletindo os conhecimentos agrícolas herdados das áreas de agricultura familiar e dos quintais rurais.

Figura 2 - Cultivo de plantas em canteiro suspenso

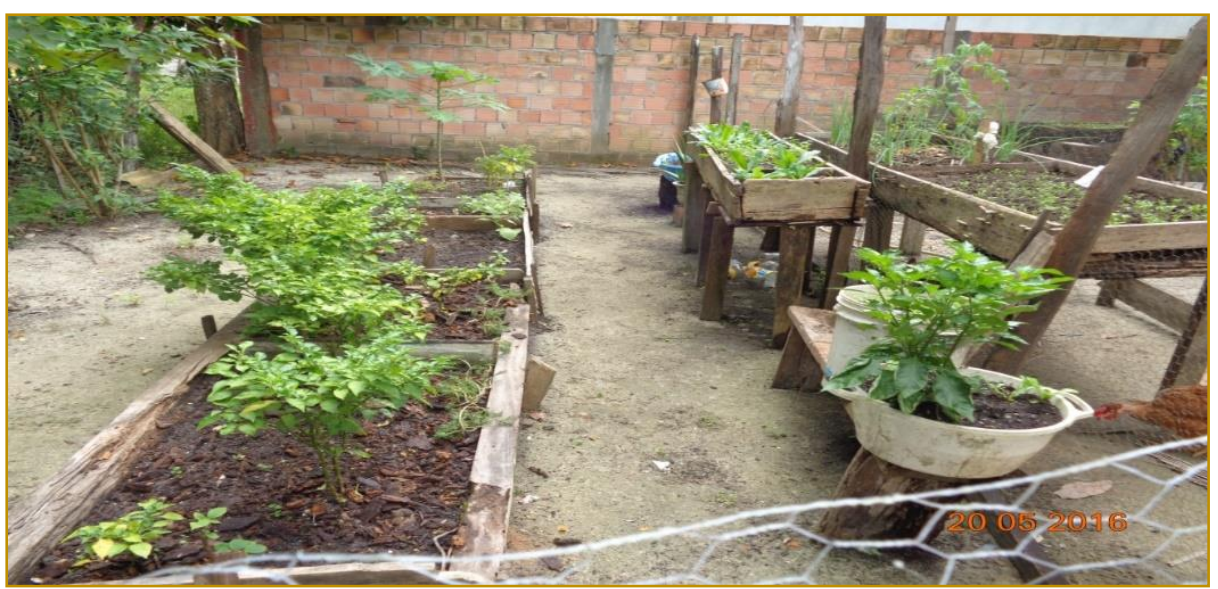

\subsection{IDENTIFICAÇÃO DAS ESPÉCIES MEDICINAIS CULTIVADAS}

Dos grupos de espécies botânicas cultivadas, o de maior expressão quanto a categoria de uso é o medicinal, sendo observada associação ao uso alimentar. De modo similar, Murrieta e Winklerprins (2003) caracterizaram os quintais agroflorestais urbanos e periurbanos na Amazônia destacando o cultivo de diversas espécies vegetais para usos distintos e múltiplos.

Entre as plantas medicinais mais usadas nos bairros estudados destacam-se alfavaca (Ocimum canum Sims.), babosa e (Aloe vera L. ex Webb.), boldo (Plectranthus barbatus Andr.). Em estudo, Santandreu e colaboradores (2010) destacam babosa (Aloe vera L. ex Webb.), alecrim (Rosmarinum officinalis L.) e anacahuita (Schinus molle L.) entre as espécies de plantas medicinais mais utilizadas na agricultura urbana na América do Sul.

A indicação terapêutica das plantas seguiu um padrão constante nos bairros apresentando versatilidade quanto ao uso, neste estudo predominaram as indicações para tratamento das afecções intestinais e respiratórias, seguindo das inflamações em geral, com poucas contradições. Foram identificadas diversas formas de uso, variando de acordo com as espécies e objetivos de tratamento, prevalecendo o uso na forma de chá preparado com folhas (70\%).

\section{CONCLUSÕES}

As informações obtidas nos levantamentos de campo desta pesquisa revelaram uma elevada diversidade genética de espécies de plantas medicinas nos quintais urbano da cidade de Manaus demostra que os moradores possuem conhecimento elevado das plantas de seus quintais e que, apesar da alta similaridade muitas destas apresentam uso alimentar, ornamental e mágica, sendo de uso distintos e múltiplos. Os quintais não se restringem ao meio rural, em áreas urbanas destacam-se por apresentarem um papel importante na complementação da dieta alimentar. Os quintais são formados por seus moradores, à maioria são mulheres que contribuem pela conservação, sendo as principais as idosas que são detentoras de conhecimento tradicional a respeito do uso das plantas, essas aperfeiçoam os quintais, com base nas suas necessidades plantando e mantendo uma variada composição de plantas A manutenção do quintal na residência possui valores intangíveis e difíceis de serem mensurados como o prazer de cultivar, espaço cultural relacionando 
cotidiano e lazer pela melhoria da ambiência e da paisagem proporcionado pelas espécies arbóreas.

\section{REFERÊNCIAS}

[1] Albuquerque, U. P.; Lucena, R. F. P.; Cunha, L. V. F. Métodos e técnicas na pesquisa etnobotânica. Recife: Editora Comunigraf/Nupeea. 2008. 322p

[2] Arruda, L.; Daniel O. Florística e diversidade em um fragmento de floresta estacional semidecidual aluvial em Dourados, MS. Revista Floresta; 37(2):187-199, 2007.

[3] Buhring, R.; Costa, L. A. da; BARBOSA, E.B. 2006. Cadastramento qualiquantitativo georreferenciado das árvores localizadas nas ruas do centro da cidade de Manaus - AM. In. VII Seminário em Atualizacão em Sensoriamento Remoto e Sistemas de Informações Geográficas Aplicados à Engenharia Florestal. Curitiba, Paraná. p. $210-218$.

[4] Brasil. Ministério da Saúde. Alimentos regionais brasileiros. Brasília, 2002. 140 p. (Série Comunicação e Educação em Saúde, 21).

[5] Caballero, J. 1979. La Etnobotânica. In: A. Barrera (ed.). La Etnobotânica: tres puntos de vista y uma perspectiva. Xalapa: INIREB. p. 27-30.

[6] Costa, L.A. 2001. Proposta de Zoneamento de Áreas Rurais utilizando Sistema de Informações Geográficas. Tese de Doutorado, Universidade Federal de Viçosa, Viçosa, Minas Gerais. 158pp.

[7] Clement, C. 1492 and the loss of Amazonian crop genetic resources: th relation between domestication and human population delcline. Economic Botany, Bronx, v. 53 n.2, p. 188202, 1999

[8] Ferro, D. Fitoterapia: conceitos clínicos. São Paulo:Atheneu, 502p., 2006.

[9] Lamprecht, H. Ensayo sobre unos métodos para el análisis estructural de los bosques tropicales. Acta Científica Venezoelana, Caracas, v. 13, n. 2, p. 57-65, 1962.

[10] Lima, R. X.; Silva, S. M. Kuniyoshi, Y. S.; Silva, L. B. Etnobiologia de comunidades continentais da Área de Proteção Ambiental de Guaraqueçaba - Paraná, Brasil. Etnoecológica, v. 4, n. 6, p. 33-55, 2000.

[11] lima, R. M. B. Descrição, composição e manejo dos cultivos mistos de quintal na várzea da "Costa do Caldeirão", Iranduba, AM. 1994. 293 p. Dissertação (Mestrado em Manejo Florestal) -

\section{AGRADECIMENTOS}

Os autores agradecem aos moradores dos bairros Parque Riachuelo I e Parque Riachuelo II pelas entrevistas concedidas e a Universidade Federal do Amazonas (UFAM) e a Fundação de Amparo de Amparo à Pesquisa do Estado do Amazonas (FAPEAM) pela bolsa de estudo e apoio financeiro.

Instituto Nacional de Pesquisas da Amazônia, Universidade do Amazonas, Manaus, 1994.

[12] Madaleno, I. Urban agriculture in Belém, Brazil. Cities, London, v. 17, n. 1, p. 73-77, 2000.

[13] Magurran, A. E. Ecological diversity and its measurement. Princeton: Princeton University, 177 p., 1988

[14] Millat-Mustafa, M. D. An approach towards analysis of homegardens. In: RASTOGI, A.; Godble, A.; Shengji, P. (Eds.). Applied ethnobotany in natural resource management traditional home gardens. Nepal: International Centre for Integrated Mountain Development Kathmandu, p. 39-48, 1998.

[15] Moreira, R. C. T.; Costa, L. C. B.; Costa, R. C. S.; Rocha, E. A.. Abordagem etnobotânica acerca do uso de plantas medicinais na vila Cachoeira, Ilhéus, Bahia, Brasil. Acta Farmacêutica Bonaerense, 21(3): 205-211, 2002.

[16] Mota, A. C. Comparação de duas metodologias multivariadas no estudo de similaridade entre fragmentos de floresta atlântica. Recife, 2007. 74 f. Dissertação (Curso de Mestrado em Biometria). Universidade Federal Rural de Pernambuco, Recife, 2007.

[17] Murrieta, R. S. S.; Winklerprins, A. M. G. A. Flowers of water: homegardens and gender roles in a riverine caboclo community in the lower Amazon, Brazil. Culture and Agriculture, v.25, p.35-47, 2003.

[18] Odum, E. P. Ecologia. Rio de Janeiro: Guanabara, 1988.

[19] Pielou, E. C. Ecological diversity. New York: J. Wileyand Sons, 165 p., 1975.

[20] Semedo, R. J. C. G.; Barbosa, R. I. Árvores frutíferas nos quintais urbanos de Boa Vista, Roraima, Amazônia brasileira. Acta Amazônica, Manaus, v. 37, n. 4, 2007.

[21] Siviero, A.; Delunardo, T. A.; Haverroth, M.; Oliveira, L. C.; Mendonça, A. M. S. Plantas medicinais em quintais urbanos de Rio Branco, Acre. Rev. Bras. PI. Med., Botucatu, v.14, n.4, p.598-610, 2012.

[22] Toledo, V. M., Batis, A. I., Becerra, R., Martinez, E.; Ramos, C. H. 1995. La selva útil: etnobotánica quantitativa de los grupos indígenas del los grupos indígenas del trópico húmedo de México. Interciência, 20: 177-87. 


\section{Bapítulo 3}

CRESCIMENTO INICIAL DE MUDAS DE ACACIA NEGRA (ACACIA MEARNSII DE WILD) SOB OMISSÃO DE MICRONUTRIENTES

\section{Elias de Sá Farias}

\section{Nelson Venturin}

\section{Diana Suzete Nunes da Silva}

\section{Paloma Carvalho Diniz}

\section{Katya Kavuya Jeannot}

\section{João Faustino Munguambe}

Resumo - O objetivo deste trabalho foi avaliar o efeito da omissão de micronutrientes no crescimento inicial de mudas de Acacia negra (Acacia mearnsii). Foram utilizados 7 tratamentos: $\mathrm{T} 1=$ Solução Completa (Testemunha); $\mathrm{T} 2=$ Completa $-\mathrm{B} ; \mathrm{T} 3=$ Completa $-\mathrm{Cu} ; \mathrm{T} 4=$ Completa $-\mathrm{Fe}$; $55=$ Completa $-\mathrm{Mn} ; \mathrm{T} 6=$ Completa - Mo e T7= Completa - Zn. O experimento foi montado esquematicamente com um DIC de $7 \times 4$ totalizando um número de 28 mudas. As mudas foram produzidas em sistema de solução nutritiva, e as soluções foram trocadas quinzenalmente durante o período experimental. Não houve diferença estatística entre os tratamentos para o índice de qualidade de mudas de Dickson IQD. A omissão de ferro foi a condição que mais prejudicou o crescimento inicial das mudas. A ausência de manganês não afetou significativamente o desenvolvimento das mudas, revelando baixa exigência deste nutriente para Acacia mearnsii durante o período estudado.

Palavras-chave: Silvicultura. Acacia mearnsii. Nutrição. Reflorestamento. 


\section{INTRODUÇÃO}

A acácia negra (Acacia mearnsii De Wild.) é uma espécie australiana introduzida no Brasil em 1918, pertencente à família Fabaceae, subfamília Mimosaceae (ex. leguminosa Mimosaideae). É uma espécie que cresce de 6 a 35 metros de altura, sendo que seu maior desenvolvimento é atingido em ambientes temperados e em solos profundos (COSTERMANS, 1981).

No Brasil, a espécie é intensamente cultivada no Estado do Rio Grande do Sul. Produz madeira de qualidade para energia, papel e celulose, para a fabricação de aglomerados (MAESTRI, 1992); e é muito procurada pelas indústrias de fabricação de móveis e artesanato (BRITTON, 1996). Entretanto, sua principal aplicação é a produção de tanino, extraído de sua casca, com aplicação no curtimento de couro. O tanino é também utilizado no tratamento de efluentes, na fabricação de colas fenólicas e na clarificação de cervejas e vinhos.

A demanda por mudas desta espécie para a implantação de áreas de exploração comercial vem aumentando, devido ao alto valor comercial da madeira, crescimento rápido, capacidade de fixação de nitrogênio e de recuperação de solo em áreas degradadas, qualidades estas compatíveis ou superiores em relação a outras espécies florestais de grande potencial no mercado (TONIETTO; STEIN, 1997; TONINI; HALFELDVIEIRA, 2006).

Yap e Wong (1983) ressaltaram que um dos fatores que dificultam a propagação da acácia negra é o alto grau de dormência das sementes, impedindo a sua germinação. Popinigis (1985) justificou que esta dormência pode ocorrer devido à impermeabilidade do tegumento à água, fenômeno considerado como uma das causas mais comuns da dormência nas leguminosas. Assim, de acordo com Martins-Corder et al. (1999), antes da semeadura, as sementes de Acacia mearnsii devem ser imersas em água quente a $80^{\circ} \mathrm{C}$ por 5 minutos.

Outro fator limitante para a maior difusão da espécie em reflorestamentos é a carência de informações sobre a nutrição da espécie. As espécies florestais apresentam exigências nutricionais e respostas ao estresse nutricional diferenciadas e a complementação nutricional é um dos principais fatores determinantes do sucesso dos plantios florestais e dos projetos de recuperação florestal. Considerando isso, infere-se que a carência ou o suprimento inadequado de nutrientes para espécies florestais pode comprometer o sucesso de um sistema de produção florestal bem como de projetos de recuperação de áreas degradadas por meio do plantio de espécies nativas ou exóticas (SORREANO, 2006).

Para produção de mudas de qualidade de qualquer espécie florestal, uma das premissas consiste no conhecimento de seus requerimentos nutricionais e comportamento em condições de restrição nutricional. Neste sentido, o objetivo deste trabalho foi avaliar o efeito da omissão de micronutrientes em mudas de Acacia negra.

\section{MATERIAL E MÉTODOS}

O experimento foi executado na Universidade Federal de Lavras, em duas partes, a primeira que se tratou do preparo e germinação das sementes foi realizada na casa de vegetação localizada no viveiro florestal do Departamento de Ciências Florestais (DCF) e a segunda parte, referente à implantação das mudas em solução nutritiva com elemento faltante, em casa de vegetação do Departamento de Ciência do Solo (DCS).

As sementes para a produção das mudas de Acácia-negra (Acacia mearnsil) foram fornecidas pelo Instituto Brasileiro de Florestas - IBFLORESTAS, o lote de sementes foi oriundo de cerca de 50 matrizes e foram coletadas na safra de agosto de 2013 na cidade de Encruzilhada do Sul - RS. Antes da semeadura, as sementes foram imersas em água quente a $80^{\circ} \mathrm{C}$ por 5 minutos de acordo com Martins-Corder et al. (1999).

Posteriormente as sementes foram colocadas para germinar em bandejas de isopor com substrato vermiculita e irrigadas diariamente no turno da manhã.

Após atingirem cerca de sete centímetros de altura as mudas foram colocadas em solução de adaptação. A adaptação consiste na submissão das mudas a diferentes concentrações da Solução Padrão estabelecida por Hoagland \& Arnon (1950), em valores crescentes (Tabela 1). A primeira etapa da adaptação consiste na utilização de $25 \%$ da concentração, onde para o preparo da solução apenas um quarto dos volumes dos sais da solução completa foram aplicados para cada litro da solução de adaptação. As mudas permaneceram por 
Tabela 1. Concentração da Solução Padrão e as diferentes concentrações utilizadas nas soluções de adaptação (Hoagland e Arnon, 1950).

\begin{tabular}{|c|c|c|c|c|c|}
\hline Solução estoque & Completa & $\begin{array}{c}25 \% \\
\text { Vol. (ml) }\end{array}$ & $\begin{array}{c}50 \% \\
\text { Vol. (ml) }\end{array}$ & $\begin{array}{c}75 \% \\
\text { Vol. (ml) }\end{array}$ & $\begin{array}{c}100 \% \\
\text { Vol. (ml) }\end{array}$ \\
\hline $\mathrm{NH}_{4} \mathrm{H}_{2} \mathrm{PO}_{4} \mathrm{M}\left(115,03 \mathrm{~g} \mathrm{~L}^{-1}\right)$ & 1 & 10 & 20 & 30 & 40 \\
\hline $\mathrm{KNO}_{3} \mathrm{M}\left(101,11 \mathrm{~g} \mathrm{~L}^{-1}\right)$ & 6 & 60 & 120 & 180 & 240 \\
\hline $\mathrm{Ca}\left(\mathrm{NO}_{3}\right)_{2} \cdot 4 \mathrm{H}_{2} \mathrm{O} \mathrm{M}\left(236,16 \mathrm{~g} \mathrm{~L}^{-1}\right)$ & 4 & 40 & 80 & 120 & 160 \\
\hline $\mathrm{MgSO}_{4} .7 \mathrm{H}_{2} \mathrm{O} \mathrm{M}\left(246,9 \mathrm{~g} \mathrm{~L}^{-1}\right)$ & 2 & 20 & 40 & 60 & 80 \\
\hline $\mathrm{K}_{2} \mathrm{SO}_{4} 0,5 \mathrm{M}\left(87,13 \mathrm{~g} \mathrm{~L}^{-1}\right)$ & 0 & 0 & 0 & 0 & 0 \\
\hline $\mathrm{Ca}\left(\mathrm{H}_{2} \mathrm{PO}_{4}\right)_{2} \cdot \mathrm{H}_{2} \mathrm{O} 0,5 \mathrm{M}\left(12,6 \mathrm{~g} \mathrm{~L}^{-1}\right)$ & 0 & 0 & 0 & 0 & 0 \\
\hline $\mathrm{CaSO}_{4} \cdot 2 \mathrm{H}_{2} \mathrm{O} 0,01 \mathrm{M}\left(1,72 \mathrm{~g} \mathrm{~L}^{-1}\right)$ & 0 & 0 & 0 & 0 & 0 \\
\hline $\mathrm{Mg}\left(\mathrm{NO}_{3}\right)_{2} \cdot 6 \mathrm{H}_{2} \mathrm{O} \mathrm{M}\left(256 \mathrm{~g} \mathrm{~L}^{-1}\right)$ & 0 & 0 & 0 & 0 & 0 \\
\hline $\mathrm{NH}_{4} \mathrm{NO}_{3} \mathrm{M}\left(80,04 \mathrm{~g} \mathrm{~L}^{-1}\right)$ & 0 & 0 & 0 & 0 & 0 \\
\hline Solução 'a' & 1 & 10 & 20 & 30 & 40 \\
\hline Solução Fe-EDTA & 1 & 10 & 20 & 30 & 40 \\
\hline
\end{tabular}

Após a adaptação das mudas à solução de cultivo (21 dias após a implantação na solução de adaptação e 73 dias após a semeadura das sementes) foram montados os tratamentos com elemento faltante. O método consiste da retirada de um elemento micronutriente em cada tratamento por vez. $O$ delineamento utilizado foi um DIC com 4 repetições e 1 planta por repetição, em que os tratamentos $(\mathrm{T})$ consistiram de $\mathrm{T} 1=$ Solução Completa (Testemunha); T2= Completa - B; $\mathrm{T} 3=$ Completa $-\mathrm{Cu} ; \mathrm{T} 4=$ Completa - Fe; $\mathrm{T} 5=$ Completa $-\mathrm{Mn} ; \mathrm{T} 6=$ Completa - Mo e T7= Completa $-\mathrm{Zn}$, totalizando 7 tratamentos. O experimento foi montado esquematicamente com um DIC de $7 \times 4$ totalizando um número de 28 mudas. As soluções foram trocadas a cada quinze dias durante o período experimental.
As características biométricas, consideradas para avaliação das mudas foram: altura da parte aérea $(\mathrm{H})$ - medida do colo até a inserção do último par de folhas - e diâmetro do colo (D). Ao final do experimento, 150 dias após a semeadura das sementes, as plantas foram colhidas, separadas as partes aérea e radicular, lavadas em água corrente e em água deionizada. Posteriormente foram colocadas em estufa de circulação forçada de $\mathrm{ar}$, à temperatura de $65-70^{\circ} \mathrm{C}$, até $\mathrm{O}$ material atingir peso constante.

O material vegetal seco foi pesado em uma balança de precisão $(0,01 \mathrm{~g})$, para obtenção da massa seca da parte aérea (MSPA), massa seca da raiz (MSR) e massa seca total (MST). Foi calculado o índice de qualidade de Dickson (IQD) (DICKSON et al., 1960), obtido pela seguinte fórmula:

$$
I Q D=\frac{M S T}{\left(\frac{H}{D}\right)+\left(\frac{M S P A}{M S R}\right)}
$$


Os dados obtidos foram submetidos à análise de variância, e as médias avaliadas pelo teste Scott-Knott a 5\% de probabilidade. Foram geradas planilhas eletrônicas no Microsoft EXCEL $®$ e as análises foram realizadas com o auxílio do software R@ versão 2.11.1 (R DEVELOPMENT CORE TEAM, 2010).

\section{RESULTADOS E DISCUSSÃO}

A emergência das plântulas ocorreu aos 15 dias após o plantio, a taxa de germinação foi de 99\%. Caldeira et al. (2000) relataram a obtenção de mudas de Acacia negra aos 14 dias após as sementes serem colocadas para germinar.

As mudas de Acacia negra apresentaram diferenças significativas ( $P e \geq 0,05)$, nas variáveis biométricas devido à omissão de micronutrientes (Tabela 02), sendo que, Fe, Mo, $\mathrm{B}, \mathrm{Zn}$ e $\mathrm{Cu}$ foram os que mais influenciaram negativamente desenvolvimento da espécie.

Tabela 2. Altura, diâmetro do colo e índice de qualidade de mudas de Dickson (IQD) nos tratamentos como omissão de micronutrientes em Acacia mearnsii (Acacia negra).

\begin{tabular}{|c|c|c|c|c|c|c|}
\hline Tratamentos & Diâmetro do colo $-\mathrm{D}(\mathrm{mm})$ & Altura $-\mathrm{H}(\mathrm{cm})$ & \multicolumn{2}{|c|}{ IQD } \\
\hline Completo & 3,69 & $\mathrm{a}^{*}$ & 47,50 & $\mathrm{a}$ & 0,43 & $\mathrm{a}$ \\
\hline Completo $-\mathrm{Mn}$ & 3,30 & $\mathrm{a}$ & 35,24 & $\mathrm{~b}$ & 0,39 & $\mathrm{a}$ \\
\hline Completo - Cu & 2,86 & $\mathrm{~b}$ & 28,76 & $\mathrm{c}$ & 0,32 & $\mathrm{a}$ \\
\hline Completo - ZN & 2,62 & $\mathrm{~b}$ & 27,81 & $\mathrm{c}$ & 0,17 & $\mathrm{a}$ \\
\hline Completo - B & 2,50 & $\mathrm{~b}$ & 27,50 & $\mathrm{c}$ & 0,24 & $\mathrm{a}$ \\
\hline Completo - Mo & 2,30 & $\mathrm{~b}$ & 27,51 & $\mathrm{c}$ & 0,14 & $\mathrm{a}$ \\
\hline Completo - Fe & 1,91 & $\mathrm{~b}$ & 15,50 & $\mathrm{~d}$ & 0,10 & $\mathrm{a}$ \\
\hline
\end{tabular}

*Médias seguidas pela mesma letra pertencem a um mesmo grupo pelo teste Scott-Knott a 5\% de significância.

Para o diâmetro do colo (D) foi observado um desempenho superior nos tratamentos completos e com omissão de Mn, evidenciando a baixa influência da ausência deste micronutriente no desenvolvimento inicial das mudas.

Para a altura das mudas $(\mathrm{H})$ o tratamento com omissão de $\mathrm{Mn}$ apresentou diferença significativa para os demais em que houve omissão de micronutrientes. As mudas de Acacia mearnsii apresentaram maior desenvolvimento em altura no tratamento completo.

Tanto para $\mathrm{D}$ e $\mathrm{H}$ o tratamento com omissão de ferro apresentou o menor desempenho, o que revela uma redução drástica no crescimento das mudas da espécie em condição de baixa disponibilidade deste micronutriente.

Não houve diferença estatística entre os tratamentos para o Índice de qualidade de mudas de Dickson - IQD. Esse fato se deve à grande variabilidade observada na massa seca obtida das mudas, pois tanto para a parte aérea quanto para o sistema radicular observou-se coeficientes de variação acima de $60 \%$. Sorreano et al. (2008) ao analisarem a omissão de micronutrientes em sangra d'água observaram comportamento semelhante e concluíram que a produção de biomassa das mudas mostrou-se pouco influenciada pelos tratamentos, não apresentando diferença significativa na produção de matéria seca. $O$ pequeno número de repetições, o alto coeficiente de variação e o tempo de duração do experimento (150 dias) podem ter contribuído para esse resultado. Comportamento semelhante foi observado por Duboc (1994) e Sorreano (2006), em mudas de jatobá (Hymenaea courbaril L. var.), onde a produção de matéria seca também não apresentou diferença significativa.

\section{CONCLUSÕES}

A omissão de ferro foi a condição que mais prejudicou o crescimento inicial das mudas de Acacia mearnsii.

A ausência de manganês não afetou significativamente o desenvolvimento das mudas, revelando baixa exigência deste nutriente para Acacia mearnsii durante 0 período estudado. 


\section{AGRADECIMENTOS}

À Coordenação de Aperfeiçoamento de Pessoal de Nível Superior - CAPES pela

\section{REFERÊNCIAS}

[1] Britton, G. (1996) Untitled. In: Growing Australian Blackwood for Timber: A Strategic Workshop, Lorne, Victoria. Unpublished proceedings. RIRDC/LWRRDC/FWPRDC Joint Venture Agroforestry Program.

[2] Caldeira, M.V.W.; Schumacher, M.V.; Tedescoet, N. Seedlings growth of Acacia mearnsii according to the vermicompost doses. Scientia Forestalis, 2000.

[3] Costermans, L.F. (1981) Native Trees and Shrubs of South-eastern Australia. Rigby, Adelaide, $422 \mathrm{pp}$.

[4] Dickson, A.; leaf, A.; Hosner, J.F. Quality appraisal of white spruce and white pine seedling stock in nurseries. Forestry Chronicle, v.36, p.1013, 1960.

[5] Duboc, E. Enriquecimento nutricional de espécies florestais nativas: Hymenaea courbaril, Copaifera langsdorffii e Peltophorum dubium.1994.68f. Dissertação (Mestrado) Escola Superior de Agricultura de Lavras, Lavras, 1994.

[6] Hoagland, D.R. \& Arnon, D.I. (1950). The water-culture methodf or growing plants without soil. California Agriculture Experiment Station Circular 347, revised.

[7] Maestri, R. Estimativa de produção presente e futura de volume de madeira e peso de casca para povoamentos de acácia-negra (Acacia mearnsii De Wild). Curitiba: Universidade Federal do Paraná, 1992. 102p. Tese Mestrado.

[8] Martins-corder, M.P.; Borges, R.Z.; junior, N.B. Fotoperiodismo e quebra de dormência em sementes de acácia negra (Acacia mearnsii DE concessão de bolsas de estudos. Ao CNPq pelo apoio financeiro.

WILD.). Ciência Florestal, Santa Maria, v.9, n.1, p. 71-77, 1999.

[9] Popinigis, F. Fisiologia da semente. 2. ed. Brasília: ABRATES, 298 p., 4. 1985.

[10] R Development Core Team (2010). R: A language and environment for statistical computing. R Foundation for Statistical Computing, Vienna, Austria. ISBN 3-900051-07-0, URL http://www.R-project.org.

[11] Sorreano, M.C.M. Avaliação da exigência nutricional na fase inicial de crescimento de espécies florestais nativas. 2006. 296 f. Tese (Doutorado em Ecologia Aplicada) - Escola Superior de Agricultura "Luiz de Queiroz", Universidade de São Paulo, Piracicaba, 2006.

[12] Sorreano, M.C.M.; Malavolta, E.; Silva, D.H.; Cabral, C.P.; Rodrigues, R.R. Deficiência de micronutrientes em mudas de sangra d'água (Croton urucurana, Baill.). Cerne, Lavras, v. 14, n. 2, p. 126-132, abr./jun. 2008.

[13] Tonietto, L.; Stein, P.P. Silvicultura da acácia negra (Acacia mearnsii De Wild) no Brasil. Florestar Estatístico, v.4, n.12, p. 11-16. Nov.1996/ Out.1997.

[14] Tonini, H.; Halfeld-Vieira, B.A. Desrama, crescimento e predisposição à podridão-do-lenho em Acacia mangium. Pesq. agropec. bras., Brasília, v. 41, n. 7, p. 1077-1082, 2006.

[15] Yap, S.K.; Wong, S.M. Seed biology of Acacia mangium, Albizia falcataria, Eucalyptus spp., Gmelina arborea, Masopsis eminiis, Pinus caribaea and Tectonia grandis. The Malaysian Forester, Selangor. v.6, n.1, p.26-45. 1983. 


\section{Capítulo 4}

\section{POTENCIAL FUNGITÓXICO DO ÓLEO ESSENCIAL DE ROSMARINUS OFFICINALIS NO CONTROLE DO ASPERGILLUS FLAVUS}

\section{Lundoi Tobias Lee}

Ana Paula Martinazzo

Carlos Eduardo de Souza Teodoro

Sabrinna Aires Garcia

Ronald de Oliveira Rodrigues Junior

Resumo: Realizar o controle de fungos que atacam produtos agrícolas com compostos químicos sintéticos muitas vezes é ineficiente devido aos mesmos se tornarem resistentes aos produtos utilizados e provocarem a poluição ambiental. Por esses fatores, tem-se buscado alternativas, como os óleos essenciais, os quais se apresentam como uma alternativa eficiente devido sua ação fungitóxica e fungicida, além da ação inseticida e bactericida. Objetivou-se neste trabalho, avaliar o potencial fungitóxico do óleo essencial de alecrim (Rosmarinus officinalis) sobre o fungo Aspergillus flavus. O ensaio foi realizado por meio do método da difusão em ágar nas doses: 0,8; 1,6; 3,2; 6,4; 12,8; 15; 17,5; 20; 22,5 e $25 \mu \mathrm{L} / \mathrm{mL}$ de óleo essencial. Os resultados demonstraram que nas doses inferiores a $15 \mu \mathrm{L} / \mathrm{mL}$ o óleo não foi eficiente na inibição do crescimento fúngico, para as concentrações mais elevadas houve inibição do desenvolvimento, mas a efetividade foi variada, no fim do período de observação para as doses de 15 e 17,5 $\mu \mathrm{L} / \mathrm{mL}$ se obteve acima de $52 \%$ de inibição do crescimento micelial, sendo a dose de $25 \mu \mathrm{L} / \mathrm{mL}$ a mais eficiente apresentando a controle acima de $90 \%$ durante o período observado. 


\section{INTRODUÇÃO}

Diversas espécies fúngicas muitas vezes adquirem resistência aos produtos químicos que são utilizados para combatê-los, tornando-se ineficientes no seu controle além de provocarem a poluição ambiental. Tais fatos proporcionaram 0 incentivo de pesquisas para se buscar alternativas que controle de microrganismos considerados pragas de produtos agrícolas. Produtos como óleos essenciais, extratos brutos e tinturas, provenientes de plantas medicinais tem sido estudo de diversos autores, a exemplo de Degáspari et al. (2005) e Bakkali et al. (2008), devido à sua complexa composição com substâncias com capacidade de combater microrganismos.

Óleos essenciais são compostos naturais, voláteis, de estruturas complexas. Apresentam como característica odor forte e são extraídos de plantas aromáticas, produzidos por meio do metabolismo secundário. São substâncias repelentes ou atraentes das plantas, podendo se acumular em todos os órgãos vegetais (KNAAK e FIUZA, 2010; MACHADO et al., 2013). Tem demonstrado ação fungitóxica direta, a qual inibe 0 crescimento micelial concomitantemente a germinação de esporos, ou pela indução de fitoalexinas, metabólitos secundários, antimicrobianos, de baixo peso molecular, produzidos pelas plantas em resposta a situações de estresse, com o intuito de impedir a atividade de patógenos, o modo de ação dessas substâncias em relação aos fungos ocorre com a granulação do citoplasma, desorganização dos conteúdos celulares, rompimento da membrana plasmática e inibição das enzimas fúngicas (PEREIRA et al., 2006; HILLEN et al., 2012; SARMENTOBRUM et al., 2013).

A espécie Rosmarinus officinalis conhecida como alecrim, é uma planta de pequeno porte, aromática, nativa da região do Mediterrâneo, cultivada em quase todos os países de clima temperado, se desenvolve bem em solo rico em calcário e em ambientes úmidos de clima ameno. É utilizado como condimento na culinária, na medicina tradicional de vários países, o óleo essencial é constituído por uma mistura de componentes voláteis o que caracteriza o odor típico, entre eles estão principalmente cineol, alfa-pineno e cânfora, e os não voláteis - ácido caféico, diterpenos amargos, flavonoides e triterpenóides (LORENZI,
2008).Os fungos estão distribuídos de maneira abundante na natureza e apresentam importância econômica, são utilizados na produção de alimentos, medicamentos, enzimas e ácidos orgânicos (NI et al., 2011). Algumas espécies de fungos são consideradas fitopatogênicas e provocam deterioração em alimentos, por isso os fungos se tornam motivo de preocupação para a indústria alimentícia e para a saúde pública, pois além de reduzirem o valor nutricional dos alimentos também podem produzir micotoxinas, que são substâncias tóxicas produzidas através dos metabólitos secundários e podem provocar intoxicação em humanos e animais (TIBOLA et al. 2011; LINS et al., 2014 e NI et.al, 2011). Entre a inúmeras micotoxinas encontradas em alimentos, as aflatoxinas são as mais relevantes, são conhecidas por serem mutagênicas, teratogênicas e carcinogênicas, produzida principalmente pela espécie Aspergillus flavus (BIRCK, 2005 e NI et al, 2011), a ingestão de micotoxinas podem desencadear sérias condições de saúde que variam de acordo com a espécie animal, dosagem ingerida, idade, estado nutricional e gênero (SILVA et al., 2015; TIBOLA et al. 2011; LINS et al., 2014; BIRCK, 2005 e NI et al, 2011).

Diante o exposto, o objetivo do presente trabalho foi avaliar o potencial fungitóxico do óleo essencial de alecrim (R. officinalis) em relação ao fungo Aspergillus flavus, que é o principal produtor de aflatoxinas, buscando uma alternativa que combata a ação desta espécie fúngica sem que cause poluição ambiental e danos à saúde tanto humana ou animal.

\section{MATERIAL E MÉTODOS}

\subsection{OBTENÇÃO DOS MICRO-ORGANISMOS}

A cepa contendo o Aspergillus flavus (№ de acesso da linhagem IOC 4102) foi obtida através da Coleção de Culturas de Fungos Filamentosos (CCFF) - IOC/FIOCRUZ.

\section{2 ÓLEO ESSENCIAL}

O óleo essencial de Alecrim (Rosmarinus officinalis) foi obtido por uma empresa do ramo. 


\subsection{TESTE IN VITRO}

A metodologia utilizada foi a difusão em ágar (NOSTRO et al., 2004), observando o desenvolvimento ou inibição do fungo nas diferentes concentrações de óleo essencial usando meio de cultura BDA (Batata, Dextrose e Ágar). Ao meio de cultura autoclavado por 20 minutos a $121^{\circ} \mathrm{C}$, o óleo essencial foi diluído em uma solução contendo $800 \mu \mathrm{L}$ de DMSO (Dimetilsulfóxido) e água destilada, nas seguintes doses: 0,8; 1,$6 ; 3,2 ; 6,4 ; 12,8 ; 15 ; 17,5 ; 20 ; 22,5$ e 25 $\mu \mathrm{L} / \mathrm{mL}$, com cinco repetições cada.

O meio contendo as diferentes doses de óleo essencial foi vertido em placa de Petri de 9 $\mathrm{cm}$ de diâmetro e o inóculo, constituído por um disco de micélio de $7 \mathrm{~mm}$ de diâmetro, contendo o fungo em estudo, foi transferido para o centro da placas. As placas foram mantidas em câmara incubadora tipo B.O.D. a temperatura de $30^{\circ} \mathrm{C}$. As placas de controle, sem óleo essencial, foram inoculadas seguindo o mesmo procedimento. O diâmetro das colônias foi registrado diariamente por meio de um paquímetro digital.

\subsection{ANÁLISES ESTATÍSTICAS}

As análises estatísticas foram realizadas por análise de variância, utilizando-se o teste de
Scott-Knott, a 5\% de significância, para estudar as médias de tratamentos considerando as variáveis respostas e identificar quais dosagens diferiram significantemente entre $\mathrm{si}$, por meio do programa estatístico SISVAR ${ }^{\circledR}$.

\section{RESULTADOS E DISCUSSÃO}

O óleo essencial de alecrim (R. officinalis) utilizado no experimento apresentou como principais componentes: beta-pineno $8 \%, 1,8$ cineol $48 \%$ e cânfora $12 \%$ segundo informações obtidas por laudo técnico da empresa fornecedora.

De acordo com Nascimento et al. (2007), a variação da composição química de óleos essenciais, recebem influência de alguns fatores, como a região de cultivo, método de análise e extração, sendo fundamental o conhecimento da composição química do óleo a ser analisado.

A atividade antimicrobiana do óleo essencial para o fungo A. flavus, observada está apresentada na Tabela 01, para as dosagens acima de $15 \mu \mathrm{L} / \mathrm{mL}$, as quais se mostraram eficientes na inibição do fungo em relação às doses inicialmente testadas $(0,8 ; 1,6 ; 3,2 ; 6,4$; $12,8 \mu \mathrm{L} / \mathrm{mL})$.

Tabela 01. Porcentagem média de inibição (\%), in vitro, no crescimento do Aspergillus flavus para diferentes dosagens $(\mu \mathrm{L} / \mathrm{mL})$ do óleo essencial de alecrim (rosmarinus officinalis).

\begin{tabular}{|c|c|c|c|c|c|c|c|c|c|c|}
\hline & & rc & ger & $\ln$ & ão c & es & en & e & & \\
\hline D & & & & & & & & & & \\
\hline & 1 & 2 & 3 & 4 & 5 & 6 & 7 & 8 & 9 & 10 \\
\hline 15 & $96 a A$ & $92 \mathrm{aA}$ & $88 \mathrm{bB}$ & $87 \mathrm{bB}$ & $86 \mathrm{bB}$ & $86 \mathrm{bB}$ & $78 \mathrm{bB}$ & $72 \mathrm{cC}$ & $61 \mathrm{cD}$ & $52 \mathrm{dE}$ \\
\hline 17,5 & $95 a A$ & $92 \mathrm{aA}$ & $87 \mathrm{bB}$ & $85 b B$ & $84 \mathrm{bB}$ & $84 \mathrm{bB}$ & $77 \mathrm{bB}$ & $71 \mathrm{cC}$ & $59 c D$ & $53 \mathrm{dD}$ \\
\hline 20 & $98 a A$ & $98 a A$ & $91 \mathrm{bA}$ & $90 \mathrm{bA}$ & $89 \mathrm{bA}$ & $89 \mathrm{bA}$ & $85 \mathrm{bA}$ & $82 \mathrm{bA}$ & $72 \mathrm{bB}$ & $70 \mathrm{cB}$ \\
\hline 22,5 & $99 a A$ & $99 a A$ & $96 a A$ & $95 a A$ & $95 a A$ & $95 a A$ & $92 a A$ & 91aA & $86 a B$ & $80 b B$ \\
\hline 25 & $96 a A$ & $98 a A$ & 99aA & $95 a A$ & $99 a A$ & $99 a A$ & $94 a A$ & $94 a A$ & $93 a A$ & $91 a A$ \\
\hline
\end{tabular}

As médias seguidas pelas mesmas letras, minúsculas nas colunas e maiúsculas nas linhas, não se diferem estatisticamente entre si, pelo teste de Scott-Knott, ao nível de 5\% de significância.

Foi evidenciado a partir do terceiro dia que a doses de 15 e $17,5 \mu \mathrm{L} / \mathrm{mL}$ diferiram-se estatisticamente das demais, para as quais foi possível observar o início da redução da ação inibitória do óleo de alecrim, mantendo-se estatisticamente invariáveis até o sétimo dia, posteriormente apresentaram uma baixa no percentual de inibição demonstrando a redução da eficiência do óleo essencial, após o período de observação foi verificado que essas dosagens não diferem entre si estatisticamente, exercendo a mesma atividade antifúngica. 
A dose de $20 \mu \mathrm{L} / \mathrm{mL}$ demonstrou ação inibitória superior a $88 \%$ nos primeiros dias, apresentando uma pequena redução na ação antifúngica a partir do terceiro dia observada através do porcentual médio de inibição, se mantendo estatisticamente igual até o nono dia com ação fúngica superior a $72 \%$. $\mathrm{Na}$ avaliação do desempenho da dose de 22,5 $\mu \mathrm{L} / \mathrm{mL}$ foi observado que se manteve estatisticamente igual até o nono dia, se mantendo com ação inibitória superior a $80 \%$ durante o período observado.

Os resultados obtidos através da dosagem de $25 \mu \mathrm{L} / \mathrm{mL}$ foram superiores aos encontrados para as outras concentrações testadas, onde permaneceu estatisticamente igual em todos os dias observados, com ação inibitória superior a 91\%. Com esses resultados atestou-se que a dosagem que apresentou a melhor ação antifúngica frente ao Aspergillus flavus dentre as analisadas é a $25 \mu \mathrm{L} / \mathrm{mL}$.

Os resultados apresentados na Figura 01 enfatizam a diferença significativa, no último dia de incubação (décimo), entre as doses na inibição do crescimento micelial do fungo em questão. Todas as dosagens testadas inibiram em pelo menos $50 \%$ o crescimento micelial do A. flavus. A dose de $25 \mu \mathrm{L} / \mathrm{mL}$ foi o mais eficiente, pois causou inibição acima de 91\% no decorrer da análise.

Figura 1: Inibição média do crescimento micelial do fungo A. flavus para diferentes doses do óleo essencial de alecrim.

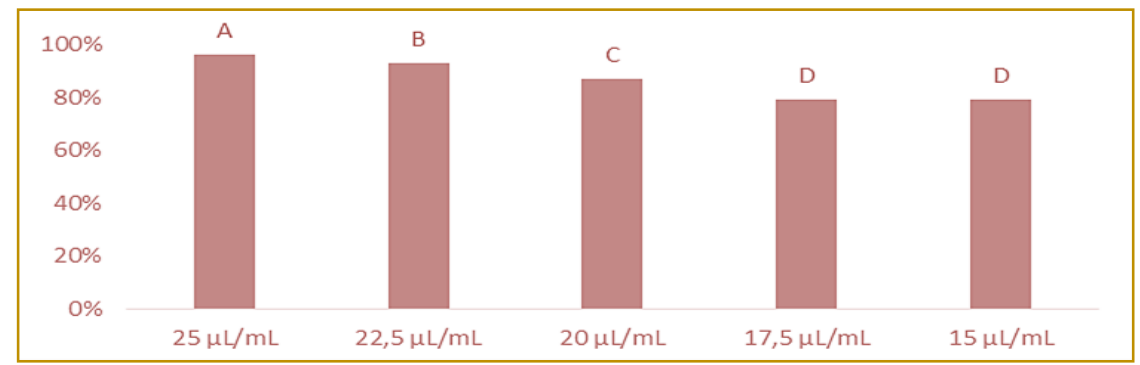

${ }^{\star}$ As médias seguidas pela mesma letra não diferem entre si pelo teste de Scott-knott a 5\% de significância.

\section{CONCLUSÕES}

O óleo essencial de alecrim (R. officinalis) se mostrou eficiente em inibir o crescimento do A. flavus, no teste in vitro, podendo ser uma alternativa no controle de fitopatógenos, sendo uma opção natural e sem causar poluição ambiental ou danos à saúde humana ou animal.

\section{REFERÊNCIAS}

[1] Bakkali, F.; Averbeck S.; Averbeck D.; Idaomar, M. Biological effects of essential oils - A review. Food and Chemical Toxicology, Amsterdam, v. 46, n. 2, p. 446-475, 2008. Birck, N. M. M. Contaminação fúngica, micotoxinas e sua relação com a infestação de insetos em trigo armazenado. Florianópolis, 2005. $146 \mathrm{f}$. Dissertação (Mestrado em Ciências dos Alimentos) Centro de Ciências Agrárias, Universidade Federal de Santa Catarina, Florianópolis, 2005.

[2] 'Degáspari, C. H.; Waszczynskyj, N.; Prado, M.R.M. Atividade antimicrobiana de Schinus terebenthifolius Raddi. Ciência e Agrotecnologia, Lavras, v. 29, n. 3, p. 617-622, maio/jun., 2005.
No ensaio realizado através da metodologia de difusão em meio, a concentração de 25 $\mu \mathrm{L} / \mathrm{mL}$ do óleo essencial de alecrim demonstrou ser a mais eficiente no controle do crescimento do fungo $A$. flavus, mantendo sua ação antinfúngica e a média de inibição estatisticamente igual no decorrer dos dias analisados.

[3] Hillen, T.; Schwan-Estrada, K.R.F.; Mesquini, R.M.; Cruz, M.E.S.; Stangarlin, J.R.; Nozaki, M. Atividade antimicrobiana de óleos essenciais no controle de alguns fitopatógenos fúngicos in vitro e no tratamento de sementes. Revista Brasileira de Plantas Medicinais, Botucatu, v.14, n.3, p.439-445, 2012.

[4] Knaak, N. Fiuza, L. M. Potencial dos óleos essenciais de plantas no controle de insetos e microrganismos. Neotropical Biology and Conservation, v.5, n.2, p.120-132, 2010.

[5] Lins, J. L. F., Silva, J. M., Silva, L. P., Santos, T. M. C., Santos, E. L. Ocorrência de fungos de campo e armazenamento em 
ingredientes e rações para suínos. Revista Verde. Mossoró, v. 9, n.2, p. 14 - 20, 2014.

[6] Lorenzi, H. Plantas medicinais no Brasil: nativas e exóticas. 2. Ed. Nova Odessa, SP: Instituto Plantarum, 2008, 544p.

Machado, R. M. A.; Mussi-Dias, V.; Souza, C. L. M. S.; Silva, L. B.; Freire, M. G. M. Avaliação de óleos essenciais sobre o crescimento in vitro do fungo colletotrichum gloeosporioides. Perspectivas Online: Biológicas \& Saúde, v. 8, n. 3, p.64-75, 2013

[8] Nascimento, P. F. C.; Nascimento, A. C.; Rodrigues, C. S.; Antoniolli, A. A.; Santos, P. O.; Barbosa Junior, A. M.; Trindade, R. C. Atividade antimicrobiana dos óleos essenciais: uma abordagem multifatorial dos métodos. Revista Brasileira de Farmacognosia, João Pessoa, v. 17, n. 1, p. 108-113, 2007.

[9] NI, M., GAO, N., Kwon, N. J., Shin, K. S., YU, J. H. Regulation of Aspergillus Conidiation In: Cellular and Molecular Biology of Filamentous Fungi. Katherine Borkovich, Daniel J. Ebbole American Society for Microbiology Press, 2010, 802 p.
[10] Nostro A., Blanco A.R., Cannatelli M.A., Enea V., Flamini G., Morelli I., Roccaro A.S., Alonzo V. Susceptibility of methicillin-resistant staphylococci to oregano essential oil, carvacrol and thymol. FEMS Microbiol Letters, v. 230, n.2, p. 191-195, 2004

[11] Sarmento-Brum, R. Santos, G.R., Castro, H.G., Gonçalvez, C.G., JÚNIOR, A.F.C., NASCIMENTO, I.R. Efeito de óleos essenciais de plantas medicinais sobre a Antracnose do sorgo. Bioscience Journal, Uberlândia, v. 29, n. 1, p. 1549-1557, 2013.

[12] Silva, F. C.; Chalfoun, S. M.; Batista, L. R.; Santos, C. Lima, N. Taxonomia polifásica para identificação de Aspergillus Seção flavi: uma revisão. Revista Ifes Ciência, Santa Tereza, v. 1, n.1, p. 18-40, 2015.

Tibola, C.S., Mori, C., Guarienti, E.M., Lorini, I., Lima, M. I. P. M., Miranda, M. Z. Gestão da qualidade do trigo na pós-colheita. In: Pires, J.L.F., Vargas, L., Cunha, G.R. Trigo no Brasil Bases para a produção competitiva e sustentável. Passo Fundo: Embrapa Trigo, 2011. cap 16, p.391-426. 


\title{
Bapítulo 5
}

\section{ESPOROS DE FUNGOS MICORRIZZICOS ARBUSCULARES EM LAVOURAS DE CAFEEIROS (COFFEA CANEPHORA L.) NO ESTADO DE RONNDONIA}

\author{
Marta de Souza da Silva \\ Franklin dos Santos Amaral \\ Ana Lucy Caproni \\ Gabriel Cestari Vilardi \\ José Rodolfo Dantas de Oliveira Granha \\ Ricardo Luis Louro Berbara
}

Resumo: Os fungos micorrízicos arbusculares (FMAs) atuam na fertilidade do solo e nutrição vegetal, estando presentes como facilitadores da nutrição do cafeeiro. Este trabalho teve por objetivo analisar as comunidades dos FMAs em solos sob sistemas de cafeeiro a pleno sol e em sistemas agroflorestais, como indicadores de estabilidade de ecossistemas agrícolas nos municípios de Nova Mamoré e de Guajará Mirim/RO. Foram realizadas amostragens aleatórias de solos sob plantas de café na profundidade de $0-10 \mathrm{~cm}$. As extrações dos esporos foram feitas pela técnica de peneiramento em via úmida seguindo-se centrifugação com sacarose. Os esporos foram então contados e transferidos para lâminas para serem identificados e contados por espécie. Foram calculados a densidade dos esporos, a densidade de cada espécie, a frequência de ocorrência de cada espécie e os índices de diversidade de Shannon e de dominância de Simpson. A densidade média dos esporos dos FMAs diferiu entre os sistemas de cafeeiros, sendo as maiores médias observadas em dois sistemas de café a pleno sol, um no município de Nova Mamoré e outro no de Guajará Mirim. Os sistemas apresentaram um total de 34 espécies, pertencentes a 11 gêneros e 10 famílias. Desse total, 30 espécies ocorreram nas amostras de solo coletadas no município de Nova Mamoré e 27 espécies no município de Guajará Mirim. As famílias identificadas foram Glomeraceae, Acaulosporaceae, Entrophosporaceae, Scutellosporaceae, Archeosporaceae, Dentiscutataceae, Gigasporaceae, Racocetraceae, Sacculospoceae e Paraglomeraceae. Em todos os sistemas avaliados, a maior frequência de ocorrência de espécies pertenceu aos gêneros Glomus e Acaulospora. Os índices de diversidade de espécies não diferiram entre os sistemas de cafeeiro.

Palavras-Chave: Fungos Micorrizicos Arbusculares; Café; Densidade de espécies; Indices de diversidade. 


\section{INTRODUÇÃO}

A cultura do cafeeiro na Amazônia ocupa uma área de aproximadamente 180.000 ha, tendo Rondônia, a maior área plantada (83334 ha), entretanto com produtividade média (CONAB, 2018; IBGE, 2012). A produtividade da cafeicultura regional alcançou em 2013 apenas $13 \mathrm{sc} /$ há, sendo considerada baixa. $\mathrm{O}$ sistema de produção prevalecente na região condicionou este resultado que é conduzido com ausência de tratos culturais como desbrota, poda e adubação, assim como métodos inadequados de colheita e póscolheita. Por ser característico da pequena produção familiar em muitas regiões da Amazônia, o café é cultivado em pequenas áreas (MARCOLAN et al., 2015).

Para amenizar os custos da produção do cafeeiro e melhorar a fertilidade do solo tornam-se necessários estudos relacionados aos microrganismos do solo. No contexto da fertilidade do solo e nutrição vegetal, os microrganismos podem atuar como "facilitadores" da nutrição, interferindo na disponibilidade dos nutrientes, contribuindo assim, para reduzir a necessidade ou maximizar o uso de fertilizantes manufaturados (SIQUEIRA; MOREIRA, 1996). Para que as associações plantasmicrorganismos possam contribuir efetivamente para uma melhor nutrição das plantas, primeiro é necessário avaliar as características simbióticas da microbiota natural dos solos e posterior inoculação dos microrganismos mais eficientes previamente selecionados e testados (COSTA, 2010). Um dos microrganismos que atuam no incremento da nutrição das plantas são os FMAs.

Os FMAs formam uma importante associação mutualística com as raízes de grande parte das plantas no planeta terrestre. A planta fornece carboidratos ao fungo, que em troca transfere para a planta hospedeira os nutrientes que absorvem do solo através de sua rede micelial, desempenhando assim um papel importante no crescimento e nutrição das mesmas (SIEVERDING, 1991). A associação mutualística destes fungos com as plantas é chamada de micorrizas arbusculares, isto é, quando as hifas penetram nas células corticais das raízes das plantas. Após este processo as hifas se estendem no solo próximo às raízes. Segundo Hoffmann e Lucena (2006), as hifas funcionam como extensão das raízes das plantas, uma vez que, devido à sua grande capacidade de ramificação, exploram o solo, realizando absorção de água e nutrientes minerais, que são transferidos para as plantas por meio de estruturas intracelulares, efêmeras, denominadas arbúsculos. Segundo Berbara et al. (2006), micorrizas arbusculares são reconhecidas por sua habilidade em estimular 0 crescimento de plantas, principalmente por meio do incremento na absorção de nutrientes, principalmente o fósforo, dentre outros que também são pouco móveis no solo tais como o $\mathrm{Cu}, \mathrm{Mg}$ e $\mathrm{Zn}$. Outros pesquisadores afirmam ainda que:

As micorrizas têm apresentado efeitos benéficos nas mais variadas condições e espécies vegetais, sobretudo em solos de baixa fertilidade. Pode-se destacar o aumento na absorção e melhor conservação de nutrientes, como o fósforo; o aumento na nodulação e fixação do $N_{2}$ atmosférico; a alteração na relação planta-patógenos; as alterações na relação água-solo-planta; a alteração sobre a estruturação e estabilidade de agregados no solo, o aumento na produção de fitohormônios; as modificações anatômicas e fisiológicas do hospedeiro, proporcionando melhor adaptabilidade da planta às condições adversas e ainda, colaboram para o aumento do dreno de carbono (C) da atmosfera (JAKOBSEN et al., 2002; LEAKE et al., 2004).

Os FMAs têm sido estudados, visando à sua aplicação para incrementar o desenvolvimento e a produção das culturas mediante seus efeitos na nutrição das plantas e outros benefícios diretos e indiretos (TRINDADE, 2000). A utilização de micorrizas arbusculares com elevada eficiência simbiótica e competitividade no agrossistema de cafeeiro na região Amazônica, contribuirá para um manejo eficientemente econômico e adequado à realidade ambiental, ajudando à fixação do homem na região, quebra da agricultura itinerante e manutenção do equilíbrio ecológico e da agricultura familiar (COSTA, 2010).

Entretanto, existem poucos estudos com relação à identificação e seleção de espécies de FMAs com elevada eficiência simbiótica e competitividade e possíveis interações com outros microrganismos e plantas multiplicadoras no agrossistema cafeeiro (Coffea canephora L.) na região Amazônica.

Diante da importância ecológica dos FMAs, o presente trabalho vem contribuir para o conhecimento sobre a sua diversidade em ecossistemas de cafeeiros nos municípios de 
Nova Mamoré e Guajará Mirim/RO, possibilitando assim o desenvolvimento de pesquisas que visam a melhoria da produção de café nos diferentes ecossistemas no estado de Rondônia. Este conhecimento vem contribuir para novas pesquisas no sentido de amenizar os custos de manutenção desta cultura agrícola e otimização da produção do café.

Este trabalho teve por objetivo analisar as comunidades dos fungos micorrízicos arbusculares em solos sob sistemas de cafeeiro solteiro e em sistemas agroflorestais, como indicadores de estabilidade de ecossistemas agrícolas nos municípios de Nova Mamoré e de Guajará Mirim/RO. E teve como objetivo específico identificar os esporos dos FMAs presentes nas proximidades das raízes de cafeeiros no período chuvoso (abril de 2016).

\section{MATERIAL E MÉTODOS}

Os sistemas estudados estão localizados no Município de Nova Mamoré e de Guajará Mirim - RO (a 280 e 320 Km, respectivamente, de Porto Velho) próximos ao Rio Madeira Mamoré e são de propriedades de pequenos produtores rurais. Nestes, foram coletadas amostras de solos sob o cultivo de cafeeiros em sistemas agroflorestais e em sistemas a pleno sol, sendo quatro em Nova Mamoré e quatro em Guajará Mirim sendo dois com café arborizado e dois com café solteiro em cada município como seguem as descrições:

\begin{tabular}{|c|c|}
\hline \multicolumn{2}{|l|}{ Nova Mamoré } \\
\hline $\begin{array}{l}\text { Cultivo de café } \\
\text { em SAF (Ar): }\end{array}$ & $\begin{array}{l}\text { Constituído por café, jaqueira (Artocarpus heterophyllus. Lam.), mangueira } \\
\text { (Mangifera indica L.), gravioleira (Annona muricata L.), cupuaçu (Theobroma } \\
\text { grandiflorum (Willd. ex Spreng.) K. Schum.) e bambu (Bambusa vulgaris Schrad. ex } \\
\text { J.C.Wendl.), com espaçamento } 3 \times 2 \mathrm{~m} \text {, com } 30 \text { anos de idade, área de } 0,5 \text { ha, } \\
\text { realizava os tratos culturais como podas e roçado manual, o sistema se } \\
\text { apresentava bem arborizado, e foi implantado após derrubada de floresta. }\end{array}$ \\
\hline $\begin{array}{l}\text { Cultivo de café } \\
\text { em SAF (Mc): }\end{array}$ & $\begin{array}{l}\text { Constituído por café, ipê (Handroanthus albus (Cham.) Mattos), com espaçamento } \\
\text { de } 3 \text { × } 6 \text { m, com } 10 \text { anos de idade, } 1,5 \text { ha, realizava os tratos culturais como podas, } \\
\text { roçadas semi-mecânicas e controle químico, o sistema apresentava poucas plantas } \\
\text { invasoras e foi implantado após derrubada da floresta. }\end{array}$ \\
\hline $\begin{array}{l}\text { Cultivo de } \\
\text { pleno sol }\end{array}$ & $\begin{array}{l}\text { Com espaçamento de } 3 \times 2 \mathrm{~m} \text {, com } 8 \text { anos de idade, } 2,0 \text { ha, realizava os tratos } \\
\text { culturais como podas, roçadas semi-mecânicas e controle químico, o sistema } \\
\text { apresentava poucas espécies de plantas invasoras e foi implantado após cultivo de } \\
\text { pastagem. }\end{array}$ \\
\hline $\begin{array}{l}\text { Cultiv } \\
\text { plen }\end{array}$ & $\begin{array}{l}\text { Com espaçamento também de } 3 \times 2 \mathrm{~m} \text {, com } 8 \text { anos de idade, } 1,5 \text { ha, realizava os } \\
\text { tratos culturais como podas e roçado manual, havia presença considerável de } \\
\text { plantas invasoras e o sistema foi implantado após cultivo de pastagem, o solo se } \\
\text { apresentava pedregoso. }\end{array}$ \\
\hline \multicolumn{2}{|l|}{ Guajará-Mirim } \\
\hline $\begin{array}{l}\text { Culti } \\
\text { em }\end{array}$ & $\begin{array}{l}\text { Constituído por café, biribá (Annona (Rollinia), mucosa Jacq. Baill.), palheira } \\
\text { (Orbignya speciosa (Mart.) Barb. Rodr.), cupuaçu (Theobroma grandiflorum (Willd. } \\
\text { ex Spreng.) K. Schum.) e mamão (Carica papaya L.), com espaçamento } 3 \times 2 \text { m, } \\
\text { com } 5 \text { anos de idade, área de } 0,5 \text { ha, realizava os tratos culturais como podas e } \\
\text { roçado manual, o sistema se apresentava bem arborizado, havia presença de } \\
\text { muitas plantas invasoras e foi implantado após derrubada de floresta. }\end{array}$ \\
\hline $\begin{array}{l}\text { Cultiv } \\
\text { em S }\end{array}$ & $\begin{array}{l}\text { Constituído por café, acerola (Malpighia emarginata DC.), cupuaçu, manga } \\
\text { (Mangifera indica L.), abacate (Parsea americana L.), com espaçamento de } 3 \times 2 \\
\text { m, com } 8 \text { anos de idade, } 1,0 \text { ha, realizava os tratos culturais como podas, roçadas } \\
\text { manuais e controle químico, o sistema apresentava com poucas plantas invasoras } \\
\text { e foi implantado após cultivo de pastagem. }\end{array}$ \\
\hline $\begin{array}{l}\text { Cultivo de } \\
\text { pleno sc }\end{array}$ & $\begin{array}{l}\text { Com espaçamento de } 3 \times 2 \mathrm{~m} \text {, com } 8 \text { anos de idade, } 1,0 \text { ha, realizava os tratos } \\
\text { culturais como podas, roçadas semi-mecânicas e controle químico, o sistema } \\
\text { apresentava poucas espécies de plantas invasoras e foi implantado após cultivo de } \\
\text { pastagem; }\end{array}$ \\
\hline $\begin{array}{l}\text { Cultivo d } \\
\text { pleno sc }\end{array}$ & $\begin{array}{l}\text { Com espaçamento também de } 3 \times 2 \mathrm{~m} \text {, com } 8 \text { anos de idade, 1,0 ha, realizava os } \\
\text { tratos culturais como podas e roçado manual, havia presença considerável de } \\
\text { plantas invasoras e o sistema foi implantado após cultivo de pastagem, o solo se } \\
\text { apresentava pedregoso }\end{array}$ \\
\hline
\end{tabular}


Em cada sistema constituído de cultivo de café a pleno sol ou em sistemas agroflorestais coletaram-se solos próximos ao caule da planta de café para serem utilizados para as análises dos esporos dos FMAs.

Foram coletadas, aleatoriamente, oito amostras de solos compostas de 4 sub amostras em cada ecossistema em avaliação, sob as plantas de café. Foi usado um trado com capacidade para $500 \mathrm{~mL}$ de solo, a uma profundidade de $0-10 \mathrm{~cm}$. As amostras foram homogeneizadas e secadas à sombra e armazenadas até o seu processamento.

De cada amostra foram utilizados $100 \mathrm{~mL}$ de solo para a extração dos esporos pela técnica de peneiramento em via úmida (GERDEMANN; NICOLSON, 1963), seguindose centrifugação com sacarose $50 \%(\mathrm{~V}: \mathrm{V})$. Os esporos foram contados e transferidos para uma placa de Petri, sendo que uma parte, escolhida aleatoriamente, foi agrupada por tamanho, cor e forma, colocados em lâminas com álcool polivinil em lactoglicerol (PVLG) e quebrados sob a lamínula, para expor as paredes internas. Na mesma lâmina, um segundo grupo de esporos foi montado com PVLG + reagente de Melzer (1:1). Os resultados da reação de cor ao reagente de Melzer foram usados para caracterizar as paredes dos esporos, melhorando, em alguns casos, a visibilidade, especialmente daqueles com paredes aderentes ou muitos finas. Os esporos foram então identificados e contados por espécie.

A identificação das espécies dos FMAs foi feita segundo Schenck e Perez (1988) e conforme descrição morfológica disponível na internet na página da International Culture Collection of Arbuscular Mycorrhizal Fungi (http://invam.wvu.edu),

(http://www.zor.zut.edu.pl/, e outros, mediante observações em microscópio óptico com iluminação de campo-claro e objetiva de imersão. Os esporos foram contados, mesmo quando parasitados ou não viáveis.

A densidade (D) dos FMAs foi estimada através do número de esporos em $100 \mathrm{~mL}$ de solo e a densidade de cada espécie de FMAs $\left(D_{i}\right)$, como sendo a relação entre o número de esporos de determinada espécie por $100 \mathrm{~mL}$ de solo. As diferenças nas densidades total de esporos e a de espécies, entre as épocas de amostragens e as áreas amostradas, foram analisadas pelo teste não paramétrico de Kruskall-Wallis (SILVA; AZEVED0, 2016). A frequência de ocorrência de cada espécie $\left(F_{i}\right)$ foi calculada conforme a época de amostragens (chuvosa) (BROWER et al., 1990), de acordo com a equação $F_{i}=J_{i} / K$, onde $\mathrm{Fi}=$ Frequência de ocorrência da espécie $\mathrm{i} ; \mathrm{Ji}=$ Número de amostras nos quais a espécie i ocorreu e $\mathrm{k}=$ Número total de amostra.

Os dados obtidos das contagens e identificações dos FMAs foram avaliados quanto aos: índice de diversidade de Shannon-Wiener $\left(H^{\prime}\right)$ e seu correspondente índice de equitabilidade (J'), conforme descrito por Pielou (1977) e Brower (1990) e índice de Diversidade de Simpson (D) conforme descrito por Pielou (1977).

\section{RESULTADOS E DISCUSSÃO}

\subsection{AVALIAÇÃO DOS ESPOROS DOS FMAS}

A densidade média dos esporos dos FMAs diferiu entre os sistemas de cultivo dos cafeeiros, na coleta de amostras de solo feita em abril de 2016 no município de Nova Mamoré e no município de Guajará-Mirim. A maior densidade média observada, no município de Nova Mamoré, foi no sistema de cultivo de cafeeiro do Sr. Jos, no município de Nova Mamoré (Figura 1). Sendo que este sistema de cultivo de café a pleno sol, havia tratos culturais com controle químico, presença de algumas plantas invasoras, porém esta área foi implantada após o cultivo de pastagem. Enquanto que a maior densidade média de esporos observada, no município de Guajará Mirim, foi no sistema de cultivo do Sr. Ve onde era cultivado em sistema agroflorestal constituído de várias espécies de plantas frutíferas (Figura 2). Era um sistema com cinco anos de idade, não realizava controle químico, havia ainda a presença de grande quantidade de plantas invasoras. A produção de esporos de FMAs neste sistema está em concordância com a produção encontrada por Durazzini; Teixeira; Adami (2016), quando compararam o número de esporos em cultivos de cafeeiro em sistema convencional e em sistema agroflorestal no sul do estado de Minas Gerais, que concluíram que o sistema de manejo do café influencia na produção de esporos. 
Figura 1- Densidade média de esporos dos FMAs em amostras de $100 \mathrm{~mL}$ de solo coletadas em abril/2016, nos sistemas de cultivo de café solteiro e sombreado (SAF) no município de Nova Mamoré/RO. Colunas com letras iguais não diferem entre si (teste de Kruskal-Wallis $P>0,05$ ).

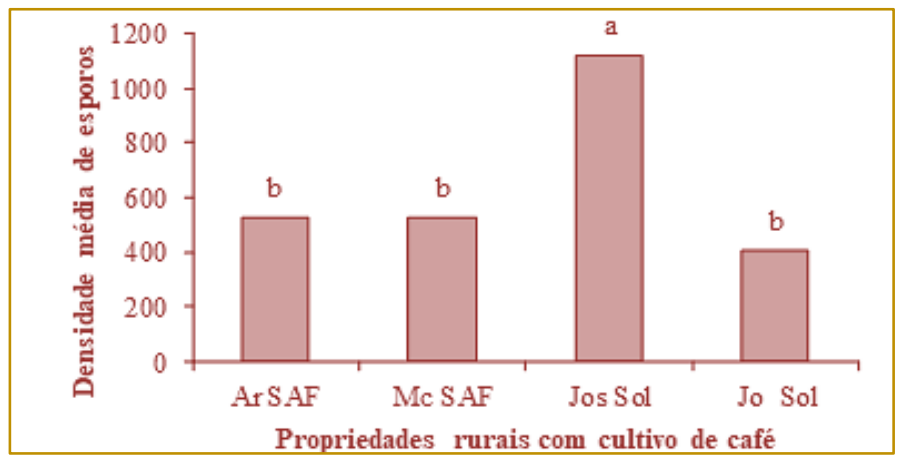

Figura 2- Densidade média de esporos dos FMAs em amostras de $100 \mathrm{~mL}$ de solo coletadas em abril/2016, nos sistemas de cultivo de café solteiro e sombreado (SAF) no município de Guajará-

Mirim/RO. Colunas com letras iguais não diferem entre si (teste de Kruskal-Wallis $P>0,05$ ).

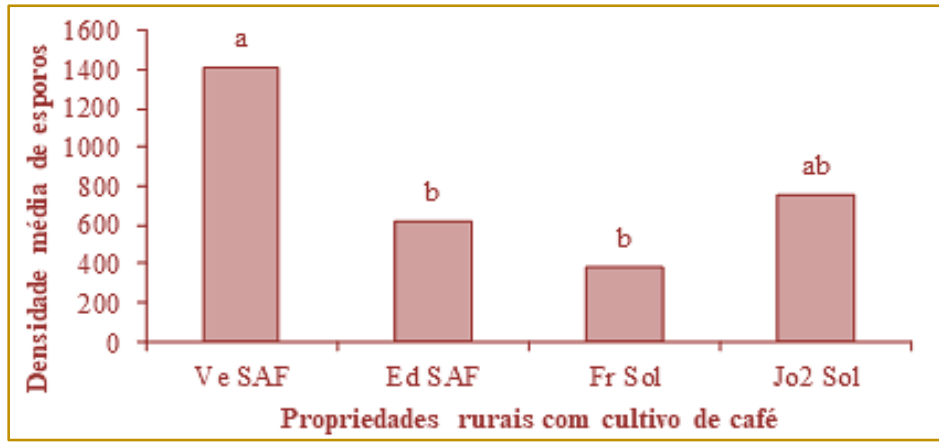

Nos dois sistemas que apresentaram maior número de esporos de FMAs, a presença do componente arbóreo não foi decisiva para a esporulação, mas observou-se a presença de gramíneas e de plantas invasoras. Sendo assim, importante frisar que as gramíneas possuem sistema radicular abundante e de rápido crescimento, com intenso contato entre raízes e propágulos de FMAs e grande capacidade de fornecer fotossintatos ao fungo, que favorece a esporulação (DANIELSHETRICK; BLOOM, 1986), Para Colozzi Filho e Cardoso (2000), a maioria das plantas invasoras são gramíneas, geralmente de sistema radicular fasciculado que tendem a favorecer a micorrização e possibilitar que diferentes espécies de FMAs se mantenham no solo. Para a área do Sr. Ve, com considerável diversidade de espécies cultivadas com o cafeeiro teriam influência na esporulação dos FMAs aliado à época de coleta das amostras de solo no período chuvoso. Fato semelhante foi encontrado por Bonfim et al. (2010) que analisando a influência do sombreamento de grevíleas (Grevillea robusta A. Cunn.) em cultivo de cafeeiro observaram maiores números de esporos em áreas sombreados que não sombreadas.

Com relação aos sistemas de cultivo de café que apresentaram as menores médias nas densidades dos esporos, estas podem ter sido influenciadas por fatores do solo e da planta. No entanto, a produção dos esporos é dependente do grau de colonização das raízes dos cafeeiros. E para Saggin-Júnior e Siqueira (1996) a colonização micorrízica pode ser afetada por diversos fatores, como espécie vegetal, idade da planta, densidade de raízes, propágulos de FMAs presentes no solo, eficiência de colonização, manejo do solo, dentre outros. E a esporulação dos FMAs vai depender de fatores do fungo, da planta da sazonalidade e do manejo da cultura (CARDOSO et al., 2003). $\mathrm{Na}$ propriedade do Sr. Jo, o cafezal com a existência de 30 anos localizada no município de Nova Mamoré, registrou-se baixo número de esporos, notadamente, na época de coleta das amostras de solo, mês de abril de 2016, os cafezais estavam frutificando. De acordo com Balota e Lopes (1996), a esporulação de 
FMAs também estaria relacionada com o período de menor disponibilidade de fontes de carbono para o fungo, que corresponderia à frutificação do cafeeiro, quando os carboidratos são requeridos em maior intensidade pela planta. Este fenômeno ocorre de outubro a abril, com o consumo de nutrientes para frutificação centralizada nesta temporada, diminuindo assim o dreno de fotoassimilados para as hifas dos fungos e consequentemente para a formação de novos esporos no solo (LAVIOLA et al., 2007). Prates Junior (2014) observou houve diferença sazonal, com menor número de esporos de FMAs no período floração do cafeeiro quando comparado ao período de granação e colheita.

\subsection{AVALIAÇÃO DAS ESPÉCIES DOS FMAS}

Os sistemas de cultivo de café a pleno sol e em sistema agroflorestal (sombreado), apresentaram um total de 33 espécies, pertencentes a 11 gêneros, 10 famílias. Desse total, 30 espécies ocorreram nas amostras de solo coletadas no município de Nova Mamoré e 27 espécies no município de Guajará Mirim. Destas, seis foram identificadas somente no município de Nova Mamoré (Acaulospora laevis Gerd. e Trappe (1974), A. morrowia Spain e Schenck (1984), A. callosa Walker, Vestberg e Schuessler (2007), Dentiscutata heterogama Sieverd., F.A. Souza e Oehl (2008) e Gigaspora sp.) e quatro somente no de Guajará-Mirim (Acaulospora capsicula Błaszk., A. excavata Ingleby e C. Walker (1994), A. lacunosa Morton (1986) e Racocetra intraornata Goto e Oehl (2009). As famílias identificadas foram Acaulosporaceae (Acaulospora capsicula, A. colossica Schultz, Bever e Morton (1999), A. excavata, A. foveata Trappe, Janos (1982), A. lacunosa Morton (1986), A. laevis, A. mellea Spain e Schenck (1984), A. morrowiae, A. rehmii Sieverd. \& S. Toro (1987), A. scrobiculata Trappe (1977), A. tuberculata Janos e Trappe (1982), Ambispora brasiliensis Goto, Maia e Oehl (2008), Ambisporaceae (Ambispora. callosa, A. leptoticha Walker, Vestberg e Schuessler (2007), Claroideoglomaceae (Claroideoglomus etunicatum Walker e Schuessler (2010), Gigasporaceae (Dentiscutata heterograma, Gigaspora albida Schenck e Sm. (1982), Gi. decipiens Hall \& L.K. Abbott (1984), Gi. Margarita Becker e Hall (1976), Gigaspora sp., Racocetra verrucosa Oehl, Souza e Sieverd. (2008), Ra. Intraornata Goto e Oehl (2009), Ra. weresubiae Oehl, Souza e Sieverd. (2008), Rhizoglomus clarus Walker e Schuessler (2010), Scutellospora dipurpurescens Morton e Koske (1988), Glomeraceae (Funneliformis geosporum Walker e Schuessler (2010), Glomus ambisporum Sm. e N.C. Schenck (1985), Rhizophagus diaphanus Walker e Schuessler (2010), Gl. macrocarpum Gerdemann e Trappe (1974), Gl. aff nanolumem, Glomus sp., G/. microaggregatum Koske, Gemma e Olexia), Paraglomeraceae (Paraglomus brasilianum Morton e D. Redecker (2001) (Tabela 1).

Segundo Redecker et al. (2013), algumas destas espécies ainda não estão estabelecidas em famílias, mas foi colocada aqui conforme critério de outros pesquisadores citados em Jobim (2015). 
Tabela 1- Densidade média dos esporos por espécies e frequência de ocorrência das espécies de

FMAs em $100 \mathrm{~mL}$ das amostras de solos coletadas em Abril/2016 nos sistemas cultivo de café solteiro e de café sombreado, nos municípios de Nova Mamoré (NM) e de Guajará-Mirim (GM)/RO.

\begin{tabular}{|c|c|c|c|c|c|c|c|c|c|c|}
\hline \multirow{2}{*}{ Espécies } & \multicolumn{4}{|c|}{ Nova Mamoré } & \multicolumn{4}{|c|}{ Guajará-Mirim } & \multicolumn{2}{|c|}{ Freq. de ocorrência (\%) } \\
\hline & $\mathrm{Ar}$ & Mc & Jos & Jo & Ve & Ed & $\mathrm{Fr}$ & Jo2 & NM & GM \\
\hline Acaulospora capsicula & - & - & - & - & - & - & 8 & - & - & 6 \\
\hline A. colossica & 26 & - & - & 2 & - & 9 & 1 & 78 & 16 & 31 \\
\hline A. excavata & - & - & - & - & - & 16 & - & - & - & 9 \\
\hline A. foveata & 4 & - & 3 & 4 & 4 & - & - & 3 & 13 & 6 \\
\hline A. lacunosa & - & - & - & - & - & - & 2 & - & - & 3 \\
\hline A. laevis & 2 & - & - & - & - & - & - & - & 3 & - \\
\hline A. mellea & 198 & 195 & 143 & 91 & 98 & 142 & 167 & 204 & 97 & 78 \\
\hline A. morrowiae & 7 & - & - & - & - & - & - & - & 3 & - \\
\hline A. rehmii & 1 & - & 7 & 8 & - & 6 & - & - & 9 & 6 \\
\hline A. scrobiculata & 8 & 12 & 101 & 47 & 28 & 20 & - & 19 & 41 & 38 \\
\hline A. tuberculata & 19 & - & - & 9 & 5 & - & 5 & - & 19 & 9 \\
\hline Ambispora brasiliensis & 5 & - & - & - & 6 & 27 & - & 14 & 3 & 31 \\
\hline A. calosa & - & 5 & - & - & - & - & - & - & 3 & - \\
\hline A. leptoticha & - & 10 & - & - & 4 & 3 & 2 & - & 6 & 9 \\
\hline Claroideoglomus etunicatum & 47 & 129 & 170 & 124 & 174 & 32 & 47 & 12 & 88 & 75 \\
\hline Dentiscutata heterograma & 8 & - & - & - & - & - & - & - & 6 & - \\
\hline Especies não identificadas & - & 4 & - & 17 & 4 & 7 & 5 & - & 16 & 19 \\
\hline Funneliformis geosporum & 121 & 14 & 257 & - & 294 & 17 & - & 179 & 50 & 63 \\
\hline Gigaspora álbida & 1 & - & - & - & - & - & - & - & 3 & - \\
\hline Gi. decipiens & - & - & 13 & - & 7 & - & 6 & - & 6 & 9 \\
\hline Gi. margarita & - & 4 & - & - & 11 & - & 9 & - & 3 & 9 \\
\hline Gigaspora sp. & - & 1 & - & - & - & - & - & - & 3 & - \\
\hline Glomus ambisporum & 25 & 7 & - & 4 & - & - & 2 & - & 19 & 3 \\
\hline Gl. macrocarpum & 286 & 517 & 1403 & 642 & 2050 & 384 & 895 & 885 & 100 & 100 \\
\hline Gl. microaggregatum & 28 & 114 & 84 & 72 & 88 & 13 & 51 & 79 & 43,8 & 56,3 \\
\hline Gl. aff nanolumem & 2 & - & - & - & 5 & - & - & - & 3 & 3 \\
\hline Glomus sp. & 8 & 28 & - & 25 & 21 & 59 & 30 & 40 & 34,4 & 68,8 \\
\hline Paraglomus brasilianum & - & - & - & 2 & - & 8 & - & - & 3,13 & 3,13 \\
\hline Racocetra verrucosa & - & - & 14 & - & - & - & 7 & - & 6,25 & 3,13 \\
\hline Ra. intraornata & - & - & - & - & 9 & - & - & - & - & 3,13 \\
\hline Ra. weresubiae & - & - & - & 2 & - & 3 & 3 & - & 3,13 & 6,25 \\
\hline Rhizoglomus clarus & - & - & 27 & 7 & 5 & 7 & 3 & - & 15,6 & 15,6 \\
\hline Rh. diaphanum & - & 2 & 8 & 6 & - & - & - & - & 13 & - \\
\hline S. dipurpurescens & 9 & 9 & 8 & - & 13 & 10 & 3 & 7 & 15,6 & 28,1 \\
\hline N esporos total & 807 & 1053 & 2238 & 1061 & 2825 & 764 & 1246 & 1518 & - & - \\
\hline N. Especies & 19 & 15 & 13 & 16 & 18 & 17 & 18 & 11 & 30 & 27 \\
\hline
\end{tabular}

Ar, Mc: cultivo em SAF; Jos, Jo: cultivo a pleno sol; Ve, Ed: cultivo em SAF; Fr, Jo2: cultivo a pleno sol.

De modo geral os gêneros Acauloposra e Glomus se apresentaram com maiores números de espécies sendo 11 e cinco, respectivamente. Resultados diferentes também, com relação ao número de espécies por gênero são encontrados por outros pesquisadores. Em um sistema agroflorestal com café, em Bonga na Etiópia, Sewnet e Tuju (2013) identificaram quatro gêneros e nove espécies de FMAs onde Glomus se apresentou com quatro espécies e o Gênero Acaulospora se apresentou com uma espécie.

Observa-se que os gêneros Glomus e Acaulospora se apresentaram com maior frequência de ocorrência que os demais. Em outros locais também observaram resultados semelhantes. Collozzi Filho e Nogueira (2007) identificaram os gêneros Acaulospora e Glomus com maior frequência que as demais espécies de FMAs em cultivos de cafeeiro. Em 2012, Lebron; Lodge; Bayman, identificaram morfotipos do gênero Glomus em diferentes abundâncias em três cultivares de café em Porto Rico. Os trabalhos realizados com identificação de espécies em cafeeiros a pleno sol ou em sistemas agroflorestais tem resultado em diferenças 
quanto aos gêneros e espécies, porém, os gêneros Glomus e Acaulospora estão sempre presentes. De acordo com Carrenho (1998), estes apresentam maior capacidade de adaptação aos solos submetidos a diferentes alterações nos teores de matéria orgânica e técnicas de adubação, calagem e cultivo, demonstrando serem espécies com grande resistência a perturbações ambientais, e sendo também predominantes em outros cultivos de café, em solos na Venezuela, Colômbia e México (SAGGIN-JUNIOR; SIQUEIRA, 1996).

Neste trabalho, no município de Nova Mamoré, identificaram-se exclusivamente sete gêneros de FMAs e no de Guajará-Mirim exclusivamente quatro gêneros, as demais espécies ocorreram nos cafezais em ambos os municípios. A segunda espécie com maior frequência de ocorrência foi Acaulospora mellea com $97 \%$ e $78 \%$, seguida pelo Claroideoglomus etunicatum 88\% e $75 \%$ respectivamente nos municípios de Nova Mamoré e de Guajará Mirim. Estes resultados estão de acordo com Vilatoro (2004), que identificou Acaulospora mellea com maior frequência de ocorrência em Guatemala. As presenças dos esporos de determinadas espécies podem estar relacionadas com as espécies de vegetação presentes. Observouse que em todos os sistemas de cultivo de café avaliados haviam a presença de gramíneas, provavelmente por fazerem parte do banco de sementes. Segundo Miranda; Silva; Saggin-Júnior (2007), a dominância de espécies de FMAs pode estar associada à presença destas plantas invasoras, sugerindo uma alta afinidade fungo-planta entre estes simbiontes, nas condições edafoclimáticas locais e também a grande plasticidade da $A$. mellea e do G. macrocarpum em adaptar-se a áreas com diferentes graus de perturbação e a diferentes plantas hospedeiras, ainda para Caproni et al. (2003) a elevada frequência de ocorrência dessa espécie demonstra uma alta capacidade de esporulação ou alta adaptabilidade à região e à situações iniciais independentes das condições climáticas.

Tanto em Nova Mamoré quanto em GuajaráMirim, as espécies com a menor frequência de ocorrência foram, Acaulospora lacunosa, Acaulospora morrowiae, Ambispora callosa, Gigaspora albida e Gigaspora sp., ambas com 3\% de frequência de ocorrência, indicando ser espécies sensíveis os sistemas de manejo.

Nos sistemas de cultivo de café a pleno sol e em sistema agroflorestal no município de Nova Mamoré foram identificadas 30 espécies de FMAs sendo: Acaulospora colossica, A. foveata, $A$. laevis, A. mellea, A. morrowiae, $A$. rehmii, $A$. scrobiculata, $A$. tuberculata, Ambispora brasiliensisa, Ambispora callosa, Ambispora leptoticha, Claroideoglomus etunicatum, Dentiscutata heterogama, Espécies Não Identificadas (ENI), Funneliformis geosporum, Gigaspora albida, Gigaspora decipiens, Gigaspora margarita, Gigaspora sp., Glomus ambisporum, G. diaphanum, G. macrocarpum, G. affin nolumem, Glomu sp., Paraglomus brasilianum, Racocetra verrucosa, Racocetra weresubiae, Rhizoglomus clarum, Rhizoglomus microaggregatum, Scutellospora calospora. Este número de espécies pode ser considerado alto em relação ao encontrado em Guatemala onde Vilatoro (2004) identificou sete espécies em amostras de solos provenientes de sistemas agroflorestais, estes solos possuíam características de Franco argiloso.

Nos sistemas de cultivo de café no município de Guajará Mirim foram identificadas 27 espécies sendo elas a Acaulospora capsicula, A. collosica, $A$. excavata, $A$. foveata, $A$. lacunosa, A. mellea, A. rehmii, $A$. scrobiculata, A. tuberculata, A. brasiliensis, Ambispora leptoticha, Clareoideoglomus etunicatum, ENI, Funneliformis geosporum, Gigaspora decipiens, Gigaspora margarita, Glomus ambisporum, G. macrocarpum, G. affin nanolumem, $G$. sp., Paraglomus brasilianum, Racocetra verrucosa, $R$. intraornata, $R$. weresubiae, Rhizoglomus clarum, Rhizoglomus microaggregatum e Scutellospora calospora.

\subsection{AVALIAÇÃO DOS ÍNDICES DE DIVERSIDADE DE ESPÉCIES DE FMA}

Os índices de diversidade de espécies para os FMAs não diferiram significativamente pelo teste não paramétrico de Kruskal-Wallis $(p>0,05)$, entre os sistemas agroflorestal com café e a pleno sol (Figuras 3 e 4). Apesar de não haver diferença significativa o sistema agroflorestal (SAF) com café no município de Nova Mamoré, a propriedade do Sr. Ar foi a que apresentou a maior diversidade de espécies representada pelo índice de Shannon e equitabilidade de Pielou com 
baixas dominâncias de espécies representadas pelo índice de dominância de Simpson. No município de Guajará-Mirim a maior diversidade de espécies de FMAs foi encontrada no sistema de cultivo de café solteiro no ecossistema pertencente ao Sr. Fr. Independentemente de ser um sistema agroflorestal ou sistema de cultivo de café solteiro nestes dois cafezais a presença de plantas invasoras, normalmente é constituída por capim braquiária. Segundo Collozi-Filho e Cardoso (2000), a presença de invasoras que crescem na área entre uma capina e outras estimulam a esporulação de espécies FMAs diferentes mantendo alta diversidade de espécies no ecossistema.

Figura 3 - Índices de diversidade de espécies de FMAs (abril/2016), em sistemas de cultivo de café solteiro e sombreado no município de Nova Mamoré (Mc SAF, Jo SAF, Jos sol, Ar sol). *SAF: sistemas agroflorestais; Sol: café solteiro.

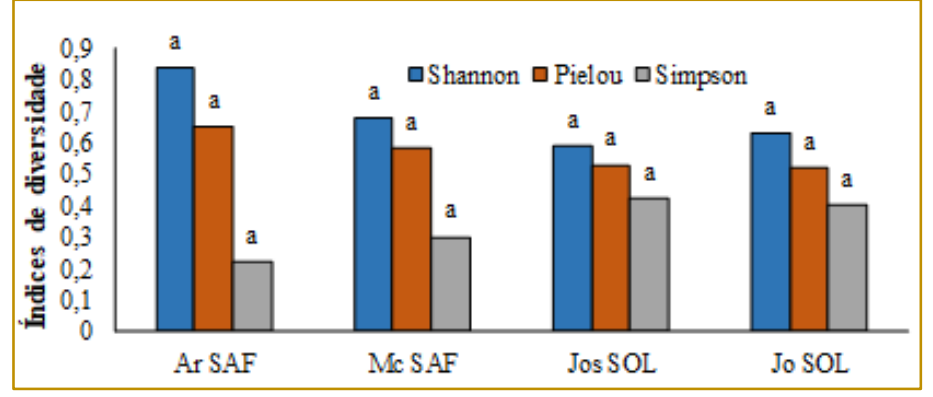

Figura 4 - Índices de diversidade de espécies de FMAs (abril/2016), em sistemas de cultivo de café solteiro e sombreado no município de Guajará-Mirim (Ve SAF, Fr SAF, Ed sol, Jo2 sol). *SAF: sistemas agroflorestais; Sol: café solteiro.

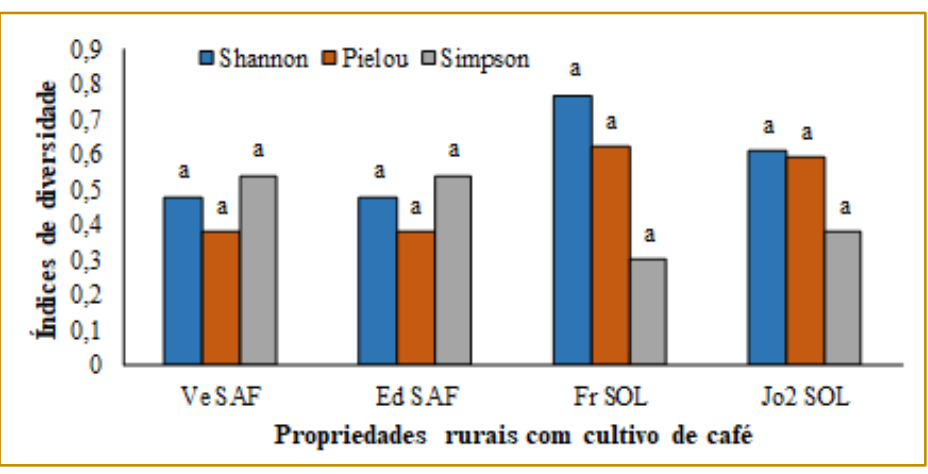

Com relação aos demais sistemas de cultivo de café, no período chuvoso, deve ser considerado que em abril os cafezais estavam frutificando, sugerindo que este evento tenha contribuído para a semelhança dos resultados nos índices de diversidade de espécies de FMAs. Pois, segundo Balota e Lopes (1996), nessas épocas ocorre baixa esporulação devido à umidade maior do solo e conta com uma menor disponibilidade de fontes de carbono para o fungo, pois no estágio de frutificação as plantas necessitam dos carboidratos com maior intensidade; portanto, pode-se considerar que há influência das plantas invasoras na manutenção da diversidade das espécies dos FMAs.
Analisaram-se também o dendrograma contendo o agrupamento dos sistemas de cultivos de café a pleno sol e sombreado (SAF), com base nas espécies identificadas nas comunidades dos FMAs nos municípios de Nova Mamoré e de Guajará-Mirim. Observou-se que o sistema de cultivo do café do Sr. Ar, com a presença de quatro espécies frutíferas e uma espécie bambu e tratos culturais tradicionais, no município de Nova Mamoré demonstrou ser $100 \%$ diferente dos demais sistemas de cultivo. Enquanto que no município de Guajará-Mirim o ecossistema de cultivo de café do Sr. Ve também apresentou um grupo diferenciado em $100 \%$ dos demais cultivos. Este ecossistema contava com a presença de cinco espécies frutíferas e os tratos culturais eram tradicionais. Este 
agrupamento indicou que a composição da flora presente no cafezal e o sistema de manejo interfere nas comunidades dos FMAs

Figura 5 - Análise de agrupamento dos ecossistemas cultivados com café solteiro (Sol) e com café em sistemas agroflorestais (SAF), com base nas comunidades dos FMAs, cultivados no município de Nova Mamoré /RO.

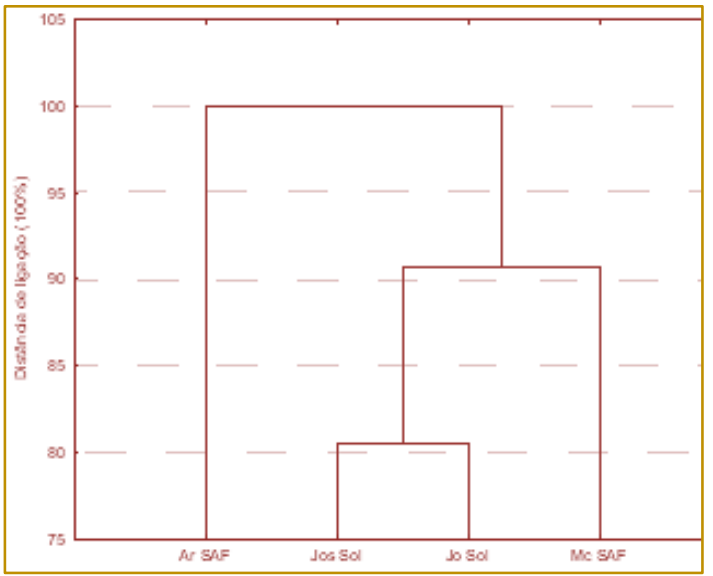

Enfim existem vários estudos relacionados à influência dos sistemas agroflorestais nas comunidades dos FMAs. Porém, alguns relatos são contraditórios, como por exemplo em revisão feita por Bainard; Klironomos; Gordon (2011), onde concluíram que os sistemas agroflorestais podem ter um efeito positivo na comunidade de fungos MA, e afirmam ainda que pode haver casos em que não há nenhum efeito significativo ou há algum efeito negativo. Estes pesquisadores entendem que estes fatos podem ocorrer devido à variedade de locais e climas onde esses estudos ocorreram e as diversas combinações de espécies de árvores e culturas utilizadas dentro desses sistemas.

\section{CONSIDERAÇÕES FINAIS}

A produção de esporos dos FMAs está relacionada ao sistema de cultivo do cafeeiro,
Figura 6 - Análise de agrupamento dos ecossistemas cultivados com café solteiro (Sol) e com café em sistemas agroflorestais (SAF), com base nas comunidades dos FMAs, cultivados no município de Guajará-Mirim/RO.

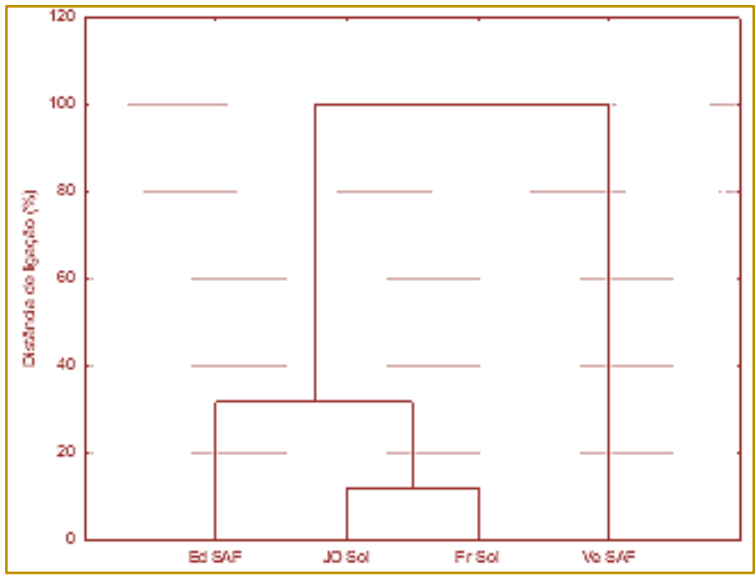

aos tratos culturais e à presença de gramíneas.

Os gêneros dos FMAs mais comuns nos ecossistemas de cafeeiro nos municípios de Nova Mamoré e Guajará Mirim são Glomus e Acaulospora e a espécie com 100\% de frequência de ocorrência é Glomus Macrocarpum em ambos municípios.

Os índices de diversidade de espécies não detectaram diferenças na diversidade de espécies dos FMAs entre os cultivos de cafeeiro em sistemas agroflorestais e a pleno sol, porém em análise do dendrograma de agrupamento dos diferentes cultivos de café indicou que o sistema agroflorestal mais diverso se diferencia em 100\% dos demais cultivos.

A utilização de herbicida nos ecossistemas de café influencia nas comunidades dos FMAs. 


\section{REFERÊNCIAS}

[1] Bainard, L.D.; Klironomos, J.N.; Gordon, A.M. Arbuscular mycorrhizal fungi in tree-based intercropping systems: A review of their abundance and diversity. Pedobiologia, n.54, p. 57-61, 2011.

[2] Balota, E.L.; Lopes, E.S. Introdução de fungo micorrízico arbuscular no cafeeiro em condições de campo. II. Flutuação sazonal de raízes, de colonização e de fungos micorrízicos arbusculares associados. Revista Brasileira de Ciência do Solo, v.20, n.2, p.225-232, 1996.

[3] Berbara, R. L. L.; Souza, F. A. de; Fonseca, H. M. A. C. Fungos micorrízicos arbusculares: muito além da nutrição. In: Fernandes, M. S. (Ed.). Nutrição mineral de plantas. Viçosa: Sociedade Brasileira de Ciência do Solo, 2006. p. 53-88.

[4] Bonfim, J.A. et al. Arbuscular Mycorrhizal Fungi and Physiological Aspects of Coffee Conducted in Agroflorestal System and at full Sun. Bragantia, v. 69, n.1, p.201-206, 2010. (in Portuguese with abstract in English).

[5] Brower, J. E.; ZAR, J. H.; Von Ende, C. N. Field and laboratory methods for general ecology. 3. ed. Dubuque: Wm C. Brown Publischers, 1990.

[6] Caproni, A. L. et al. Ocorrência de fungos micorrízicos arbusculares em áreas revegetadas após mineração de bauxita em Porto Trombetas, Pará. Pesquisa Agropecuária Brasileira, Brasilia, v.38, n.12, p.1409-1418, dez. 2003.

[7] Cardoso, I.M.; Boddington, C.; Janssen, B.H.; Oenema, O.; Kuyper, T.W. Distribution of mycorrhizal fungal spores in soils under agroforestry and monocultural coffee systems in Brazil. Agroforestry Systems, v.58, p.33-43, 2003.

[8] Carrenho, R. Influência de diferentes espécies de plantas hospedeiras e fatores edáficos no desenvolvimento de fungos micorrízicos arbusculares (FMA). 1998. 226f. Tese (Doutorado em Biologia) - Curso de Pós-graduação em Biologia, Universidade Estadual Paulista, SP

[9] Colozzi Filho, A.; Nogueira, M. A Micorrizas arbusculares em plantas tropicais: café, mandioca e cana-de-açúcar. In: Silveira, A. P. D.; Freitas, S. F. (Eds). Microbiota do Solo e Qualidade Ambiental. Campinas: Instituto Agronômico, p. 3956, 2007.

[10] Colozzi-Filho, A.; Cardoso, E. J. B. N. Detecção de fungos micorrízicos arbusculares em raízes de cafeeiro e de crotalária cultivada na entrelinha. Pesquisa Agropecuária Brasileira, v. 35, p. 2033-2042. 2000

[11] Conab. Companhia Nacional de Abastecimento. Acompamento da safra brasileira café: Segundo levantamento, maio 2018 - safra 2018.: Brasília: Companhia Nacional de Abastecimento. v. 5, n.2, 2018. Disponível em: $<$ file:///C:/Users/Particular/Downloads/BoletimZCafe ZmaioZ2018.pdf>. Acesso em 09 set. 2018.
[12] Costa, R.S.C. Micorrizas Arbusculares em Sistemas Agroflorestais em duas comunidades rurais do Amazonas. 2010. 155f. Tese (Doutorado em Biotecnologia) - Curso de Pós-Graduação em Biotecnologia, Universidade Federal do Amazonas, AM.

[13] Daniels-Hetrick, B. A.; Bloom, J. The influence of host plant on production and colonization ability of vesicular-arbuscular mycorrhizal spores. Mycologia, v.78, n.1, p.32-36, 1986.

[14] Durazzini, A. M. S.; Teixeira, M. A.; Adami, A. A. V. Quantificação de esporos de fungos micorrízicos arbusculares (FMAs) em solo sob diferentes cultivos de cafeeiros. Revista Agrogeoambiental, Pouso Alegre, v. 8, n. 4, p. 8391, dez. 2016.

[15] Gerdemann, J.W.; Nicolson , T.H. Spores of mycorrhizal endogone species extracted from Transaction of the Bristish Mycological Society, soil by wit sieving and decanting. Transactions of the British Mycological Society, v.46, p.235-244, 1963.

[16] Giovannetti, M.; MOSSE, B. An evaluation of techniques for measuring vesicular arbuscular mycorrhizal infection in roots. New Plytologist, v.84, p.489-500. 1980.

[17] Hoffmann, L. V.; Lucena, V. S. Para entender micorrizas arbusculares. Campina Grande: Embrapa Algodão, 2006. 22 p. (Embrapa Algodão. documentos, 156)

[18] Ibge - Instituto Brasileiro de Geografia e Estatística. Disponível em:<http:// www.ibge.gov.br. Acesso em: julho 2012

[19] Jakobsen, J.H. et al. Genetic parameters for milk production and persistency for Danish Holstein estimated in random regression models using REML. Journal of Dairy Science, v.85, n.6, p.1607-1616, 2002.

[20] Jobim, K. Fungos micorrízicos arbusculares (glomeromycota) $\mathrm{mm}$ diferentes níveis de profundidade em fragmentos florestais. 2015, 149 f. Dissertação (Mestrado em Sistemática e Evolução) - Universidade Federal do Rio Grande do Norte, RN.

[21] Laviola, B.G. et al. Dinâmica de P e S em folhas, flores e frutos de cafeeiro arábico em três níveis de adubação. Bioscience Journal, v.23, n.1, p.29-40, 2007.

[22] Leake, J. R. et al. Networks of power and influence: the role of mycorrhizal mycelium in controlling plant communities and agroecosystem functioning. Canadian Journal of Botany, v. 82, n. 08 , p. $1016-1045,2004$

[23] Lebron, D.; Lodge, J.; Bayman, P. Differences in Arbuscular Mycorrhizal Fungi among Three Coffee Cultivars in Puerto Rico. Agronomy, v. 2012, 2012 
[24] Miranda, E. M.; Silva, E.M.R.; Saggin Júnior, O. J. 2007. Comunidades de fungos micorrízicos arbusculares associados ao amendoim forrageiro em pastagens consorciadas no sudoeste amazônico. In: Workshop PANAmazônico "Biodiversidade do solo", Rio Branco. 26 a $29 / 09 \quad$ (Disponível em: http://www.iamazonica.org.br/conteudo/evento s/biodiversidadeSolo/pdf/resumos/Painel1_MeloE.p df. Acesso: 23-05-17.

[25] Pielou, E. C. Mathematical ecology. 2 nd. New York: Wiley, 1977.

[26] Prates Junior, P. Comunidade de fungos micorrízicos arbusculares em diferentes sistemas de manejo do cafeeiro. 2014, 52f. Dissertação (Mestrado em Agroecologia) - Universidade Federal de Viçosa, MG.

[27] Silve, M. E. Ocorrência e diversidade de fungos micorrízicos arbusculares em um ecossistema de cafeeiro submetido a diferentes métodos de controle de plantas daninhas. 2011, 79 f. Dissertação (Mestrado em Meio Ambiente e Recursos Hídricos) - Universidade Federal de Itajubá, MG.

[28] Redecker, D. et al. An evidence-based consensus for the classification of arbuscular mycorrhizal fungi (Glomeromycota). Mycorrhiza, v.23, p.515-31, 2013.

[29] Saggin-Júnior, O. J.; Siqueira, J. O. Micorrizasarbusculares em cafeeiro. In: Siqueira, J. O. (Ed). Avanços em fundamentos e aplicação de micorrizas. Lavras: Universidade Federal de Lavras, 1996. p. 203-254.
[30] Schenck, N.C.; Perez, Y. Manual for identification of vesicular-arbuscular mycorrhizal fungi. (Invam). Gainesville: University of Florida, 1988.

[31] Sewnet, C.; Tuju, F. A. Arbuscular mycorrhizal fungi associated with shade trees and Coffea arabica L. in a coffee-based agroforestry system in Bonga. Afrika focus, v.26, n.2, p. 111131, 2013

[32] Silva, F. de A. S. e.; Azevedo, C. A. V. de. The Assistat Software Version 7.7 and its use in the analysis of experimental data. African Journal of Agricultural Research, v.11, n.39, p.3733-3740, 2016.

[33] Siqueira, J. O.;Moreira, F. M. S. Microbiologia do solo e sustentabilidade agrícola: enfoque em fertilidade do solo e nutrição vegetal. In: Reunião Brasileira Em Fertilidade do Solo E Nutrição de Plantas, 22, 1996, Manaus. Resumos... Manaus: SBCS,1996, p.1-42.

[34] Trindade, A.V. Eficiência simbiótica de fungos micorrizicos arbusculares em solo não fumigados, para mamoeiro. Revista Brasileira de Ciência do Solo, 24:505-513, 2000.

[35] Vilatoro, M.A.A. Matéria Orgânica e Indicadores Biológicos da Qualidade do Solo na Cultura do Café sob Manejo Agroflorestal e Orgânico. 2004. 176 f. (Tese de Doutorado em Ciência do solo) - Universidade Federal Rural do Rio de Janeiro, Seropédica, 2004. 


\section{Bapítulo 6}

\section{FUNGOS MICORRIZICOS ARBUSCULARES EM FLORESTA NATIVA, CERRADO E PASTAGEM NO MUNICIPIO DE GUAJARÁ-MIRIM/RO COMO BIOINDICADOR DE ESTABILIDADE}

\section{Thais Ponhês dos Santos \\ Wesley de Paulo Morais \\ Ana Lucy Caproni \\ Ricardo Luis Louro Berbara \\ José Rodolfo Dantas de Oliveira Granha}

Resumo - O objetivo deste trabalho foi identificar e estimar a diversidade das comunidades dos fungos micorrízicos arbusculares (FMAs) em três ecossistemas existentes no município de Guajará-Mirim/RO. As amostragens de solo foram coletadas aleatoriamente de 0 a $20 \mathrm{~cm}$ de profundidade, em ecossistemas de mata nativa, pastagem e cerrado nas estações seca (ago/2015) e chuvosa (jan/2016). Os esporos foram extraídos, contados e identificados taxonomicamente. Estimou-se a densidade dos esporos e calcularam-se a frequência de ocorrência de cada espécie em cada ecossistema e época de amostragem, o índice de diversidade de Shannon $(H)$, Pielou $(\mathcal{J}$ e de Simpson (S). A maior densidade de esporos foi encontrada no ecossistema de cerrado e pastagem independente da época, o ecossistema de mata nativa teve uma baixa densidade de esporos. A espécie Glomus macrocarpum apresentou $100 \%$ de frequência de ocorrência em todos os ecossistemas e nas duas épocas. Foi verificada a ocorrência total de 26 espécies nos três ecossistemas em avaliação e nas duas estações climáticas. A diversidade foi maior no período seco com 23 espécies, enquanto que no período chuvoso houve a ocorrência de 19 espécies. As espécies estão distribuídas em 13 gêneros e 10 famílias. Alguns fatores como queimadas anteriores foram determinantes na densidade final e na diversidade das espécies dos FMAs.

Palavras-Chave: Fungos Micorrizicos Arbusculares. Bioindicardor ambiental. Diversidade de espécies. 


\section{INTRODUÇÃO}

Os fungos micorrízicos arbusculares (FMAs) representam um importante componente da microbiota do solo em ecossistemas naturais e agrícolas (GOMIDE et al., 2014). Estes fungos formam simbiose mutualística com espécies de grande parte das espécies de plantas terrestres. Nessa simbiose, a planta supre o fungo com energia para crescimento e reprodução via fotossintatos, e o fungo provê a planta e o solo com uma gama de serviços (Souza et al., 2007).

Os FMAs exercem efeitos marcantes sobre as plantas através da melhoria nutricional (Harrison, 2005; Mergulhão et al. 2014), especialmente quanto ao fósforo; à tolerância ao estresse abiótico; ao favorecimento das relações hídricas; aos efeitos fisiológicos e favorecimento de processos reabilitadores como o estabelecimento da vegetação; ao aumento da produção de material orgânico, ao aumento do acúmulo de nutrientes na fitomassa, ao aumento da produção de raízes, à maior proteção ao solo (estabilização); a melhoria das relações tróficas; ao favorecimento indireto do fluxo hídrico (erosão); ao estímulo da transformação e ciclagem dos nutrientes e ao favorecimento da estruturação e sucessão vegetal (PORRAS-SORIANO et al., 2009). Podem oferecer ainda proteção contra os patógenos das raízes das plantas. Os efeitos benéficos dos FMAs são importantes nas mais variadas condições do solo e das espécies vegetais, sobretudo em solos com baixa fertilidade.

Mesmo diante de tantos benefícios resultantes desta simbiose, a dinâmica dos FMAs é pouco estudada em solos da Amazônia, pois um maior entendimento das interações destes organismos com as plantas auxiliará na aplicação de pesquisas futuras e para o manejo destes simbiontes. Assis et al. (2014) vêem de extrema importância se fazer um estudo voltado para os microorganismos do solo, devido à grande relação do solo com as diversidades ecológicas, por estes fungos também serem os principais microorganismos que influenciam no desenvolvimento e crescimento de algumas espécies de plantas existentes na região Amazônica, principalmente em locais de solo com baixa fertilidade. Estes pesquisadores salientam que os FMAs são componentes importantes e muito diversos em ambientes naturais e também nos alterados pelo homem como nos solos agrícolas, podendo ainda serem utilizados como bioindicadores de qualidade de solo. Pouco se conhece sobre a diversidade destes micossimbiontes e sobre a sua ecologia na região amazônica.

Em se tratando da Região Amazônica, a diversidade de espécies de FMAs ainda é bastante desconhecida. Conhecer a diversidade destas espécies na Amazônia é de grande interesse, diante do potencial destes fungos como alternativa para produção agrícola em áreas desmatadas da região (SILVA et al., 2009) e também para a sua preservação. Os poucos estudos já publicados evidenciam a ocorrência de várias espécies neste bioma, mas a dimensão da biodiversidade destas e suas características precisam ser elucidadas (Silva, 2009).

O objetivo deste trabalho foi identificar e estimar a diversidade de comunidades dos FMAs em ecossistemas de mata nativa, de pastagem, e de cerrado, no município de Guajará-Mirim/RO em duas épocas do ano.

\section{MATERIAL E MÉTODOS \\ 2.1 CARACTERIZAÇÃO DA ÁREA}

Este trabalho foi realizado em ecossistemas de mata nativa, de pastagem e de cerrado. Localizados no município de guajará-mirim/ro. Os ecossistemas se situam entre as coordenadas geográficas $65^{\circ} 17^{\prime} 53,6345^{\prime \prime} \mathrm{w}$ $10^{\circ} 45^{\prime} 13,2668$ "s, se localizam no bioma amazônia, e o clima da região é equatorial úmido. Foram identificadas as vegetações dominantes em cada ecossistema, como listadas a seguir.

No ecossistema de mata nativa a vegetação dominante era composta por samaúma (ceiba pentandra I.), uchi (endopleura uchi huber), tucumã (astrocaryum aculeatum g.f.w. Maye), cumaru ferro (dipteryx odorata aubl.), açaí (euterpe oleracea mart.), babaçu (attalea speciosa mart.), bananeira (musa sp.), breu (protium heptaphyllum (aubl.) Marchand), cedro (cedrela fissilis vell.), castanheira (bertholletia excelsa bonpl.), embaúba (cecropia sp.), sucupira (pterodon emarginatus vogel.), gameleira (ficus adhatodifolia schot.) E angelim (dinizia excelsa ducke.). Este ecossistema é constituído de um pequeno fragmento de mata amazônica pertencente ao campus da universidade federal de rondônia em guajarámirim com aproximadamente 5 ha (foto 1).

No ecossistema de pastagem a vegetação dominante era composta por capim brachiaria 
(brachiaria decumbens stapf.) Cultivada; freijó (cordia goeldiana huber), cipó de fogo (pyostegia venusta ker gawl.), lacre (vismia antiscrophylla aubl.), peroba (aspidosperma polyneuron muell. Arg.) E tucumã (astrocaryum aculeatum g. Mey) nativas (foto 1).

O ecossistema de cerrado era composto por uma vegetação dominada por gengibre do mato (zingiber sp.), ouricuri (syagrus coronata I.), jenipapo (genipa americana I.), capim brachiaria (b. Decumbens stapf), tachi (tachigalia paniculata aublet), embaúba (cecropia sp.) E murici (byrsonima verbascifolia rich.). Eventualmente, este ecossistema, situado em uma serra, com superfície plana, sofre com incêndios criminosos ocasionalmente (foto 1).

Foto 1 - Vista aérea dos ecossistemas de mata nativa, de pastagem e do cerrado (Serra dos Parecis) no município de Guajará-Mirim/RO, e delimitação das áreas das coletas das amostras de solo em set/2015 e jan/2016, para avaliação dos FMAs.

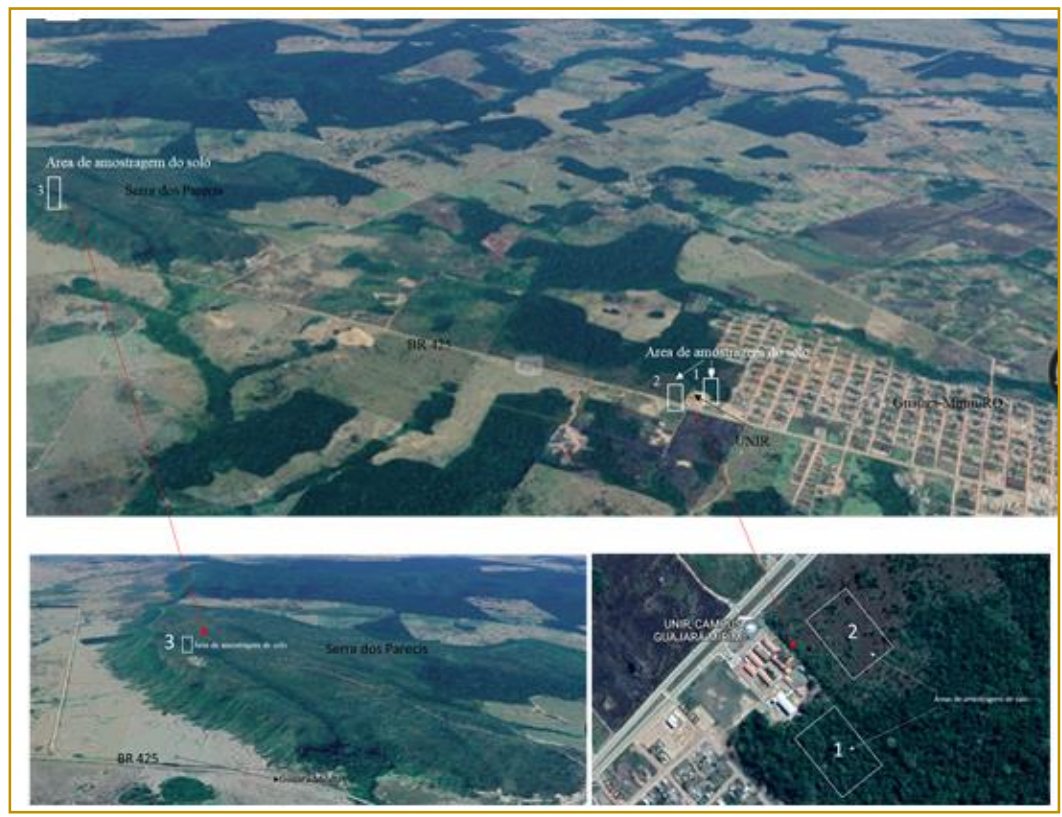

Fonte: https://www.google.com.br/maps, em outubro de 2018.

\subsection{AMOSTRAGENS}

Foram coletadas 20 amostras simples de solo, para a avaliação da diversidade das espécies dos FMAs, em cada ecossistema (mata nativa, pastagem e cerrado), nas estações seca (ago/2015) e chuvosa (jan/2016). Para as amostragens de solo foi utilizado um trado com capacidade para $500 \mathrm{~mL}$. As amostras foram retiradas na profundidade de 0 a 20 $\mathrm{cm}$, próximas às raízes das plantas.

Após a coleta, as amostras de solo foram homogeneizadas, secadas à sombra, acondicionadas em sacolas de plástico e armazenadas a $10^{\circ} \mathrm{C}$ até $\mathrm{O}$ seu processamento em laboratório para a avaliação dos FMAs. As amostras foram processadas no laboratório de biologia e química da Universidade Federal de Rondônia, Campus de Guajará-Mirim.

\subsection{AVALIAÇÃO DO NÚMERO DE ESPOROS}

Este trabalho foi realizado a partir de esporos coletados diretamente do campo. De cada amostra de solo tomou-se $100 \mathrm{~mL}$ para as extrações dos esporos dos FMAs pela técnica de peneiramento em via úmida (Gerdemann; Nicolson, 1963), seguindo-se de centrifugação com sacarose $50 \%(\mathrm{~V}: \mathrm{V})$. Após as extrações, os esporos foram colocados com água em placa de petri canaletada para a contagem e depois transferidos para uma placa de petri para montagens em lâminas. Eles foram agrupados pelo tamanho, cor e forma, colocados em lâminas com álcool polivinil em lactoglicerol (PVLG) e quebrados sob a lamínula, para expor as paredes internas. Na mesma lâmina, um segundo grupo de esporos foi montado com PVLG + 
reagente de Melzer (1:1), sob outra lamínula. Os resultados da reação de cor ao reagente de Melzer foram usados para caracterizar as paredes dos esporos, melhorando, em alguns casos, a visibilidade, especialmente daqueles com paredes aderentes ou muitos finas.

\subsection{IDENTIFICAÇÃO DAS ESPÉCIES}

As espécies dos FMAs foram identificadas segundo Schenck; Perez (1988), conforme descrição morfológica disponível na internet na página da International culture Collection of Arbuscular Mycorrhizal Fungi (INVAM http://invam.caf.wvu.edu) e outras fontes pertinentes ao assunto, mediante observações em microscópio óptico com iluminação de campo-claro e objetiva de imersão. Após a identificação contou-se a população de cada espécie.

\subsection{VARIÁVEIS ANALISADAS}

Fez-se uma avaliação da curva espécienúmero de amostras e número cumulativo de espécies de FMAs para cada ecossistema em que foi realizado amostragens de solo. A finalidade desta curva foi determinar o melhor número de amostras simples em cada ecossistema. A curva espécie-número de amostras foi obtido pelo número cumulativo de espécies identificadas em cada ecossistema no eixo $\mathrm{Y}$ e o número cumulativo de amostras no eixo $X$ do gráfico conforme Brower; Zar; Von Ende (1990) com modificações. Quando a curva começa a se estabilizar então define-se o número ideal de amostras para caracterização das espécies de cada ecossistema. Tradicionalmente este procedimento é o mais usado para definir a suficiência amostral e vem da interpretação extraída por meio da curva do coletor, pela "inspeção visual" da curva, para identificar o ponto em que se inicia o patamar de estabilização (Freitas; Magalhães, 2012) do número de espécies identificadas.

O número total dos esporos e de cada espécie de FMA foi estimado em $100 \mathrm{~mL}$ de solo, e as diferenças estatísticas entre as épocas de amostragens e os ecossistemas amostrados, foram analisados pelo teste de Kruskal-Wallis (Silva; Azeved0, 2016).

A frequência de ocorrência de cada espécie (Fi) foi calculada em cada época de amostragem (seca e chuvosa) (BROWER et al., 1990), de acordo com a equação $\mathrm{Fi}=\mathrm{Ji} /$
$\mathrm{K}$, onde $\mathrm{Fi}=$ Frequência de ocorrência da espécie i; $\mathrm{Ji}=$ Número de amostras nos quais a espécie i ocorreu e $\mathrm{k}=$ Número total de amostras.

Foram calculados os índices de diversidade de Shannon-Wiener $\left(H^{\prime}\right)$ para cada ecossistema e cada época de coleta de amostra de solo, de acordo com a fórmula: $H^{\prime}=-\Sigma\left(X_{i} / X_{0}\right) \cdot \log \left(X_{i} / X_{0}\right)$, onde: $X_{i}$ corresponde à densidade de esporos de cada espécies em $100 \mathrm{~mL}$ de solo, $X_{0}$ corresponde à densidade total de esporos de todas as espécies; o índice de dominância de Simpson (D) pela fórmula: $D=\Sigma\left(X_{i} / X_{0}\right)^{2}$, e o índice de equitabilidade de Pielou (J') pela fórmula: J' = $\mathrm{H}^{\prime} / \log S$, onde: S corresponde ao número total de espécies de FMAs em $100 \mathrm{~mL}$ de solo (PIELOU, 1977).

Foi feita uma representação simplificada das distâncias Euclidianas por meio de um dendrograma, obtido pelo programa Statistica através do Unweighted Pair-group Average, efetuado pelo coeficiente de Pearson-r (Statsoft, 1993). Os dados dos números de esporos por espécie de FMAs foram submetidos à análise multivariada de agrupamento, utilizando como medida de similaridade/ dissimilaridade a distância Euclidiana.

\section{RESULTADOS E DISCUSSÃO}

Neste trabalho, para cada época de amostragem foi gerado um gráfico curva espécie-número de amostras para os ecossistemas de mata nativa, de pastagem e de cerrado. Foi considerado o número ideal de amostras quando a curva de acumulação de espécies foi estabilizada. Para os ecossistemas de mata nativa, de pastagem e de cerrado para o período seco as curvas se estabilizaram entre 15 e 18 amostras de 100 $\mathrm{mL}$, pois, a partir destes valores não houve mais acréscimo de espécies novas (Figura 1). Com respeito à estabilização das curvas referentes ao período chuvoso para a mata nativa a curva se estabilizou com 14 amostras, para a pastagem a estabilização da curva se deu com 17 amostras e para o ecossistema de cerrado a estabilização se deu com seis amostras (Figura 2). No entanto para recuperar o máximo de espécies de FMAs o número de amostragens durante o ano pode ser mais importante que o número de amostras, pois em cada época é necessário um número de amostragens diferentes em cada ecossistema. 
Figura 1 - Curva espécie-número de amostras e número cumulativo de espécies nos ecossistemas de mata nativa, de pastagem e de cerrado no município de Guajará-Mirim/RO, em set/2015, época seca.

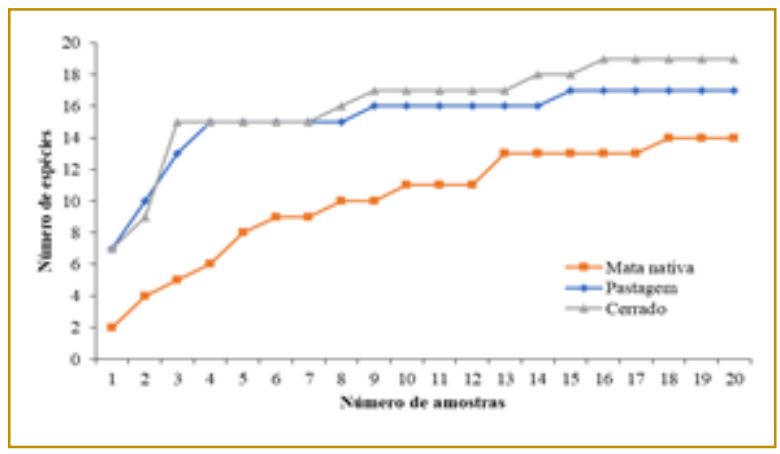

Figura 2 - Curva espécie-número de amostras e número cumulativo de espécies nos ecossistemas de mata nativa, de pastagem e de cerrado no município de Guajará-Mirim/RO, em jan/2016, época chuvosa.

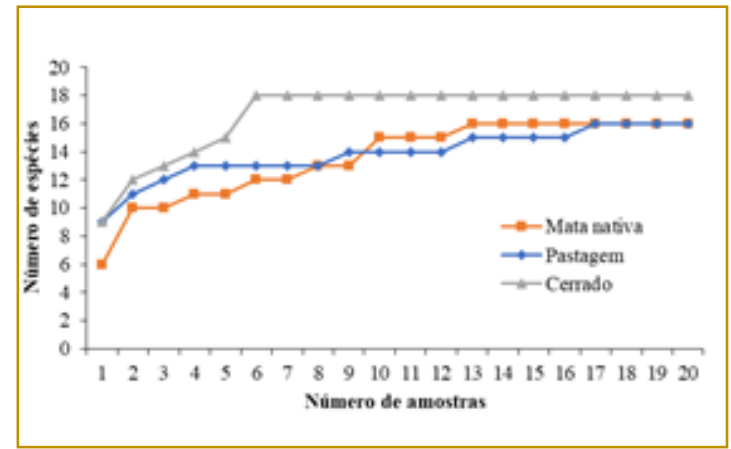

Fonte: Ana Lucy Caproni

\subsection{AVALIAÇÃO DOS ESPOROS DOS FMAS}

No ecossistema de cerrado houve diferença significativa no número de esporos entre as épocas seca (ago/2015) e chuvosa (jan/2016) (Figura 3). Para Silveira (1992), a população dos esporos dos FMAs pode variar com o clima e também com as plantas, além de melhorar a qualidade biológica do solo. Segundo este pesquisador, os solos de florestas nativas ou de cerrado nativo são importantes por manter a biodiversidade e servir como fonte de propágulos para o desenvolvimento de outras culturas com a utilização de menores quantidades de insumos agrícolas.

O número de esporos dos FMAs, no período seco (ago/2015), no solo do ecossistema de pastagem (1215) foi significativamente superior aos da mata nativa (304) e de cerrado (521) (Figura 3). A sazonalidade da esporulação dos FMAs (ZANGARO;
MOREIRA, 2010); GOMIDE et al., 2014) aliado ao desenvolvimento de esparsa vegetação e ao pastejo contínuo, provavelmente, provocaram um impacto negativo no solo levando ao mecanismo de mais alta produção de esporos neste ecossistema em relação aos ecossistemas de mata nativa e de cerrado. Em condições de clima seco, elevado número de esporos em pastagens com relação a ecossistemas nativos também foram encontrados por outros pesquisadores. Melloni et al. (2011) encontraram maior número de esporos de FMAs em solo sob pastagem em relação a outras áreas da Reserva Biológica Municipal Serra dos Toledos, em Itajubá/MG. Estes pesquisadores relacionaram a elevada população de esporos às condições climáticas mais secas e frias do inverno comparadas às médias do verão, podendo ter ocasionado situação de estresse mais elevado nesta área. 
Figura 3 - Número de esporos dos FMAs em amostras de $100 \mathrm{~mL}$ de solo coletadas nos meses de ago/2015 e de jan/2016, nos ecossistemas de mata nativa, de pastagem e de cerrado. (Colunas de mesma cor com letras iguais (minúsculas e maiúsculas) não diferem entre si nos ecossistemas em cada época, pelo teste de Kruskal-Wallis a 5\% de probabilidade); ns: não significativo entre as épocas; * significativo entre as épocas.

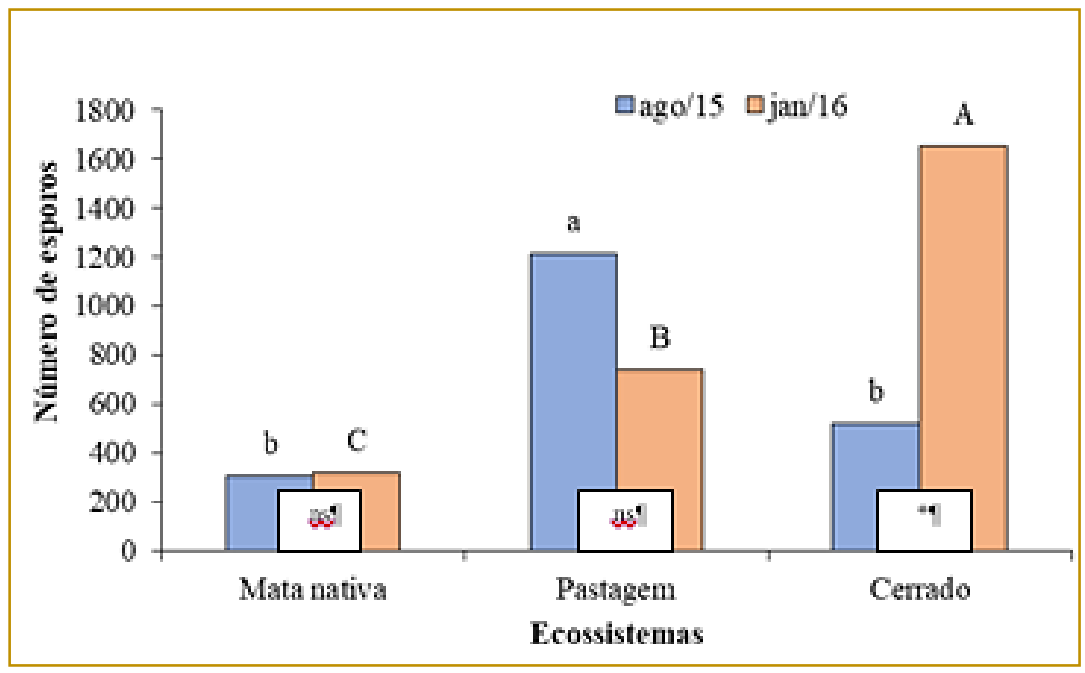

Já no período chuvoso o número médio de esporos no cerrado (1651) foi significativamente superior aos da pastagem e da mata nativa (Figura 3). Há relatos de queimadas clandestinas no ecossistema de cerrado em algumas épocas secas, inclusive no ano anterior à coleta de amostras de solo no local. Esses eventos promoveram a esse ecossistema uma perturbação no solo devido ao ressurgimento da vegetação natural com a formação de novos sistemas radiculares, o que pode ter contribuído para essa alta produção dos esporos dos FMAs. Número alto de esporos de FMAs em áreas perturbadas foi observado por outros pesquisadores. Cordeiro et al. (2005) analisando dois solos de cerrado sob diferentes sistemas de manejo, constatou que o maior número de esporos de FMAs foi encontrado em um local em que sofreu perturbação humana do que em um local sem interferência antrópica. Portanto, as respostas à esporulação em ambientes perturbado é contraditória, em solo em regeneração após queimada, Longo et al. (2014) não observaram influência do fogo sobre as populações dos esporos dos FMAs.

Com relação ao baixo número de esporos no ecossistema de mata nativa foi comumente relatado por alguns pesquisadores, independente do clima (Santos; Scoriza; Ferreira, 2013; Caproni et al., 2001). Em ecossistemas de mata nativa de cerrado, sem interferência humana, é comum encontrar baixa densidade de esporos de FMAs,
Cordeiro et al. (2005) encontraram mais baixa densidade de esporos em floresta de cerrado do que em sistemas de pastagem natural e em processo de reabilitação. Trabalhos realizados sobre FMAs em áreas preservadas mostram que a densidade de esporos são baixas e em áreas perturbadas mostram densidade de esporos altas, indicando a importância desses fungos nos ecossistemas como indicadores de estabilidade (CAPRONI et al., 2005; Silva et al., 2005 Mergulhão et al., 2007).

\subsection{AVALIAÇÃO DAS ESPÉCIES DOS FMAS}

Os ecossistemas de mata nativa, de pastagem e de cerrado apresentaram um total de 26 espécies, pertencentes a 13 gêneros, 10 famílias, das quais uma não foi identificada por gênero ou por espécie. Desse total, 23 espécies ocorreram nas amostras de solo coletadas na época seca (ago/2015) e 19 espécies na época chuvosa (jan/2016). As famílias mais representativas em relação ao número de espécies foram Acaulosporaceae e Glomeraceae. Em estudo feito por Ferreira; Carneiro; Saggin-Júnior (2012), também foi observado a grande representatividade da família Acaulosporaceae e Glomeraceae. Sendo uma das explicações a adaptabilidade destes gêneros nos solos estudados, ou segundo Benedetti et al. (2005), por suportarem grandes variações de $\mathrm{pH}$ do solo. Os gêneros mais representados neste trabalho foram Acaulospora (8 espécies) 
seguido pelo gênero Glomus (4 espécies) ambos pertencentes às famílias Acaulosporaceae e Glomeraceae.

O número de espécies de FMAs identificadas é bastante variável nos ecossistemas do país, como por exemplo em trabalhos de identificação de espécies de FMAs realizados por Carneiro et al. (2015), em Campus dos Murundus no estado de Goiás, contabilizaram 21. O número de espécies dos FMAs identificados no ecossistema de mata nativa (16 espécies) neste trabalho, foi maior do que aquela encontrada por Santos et al. (2013) em fragmentos de Floresta Estacional Semidecidual Montana (15 espécies) e plantio de eucalipto no sul da Bahia. E foi menor que os encontrados por Caproni (2001) em solos de mata nativa natural e em solos recuperados com vegetação nativa após mineração de bauxita no estado do Pará.

As 23 espécies que foram identificadas no período seco em todos os ecossistemas foram Acaulospora callosa (Sieverd.) Walker, Vestberg e Schuessler, A. foveata Trappe e Janos, $A$. mellea Spain e Schenck, $A$. longula Spain e Schenck, A. scrobiculata Trappe, $A$. tuberculata Janos e Trappe, Ambispora leptoticha C. Walker, Vestberg e Schuessler, Cetraspora pelúcida Oehl, Souza e Sieverd., Claroideoglomus etunicatum Walker e Schuessler, Dentiscutata heterogama Sieverd., Souza e Oehl, ENI, Glomus sp., Funneliformis geosporum Walker e Schuessler, F. verruculosum Walker e Schuessler, Gigaspora decipiens Hall e Abbott, Glomus ambisporum Sm. e Schenck, Rhizophagus diaphanus Walker e Schuessler, G. macrocarpum Tulasne e Tulasn, Kuklospora colombiana Oehl e Sieverd., Racocetra pérsica Oehl, Souza e Sieverd., Racocetra weresubiae Oehl, Souza e Sieverd. Rhizoglomus microaggregatum Sieverd., Silva e Oehl, Scutellospora calospora Walker e Sanders (Tabela 1). A estação seca foi a que houve maior incidência de espécies de FMAs em relação à estação chuvosa. O período seco tem sido considerado, por alguns autores, como o período de maior riqueza de espécies de FMAs (CAPRONI et al., 2003; TCHABI et al., 2008).

As 19 espécies que ocorreram no período chuvoso foram Acaulospora capsicula, Acaulospora sp., A. foveata, A. mellea, A. scrobiculata, A. tuberculata, Ambispora leptoticha, Claroideoglomus clarum e C. etunicatum, Dentiscutata heterogama, espécies não identificadas, Glomus sp.,
Funneliformis geosporum, Gigaspora decipiens, Glomus ambisporum, $G$. diaphanum, G. macrocarpum, Rhizoglomus microaggregatum e Scutellospora calospora (Tabela 1). A composição das espécies dos FMAs, em determinadas épocas, pode estar associada às diferentes espécies da vegetação local às quais possuem diferentes suscetibilidade de associação (ALLEN, 1991) favorecendo ou não a esporulação de cada espécie. Podendo também estar associadas às propriedades químicas e físicas do solo e climáticas com diferentes graus de afinidade (SMITH; READ, 1997), à planta hospedeira através de sinalizadores moleculares (VIERHEILIG; LERAT; PICHE, 2003) e espécies que esporulam e que não esporulam em alguma época do ano.

Observou-se o predomínio do gênero Acaulospora em relação aos demais gêneros, tanto no clima seco quanto no chuvoso. Estes dados estão de acordo com aqueles encontrados por Caproni et al. (2003) em áreas revegetadas e mata nativa no estado do Pará, em que o gênero que predominou em ambos os períodos seco e chuvoso foi o de Acaulospora. Em área experimental da Embrapa Acre em áreas de capoeira e de mata, Miranda; Silva; Saggin-Júnior (2010), identificaram o gênero Acaulospora com predomínio em relação aos demais gêneros no período seco e Glomus com predomínio no período chuvoso. Parte da explicação para o fato de haver maior predominância dos gêneros Acaulospora e Glomus é que o maior número de espécies identificadas até o momento pertence a estes gêneros, conforme relatado por Souza; Silva; Berbara (2008).

O gênero Acaulospora destacou, onde constataram-se oito espécies ( $A$. capsicula, $A$. callosa, $A$. foveata, $A$. longula, $A$. mellea, $A$. scrobiculata, $A$ sp., $A$. tuberculata.); seguido do gênero Glomus com quatro espécies ( $G$. ambisporum, G, diaphanum, G. macrocapum e $\quad G$. sp.). Os gêneros que tiveram constatação de duas espécies foram o Claroideoglomus (C. Clarum e C. etunicatum), Funneliformis ( $F$. geosporum e $F$. verruculosum) e Scutellospora (S. calospora e $S$. weresubiae) e os gêneros com apenas uma espécie cada foram a Ambispora ( $A$. leptoticha), Cetraspora (C. pellucida), Dentiscutata ( $D$. heterogama), espécie não identificada, Gigaspora (G. decipiens), Kuklospora (K. colombiana), Racocetra (R. verrucosa) e Rhizoglomus ( $R$. microaggregatum). 
Tabela 1- Número médio dos esporos e Frequência de Ocorrência das espécies de FMAs em $100 \mathrm{ml}$ das amostras de solos coletadas em set/2015 (período seco) e jano/2017 (período chuvoso) nos ecossistemas de Mata Nativa, Pastagem e Cerrado, no município de Guajará-Mirim/RO.

\begin{tabular}{|c|c|c|c|c|c|c|c|c|}
\hline \multirow{2}{*}{ Espécie } & \multicolumn{2}{|c|}{ Mata Nativa } & \multicolumn{2}{|c|}{ Pasto } & \multicolumn{2}{|c|}{ Cerrado } & \multicolumn{2}{|c|}{$\mathrm{FO} \%$} \\
\hline & Seca & Chuva & Seca & Chuva & Seca & Chuva & Seca & Chuva \\
\hline Acaulospora capsicula & 0 & 0 & 0 & 0 & 0 & 12 & 0 & 8,3 \\
\hline Acaulospora callosa & 0 & 0 & 6 & 0 & 0 & 0 & 1,7 & 0 \\
\hline Acaulosporasp. & 0 & 1 & 0 & 0 & 0 & 2 & 0 & 8,3 \\
\hline Acaulospora foveata & 8 & 2 & 31 & 2 & 1 & 4 & 30 & 16,7 \\
\hline Acaulospora mellea & 8 & 18 & 89 & 4 & 22 & 66 & 58,3 & 71,7 \\
\hline Acaulospora longula & 0 & 0 & 4 & 0 & 20 & 0 & 10 & 0 \\
\hline Acaulospora scrobiculata & 1 & 4 & 41 & 2 & 1 & 1 & 21,7 & 25 \\
\hline Acaulospora tuberculata & 0 & 1 & 12 & 1 & 0 & 16 & 3,3 & 35 \\
\hline Ambispora leptoticha & 1 & 0 & 42 & 2 & 5 & 22 & 13,3 & 26,7 \\
\hline Cetraspora pellucida & 0 & 0 & 0 & 0 & 2 & 0 & 1,7 & 0 \\
\hline Claroideoglomus clarum & 0 & 0 & 0 & 0 & 0 & 2 & 0 & 1,7 \\
\hline Claroideoglomus etunicatum & 1 & 12 & 22 & 1 & 42 & 139 & 41,7 & 86,7 \\
\hline Dentiscutata heterogama & 0 & 0 & 2 & 0 & 0 & 0 & 3,3 & 10 \\
\hline $\mathrm{ENI}$ & 2 & 3 & 3 & 0 & 8 & 29 & 18,3 & 30 \\
\hline Funneliformis geosporum & 6 & 65 & 331 & 17 & 139 & 321 & 75 & 98,3 \\
\hline Funneliformis verrucullosum & 0 & 0 & 18 & 1 & 6 & 0 & 11,7 & 0 \\
\hline Gigaspora decipiens & 10 & 2 & 7 & 0 & 12 & 33 & 36,7 & 30 \\
\hline Glomus sp. & 0 & 2 & 0 & 0 & 5 & 11 & 6,7 & 15 \\
\hline Glomus ambisporum & 3 & 43 & 132 & 7 & 10 & 118 & 40 & 98,3 \\
\hline Glomus diaphanum & 0 & 0 & 2 & 0 & 3 & 34 & 16,7 & 26,7 \\
\hline Glomus macrocarpum & 240 & 96 & 371 & 19 & 178 & 435 & 96,7 & 100 \\
\hline Kuklospora colombiana & 0 & 0 & 0 & 0 & 14 & 0 & 18,3 & 0 \\
\hline Racocetra pérsica & 1 & 0 & 0 & 0 & 0 & 0 & 3,3 & 0 \\
\hline Rhizoglomus microaggregatum & 10 & 60 & 76 & 4 & 28 & 324 & 36,7 & 85 \\
\hline Scuttelospora calospora & 6 & 7 & 3 & 0 & 25 & 84 & 28,3 & 78,3 \\
\hline Scuttelospora weresubiae & 0 & 0 & 0 & 0 & 6 & 0 & 1,7 & 0 \\
\hline Total de esporos & 297 & 316 & 1192 & 60 & 527 & 1653 & & \\
\hline Desvio padrão & 46,7 & 25,0 & 95,7 & 4,8 & 42,4 & 116,8 & & \\
\hline Total de espécie & 13 & 14 & 18 & 18 & 19 & 18 & 23 & 19 \\
\hline
\end{tabular}

As espécies $A$. mellea, $A$. foveata, $A$. scrobiculata, C. etunicatum, F. geosporum, G. ambisporum, $G$. macrocarpum e $R$. microaggregatum foram às espécies constatadas nos três ecossistemas, nas duas estações em estudo. Algumas destas espécies de FMAs foram constatadas como espécies comumente encontrada em vários ecossistemas diferentes, como no trabalho realizado por Assis et al. (2014) que encontraram as espécies $A$. scrobiculata, $G$. macrocarpum e $C$. etunicatum em sua pesquisa em todas as suas áreas estudadas.

Destacou-se na frequência de ocorrência (Tabela 1) a espécie Glomus macrocarpum, que esteve presente em 100\% das amostras coletadas em todos os ecossistemas, seguido das espécies Funneliformis geosporum e Glomus ambisporum, com 98,3\% de frequência de ocorrência. A espécies $G$. macrocarpum é comumente encontrada por outros pesquisadores como Santos et al.
(2013) em três diferentes coberturas florestais. Em um estudo feito por Miranda et al. (2010), a espécie G. macrocarpum também teve alta frequência de ocorrência e dominância na maioria das áreas amostradas, sugerindo estar associada a presença de gramíneas, tendo alta afinidade desta espécie com a planta nas condições edafoclimáticas locais. Miranda (2010) enfatiza que a espécie G. macrocarpum é uma espécie que se adapta em áreas com diferentes graus de perturbação. A alta frequência e a alta densidade desta espécie indicou para Caproni et al. (2003) uma alta capacidade de esporulação ou alta adaptabilidade à região e à situações iniciais independentes das condições climáticas.

Nos três ecossistemas ocorreram 13 espécies (Tabela 2), independente das estações do ano, sendo elas Acaulospora foveata, Acaulospora mellea, Acaulospora scrobiculata, Acaulospora tuberculata, 
Ambispora leptoticha, Claroideoglomus etunicatum, Espécie Não Identificadas, Funneliformis geosporum, Gigaspora decipiens, Glomus ambisporum, Glomus macrocarpum, Rhizoglomus microaggregatum e Scutellospora calospora.

Espécies como Acaulospora capsicula, Cetraspora pellucida, Claroideoglomus clarum, Kuklospora colombiana e Scutellospora weresubiae tiverem incidência apenas no ecossistema de cerrado. As espécies como Acaulospora callosa e Dentiscutata heterogama teve incidência no ecossistema de pastagem. A espécie Racocetra pérsica foi encontrada somente no ecossistema de mata nativa, indicando ser uma espécie muito sensível às variações ambientais proporcionadas pelos ecossistemas de pastagem e de cerrado.

\subsection{AVALIAÇÃO DOS ÍNDICES DE DIVERSIDADE DE ESPÉCIES DE FMA}

O índice de diversidade de Shannon-Wiener expressa a riqueza e uniformidade de espécies, quanto maior for o valor de $\mathrm{H}^{\prime}$, maior será a diversidade de espécies dos FMAs presentes. A diversidade de espécies analisada através do índice de Shannon-

Figura 4 - Índices de diversidade de espécies dos FMAs em ago/2015, em ecossistemas de mata nativa, de pastagem e de cerrado, no município de Guajará-Mirim/RO.

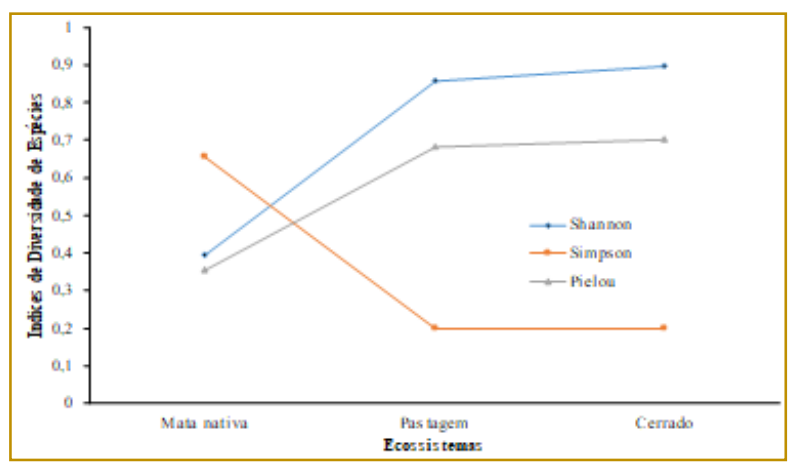

O ecossistema de pastagem e de cerrado sofreram queimadas no ano de 2014 e se encontravam em processo de regeneração natural o que pode ter favorecido a presença de maior diversidade de espécies de FMAs. Esta perturbação, provavelmente, afetou a diversidade das espécies dos FMAs com o decorrer do tempo e a modificação da vegetação sobre ela. Entretanto, estas
Wiener, revelou resultados diferentes entre os ecossistemas quando avaliada através dos esporos de FMAs, no período seco (ago/2015) (Figura 4). Este índice indicou que houve maior diversidade de espécies de FMAs nos ecossistemas de Cerrado $(0,89)$ e de Pastagem $(0,85)$ do que no de mata nativa $(0,39)$. Nestes ecossistemas foram identificados os maiores números de espécies, 18 e 23 respectivamente com baixa dominância de Simpson. Já na mata nativa menor número de espécies esporularam no período seco (13), o que colaborou para o menor índice de diversidade de ShannonWiener. O que ocorre mais comumente é uma alta diversidade de espécies em ecossistemas de mata nativa, desde que esta não apresente algum grau de perturbação (CAPRONI et al., 2001). Os ecossistemas de pastagens e de cerrado se encontravam em maior nível de perturbação, apresentaram maior diversidade de espécies de FMAs que o de mata nativa. Estes dois ecossistemas se renovam constantemente no período chuvoso, após os impactos que sofrem durante 0 período seco.

Figura 5 - Índices de diversidade de espécies dos FMAs em jan/2016, em ecossistemas de mata nativa, de pastagem e de cerrado, no município de Guajará-Mirim/RO.

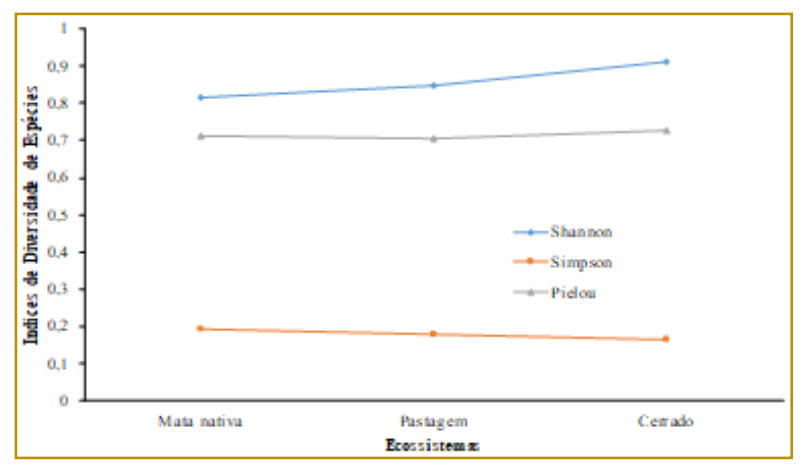

mudanças não podem ser previstas, a diversidade de espécies de FMAs pode aumentar ou diminuir ao longo do tempo (Wardle; Giller, 1997) podendo apresentar flutuações em ambientes naturais (Dajoz, 1983).

Observando-se o índice de dominância de espécies de Simpson, no período seco (2015), e comparando com o índice de 
equitabilidade de espécies de Pielou, nota-se que na mata nativa houve alta dominância, baixa diversidade e equitabilidade de espécies, enquanto que nos ecossistemas de pastagem e de cerrado houve baixa dominância e alta diversidade e equitabilidade de espécies (Figura 4). A principal espécie responsável por este efeito foi Glomus macrocarpum, que apresentou alta esporulação indicando alta competitividade nos três ecossistemas sendo mais significativo no ecossistema de mata nativa. $\mathrm{O}$ ecossistema de mata nativa pertence ao Campus de Guajará-Mirim está localizado no perímetro urbano da cidade, podendo estar sofrendo algum impacto, o que justifica a dominância de alguma espécie de FMA. É comum observar que há tendência de aumento na dominância de espécies em ecossistemas com algum impacto ambiental (CAPRONI et al., 2001). Outro provável fator relacionado à presença de menor diversidade e maior dominância das espécies dos FMAs estaria relacionada à maior participação da Matéria orgânica no solo da mata nativa em relação aos ecossistemas de pastagem e de cerrado.
No período chuvoso, os índices de diversidade de Shannon, de equitabilidade de Pielou e de dominância de Simpson apresentaram o mesmo padrão para os ecossistemas de mata nativa, pastagem e cerrado (Figura 5). Neste período a alta precipitação da região favoreceu igualmente, nos três ecossistemas, o maior número de espécies a esporularem elevando o índice de Shannon e de Pielou e consequentemente diminuindo a dominância de espécies de FMAs.

No agrupamento dos ecossistemas de mata nativa, pastagem e de cerrado com base nas populações das comunidades dos fungos micorrízicos arbusculares observou-se a ordenação em dois grupos que apresentaram 100\% de distância de ligação (Figura 6). Por um lado o ecossistema de cerrado no período seco se isolou indicando ter uma característica bem diferenciada dos demais ecossistemas. Esta diferença foi também respaldada pelo maior valor do índice de Shannon-Wiener em relação aos demais. No segundo grupo os ecossistemas de pastagem e de mata nativa na época chuvosa foram os mais similares.

Figura 6 - Análise de agrupamento das espécies dos FMAs nos ecossistemas de mata nativa, de pastagem e de cerrado no período da seca (ago/2015) e no período da chuva (jan/2016), no município de Guajará-Mirim/RO.

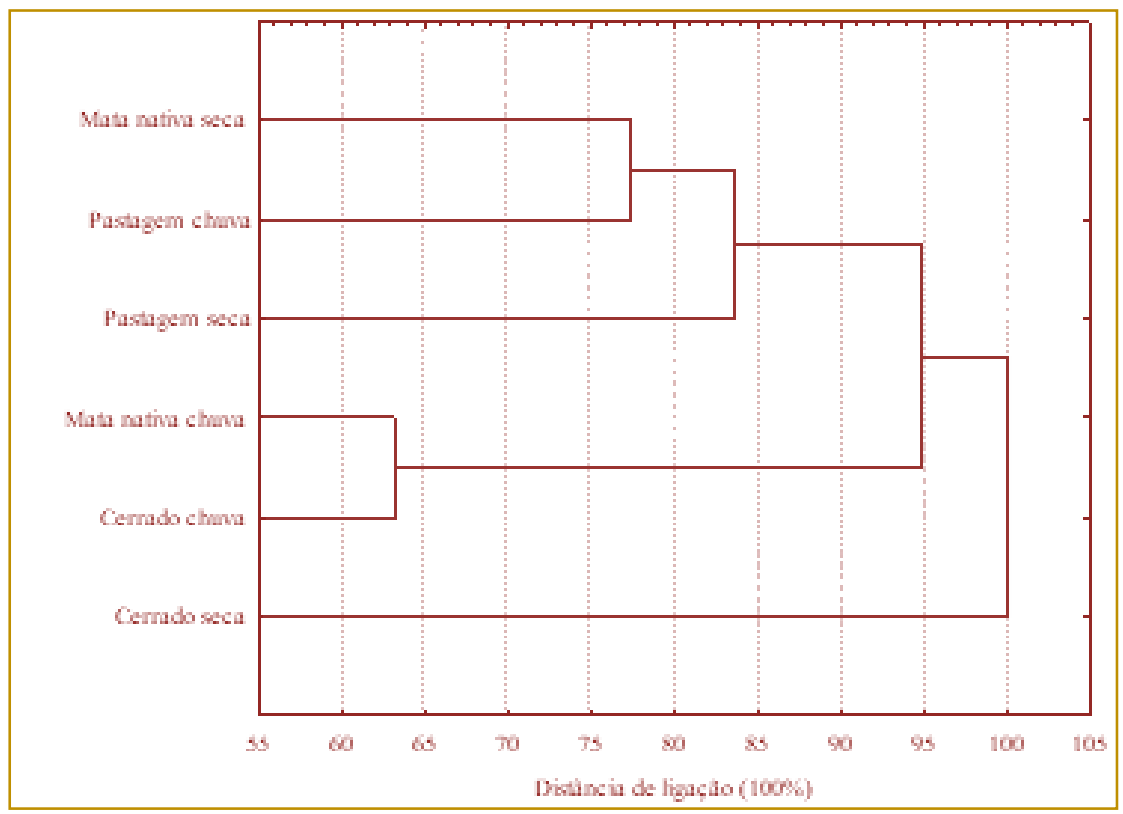




\section{CONCLUSÕES}

No período seco é necessário maior número de amostras de solo para a recuperação de maior número de espécies de FMAs, nos ecossistemas de mata nativa, de pastagem e de cerrado.

Ecossistemas mais perturbados, ou menos estáveis, como os de cerrado e de pastagem favorecem a maior produção de esporos em relação ao ecossistema de mata nativa.
A época seca propicia uma maior incidência de esporos e espécies nos ecossistemas de pastagem e cerrado.

Os gêneros Acaulospora e Glomus apresentam grande adaptabilidade em solos da região de Guajará-Mirim/RO, sendo os que apresentam maior número de espécies, nos ecossistemas de mata nativa, pastagem e de cerrado.

A espécie Glomus macrocarpum predomina nos ecossistemas de mata nativa, pastagem e de cerrado.

Cerrado. Revista Brasileira de Ciência do solo, v. 36, p. 51-61, 2012.

[11] Gerdemann, J. W.; Nicolson, T.H. Spores of mycorrhizalEndogone species extracted from soil by wet sieving and decanting. Trans. $\mathrm{Br}$. Mycol. Soc., v. 46, p. 235-246, 1963.

[12] Gomide, P. H. O. et al. Processos e propriedades do solo. Fungos micorrízicos arbusculares em fitofisionomias do pantanal da nhecolândia, mato grosso do sul. Revista Brasileira de Ciência do Solo, v. 38, p. 1114-1127, 2014.

[13] Harrison, M. Signaling in the mycorrhizal symbiosis. Annual Review of Microbiology, v, 59, p. 19-42, 2005

[14] Invam. International culture collection of vesicular and arbuscularmycorrhizal fungi: species description. Morgantown: West Virginia Agriculture and Forestry Experimental Station, 2000. Disponívelem: <http:www.invam.caf.wvu.edu>. Acesso em 09.2015, 02.2016.

[15] Longo, S. et al. Effects of fire on arbuscular mycorrhizal fungi in the Mountain Chaco Forest. Forest Ecology and Management, v. 315, p.86-94, 2014.

[16] Melloni, R. et al. Fungos micorrízicos arbusculares em solo da Reserva Biologica municipal Serra dos Toledos, Itajubá/MG. Ciência Florestal, Santa Maria, v.21, n.4, p. 799-809, out.dez., 2011.

[17] Mergulhão, A. C. E. S. et al. Potencial de infectividade de fungos micorrízicos arbusculares em áreas nativas e impactadas por mineração gesseira no semiárido brasileiro. Hoehnea, v. 34, n. 3, p.3 41-348, 2007.

[18] Mergulhão, A.C.E.S et al. Caracterização morfológica e molecular de fungos micorrízicos arbusculares isolados de áreas de mineração de gesso, Araripina, PE, Brasil. Hoehnea, v.41, n.3, p.393-400, 2014.

[19] Miranda, E.M.; Silva, E.M.R.; Sagin Júnior, O.J. Comunidades de fungos micorrízicos 
arbusculares associados ao amendoim forrageiro em pastagens consorsidas no Estado do Acre, Brasil. Acta Amazônia, v. 40, n. 1, p. 13-22, 2010.

[20] Pielou, E. C., Mathematical ecology. 2. ed. Wiley, NY. 1977.

[21] Porras-Soriano, A. et al. Arbuscular mycorrhizal fungi increased growth, nutrient uptake and tolerance to salinity in olive trees under nursery conditions. Journal of Plant Physiolog, v. 166, p. 1350-1359, 2009.

[22] Schenck, N. C.; Perez, Y. Manual for identification of vesicular-arbuscularmycorrhizal fungi. Gainesville, Invam, 1988.

[23] Santos, R. S.; Scoriza, R. N.; Ferreira, J. S. Fungos micorrízicos arbusculares em diferentes coberturas florestais em Vitória da Consquista, Bahia. Floresta e Ambiente, jul/set, v. 20, n. 3, p. 344-350, 2013.

[24] Silva, G. A.; Diversidade funcional de fungos micorrízicos arbusculares oriundos de solos da Amazônia Ocidental/Lavras: UFLA, 2009. 90p.:il tese (Doutorado)

[25] Silva, F. de A. S. e.; Azevedo, C. A. V. de. The Assistat Software Version 7.7 and its use in the analysis of experimental data. African Journal of Agricultural Research, v. 11, n. 39, p. 3733-3740, 2016.

[26] Silveira, A. P. D. Micorrizas. In: CARDOSO, E. I. B.; TSAI, S. M.; NEVES, M. C. P. eds.
Microbiologia do solo. Campinas: Sociedade Brasileira de Ciência do Solo, p. 257-282,1992.

[27] Smith, S. E.; Read, D. J. Mycorrhizal Symbiosis. 2. ed. London: Academic Press, 1977

[28] Souza, F. A. de; Silva, I. C. L.; Berbara, R. L. L. Fungos micorrízicos arbusculares: muito mais diversos do que se imaginava. In: Moreira, F. M. S.; Siqueira, J. O.; Brusssard, L., eds. Biodiversidade do solo em ecossistemas brasileiros. Lavras, Universidade Federal de Lavras, 2008. p.483-536.

[29] Tchabi, A. et al. Arbuscular mycorrhizal fungal communities in sub-Saharan Savannas of Benin, West Africa, as affected by agricultural land use intensity and ecological zone. Mycorrhiza, v.18, p. 181-195, 2008

[30] Vierheilig, H.; Lerat, S.; Piche, Y. Systemic inhibition of arbuscular mycorrhiza development by root exudates of cucumber plants colonized by Glomusmosseae. Mycorrhiza, v. 13, p. 167-170, 2003.

[31] Wardle, D. A.; Giller, K. E. The quest for a contemporary ecological dimension to soil biology. Soil Biology and Biochemistry, Oxford, v. 28, p. 1549-1554, 1997.

[32] Zangaro, W; Moreira, M. MicorrizasArbusculares nos Biomas Floresta Atlântica e Floresta de Araucária. In: Siqueira, et al. (Eds) Micorrizas: 30 anos de pesquisa no Brasil. Lavras: Ufla, 2010. 


\section{Capítulo 7}

\section{INTERFERÊNCIA DA APLICAÇÃO DE MORDENTES NA IMPRESSÃO BOTÂNICA DE TECIDOS DE SEDA}

\section{Carolina Bittencourt de Souza dos Santos}

\section{Doralice de Souza Luro Balan}

Resumo: A impressão botânica é uma técnica que utiliza materiais vegetais contendo corantes como folhas, flores, frutos, caules e raízes, que transferem cor por contato direto à superfície a ser colorida. É uma técnica que imprime as formas, cores e aromas das plantas no tecido através de uma reação química, gerando estampas únicas e especiais. Algumas substancias solúveis em água são capazes de se ligar às fibras e ao corante, tornando-o insolúvel e fixando a cor, elas são conhecidas como mordentes. O objetivo desta pesquisa foi avaliar o uso de diferentes mordentes no material botânico, verificando sua ação na qualidade da impressão final no tecido. Como metodologia foram realizados ensaios práticos utilizando pré-mordência nas folhas de mamona (Ricinus communis), selecionadas como material botânico para impressão em tecido de seda. Foram empregados como mordentes sulfato de alumínio, sulfato de ferro e sulfato de cobre. A impressão na seda apresentou resultados de sucesso, com cores intensas e imagens bem delineadas. O mordente sulfato de ferro exibiu destaque e originou impressão nítida em tons de preto, cinza e verde singulares e distintos. Estes biomateriais para impressão são fontes ecologicamente amigáveis, seguras e acessíveis, sendo que a aplicação de métodos de impressão botânica em têxteis, pode ser viável como um negócio de finalidade comercial com alto valor agregado, empregando tecidos nobres como a seda. A técnica de impressão botânica apresenta vantagens econômicas, ecológicas e produtivas.

Palavras-chave: impressão botânica; corantes naturais; artesanato têxtil; mordentes 


\section{INTRODUÇÃO}

A técnica de impressão botânica utiliza materiais vegetais como folhas, flores, frutos, caules, raízes, que contém corantes e transferem cor por contato direto à superfície a ser colorida, não sendo necessário extrair o corante do fragmento vegetal para utilizá-lo. É uma técnica que imprime as formas, cores e aromas das plantas no tecido através de reações químicas, gerando estampas únicas e especiais (ISMAL, 2016).

A técnica também denominada ecoprint ou estamparia botânica, representa um sistema de impressão/coloração/estampagem em substratos têxteis que se utiliza de produtos químicos fixadores, conhecidos como mordentes, para que seja realizada a estampagem da silhueta detalhada de folhas, flores e outros materiais botânicos em tecidos, por meio de vaporização ou imersão. Preferencialmente nesta técnica, utiliza-se tecidos naturais tal como seda, lã ou algodão (FLINT, 2008).
Para FERREIRA (1998) são chamadas mordentes as substâncias solúveis em água e capazes de se ligar às fibras e ao corante, tornando-o insolúvel. Desse modo, o corante adere à fibra por sua intervenção. São três os grandes grupos de mordentes: origem vegetal são bio-mordentes (tanino); origem de sais orgânicos (água de cinzas ou decoada, acetato de ferro) e origem mineral (alúmen; sulfato de cobre, sulfato de ferro). Sua aplicação no período anterior ao processo de tingimento ou estampagem recebe denominação de pré-mordente, simultâneo ao processo co-mordente e após o final do processo pós- mordente.

Posteriormente à disposição do material vegetal sobre o tecido, é realizado um enrolamento ou amarração para gerar diferentes efeitos no momento de tingir ou estampar. A formação deste "pacote" é conhecida como a técnica de shibori, utilizada em diversos outros métodos de tingimento e estamparia manuais (Figura 01).

Figura 01 - Shibori para impressão botânica

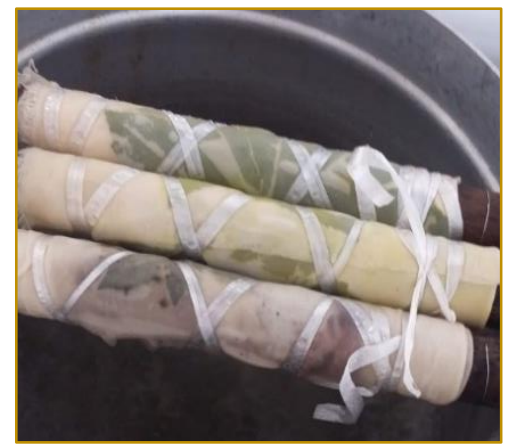

Fonte: registro elaborado por Carolina B.S. Santos, maio 2018

Com o shibori pronto, o próximo passo é o banho de estampagem, que ocorre por meio de imersão ou vaporização. No caso de ser escolhida a imersão, o substrato permanece mergulhado em água, ou em solução fixadora mordente por um período pré-estabelecido de tempo. No caso da vaporização, o substrato é deixado numa espécie de banho-maria, onde recebe vapor constante por um período de tempo que varia de acordo com o resultado almejado (ISMAL, 2016).

O objetivo geral deste trabalho é a investigação e divulgação da técnica têxtil artesanal da impressão botânica, que é pouco estudada e pouco conhecida do profissional têxtil brasileiro.
Como objetivo específico realizou-se a avaliação do uso de diferentes mordentes no material botânico, verificando sua ação na qualidade da impressão final no tecido.

Os resultados poderão ser um instrumento de informação para aqueles que procuram novas oportunidades e almejam atingir um público que busca alternativas sustentáveis, associadas à área têxtil.

\section{METODOLOGIA}

Para a elaboração deste trabalho optou-se pelo método de pesquisa exploratório, que implica na realização de testes em laboratório, 
que permitem simulações de situações em potencial.

Foram conduzidos como experimentos testes de impressão botânica em tecidos 100\% seda branca PT (pronta para tingir), a fim de verificar as condições e os procedimentos de realização da técnica e suas variantes. Foram utilizadas amostras com tamanho de 29 por 26 centímetros.

Como material botânico para a realização dos ensaios optou-se por folhas da mamoneira, Ricinus communis L., encontradas nas ruas da cidade de Americana, SP, região metropolitana de Campinas, SP, consideradas plantas de fácil acesso.

$\mathrm{Na}$ aplicação de mordentes foram empregados o sulfato de ferro (utilizado em forma cristalizada) 02 gramas, para $250 \mathrm{ml}$ de água; o sulfato de alumínio (utilizado em forma liquida): 25 mililitros (ml), para $225 \mathrm{ml}$ de água e o sulfato de cobre (utilizado em pó): 02 gramas, para $300 \mathrm{ml}$ (FERREIRA, 1998).
Optou-se pela aplicação de pré-mordência apenas no material botânico, desse modo as folhas da mamoneira ficaram imersas na solução de mordente por 11 horas antes de seu uso.

Após o período de pré-mordencia, as folhas foram posicionadas no tecido de seda que foi dobrado, e enrolado em shibori. Os rolos ficaram em vapor constante por um total de 03 horas, deixando-se esfriar naturalmente, antes da revelação dos resultados finais.

\section{RESULTADOS E DISCUSSÃO}

Os resultados dos testes de impressão botânica no tecido de seda, após a prémordência das folhas de mamona ( Ricinus communis ) em diferentes mordentes, são mostrados na Tabela 01.

Os efeitos causados pela reação entre as folhas, solução mordente e tecido, são bem aparentes nas amostras de seda.

Tabela 01 - Resultado da impressão botânica no tecido de seda - comparação entre diferentes mordentes aplicados

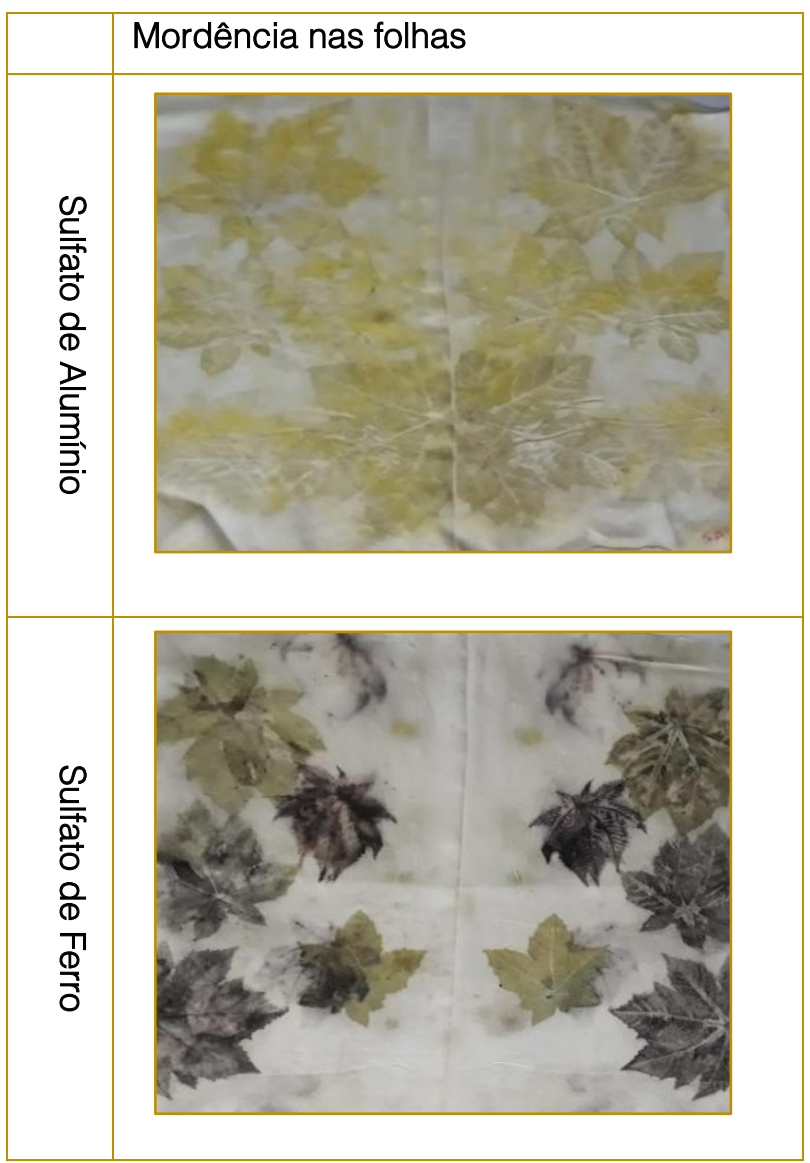




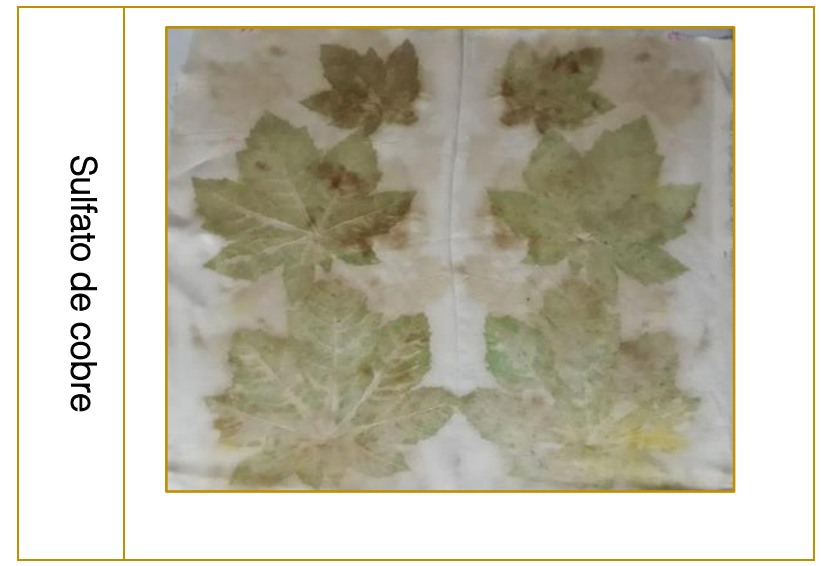

Utilizando-se sulfato de alumínio foi possível visualizar na coloração da seda em tom amarelado, as nervuras e silhuetas das folhas com muita clareza (Tabela 01).

O sulfato de ferro exibiu o resultado com a pigmentação mais intensa revelando cores do preto, cinza ao verde e, considerado o resultado de maior sucesso, graças a riqueza de detalhes presentes na estampa, e a clareza com a qual é possível visualizá-los (Tabela 01).

O sulfato de cobre revelou coloração esverdeada, evidente onde as folhas foram posicionadas (Tabela 01).

As cores reveladas pelos mordentes derivam dos corantes presentes nas folhas vegetais: grupo das clorofilas (verde) e grupo dos carotenóides (do amarelo ao laranja), além do tanino (do amarelo ao castanho forte, até o negro) (ARAÚJO, 2006).

A escolha do mordente demonstra influência nos efeitos buscados pelo artesão têxtil e no que ele pretende estampar.

O uso de diferentes mordentes leva ao desfecho de que a indicação do tecido de

\section{REFERÊNCIAS}

[1] Araujo, M.E.M. Corantes naturais para têxteis - da Antiguidade aos tempos modernos. Conservar Património, nํ-4, dez. 2006, pag.39 51, Lisboa, Portugal.

[2] Ferreira, E.L. Corantes Naturais da Flora Brasileira - Guia Prático de Tingimento com Plantas. Curitiba, 1ํㅡ ed. , 1998, 98p. seda para a realização da impressão botânica é justificável, graças a interação muito intensa entre esse tecido e as folhas da mamoneira, representada na exuberância das cores resultantes.

\section{CONCLUSÕES}

A técnica de impressão botânica ou eco-print como um tipo de beneficiamento natural, colabora para a exposição das possibilidades de produções sustentáveis dentro do âmbito têxtil, cujo setor produtivo é tradicionalmente associado a atividades industriais altamente poluentes.

Estes biomateriais são fontes ecologicamente amigáveis, seguros e acessíveis, sendo possível afirmar que a aplicação de métodos de impressão botânica em têxteis, é viável como um negócio de finalidade comercial, com alto apelo ecológico e, alto valor agregado.

A técnica de impressão botânica apresenta vantagens econômicas, ecológicas e produtivas.

[3] Flint, India . Eco colour - botanical dyes for beautiful textiles. Interweave.com, Austrália, 2008, $238 \mathrm{p}$.

[4] Ismal, O.E. Patterns from nature:contact print. Journal of the Textile Association, jul-aug. 2016, pg.81- 91 . 


\section{Bapítulo 8}

\section{PRODUCÃO DE MUDAS DE SERINGUEIRA PARA VIVEIROS COMERCIAIS}

\section{Rafaella Gouveia Mendes}

Amanda Fialho

Josef Gastl Filho

Rosenvaldo da Silva Araujo

Danylla Paula de Menezes

Pedro Henrique de Freitas Deliberto Ferreira

Resumo: O seringal é uma floresta plantada de grande importância socioeconômica e ambiental, sendo formada a partir do plantio de mudas de Hevea brasiliensis L., as quais são obtidas a partir de sementes, que de modo geral apresentam rápida perecibilidade, fator limitante para implantação do empreendimento. Desse modo, o presente estudo teve por objetivo avaliar o efeito do ácido giberélico (GA3) na germinação de sementes armazenadas de seringueira. Após a coleta, beneficiamento, armazenamento e assepsia, as sementes foram embebidas por $12 \mathrm{~h}$ em seus respectivos tratamentos. Em seguida, as sementes foram semeadas em papel germitest, areia, solo do cerrado, areia + terra vegetal, terra vegetal + solo do cerrado. Foram realizados 4 tratamentos $(\mathrm{T})$ com as seguintes concentrações de GA3: T1 (testemunha) - 0 mg L-1, T2- $250 \mathrm{mg}$ L-1, T3- $500 \mathrm{mg} \mathrm{L-1;} \mathrm{T4-} 1000 \mathrm{mg} \mathrm{L-1.} \mathrm{Os} \mathrm{parâmetros} \mathrm{avaliados} \mathrm{foram:}$ porcentagem de germinação (PG), índice de velocidade de germinação (IVG), porcentagem de emergência (PE) e índice de velocidade de germinação (IVE), teste de emergência (TE). Os tratamentos T3 e T4 apresentaram melhores resultados paras as variáveis de PG, PE e IVG, já para IVE, o T3 apresentou melhor resultado, com 9,01. Em relação aos substratos, o melhor resultado foi para solo do cerrado. Os resultados obtidos para os tratamentos pré-germinativos com GA3 foram satisfatórios, uma vez que os percentuais de germinação foram superiores a $50 \%$, e segundo registros na literatura, sementes armazenadas possuem menos de $45 \%$ de germinação. Conclui-se que a aplicação da solução de GA3 em sementes de seringueira armazenadas por 30 dias, é benéfica, principalmente na concentração de $500 \mathrm{mg} \mathrm{L-1}$, sendo possível potencializar a produção de mudas, e concomitantemente a instalação de seringais.

Palavras-chave: Hevea brasiliensis L.; ácido giberélico; armazenamento; vigor. 


\section{INTRODUÇÃO}

As florestas plantadas são de grande importância econômica e ambiental. Em termos ambientais, as florestas plantadas otimizam o uso de áreas degradadas, promove a conservação do solo e dos recursos hídricos. Além da sua intensa atividade fotossintética contribuir para redução do oxigênio atmosférico. Em termos econômicos, produzem uma grande diversidade de matérias primas, que dão origem ao papel, borracha, móveis e energia.

O seringal é uma floresta plantada de grande importância econômica, composta pela seringueira (Hevea brasiliensis L.), árvore pertencente à família Euphorbiaceae, famosa pela produção e fornecimento do látex para fabricação da borracha. É originária da bacia hidrográfica do Rio Amazonas e difundiu-se para outras partes do país e do mundo (GOUVÊA, 2008).

Os seringais se formam a partir do plantio de mudas, e para garantir a consistência e qualidade dos novos plantios, são necessárias mudas de seringueira com qualidade fitossanitária e genética (SÃO PAULO, 2013).

As mudas são produzidas a partir de sementes, que são coletadas em seringais cultivados com a finalidade de produzir borracha, tornando-se um subproduto da atividade (WETZEL et al., 1992). Contudo, a característica recalcitrante dessas sementes faz com que elas percam, rapidamente, seu poder germinativo (CÍCERO, 1986).

A curta longevidade das sementes recalcitrantes reduz o período de sua utilização, limitando o armazenamento, e levando a necessidade de se realizar a semeadura mais rapidamente (STUBSGAARD, 1990). De modo geral, a rápida perecibilidade das sementes de seringueira é o fator mais limitante na implantação de empreendimentos heveícolas, pois, limita o período de produção de mudas, devido à baixa faixa de germinação (PEREIRA, 1980).

No que se refere à germinação de sementes, Metivier (1986) ressalta o papel das giberelinas na germinação, estando envolvidas tanto na quebra da dormência como no controle da hidrólise de reservas, da qual depende o embrião em crescimento. Além da quebra de dormência, as giberelinas aceleram a germinação em sementes não dormentes e aumentam a hidrólise de reservas, tornando $\mathrm{o}$ embrião maduro $\mathrm{e}$ disponível para a germinação.

Segundo Abreu et al. (2005), mesmo que os embriões estejam completamente maduros, o substrato é um fator importante tanto para a velocidade quanto para porcentagem de germinação. Os substratos adequados são fundamentais como suprimento dos nutrientes necessários ao crescimento e desenvolvimento das plantas, além de contribuir com condições ideais para 0 processo germinativo.

A partir dos testes de germinação e emergência, é possível avaliar a influência do $\mathrm{GA}_{3}$, em diferentes concentrações, e concomitantemente da eficiência do substrato, para otimização do processo de germinação da seringueira e proporcionar a expressão máxima do vigor. Dessa forma, o presente trabalho objetivou avaliar o efeito do $\mathrm{GA}_{3}$ na germinação de sementes armazenadas de seringueira (Hevea brasiliensis L.), em diferentes substratos.

\section{METODOLOGIA}

O experimento foi conduzido em casa de vegetação e no laboratório de sementes (LASE) da Universidade do Estado de Minas Gerais (UEMG), unidade Ituiutaba-MG. O clima na região é classificado em Aw de acordo com Köppen e Geiger, a temperatura média é de $23.9^{\circ} \mathrm{C}$ e a precipitação média anual é de $1.352 \mathrm{~mm}$. Sua realização deu-se no período de fevereiro a maio de 2017.

As sementes de seringueira foram obtidas de árvores matrizes ( $18^{\circ} 57^{\prime} 55^{\prime \prime}$ Sul, $49^{\circ} 27^{\prime} 49^{\prime \prime}$ Oeste), no município de Ituiutaba (MG), região no Triângulo Mineiro, as quais foram coletadas após a deiscência natural dos frutos. As sementes passaram por processo de beneficiamento (seleção de pureza), em que foram retiradas as de tamanho irregular, danificadas e anormais. As sementes puras foram armazenadas em saco de papel kraft, em temperatura e umidade ambiente por um período de 30 dias.

Após o período de armazenamento, as sementes foram submetidas a um processo de assepsia, em imersão em solução de hipoclorito de sódio a $2 \%$, por 10 minutos, e em seguida, foram lavadas em água destilada corrente. 
Após a sanitização, as sementes foram embebidas em soluções de $\mathrm{GA}_{3}$ pelo período de $12 \mathrm{~h}$ de acordo com seus respectivos tratamentos (Tabela 1). Após a embebição, as sementes foram lavadas em água destilada e destinadas à semeadura.

Tabela 1. Tratamentos pré-germinativos, e respectivas concentrações de $\mathrm{GA}_{3}$.

\begin{tabular}{|c|c|}
\hline Tratamento & Concentração da solução de ácido giberélico \\
\hline T1(testemunha) & $0 \mathrm{mg} \mathrm{L}^{-1}$ de $\mathrm{GA}_{3}$ \\
\hline T2 & $250 \mathrm{mg} \mathrm{L}^{-1}$ de $\mathrm{GA}_{3}$ \\
\hline T3 & $500 \mathrm{mg} \mathrm{L}^{-1} \mathrm{de} \mathrm{GA}_{3}$ \\
\hline $\mathrm{T} 4$ & $1000 \mathrm{mg} \mathrm{L}^{-1} \mathrm{de} \mathrm{GA}_{3}$ \\
\hline
\end{tabular}

Para avaliar a qualidade fisiológica das sementes foi realizado o teste padrão de germinação e o teste padrão de emergência. Os mesmos foram conduzidos em delineamento inteiramente casualizado (DIC), com um total de 4 tratamentos com $\circ \mathrm{GA}_{3}(0$ $\mathrm{mg} \mathrm{L}^{-1}$ de $\mathrm{GA}_{3}, 250 \mathrm{mg} \mathrm{L}^{-1}$ de $\mathrm{GA}_{3}, 500 \mathrm{mg} \mathrm{L}^{-1}$ de $\mathrm{GA}_{3}, 1000 \mathrm{mg} \mathrm{L}^{-1}$ de $\mathrm{GA}_{3}$ ) e 5 repetições de 50 sementes cada.

No teste padrão de germinação as sementes foram semeadas em papel germitest, umedecidos com água destilada em quantidade equivalente a 2,5 vezes a massa do papel seco, e por fim, destinadas à câmara de germinação com temperatura controlada a $25 \stackrel{\circ}{\circ}$ (BRASIL, 2009), sendo os parâmetros analisados: porcentagem de germinação (PG) e índice de velocidade de germinação (IVG). Avaliou-se diariamente, durante 50 dias, a quantidade de sementes germinadas, tendo por critério a emissão da raiz primária. A primeira contagem se deu no décimo nono dia, e a última contagem no trigésimo sétimo dia.

Já para o teste padrão de emergência as sementes foram semeadas em vasilhames plásticos contendo areia, os quais foram umedecidos diariamente, sendo mantidos em câmara de germinação com temperatura controlada a $25{ }^{\circ} \mathrm{C}$. Sendo os parâmetros avaliados: porcentagem de emergência (PE) e índice de velocidade de emergência (IVE). Avaliou-se diariamente, durante 50 dias, a quantidade de sementes emergidas, tendo como critério a exposição de qualquer parte da plântula sobre o substrato. A primeira contagem se deu no vigésimo primeiro dia, e a última contagem no quadragésimo primeiro dia.

Para avaliar a viabilidade de produção de mudas em diferentes substratos, foi realizado o teste de emergência em DIC, em esquema fatorial $4 \times 3$, ou seja, 4 concentrações de $\mathrm{GA}_{3}$ (0 $\mathrm{mg} \mathrm{L}^{-1}$ de $\mathrm{GA}_{3} ; 250 \mathrm{mg} \mathrm{L}^{-1}$ de $\mathrm{GA}_{3} ; 500 \mathrm{mg}$ $\mathrm{L}^{-1}$ de $\mathrm{GA}_{3}$ e $1000 \mathrm{mg} \mathrm{L}^{-1}$ de $\left.\mathrm{GA}_{3}\right)$ e 3 substratos (Solo do cerrado; Areia + Terra Vegetal e Solo do cerrado + Terra Vegetal), perfazendo o total de 12 tratamentos, com 5 repetições de 50 sementes cada.

O solo utilizado como substrato foi o proveniente de área de cerrado, sendo este caracterizado como latossolo vermelho distrófico de textura média. Por sua vez, a areia utilizada foi a classificada como sendo areia média lavada. A terra vegetal utilizada foi da marca Terral ${ }^{\circledR}$, composta por $50 \%$ de terra vegetal e $50 \%$ de esterco bovino, composto esterilizado.

As sementes foram semeadas em bandejas sementeiras de isopor de 150 células (136 $\mathrm{mL} /$ célula), preenchidas com diferentes substratos (Tabela 2), destinadas à casa de vegetação com $50 \%$ de sombreamento com temperatura e umidade ambiente, sendo umedecidas diariamente.

Tabela 2. Substratos utilizados para o teste de emergência, de Hevea brasiliensis L.

\begin{tabular}{|l|c|}
\hline \multicolumn{1}{|c|}{ Substrato } & Proporção \\
\hline Solo do Cerrado & 1 \\
\hline Areia + Terra Vegetal & $1: 1$ \\
\hline Solo do Cerrado + Terra Vegetal & $1: 1$ \\
\hline
\end{tabular}

Foi avaliada diariamente, durante 50 dias, a quantidade de sementes emergidas, tendo como critério a exposição de qualquer parte da plântula sobre os substratos. A primeira contagem foi realizada no vigésimo quarto dia, e a última contagem no quadragésimo terceiro dia após a semeadura. 
Os dados obtidos foram submetidos ao cálculo das medidas de dispersão e análise de variância (ANOVA), sendo comparados por meio do Teste de Tukey a $5 \%$ de probabilidade, através do software estatístico SISVAR $^{\circledR}$ 5.6.

\section{RESULTADOS E DISCUSSÃO}

Os dados obtidos das variáveis PG, IVG, PE e IVE das sementes de seringueira submetidas aos tratamentos pré-germinativos com $\mathrm{GA}_{3}$, estão descritos na Tabela 3.

Tabela 3. Valores médios de germinação (\%) e emergência (\%) de sementes de Hevea brasiliensis $\mathrm{L}$., submetidas a diferentes tratamentos com $\mathrm{GA}_{3}$.

\begin{tabular}{|c|c|c|c|c|}
\hline Tratamentos & Germinação (\%) & IVG & $\begin{array}{l}\text { Emergência } \\
(\%)\end{array}$ & IVE \\
\hline T1 & $46,0 \pm 0,20 b$ & $8,35 \pm 0,044 \mathrm{~b}$ & $41,0 \pm 0,40 b$ & $7,52 \pm 0,039 \mathrm{~b}$ \\
\hline $\mathrm{T} 2$ & $62,0 \pm 0,24 b$ & $8,64 \pm 0,042 b$ & $58,0 \pm 0,40 \mathrm{~b}$ & $8,14 \pm 0,038 b$ \\
\hline T3 & $87,0 \pm 0,24 \mathrm{a}$ & $9,18 \pm 0,040 \mathrm{a}$ & $85,0 \pm 0,50 a$ & $9,01 \pm 0,037 \mathrm{a}$ \\
\hline T4 & $69,0 \pm 0,37 \mathrm{a}$ & $8,90 \pm 0,037 \mathrm{a}$ & $65,0 \pm 0,48 a$ & $8,48 \pm 0,041 b$ \\
\hline \multicolumn{5}{|c|}{$\begin{array}{c}\text { Média } \pm \text { Desvio padrão. Médias seguidas pela mesma letra na coluna não diferem } \\
\text { estatisticamente entre si, pelo Teste Tukey }(p<0,05) \text {. }\end{array}$} \\
\hline
\end{tabular}

Houve diferenças significativas $(p<0,05)$ entre os tratamentos para todos os parâmetros avaliados nos testes padrão de germinação e emergência. Em PG, IVG e PE os tratamentos que apresentaram maiores índices fora T3 e T4, já em IVE T3 apresentou maior resultado, o que demonstra que estes tratamentos prégerminativos proporcionaram maior vigor, indicando melhor qualidade fisiológica das sementes.

É possível destacar o tratamento T3, que apresentou índices de germinação e emergência de 87 e $85 \%$, respectivamente. Valor considerado expressivo, pois, de acordo com Benesi et al. (1999) as sementes desta espécie, mesmo quando coletadas adequadamente, apresentam taxas de germinação entre $60 \%$ e $80 \%$, isto, segundos os mesmos autores, se colocadas para germinar imediatamente após a queda, uma vez que quanto maior o tempo decorrido entre a queda e a semeadura, menor será essa taxa.

Os resultados obtidos para os tratamentos pré-germinativos com $\mathrm{GA}_{3}$ foram satisfatórios, uma vez que os percentuais de germinação foram superiores a $50 \%$ e houve incremento em IVG e IVE, enquanto Dijkman (1951), registrou que percentual de germinação de sementes de seringueira, armazenadas sem qualquer proteção, cai para menos de $45 \%$ após 30 dias.

O teor de giberelinas decresce bastante em sementes maduras, sendo, portanto importante o tratamento pré-germinativo das sementes e, de acordo com Lavagnini et al. (2014), estas, como o $\mathrm{GA}_{3}$ são responsáveis por promover a germinação uniforme, acelerar a digestão das reservas nutritivas contidas no endosperma ao estimular a produção de enzimas hidrolíticas.

De fato a aplicação de giberelinas, apresenta diversos benefícios à fisiologia das sementes. Contudo, a dose do hormônio aplicada é decisiva para o aumento ou redução do vigor. É possível observar no gráfico da Figura 1, a relação linear obtida entre as contrações de $\mathrm{GA}_{3}$ nas soluções, e as porcentagens de germinação e emergência. 
Figura 1. Regressão linear em relação aos valores médios de germinação (\%) e emergência (\%) de sementes de Hevea brasiliensis, de acordo com as concentrações de $\mathrm{GA}_{3}$

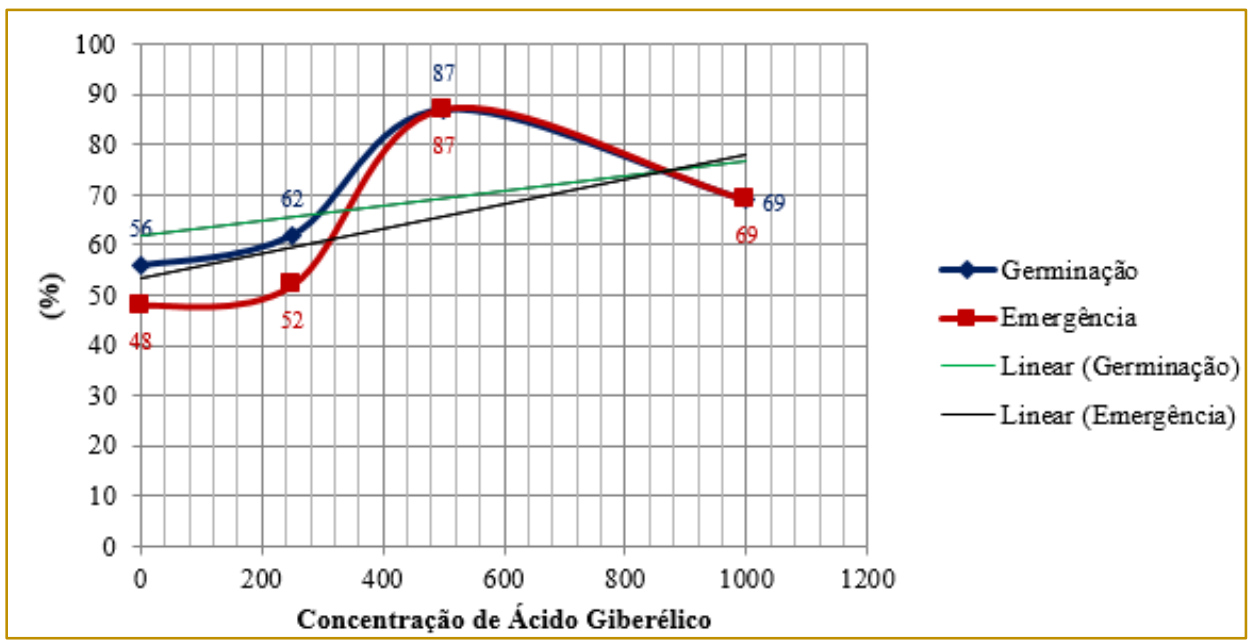

No gráfico é possível observar os baixos percentuais de germinação (46\%) e emergência $(41 \%)$ da testemunha. Em sequência crescente 0 tratamento T2, apresentou $62 \%$ de germinação e $58 \%$ de emergência. No ápice, se encontra 0 tratamento T3, com $87 \%$ de germinação e $85 \%$ de emergência. Por fim em decréscimo, o tratamento $\mathrm{T} 4$, com $69 \%$ de germinação e $65 \%$ de emergência.

O decréscimo da germinação e emergência do tratamento T4 pode ser atribuído à concentração de $\mathrm{GA}_{3}$ aplicada, já que segundo Metivier (1986) as giberelinas atuam no controle da hidrólise de reservas, sendo que o excesso do ácido pode ocasionar uma hidrólise desordenada das reservas.

$\mathrm{Na}$ Tabela 4, é possível observar os percentuais de emergência das sementes de seringueira submetidas aos tratamentos prégerminativos com $\mathrm{GA}_{3}$, e semeadas em diferentes substratos.

Tabela 4. Valores médios de germinação (\%) das sementes de Hevea brasiliensis L., submetidas a diferentes tratamentos com $\mathrm{GA}_{3}$, e em diferentes substratos.

\begin{tabular}{|c|c|c|}
\hline Tratamento & Substrato & Emergência (\%) \\
\hline \multirow{3}{*}{ T1 } & Solo do Cerrado + Terra Vegetal & $48,0 \pm 0,40 \mathrm{~b}$ \\
\hline & Solo do Cerrado & $50,0 \pm 0,44 b$ \\
\hline & Areia + Terra Vegetal & $56,0 \pm 0,20 b$ \\
\hline \multirow{3}{*}{ T2 } & Solo do Cerrado + Terra Vegetal & $52,0 \pm 0,40 \mathrm{~b}$ \\
\hline & Solo do Cerrado & $55,0 \pm 0,44 b$ \\
\hline & Areia + Terra Vegetal & $61,0 \pm 0,24 b$ \\
\hline \multirow{3}{*}{ T3 } & Solo do Cerrado + Terra Vegetal & $67,0 \pm 0,50 \mathrm{~b}$ \\
\hline & Solo do Cerrado & $83,0 \pm 0,67 a$ \\
\hline & Areia + Terra Vegetal & $86,0 \pm 0,24 a$ \\
\hline \multirow{3}{*}{ T4 } & Solo do Cerrado + Terra Vegetal & $59,0 \pm 0,48 b$ \\
\hline & Solo do Cerrado & $63,0 \pm 0,50 \mathrm{~b}$ \\
\hline & Areia + Terra Vegetal & $69,0 \pm 0,37 b$ \\
\hline
\end{tabular}


O índice de emergência apresentou diferenças significativas entre os tratamentos $(p<0,05)$, ou seja, os diferentes substratos e concentrações de $\mathrm{GA}_{3}$ influenciaram $\mathrm{O}$ processo de emergência de seringueira. Os melhores resultados obtidos foram para 0 tratamento pré-germinativo T3 $\left(1.000 \mathrm{mg} \mathrm{L}^{-1}\right.$ de $\mathrm{GA}_{3}$ ), utilizando os substratos solo do cerrado que apresentou com 83\% de emergência das sementes e areia com terra vegetal com $86 \%$ de emergência das sementes. Com base nos resultados indica-se o emprego do solo do cerrado, pois, é de fácil acesso e baixo custo, além do fato, que a distribuição dos diâmetros dos poros influência para uma maior quantidade de água retida (HILLEL, 1980; SILVA et al. 2005).

Gonçalves et al., (2001), afirma que mesmo que o semeio seja realizado rapidamente após a queda, a taxa de germinação raramente ultrapassa $80 \%$. O que indica ótimos resultados na aplicação de $\mathrm{GA}_{3}$ na

\section{REFERÊNCIAS}

[1] Abreu D.; Nogueira A. C.; Medeiros A. C. S. Efeito do substrato e da temperatura na germinação de sementes de cataia (Drimys brasiliensis Miers. Winteraceae). Revista Brasileira de Sementes, 2005.

[2] Benesi, J. F. C.; Furtado, E. L.; Brioschi, A.P.; Bellintani Neto, A.M.; Ortalani, A. A.; Bacchiega, A. N.; Martins, A. L. M.; P, S. A.; Oliveira Filho, N. L.; Gonçalves, P. S.; Arruda, S. T. A cultura da seringueira para o estado de São Paulo. Campinas: Coordenadoria de Assistência Técnica Integral-CATI, 1999. 99 p.

[3] Brasil, Mapa: Ministério da Agricultura Pecuária e Abastecimento. Regras para análise de sementes. Brasilia: MAPA. 2009.

[4] Chin, H. F.; Aziz, M.; Ang, B.B. \& Hamzah, $S$. The effect of moisture and temperature on the ultrastructure and viability of seeds of Hevea brasiliensis. Seed Science \& Tecnology, Zurich, n.9, p. 411-422, 1981

[5] Cícero, S. M. Produção, coleta, transporte e armazenamento de sementes de seringueira. In: Simpósio Sobre a Cultura da Seringueira no Estado de São Paulo, 1., 1986, Piracicaba. Campinas: Fundação Cargill, 1986. p. 133-138.

[6] Dijkman M. J. Hevea. Thirty years of research in the Far East: University of Miami Press, 329 p. 1951

[7] Gonçalves, P. S.; Martins, A. L. M; Furtado, E. L.; Sambugaro, R.; Ottati, E. L.; Ortolani, A. A.; Júnior, G. G. Desempenho de clones de seringueira de origem amazônica no planalto do Estado de São Paulo. Pesquisa Agropecuária concentração de $500 \mathrm{mg} \mathrm{L}^{-1}$ de $\mathrm{GA}_{3}$ no tratamento pré germinativo de sementes de seringueira, uma vez que as sementes atingiram índices de germinação e emergência superiores a $83 \%$. Tal fato pode ser atribuído a giberelinas, hormônio vegetal, levam a modificações fisiológicas ou morfológicas, influenciando na germinação, crescimento e desenvolvimento vegetal. (VIEIRA et al., 2010).

\section{CONCLUSÃO}

Conclui-se que a aplicação da solução de ácido giberélico é benéfica em todas as concentrações, contudo, a concentração de $500 \mathrm{mg} \mathrm{L}^{-1}$, em sementes de seringueira armazenadas por 30 dias, permite uma alta germinação e emergência. Ainda se ressalta que o substrato areia com terra vegetal, é o mais adequado à produção de mudas, e concomitantemente a instalação de seringais.

Brasileira, Brasília, v. 36, n. 12, p. 1469-1477, dez. 2001.

[8] Gouvêa, L. R. L. Divergência Genética estimada por descritores fenotípicos e por microssatélites. Dissertação (Mestrado em Agricultura Tropical e Sub Tropical) - Instituto Agronômico de Campinas. 2009.

[9] HILLEL, D. Fundamentals of soil physics. New York: Academic, 1980.

[10] Lavagnini, C. G.; Carne, C. A.V V. di; Correa, F.; Henrique, F; Tokumo, L. E.; Silva, M. H.; Santos, P. C. S.. Fisiologia Vegetal: Hormônio Giberelina. Revista Científica Eletrônica de Agronomia, Garça, v. 25, n. 1, p.1-5, 2014.

[11] Metivier, J. R. Citocininas e giberelinas. In: Ferri, M. G. Fisiologia vegetal. 2ed. São Paulo: Edusp, 1986. v.2, p.93-162.

[12] Pereira, J. P. Conservação da viabilidade do poder germinativo de sementes de seringueira. Embrapa, Comunicado Técnico, n. 3. p. 5. Jun/1978. Sudhevea.

[13] Pereira, J. P.; Pereira, A. V.; Conceição, H. E. O.; Celestino Filho, P.; TRINDADE, D. R. Efeito do acondicionamento sobre a germinação de sementes de seringueira (Hevea spp.). Comunicado técnico: Embrapa, Manaus, n. 11, fev. 1980.

[14] SÃO PAULO. Secretaria de Agricultura e Abastecimento (SAA), 2013. Resolução SAA - 154, de 22 de novembro de 2013. Estabelece exigências para cadastramento de viveiros, jardins clonais, plantas matrizes produtoras de sementes e 
normas técnicas de defesa sanitária vegetal, para a produção, comércio e o transporte de mudas, borbulhas e sementes de seringueira (Hevea spp.) no Estado de São Paulo. Diário Oficial do Estado de São Paulo, São Paulo, 23/11/2013, Poder Executivo - Seção I, 123 (221), páginas 27-28.

[15] Silva, M. A. S.; Mafra, A. L.; Albuquerque, J. A.; Bayer, C.; Mielniczuk, J. Atributos físicos do solo relacionados ao armazenamento de água em um Argissolo Vermelho sob diferentes sistemas de preparo. Ciência Rural. 2005.
[16] STUBSGAARD, F. Seed moisture. Humlebaek: DFSC, 1990. 30 p.

[17] Vieira, E. L.; Souza, G. S.; Santos, A. R.; Silva, J.S. Manual de fisiologia vegetal. São Luis: Edufma, 2010. 230 p.

[18] Wetzel, M. M. V. S.; Cícero, S. M.; Ferreira, B. C S. Aplicação do teste de tetrazólio em sementes de seringueira. Revista Brasileira de Sementes, Brasília, v. 14, n. 1, p. 83-88, 1992. 


\title{
Bapítulo 9
}

\section{A PRODUCÃO AGRICOLA-ENERGÉTICA E SEU IMPACTO NO MEIO AMBIENTE}

\author{
Ronaldo Alberto Pollo \\ Gabriel Rondina Pupo da Silveira \\ Lincoln Gehring Cardoso \\ Sérgio Campos
}

Resumo: Atualmente a cana-de-açúcar (Saccharum sp.) é cultivada em diversos países e o Brasil é o maior produtor e principal exportador dos produtos extraídos desta cultura como o açúcar e o etanol. Alguns subprodutos de grande importância como o bagaço (biomassa resultante do processo industrial), tem sido utilizado pelas indústrias, a partir de sua queima, na co-geração de energia, tornando-as auto-suficientes e seu excedente fornecido as grandes distribuidoras. Esta biomassa também está sendo utilizada na fabricação do etanol chamado de $2^{a}$ geração. Segundo a Novacana (2013), estes produtos como fonte limpa de energia alternativa, tem despertado grande interesse por outros países como EUA, alguns países asiáticos e União Européia, motivados por questões ambientais relativo ao aquecimento global e insegurança do suprimento dos combustíveis fósseis. Mas, um grande problema para o meio ambiente são as práticas inadequadas do uso do solo e a utilização de defensivos agrícolas utilizados na maioria das culturas comerciais, e os herbicidas são os produtos químicos mais utilizados na cultura da cana-de-açúcar, utilizados para a erradicação das ervas daninhas, tem causado muitos impactos no meio ambiente, desencadeando problemas nas matas ciliares, corpos d'água e o desaparecimento de nascentes, causando problemas de escassez de água e contribuindo com a crise de abastecimento em outras regiões. Com imagens temporais do banco de imagens do Google Earth Pró, foi analisada nos anos de 2008 e 2016, uma área com plantio de cana-de-açúcar envolvendo uma nascente e um afluente de um Ribeirão no interior do Estado de São PauloBrasil. O estudo comprovou que a área analisada sofreu degradação ambiental com a redução das matas ciliares, protegidas por lei brasileira, contribuindo assim com impactos no meio ambiente como assoreamento do córrego causando menor disponibilidade hídrica, contribuindo com as mudanças climáticas.

Palavras chave: Imagens de satélite, Matas ciliares, Recursos hídricos, Cana-deaçúcar, Degradação ambiental. 


\section{INTRODUÇÃO}

A demanda por alimentos em todo o mundo transformou-se num grande problema para a agricultura que cada vez mais necessita do aumento de áreas destinadas a agricultura, na busca por maiores produções.

O uso da terra com as atividades agrícolas tem desempenhado um grande papel para a produção de alimentos em todo o mundo, mas também tem gerado a degradação do meio ambiente pela ausência de práticas adequadas de conservação do solo e água.

A intensificação da utilização do uso do solo em diversas regiões, sem a preocupação de sua capacidade produtiva com sustentabilidade, tem acarretado sérios prejuízos e diversos impactos para o meio ambiente, gerando o esgotamento dos recursos naturais.

Vaeza et al. (2010) enfatiza que o processo de erosão intensa, perda de biodiversidade, assoreamento de reservatórios e cursos d'água, são impactos ao meio ambiente causados pelo mau uso do solo.

Pollo (2017), afirma que a busca por uma estratégia de desenvolvimento sustentável será mediante o entendimento e esforços do setor produtivo e sociedade na tentativa de conciliar a produção agrícola e a proteção ambiental.

Diante de muitos processos de deterioração dos recursos naturais, o Brasil instituiu através da Lei Federal 9.433/97 (BRASIL, 1997) o Sistema Nacional de Gerenciamento de Recursos Hídricos, estabelecendo a bacia hidrográfica como unidade territorial mais adequada para o estudo da dinâmica do meio ambiente.

Unidades fundamentais para o gerenciamento dos recursos hídricos, as bacias hidrográficas e seus componentes estão em permanente interação e respondem tudo que afeta seu ecossistema salientada pela interferência natural e antrópica (VITTALA et al. 2008).

Diante de todo o processo de utilização dos recursos naturais e suas formas de estudo para um melhor planejamento, a identificação da cobertura e uso do solo se faz cada vez mais necessária, uma vez que exercem grande influência sobre os recursos hídricos, podendo identificar e quantificar os impactos e subsidiar o planejamento para melhor utilização desse recursos.

No Brasil a atividade agrícola é um dos setores mais importantes da economia, tornando-se vários estados em grandes produtores de comodities agrícolas.

O Estado de São Paulo é o maior produtor de cana-de-açúcar do Brasil e este produto tem gerado grande interesse internacional, além do açúcar e o etanol, a cana é considerada uma alternativa energética e uma grande fonte para produção de bioenergia, podendo apresentar benefícios sociais, ambientais e econômicos para vários países.

Mas, um grande problema para o meio ambiente são os defensivos agrícolas utilizados na maioria das culturas comerciais, e os herbicidas são os produtos químicos mais utilizados na cultura da cana-de-açúcar, sendo indispensáveis no combate as ervas daninhas tendo como objetivo evitar grandes perdas com reduções de produtividade (CAPELESSO et al. 2015). Seu uso indiscriminado e sem a atenção necessária à legislação vigente, podem causar desastres ambientais.

O estudo e o monitoramento da utilização da terra através dos produtos de sensoriamento remoto tem grande importância e se faz necessário frente aos desafios em se produzir para uma crescente demanda por alimentos e água cada vez maior.

As imagens do Google Earth se mostraram adequadas na elaboração de séries temporais de uso da terra possibilitando a identificação de padrões recentes, subsidiando alternativas inteligentes para um melhor planejamento ambiental (SIMON e TRENTIN, 2009).

A presente pesquisa teve como objetivo demonstrar através do registro espaçotemporal de duas imagens de satélite do banco de imagens de alta resolução do Google Earth Pró (Google Earth Pró, 2018), a situação das Áreas de Preservação Permanentes de uma nascente e seu curso d'água envolvidas pela cultura da cana-deaçúcar no interior do Estado de São PauloBrasil, nas datas de 03/07/2008 e 17/06/2016.

\section{DESCRIÇÃO DA ÁREA}

A bacia hidrográfica está localizada no município de Igaraçu do Tietê (SP) e situa-se entre as coordenadas geográficas $48^{\circ} 36^{\prime} 12$ a $48^{\circ} 34^{\prime} 3$ de longitude Oeste de Greenwich e $22^{\circ} 35^{\prime} 49$ a $22^{\circ} 30^{\prime} 38$ de latitude Sul, totalizando uma área de 3.338, 22 hectares, 
onde um estudo pontual em um de seus afluentes foi realizado para diagnosticar o ambiente natural de uma nascente e seu curso d'água, conforme a Figura 1.

O clima da região é do tipo Aw conforme classificação de Köppen com 3 meses mais secos e frios (junho/julho/agosto), chuvas no verão, temperatura media annual de $22,3^{\circ} \mathrm{C}$ com precipitação média anual de $1.277,8 \mathrm{~mm}$, com altitude de 500 metros (CEPAGRI, 2018).

Figura 1. Bacia hidrográfica do Ribeirão das Posses, Município de Igaraçu do Tietê, São Paulo, Brasil e a localização do ponto de estudo no ribeirão (seta em vermelho).

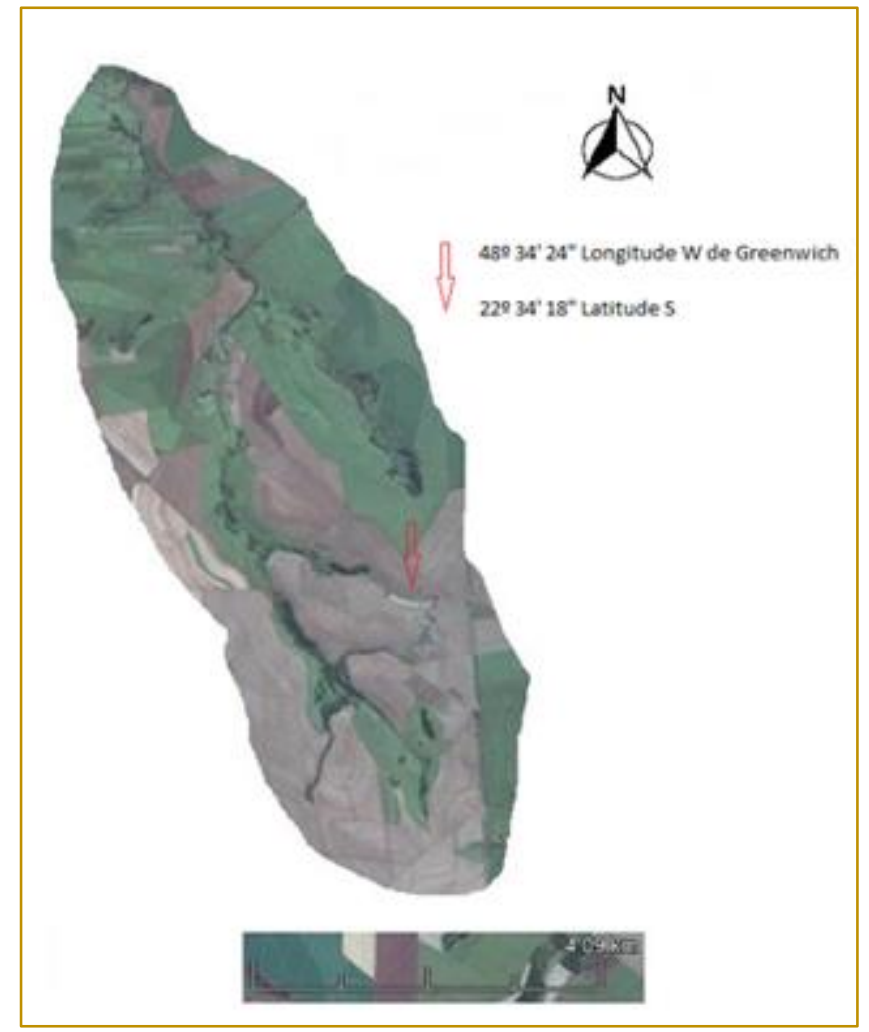

\section{RESULTADOS E DISCUSSÃO}

Nota-se na Figura 2 no ano de 2008, plantação de cana-de-açúcar e em seu interior, visualiza-se uma nascente e um curso d’água em $(A)$ com suas áreas destinadas a preservação.
Estas áreas no entorno da nascente e ao longo do curso d'água são faixas com vegetação natural destinadas a sua proteção, instituída por lei Federal através do Código Florestal Brasileiro enquadradas como Áreas de Preservação Permanentes (BRASIL, 2012) que visam a proteção dos recursos hídricos. 
Figura 2. (A) - Área de Preservação Permanente ao longo do curso d'água e ao redor da nascente no ano de 2008 e a cultura da cana-de-açúcar nas adjacências; (B)- Influência da aplicação de herbicida na lavoura de cana-de-açúcar em toda área inclusive sobre as áreas destinadas a preservação permanente

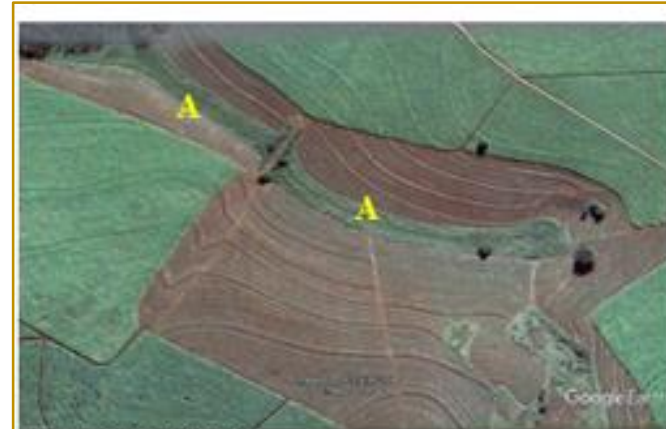

(A) $03 / 07 / 2008$

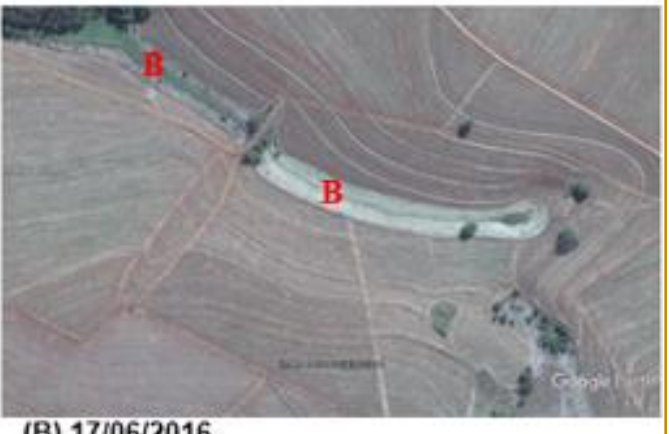

(B) $17 / 06 / 2016$
Já em (B), no ano de 2016, nota-se toda a área sob influência da aplicação de herbicidas e a vegetação que envolve a nascente e o curso d'água com ausência de produção de fotossíntese, apresentando se totalmente seca, demonstrando um problema na aplicação destes produtos chamado de deriva, onde as gotas do pulverizador não atingem somente o alvo (lavoura de cana-deaçúcar) e são levadas pelo vento para outras regiões, ocorrendo a contaminação.

Não podemos também descartar a aplicação de defensivos de forma proposital com o objetivo de aumentar a área de produção da cana-de-açúcar, deixando aquele ambiente totalmente desprotegido de qualquer vegetação natural, onde, poderá vir a causar o assoreamento do afluente e menor disponibilidade hídrica, podendo a nascente secar totalmente.

Campos (2015), estudando a bacia hidrográfica do ribeirão das Posses-SP, constatou que em virtude de vasta área de plantio sobre solos férteis e de fácil mecanização, a cultura da cana-de-açúcar apresentou a maior porcentagem de ocupação em toda a bacia e de maior conflito de uso da terra nas Áreas de Preservação Permanentes.

Segundo a Farming (2016), a aplicação de defensivos requer alguns cuidados como garantir o tamanho correto das gotas, controlando e diminuindo a velocidade de aplicação para redução da deriva e a capacitação de mão de obra com treinamento em tecnologia de aplicação.

Vale salientar que do ponto de estudo para um raio de 20 Kilometros de distância, entre quatro municípios, estão instaladas quatro unidades produtoras de açúcar e etanol que impulsionaram o desenvolvimento da cultura da cana-de-açúcar na região.

Situações semelhantes com impacto ambiental de aplicações de herbicidas em outras áreas protegidas e sobre os recursos hídricos também foram observadas na região, influenciadas por esta mesma cultura, na qual poderão ocasionar escassez de água com crise de abastecimento, favorecendo desta forma a ocorrência de alterações no micro clima local e mudanças climáticas em outras regiões.

Diante destas inconformidades ambientais sugere-se intervenções a fim de minimizar os impactos causados ao meio ambiente e um programa para conscientizar os grandes produtores sobre a necessidade de conciliar a produção agrícola e proteção dos recursos naturais.

\section{CONCLUSÕES}

A utilização das imagens orbitais temporais de alta resolução espacial do Google Earth Pró foram viáveis e de extrema importância para a realização do presente estudo, no afluente do Ribeirão das Posses, São Paulo, Brasil, mostrando os impactos negativos nas áreas protegidas por lei e sobre os recursos hídricos, causados pela expansão das atividades humanas com a cultura da canade-açúcar.

Evidenciou-se práticas inadequadas de uso do solo mediante aplicação de produtos químicos utilizados na cultura da cana-deaçúcar que se derivaram para o entorno da 
nascente e ao longo do curso d'água, ocasionando o comprometimento dos serviços ambientais com a perda de biodiversidade local, comprometendo a produção de água e sua qualidade.

Frente a estes problemas, poderá ocorrer ainda o assoreamento com carreamento de

\section{REFERÊNCIAS}

[1] Brasil. Lei no 9.433 de 8 de janeiro de 1997. Institui a Política Nacional de Recursos Hídricos, cria o Sistema Nacional de Gerenciamento de Recursos Hídricos, regulamenta o inciso XIX do art. 21 da Constituição Federal, e altera o art. 1o da Lei no 8.001, de 13 de março de 1990, que modificou a Lei no 7.990, de 28 de dezembro de 1989. Brasília, 8 de janeiro de 1997. disponível em $:<$ http://www.planalto.gov.br/ccivil_03/leis/L9433.htm > Acesso em: 22 mar. 2016.

[2] Brasil. Lei $n^{\circ} 12.727$ de 17 de outubro de 2012. Altera a Lei no 12.651, de 25 de maio de 2012, que dispõe sobre a proteção da vegetação nativa; altera as Leis nos 6.938, de 31 de agosto de 1981, 9.393, de 19 de dezembro de 1996, e 11.428, de 22 de dezembro de 2006; e revoga as Leis nos 4.771, de 15 de setembro de 1965, e 7.754, de 14 de abril de1989, a Medida Provisória no 2.166-67, de 24 de agosto de 2001, o item 22 do inciso II do art. 167 da Lei no 6.015, de 31 de dezembro de 1973, e o $\S 20$ do art. 4o da Lei no 12.651, de 25 de maio de 2012. Presidência da República. Casa Civil. Brasília, DF, 17 de out. 2012. Disponível em:< http://aiba.org.br/wpcontent/uploads/2014/10/Lei-12727-2012-Codigoflorestal.pdf> Acesso em: 23 jan.2018.

[3] Campos, M. de. Diagnóstico do conflito de uso do solo em áreas de preservação permanente do Ribeirão das Posses (Igaraçu do Tietê-SP) visando a conservação dos recursos hídricos. 2015. 75f. Dissertação (Mestrado em Agronomia/Energia na Agricultura) - Universidade Estadual Paulista Júlio de Mesquita Filho, Faculdade de Ciências Agronômicas de Botucatu, 2015.

[4] Capelesso, F.J.; Dedonatti, E.; Tironi, S.P. Efeito tóxico de herbicidas na cultura da cana-deaçúcar. Seminário de Ensino, Pesquisa e Extensão, V SEPE. Anais... V SEPE e V Jornada de Iniciação Científica UFFS Campus Chapecó-SC-Brasil, vol. V, 2015.

[5] Cepagri. Unicamp. Centro de Pesquisas Meteorológicas e Climáticas Aplicadas a Agricultura: Clima dos Municípios Paulistas. Disponível em:< material erodido e a contaminação dos corpos hídricos nas épocas de colheita e entresafra da cultura canavieira, levando a situações de menor disponibilidade hídrica e escassez em outras regiões, contribuindo para as mudanças climáticas.

https://www.cpa.unicamp.br/outras-

informacoes/clima_muni_231.html>. Acesso em: 16 jul. 2018

[6] Farming. Tecnologia 2016. 8 dicas para evitar a deriva durante a aplicação de defensivos. Disponível em: <https://sfagro.uol.com.br/8-dicaspara-evitar-a-deriva-durante-a-aplicacao-dedefensivos/>. Acesso em 10 jul. 2018.

[7] Google Earth. Google Inc, 2018. Disponível em: <earth.google.com/>. Acesso em: 22 jan. 2018.

[8] Novacana. Histórico das exportações brasileiras de etanol. Disponível em: https://www.novacana.com/estudos/historico-dasexportacoes-brasileiras-de-etanol-241013/. Acesso em 22 jan. 2018.

[9] Pollo, R. A. Mapeamento do Zoneamento da bacia Hidrográfica do ribeirão Paraíso, São Manuel-SP, visando o planejamento e gestão ambiental. 2017. 145f. Tese (Doutorado em Agronomia-Energia na Agricultura) - Faculdade de Ciências Agronômicas, Universidade Estadual Paulista, Botucatu, 2017.

[10] Simon, A. L. H.; Trentin, G. Elaboração de cenários recentes de uso da terra utilizando imagens do Google Earth. Ar@cne. Rev. Electrónica de recursos en Internet sobre Geografía y Ciencias Sociales, n. 116, 2009. Disponível em: < http://www.ub.edu/geocrit/aracne/aracne-116.htm>. Acesso em: 18 fev. 2018

[11] Vaeza, R. F. et al. Uso e ocupação do solo em bacia hidrográfica urbana a partir de imagens orbitais de alta resolução. Floresta e Ambiente, Rio de Janeiro, v.12, n.1, p. 23-29, 2010. Disponível em: $\quad<\quad$ http://www.floram.org/files/ v17n1/v17n1a3.pdf>. Acesso em: 25 fev. 2016.

[12] Vittala, S. S.; Govindaiah, S.; Gowda, H. H. Prioritization of sub-watersheds for sustainable development and management of natural resources: $\mathrm{Na}$ integrated approach using remote sensing, GIS and sócio-economic data. Current Science, Índia, v.95, n.3, 2008. Disponível em:< http://indiaenvironmentportal.org.in/files/6_14.pdf>. Acesso em: 16 jul. 2018. 


\section{Gapítulo 10}

\section{POTENCIAL DE UMA ÁREA MUNICIPAL PARA INTEGRACÃO AO SISTEMA NACIONAL DE UNIDADES DE CONSERVAÇ̃̃O: UMA ANÁLISE DA LEGISLAÇ̃̃O}

\section{Fabricio Camillo Sperandio}

Felipe Hashimoto Fengler

Gerson Araújo de Medeiros

Admilson Írio Ribeiro

Mauricio José Borges

Giovanna Frederici de Mello

\section{Sabrina Pasetto}

\section{Naiara Torres dos Santos}

Resumo: O desequilíbrio ambiental provocado pela ocupação do território, sendo cada sistema definido de acordo com aspectos, histórias, culturas e economia divergentes, são capazes de originar condições singulares como as da conservação do ambiente natural, como também causar processos erosivos pelas as ações antrópicas. A área de estudo corresponde ao Bosque Municipal "Francisco Buck" de Jaboticabal - estado de São Paulo, Brasil, e baseado em tais fundamentos, a preservação deste local passa pela implantação ao Sistema Nacional de Unidades de Conservação, onde contribuirá para a adequada preservação ambiental, tornando um local para pesquisas e aulas de educação ambiental. O objetivo deste trabalho foi mostrar os conceitos que existem espaços territoriais municipais à serem especialmente protegidos, além de auxiliar como estudo para a necessidade da conservação do solo que influenciam na qualidade da vida e dos mananciais por meio da aplicabilidade da legislação nacional e municipal no Bosque Municipal de Jaboticabal. Pela própria constituição geográfica sem floresta, a visualização dos efeitos causados pelo crescimento desordenado, pelas atividades no meio urbano e pela ocupação do território desta região, passa pela população e com isso, possa subsidiar e criar uma nova perspectiva para a preservação das características físicas da região e do município.

Palavras-chave: SNUC; Preservação. Áreas Verdes no Meio Urbano; Bosque Municipal. 


\section{INTRODUÇÃO}

A falta de cuidado em relação ao meio ambiente, seja por parte dos poderes públicos, bem como pela sociedade, é observada em diversas partes do pais, sendo visível nos diversos lugares por onde o homem passa (campos e cidades). Associada a um uso indiscriminado dos recursos naturais disponíveis, a degradação ambiental afeta de forma direta a qualidade de vida do homem (BORGES, 2005).

Isso passa pela revisão e efetiva implementação da legislação e pela criação de novas Unidades de Conservação, como por exemplo, os parques (Ricardo \& Campanili, 2008).

Observando a ocupação urbana brasileira, em médias e em grandes cidades, nota-se que a preservação dos recursos naturais assim como o respeito pelas leis ambientais brasileiras vigentes, não constituíram alvo de referência frente a expansão urbana (MORAES et al., 2009).

Com o passar do tempo, muitas áreas naturais foram sendo destruídas para dar lugar à ocupação humana. Animais e plantas foram eliminados, alguns desapareceram e outros, até os dias atuais, ainda correm risco de extinção. A Lei do Sistema Nacional de Unidades de Conservação - SNUC representou grandes avanços na criação e gestão das Unidades de Conservação nas três esferas de governo (federal, estadual e municipal), pois possibilita uma visão de conjunto das áreas naturais a serem preservadas. Além disso, estabeleceu mecanismos que regulamentam a participação da sociedade na gestão das Unidades de Conservação, potencializando a relação entre o Estado, os cidadãos e o meio ambiente (BRASIL, 2015).

O objetivo deste trabalho é de demonstrar a importância de estudos sobre a conservação e preservação de ambientes naturais dentro das cidades, demonstrar a aplicabilidade da legislação municipal e nacional e com isso contribuir para que haja harmonia entre homem e natureza como proposto na Agenda 21.

\section{MATERIAL E MÉTODOS}

\subsection{LOCAL DE ESTUDO}

O Município de Jaboticabal situa-se na região agropecuária noroeste do estado de São Paulo (21ํ 15' 22" S; 48ํ18' 58" W). O município de Jaboticabal compreende uma área de 70.700 hectares e a cidade compreende uma área estimada em 2.000 hectares O clima é do tipo subtropicalmesotérmico, com verão úmido e inverno seco. O período das chuvas e das altas temperaturas compreende 0 período relativo aos meses de outubro e março, uma estação temperada em junho e julho e seca de maio a agosto. $O$ solo predominante no município é o latossolo vermelho escuro de fase arenosa representando $47 \%$ do território, e o latossolo roxo representando $37 \%$ do território, são solos profundos, arenosos, acentuadamente drenados. O relevo predominante é suavemente ondulado com colinas amplas (BORGES, 2005).

Figura 1. Localização do Município de Jaboticabal no Estado de São Paulo

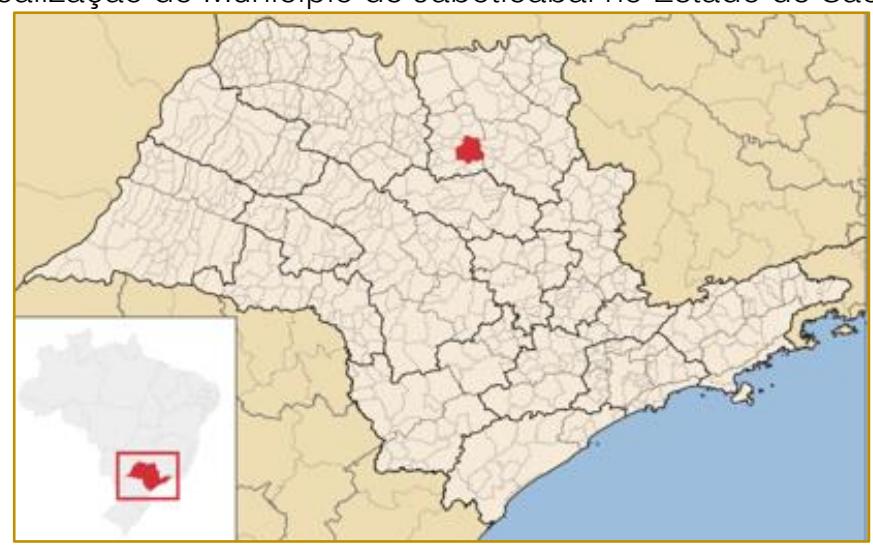

Fonte: Jaboticabal, 2018. 
O Bosque Municipal, compreende uma área de aproximadamente 5,21 hectares, localizado dentro do perímetro urbano da cidade de Jaboticabal (Figura 2). A área do bosque corresponde a aproximadamente $0,007 \%$ da área do município e a 0,26\% da área da cidade (BORGES, 2005).

Figura 2. Mapa do entorno do Bosque Municipal de Jaboticabal - S.P.

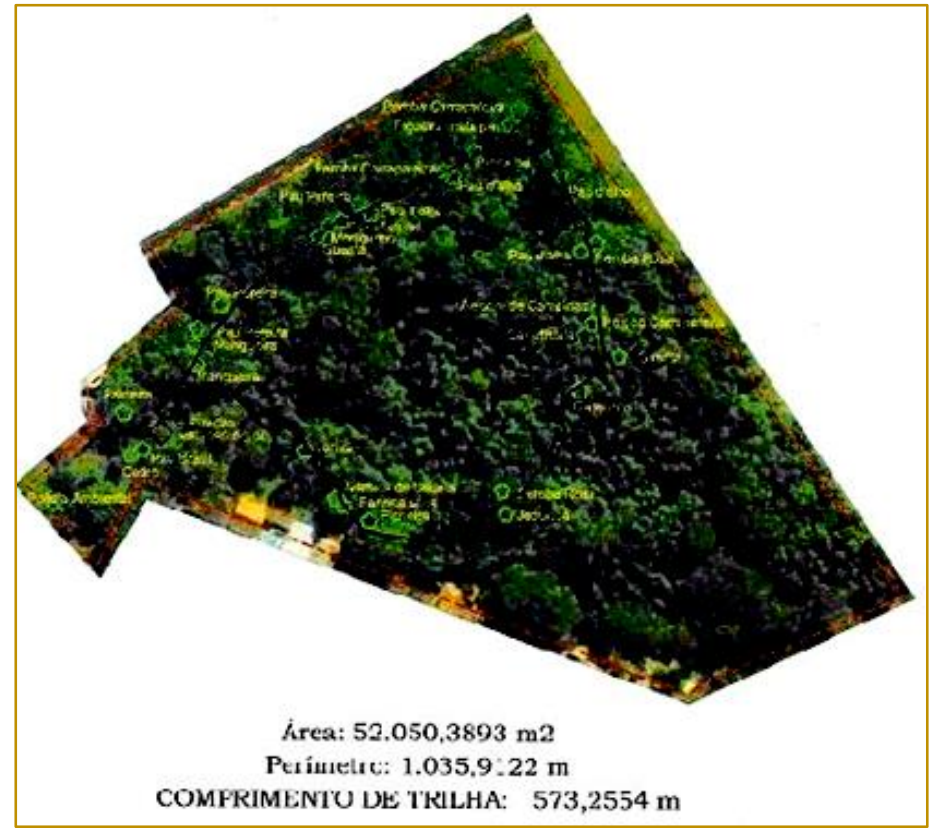

Fonte: Os autores (2015).

\subsection{UMA ANÁLISE DA LEGISLAÇÃO}

Dentro do tema estabelecido, foram feitas pesquisas na Legislação Brasileira e Municipal pertinentes, para que se tenha o instrumento legal de garantir o equilíbrio das áreas verdes no meio urbano.

Estão aqui somente os artigos, parágrafos, incisos e/ou alíneas da Legislação Brasileira diretamente relacionadas ao trabalho.

Para atingir esse objetivo de forma efetiva e eficiente, a promulgação da Lei no 9.985, de 18 de julho de 2000, o SNUC, de acordo com o disposto na Lei, tem os seguintes objetivos:

- Contribuir na manutenção da diversidade biológica e dos recursos genéticos no território nacional e nas águas jurisdicionais;

- Proteger as espécies ameaçadas de extinção em âmbito regional e nacional;

- Contribuir para a preservação e a restauração da diversidade de ecossistemas naturais;

- Promover o desenvolvimento sustentável a partir dos recursos naturais;
- Promover a utilização dos princípios e práticas de conservação da natureza entre o processo de desenvolvimento;

- Proteger paisagens naturais e pouco alteradas com notável beleza cênica;

- Proteger e preservar as características de natureza geológica, geomorfológica, espeleológica, paleontológica e cultural;

- Proteger e recuperar recursos hídricos e edáficos;

- Recuperar ou restaurar ecossistemas degradados;

- Proporcionar meios e incentivos para atividades de pesquisa científica, estudos e monitoramento ambiental;

- Valorizar econômica e socialmente a diversidade biológica;

- Favorecer condições e promover a educação e interpretação ambiental, a recreação em contato com a natureza e o turismo ecológico;

- Proteger os recursos naturais necessários à subsistência de populações 
tradicionais, respeitando e valorizando seu conhecimento e sua cultura e promovendo-as social e economicamente.

Podem integrar o SNUC, excepcionalmente, a critério do Conama, Unidades de Conservação estaduais e municipais concebidas para atender a peculiaridades regionais ou locais. Estabelece ainda a necessária relação de complementariedade entre as diferentes categorias de Unidades de Conservação, organizando-as de acordo com seus objetivos de manejo e tipos de uso sendo: Unidades de Proteção Integral e Unidades de Uso Sustentável (BRASIL, 2015).

As Unidades de Proteção Integral abrangem: Estação Ecológica, Reserva Biológica, Parque Nacional, Parque Estadual, Monumento Natural e Refúgio de Vida Silvestre. Já as Unidades de Uso Sustentável, abrangem: Área de Proteção Ambiental, Área de Proteção Ambiental Estadual, Área de Relevante Interesse Ecológico, Floresta Nacional, Floresta Estadual, Reserva Extrativista, Reserva de Fauna, Reserva de Desenvolvimento Sustentável e Reserva Particular do Patrimônio Natural (BRASIL, 2015).

No que diz respeito a preservação, proteção e conservação ambiental, a Legislação Municipal diz que:

A Legislação Municipal: Lei Complementar Municipal $n=80$, de 09 de outubro de 2006 Plano Diretor de Desenvolvimento de Jaboticabal.

Capítulo II - Dos objetivos e das diretrizes gerais.

Seção IX - Do meio ambiente.

Art. 30. A política municipal de Meio Ambiente tem por princípio a busca da sustentabilidade ambiental, evitando a deterioração da qualidade do solo, do ar e da água do município, recuperando e ampliando as condições das reservas ambientais, matas nativas, matas ciliares e Unidades de Conservação.

$\S 1$ ‥ Os princípios de que trata o caput deste artigo, estão fundados, dentre outros, na criação do sistema de proteção e tombamento de áreas verdes, e de parques lineares urbanos, formando corredores biológicos compostos por áreas de preservação permanente, Unidades de Conservação de matas nativas, áreas de proteção ambiental.

$\S 2^{\circ}$. Os sistemas, de que trata o parágrafo anterior, deverão estar integrados com os espaços de equipamentos públicos destinados às áreas de educação, saúde, promoção social, lazer, esporte, cultura, edifícios administrativos, parques, ciclovias, vias de pedestres, lagoas de contenção, lagos de lazer e outros usos turísticos, constituindo-se em espaços fundamentais para a humanização da vida no Município, em conformidade com o que espelha o Planejamento Ambiental Urbano.

$\S 3$ 3․ A política municipal, direcionada ao meio ambiente, deverá ter, por objetivos permanentes:

I) Promover, manter e controlar o meio ambiente ecologicamente equilibrado, entendido como bem de uso comum da população e de interesse público;

II) Organizar a utilização adequada dos recursos ambientais e paisagísticos baseada na precaução e na ação conjunta do poder público e da coletividade;

III) Proteger os ecossistemas, as Unidades de Conservação, a fauna e a flora, visando conservar e recuperar a qualidade ambiental, propícia à vida, garantindo desenvolvimento sustentável;

\section{RESULTADOS E DISCUSSÃO}

No âmbito da gestão ambiental urbana, as leis que têm por objetivo disciplinar e limitar as interferências antrópicas sobre o meio ambiente e que representam relevância para esse trabalho podem ser representadas pelo Código Florestal (Lei 4771/65), resoluções do CONAMA, 302, 303, 369, pela Lei de Parcelamento Territorial Urbano (Lei 6766/79), Lei de Política Nacional dos Recursos Hídricos (Lei 9433/97), pelo Estatuto das Cidades (Lei 1025/01), e as regulamentações específicas de uso e ocupação do solo municipais inseridas nos Planos Diretores (SILVA, 2010).

O Plano Diretor do Município de 2006 merece atenção especial, onde descreve a preservação do meio natural como um dever de todos. A preservação e a conservação desta área são a única atitude aceitável em nossos tempos, seja pela onda preservacionista que felizmente assola $\mathrm{O}$ Planeta, seja pelo Bosque Municipal ser praticamente o último resquício de Mata Atlântica no município de Jaboticabal, ou pela legislação vigente.

No planejamento urbano, é necessário realizar um bom diagnóstico da presença de vegetação, de modo a subsidiar planos de ação para a implantação de espaços verdes 
e manejo da arborização existente (ALVAREZ, 2004).

Nenhuma dessas medidas serão capazes de construir o caminho da sustentabilidade a curto prazo, entretanto, se por trás e ao redor delas há a necessidade de mudança na visão que a população e as políticas públicas têm com as Unidades de Conservação, passando a valorizá-las em função de sua preciosa biodiversidade e de sua diversidade social (RICARDO \& CAMPANILI, 2008).

É necessário resgatar a ideia de conjunto da natureza na cidade, superando a sua redução como sinônimo de área natural. $A$ preservação do meio natural deve ser vista como algo maior que os pássaros, árvores e animais. A natureza na cidade deve ser encarada como uma obra do homem e para o homem e não um refúgio de uma natureza que não existe mais. O respeito à natureza deve ser desenvolvido e alcançado como direito à qualidade da água, da vida em sociedade, à fauna, do ar, entre outros (SILVA, 2010).

\section{REFERÊNCIAS}

[1] Alvarez, I. A. Qualidade do espaço verde urbano: uma proposta de índice de avaliação. Tese (Doutorado em Agronomia). Escola Superior de Agricultura Luiz de Queiroz - ESALQ. Piracicaba, São Paulo, 2004. Disponível em: http://www.teses.usp.br/teses/disponiveis/11/11136 /tde-22102004.../ivan.pdf. Acesso em: 02 Jul. 2013.

[2] Borges, M.J. Diagnóstico físico conservacionista na determinação do reflorestamento compensatório para retenção de água em microbacias hidrográficas. 2005. $123 f$. Tese (Doutorado em Agronomia - Produção Vegetal) - Faculdade de Ciências Agrárias e Veterinárias, Jaboticabal, 2005.

[3] Brasil, Código Florestal Brasileiro: Lei 4.771 de 1965. Disponível em: http://www. planalto.gov.br/ccivil_03/LEIS/L4771. Acesso em 09 de mar. de 2015.

[4] Brasil, Conama - Conselho Nacional do Meio Ambiente. Disponível em: http://www.mma.gov.br/conama. Acesso em 09 de mar. de 2015

[5] Brasil, Ministério do Meio Ambiente. Disponível em: http://www.mma.gov.br/sitio/index.php. Acesso em 09 de mar. de 2015.

\section{CONSIDERAÇÕES FINAIS}

De acordo com as descrições apresentadas, fica evidente a necessidade de programas de educação ambiental direcionando e sensibilizando a população, especialmente moradores sobre como estas áreas são fundamentais para manter a qualidade da água, solo, clima e da biodiversidade.

A primeira e mais urgente das frentes de ação, é a da contenção do desmatamento, e da preservação das áreas ainda existentes. Nestes casos específicos, a sua preservação está relacionada com a manutenção das condições naturais e, portanto, da preservação da água, além da flora e fauna. Sugere-se a preservação adequada do Bosque Municipal, como uma Unidade de Conservação, fazendo-se assim com que se preserve o local, com a análise de riscos para a biota local e para a população, contudo sobre perdas econômicas e sociais em função do passivo gerado em um perímetro urbano.

[6] Jaboticabal. Lei Complementar no 80, de 09 de outubro de 2006: Plano Diretor da Prefeitura Municipal de Jaboticabal, 2006.

[7] Jaboticabal. In: Wikipédia, a enciclopédia livre. Flórida: Wikimedia Foundation, 2018. Disponível em: https://pt. wikipedia.org/w/index.php?title=Jaboticab al\&oldid=52550621. Acesso em: 4 jul. 2018.

[8] Moraes, I. C.; Correa, E. A.; Siqueira, R; Leite, B. S. Expansão Urbana e Degradação de Áreas de Proteção Permanente em Zonas Urbanas: O Caso do Córrego Conduta. /Rio Claro/SP. Unesp/Ceapla, 2009. Disponível em: http://www.ambiente-augm.ufscar.br/uploads/A2130.pdf. Acesso em: 04 jul. 2013.

[9] Ricardo, B.; Campanili, M. Almanaque Brasil Socioambiental. São Paulo: Instituto Socioambiental, 2008.

[10] Silva, L.A. As Áreas de Preservação Permanente (APP's) dos Corpos d'água Urbanos: um Espaço Híbrido. Simpósio. 2010. Disponível em:

http://www.anppas.org.br/encontro5/cd/gt12.html. Acesso em: 04 jul. 2013 


\section{Capítulo 11}

\section{TURISMO SUSTENTÁVEL NO USO DE ÁGUAS TERMAIS- BARRA DO GARÇAS (MT) - BRASIL}

\section{Rildo Vieira de Araújo}

\section{Ana Cristina de Almeida Ribeiro}

\section{Andreza da Silva Melo}

\section{Reginaldo Brito da Costa}

Resumo: 0 presente estudo ponderou o potencial turístico sustentável no uso de águas termais do Parque das Águas Quentes, localizado em Barra do Garças-MT. Foram analisados fatores ligados com a fauna, flora e recursos hídricos termais do local. Foi possível perceber a conservação das espécies referentes a fauna e flora e manejo das águas termais.

Palavras Chave: Cidade; Preservação; Ambiente; Fauna; Flora.

*Parte do trabalho foi apresentado no Congresso Nacional de Meio Ambiente de Poços de Caldas -2018 


\section{INTRODUÇÃO}

O turismo vem crescendo e desenvolvendo rapidamente, uso de recursos hídricos vem intensificando o movimento econômico das regiões. O Parque das Águas Quentes "Antônio Carlos do Nascimento"foi criado no dia 15 de setembro de 1984, localizado dentro do perímetro urbano da cidade de Barra do Garças no estado do Mato Grosso, administrado pela Prefeitura Municipal de Barra do Garças-MT, por meio da Secretaria de Indústria Comércio e Turismo, situado em meio a uma imensa área verde, abrigando ambiente único, cuja temperatura da água varia de $31^{\circ}$ a $43^{\circ}$ Graus Celsius, sendo distribuídas em piscinas, cascatas e uso potável para a comunidade.(MANSOR, 2013).

O presente estudo objetivou-se em analisar fatores ligados com a fauna, flora, recursos hídricos termais e a estrutura física do Parque das Águas quentes.

\section{METODOLOGIA}

A pesquisa foi realizada no parque termal do município de Barra do Garças-MT, o tipo de pesquisa adotado foi a descritiva, os procedimentos metodológicos consistiram em revisão bibliográfica, entrevistas com o responsável pela administração do parque termal, análises da percepção ambiental, estudos dos aspectos biológicos, ecológicos, estruturais e planejamento eco turístico do local.

\section{RESULTADOS E DISCUSSÃO}

De acordo com as informações da pesquisa, - parque apresenta um montante de 23 funcionários contratados atualmente para atender as necessidades de estrutura e manutenção.

Verificou-se que a estrutura física do Parque das Águas Quentes contém três tanques de captações de águas termais, sendo que um fica na área externa, armazenando 400 mil litros de água por hora, os outros dois tanques ficam na área interna, totalizando uma captação de 80 mil litros de água por hora, uma parte dessa reserva é disponibilizada para a população para consumo conforme figura 1 e outra parte para abastecimento das piscinas.

Figura 1. Água potável, parque das águas quentes Barra do Garças, MT.

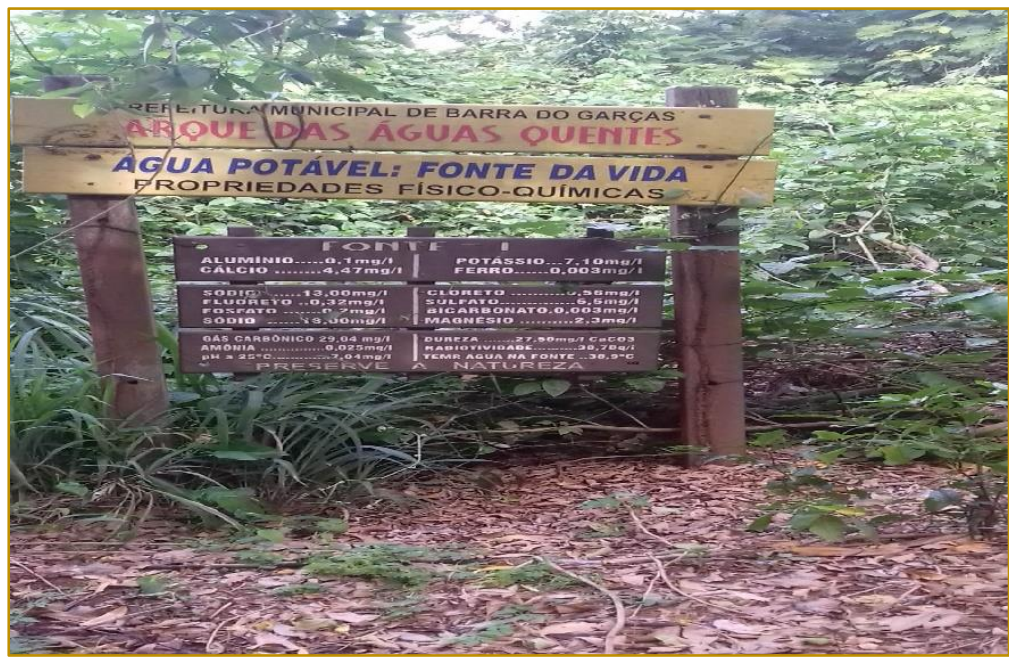

Averiguou-se que o local possui vegetação preservada formada de plantas nativas do cerrado, como: Pequi - Caryocar brasiliense, Jatobá - Hymenaea stilbocarpa, Amendoim bravo - Pterogyne nitens, Orelha de macaco Enterolobium contortisiliquum, Ingá miúdo Ingá laurina, Ipê amarelo e roxo Handroanthus albus, Handroanthus impetiginosus, Cega machado Physocalymma sacaberrimum, Pau rosa -
Aniba rosaeodora, Tingui do Cerrado Magonia pubescens, Guatambu Balfourodendron riedelianum, Baru - Dipteryx alata, Angico do Cerrado - Anadenanthera peregrina, Jequitibá branco - Anadenanthera colubrina e Açoita cavalo - Luehea divaricata identificadas pela UNEMAT - Universidade do Estado de Mato Grosso, do curso de Ciências Biológicas no ano de 2010/2014,conforme figura 2. 
Figura 2. Espécies de plantas catalogadas parque das águas quentes Barra do Garças, MT.

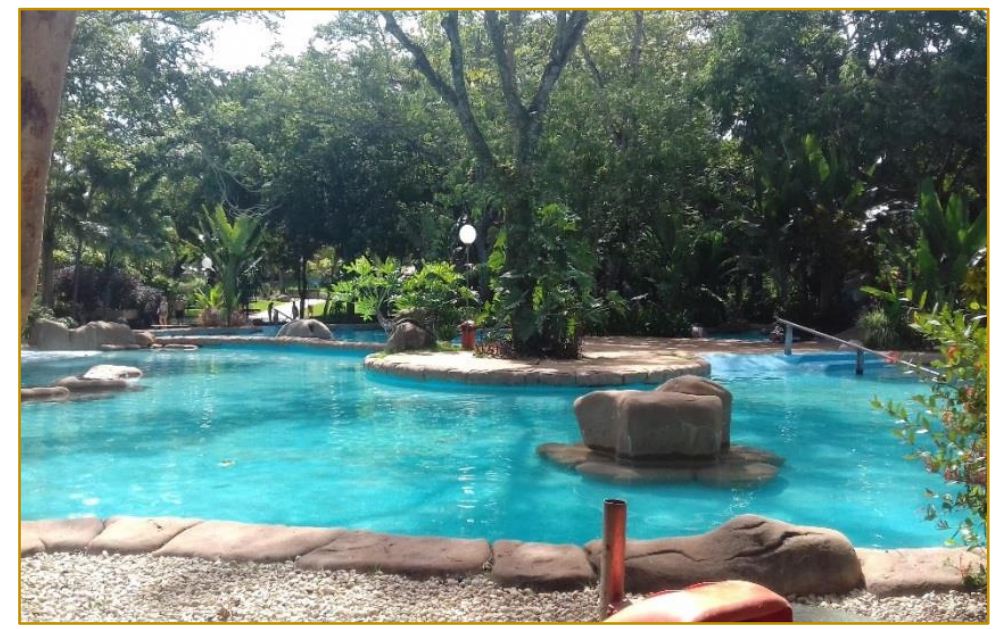

Segundo o Ministério do Meio Ambiente (2011), a conservação da biodiversidade acomoda aditamentos locais diretos, como o estoque de material genético de plantas e animais imprescindíveis para a adaptação ao manejo florestal e aos sistemas agrícolas.

Constatou-se também, que o parque possui um habitat natural de famílias de espécies de animais como: Ouriço cacheiro - Coendou prehensilis conhecido popularmente como porco espinho e a presença de Macaco prego - Sapajus, Iguana - Iguana iguana, Jiboia Boa constrictor, Arara Canindé - Ara ararauna, Cutia - Dasyprocta punctata e Tatugalinha - Dasypus novemcinctus.O espaço é utilizado para trabalhar a educação ambiental com estudantes, na reflexão crítica do compromisso da conservação do meio em que eles vivem, para que sejam multiplicadores desse conhecimento na sociedade e para turistas frequentadores do parque .Para Dutra (2003),é imprescindível que se realize o Turismo Sustentável,

\section{REFERÊNCIAS}

[1] Brasil. Ministério do Turismo. Coordenação Geral de Regionalização. Conteúdo Fundamental Turismo e Sustentabilidade. Brasília, 2007.Disponível em http://www.regionalizacao.turismo.gov.br/images/ro teiros_brasil/turismo_e_sustentabilidade.pdf.Acess o em :19/03/2018.

[2] Brasil. Ministério do Meio Ambiente. Áreas de Preservação Permanente e Unidades de Conservação \& Áreas de Risco. O que uma coisa tem a ver com a outra? Relatório de Inspeção da área atingida pela tragédia das chuvas na Região Serrana do Rio de Janeiro / Wigold Bertoldo Schäffer... [et al.]. - Brasília: MMA, 2011.Disponível garantindo a preservação do meio ambiente, com participação da comunidade local.

As águas termais da cidade de Barra do Garças-MT, são utilizadas ao mesmo tempo para fins terapêuticos, tratamentos e atividades para idosos como: hidroginástica, fisioterapia e natação com práticas de três vezes por semana. Em média, na época da alta temporada no mês de julho, chega a receber 40 mil turistas, sendo 30\% BarraGarcenses e 70\% de outras regiões do Brasil.

\section{CONSIDERAÇÕES FINAIS}

As análises resultaram em informações significativas, foi possível perceber a conservação das espécies referentes a fauna e flora do local e manejo das águas termais. É imprescindível o planejamento turístico de forma sustentável na conservação, evitando danos futuros ao ecossistema.

em:http://www.mma.gov.br/estruturas/202/_publica cao/202_publicacao01082011112029.pdf.Acesso em:14/Abr./2018.

[3] Dutra, W. A. V. Materiais especiais: turismo no Brasil.2015.

[4] Mansor, Washington. Parque das Águas Quentes. Disponível em: http://www.coisasdematogrosso.com.br/site/cidade $\mathrm{s} /$ institucional/index. asp? $\mathrm{cod}=71$ \&inst $=22$. Acesso em: 11/03/2018.

[5] Unemat. Universidade do Estado de Mato Grosso, Identificação de plantas. Curso de Ciências Biológicas .2014. 


\section{Capítulo 12}

\section{DISPOSICÃO A PAGAR PELA CONSERVAÇ̃̃O DE UNIDADES DE CONSERVAÇÃO: UM ESTUDO DE CASO NO MUNICIPIO DE PRESIDENTE FIGUEIREDO/AM}

\section{Andreia Oliveira dos Santos}

\section{Elane Conceição de Oliveira}

Resumo: A valoração ambiental possibilita indicar aos indivíduos o preço que um recurso natural possui, conciliando a preservação do meio ambiente com o crescimento econômico. As Unidades de Conservação (UCs) são detentoras de grande valor, pois proporcionam benefícios econômicos, sociais e ambientais. O artigo analisou a percepção material dos moradores do Residencial Galo da Serra (RGS) quanto à disposição a pagar (DAP) para conservar os recursos ambientais em UCs de Presidente Figueiredo. Para isso, entrevistas semiestruturadas foram realizadas com aplicação de 50 questionários. No qual capturou informações em 03 subtemas: Dados socioeconômicos, em que se constatou que $74 \%$ dos entrevistados eram do gênero feminino, 66\% estavam empregados na ocasião da pesquisa e 44\% detinham renda entre 1 a 2 salários mínimos; Dados da percepção dos moradores do RGS sobre as UCs, nesse subtema notou-se que $66 \%$ dos moradores não sabiam o significado real de uma UC, mas, 88\% deles consideram importante preservar as áreas naturais dos Parques; e, Dados sobre a DAP pela conservação de duas UCs de uso sustentável, onde verificou-se que 96\% dos moradores do RGS estavam dispostos a pagar para entrar nos parques, assim como, dispostos a pagar um valor fixo inserido na conta de luz ou de água ou de IPTU, em que $42 \%$ optaram ou aceitaram pagar exatamente $R \$ 1,00$.

Palavras-Chave: Unidades de Conservação; Valoração Ambiental; Disposição a Pagar; Presidente Figueiredo-AM. 


\section{INTRODUÇÃO}

A perda de biodiversidade - que engloba a totalidade de vida na terra - tem sido uma das grandes preocupações mundiais, especialmente a perda causada pela conversão de uso da terra para outro fim. Para tanto, urge a necessidade de se mostrar a relevância da conservação dos recursos naturais para a sobrevivência da vida no planeta. Segundo Pearce e Moran (1994, p. 33), um dos aspectos do processo da mudança de percepções governamentais e populares acerca dos recursos naturais consiste em mostrar que o uso sustentável da biodiversidade tem um valor econômico positivo e que esse valor econômico é frequentemente mais elevado que o valor dos recursos alternativos que ameaçam a biodiversidade.

Mas, as discussões sobre o valor da biodiversidade surgiram a partir de preocupações com a velocidade com que espécies estavam se extinguindo, em virtude das ações do homem sobre o meio ambiente (SERRA et al., 2004, p.194). Conforme Maia et al., (2004, p. 2), a preocupação com o valor dos recursos naturais surgiu após a difusão do conceito desenvolvimento sustentável, na Conferência sobre Meio Ambiente e Desenvolvimento das Nações Unidas, realizada no Rio de Janeiro em 1992, quando se deu inicio as discussões sobre sua mensuração.

Não por acaso que, segundo Peixer et al., (2014, p. 233), a valoração de determinado recurso ambiental tem como objetivo principal indicar a eficiência econômica de várias opções de uso dos recursos naturais e de seus ecossistemas. Da mesma forma, para Silva e Lima (2004, p.686), a valoração ambiental possibilita indicar aos indivíduos "o preço que um recurso ambiental possui, tornando possível conciliar a manutenção e conservação do meio ambiente, conjuntamente, com as necessidades humanas e econômicas".

Sendo assim, Ortiz (2003, p. 97), considera que a valoração ambiental é uma ferramenta fundamental para a formulação e a avaliação de políticas públicas orientadas ao desenvolvimento sustentável e à preservação dos recursos naturais. Ou melhor, a valoração ambiental é fundamental para a tomada de decisões que envolvam projetos com grande impacto ambiental, complementa o autor.
A questão é que o valor econômico dos recursos ambientais é derivado de todos os seus atributos e, segundo, que estes atributos podem estar ou não associados a um uso, ou seja, o consumo de um recurso ambiental se realiza via uso ou não (MOTTA, 1998, p. 25).

Logo, de acordo com Motta (1998, p.27) e Mota (2014, p. 211), o valor econômico ambiental pode ter as seguintes abordagens:

a) $\quad$ O valor de uso - direto e indireto agrega valores referentes ao uso do meio ambiente como fonte de matéria-prima, recreação e de satisfação hedônica, e de funções ecológicas exercidas pela natureza como forma de contribuir para a manutenção da biodiversidade.

b) $\quad$ valor de opção resulta das incertezas que os seres humanos têm em relação ao futuro da natureza e que os predispõem a pagar hoje pela conservação e preservação a fim de que possam, no futuro, desfrutar do recurso.

c) O valor de existência (ou valor de não uso ou valor passivo) fundamenta-se no comportamento altruísta do ser humano para com amigos, parentes, sobretudo no reconhecimento de que os ativos da natureza têm direitos, de modo que a sua atitude permite legar para as futuras gerações acesso aos recursos naturais.

Em relação aos procedimentos metodológicos utilizados para mensurar a valoração econômica ambiental, segundo Kahn e Rivas (2014, p. 144) existem três classes principais de técnicas para mensurar o valor de bens sem mercado: preferência revelada, preferência declarada e técnicas de transferência dos benefícios.

Em relação à técnica de avaliação de preferência declarada, Ortiz (2003, p. 94), Kahn e Rivas (2014, p. 144) e Motta (1998, p. 42) afirmam que a técnica de preferência declarada mais usada é a valoração contingente, a qual averigua o valor, perguntando às pessoas sua disposição a pagar (DAP) ou disposição a aceitar (DAA) por uma mudança na qualidade ambiental; além do que ela permite medir valores que não estão relacionados a um uso direto do recurso. Diversos estudos têm utilizado o método de valoração contingente para estimar o valor dos recursos ambientais inseridos em Unidades de Conservação (UCs). Entre eles podemos citar: Hildebrand et al., (2002); Cirino e Lima (2008); Peixer et al., (2014). 
Isto porque, segundo Hassler (2005, p. 87), as vantagens das áreas protegidas não estão apenas na conservação da biodiversidade, mas também são capazes de fornecer inúmeros benefícios para os seres humanos, nos quais podem ser benefícios econômicos, sociais e ambientais. A lei № 9.985 de 2000 , declara que as UCs são espaços territoriais, incluindo seus recursos ambientais, com características naturais relevantes, criadas pelo poder público, em suas três esferas. Dividem-se em dois grupos: Unidades de Proteção Integral que têm como principal objetivo preservar a natureza, sendo admitido apenas o uso indireto dos seus recursos naturais; e Unidades de Uso Sustentável que visa compatibilizar a conservação da natureza com o uso sustentável de parcela dos seus recursos naturais.
Portanto, o objetivo desse artigo é analisar a percepção material dos moradores do Residencial Galo da Serra quanto à disposição a pagar para conservar os recursos ambientais presentes em Unidades de Conservação de Presidente Figueiredo.

\section{PROCEDIMENTOS METODOLÓGICOS}

\section{1 ÁREA DE ESTUDO}

A área de estudo dessa pesquisa abrange o Residencial Galo da Serra (RGS), onde foram aplicados os surveys (questionários), o Parque Natural Municipal Cachoeira das Orquídeas (PNMCO), o Parque Natural Municipal Galo da Serra (PNMGS) e a Área de Proteção Ambiental Caverna do Maroaga (APACM), sendo que os Parques Municipais estão inseridos dentro desta APA (Figura 1).

Figura 1: Área de estudo

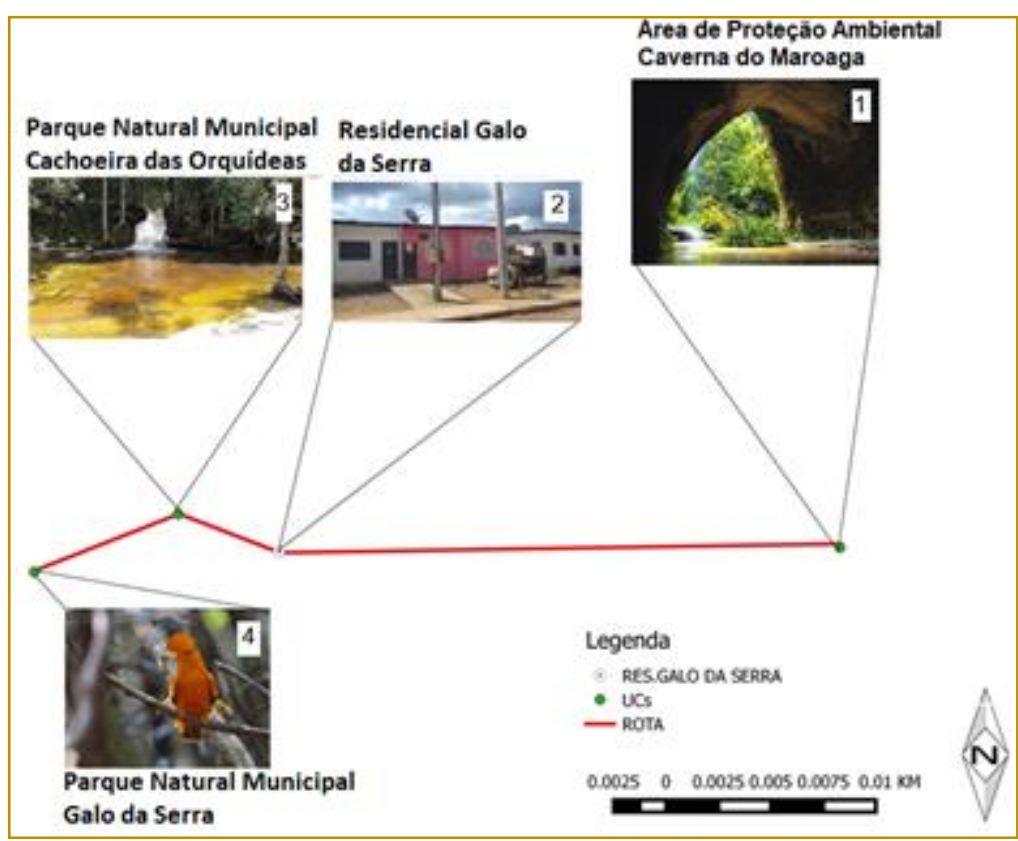

Fonte: Elaboração própria - resultado da pesquisa.

a) A APACM é uma UC estadual de uso sustentável, criada em 1990, possui uma superfície de 374.700 ha, equivalente a 14\% do município de Presidente Figueiredo, foi criada para proteger a diversidade biológica, disciplinar o processo de ocupação e assegurar a sustentabilidade do uso dos recursos naturais. (REIS, 2010; SEMMAS, 2017). São permitidas visitações na Caverna do Maroaga e na Gruta da Judéia, somente com o acompanhamento de um guia, com um limite de 60 visitantes por dia. Para visitações turísticas, paga-se uma taxa de $\mathrm{R} \$ 10 /$ pessoa. b) O PNMGS é uma UC de uso sustentável, criada em 2002, possui uma área de 28 ha e tem a finalidade de proteger a paisagem, fauna, flora $e$ as belezas panorâmicas naturais (SEMMAS, 2017). Nela é permitido: atividades educacionais, turísticas e recreativas; pesquisas científicas. Não é permitido: caçar, pescar ou perseguir animais silvestres; desmatar, tirar lascas ou explorar madeiras; causar fogo de qualquer espécie; danificar as estruturas físicas do parque; entrada de animais domésticos; entrada de menores desacompanhados; 
entrada com recipientes de vidro; retirar qualquer planta ou animal e jogar lixos nas trilhas. Segundo Mileski et al.,(2006, p. 45), o PNMGS foi criado para proteger sítios arqueológicos e os locais de reprodução do Rupícola rupícola, que utiliza as fendas na gruta do parque para construir o ninho e se reproduzir. O pássaro galo-da-serra (Rupícola rupícola) é considerado um dos símbolos de Presidente Figueiredo, geralmente habita rochas, paredões ou afloramentos rochosos. Em Presidente Figueiredo existem muitos locais com essas características, por isso, podemos observar um grande número dessas espécies. Principalmente nas UCs APACM e PNMGS.

c) O PNMCO é uma UC de uso sustentável, criada em 2002, possui uma área de 817 ha e tem o objetivo de proteger e conservar o meio ambiente, com a intenção de promover ações socioambientais (SEMMAS, 2017). A visitação pública é permitida, sendo proibido: cortar árvores; perseguir e caçar animais silvestres; entrada com armas, motosserras e demais materiais destinados ao corte; coletar e apanhar espécies vegetais; jogar lixos e realizar camping ou pernoite. O PNMCO possui um Plano de Manejo dentro das normas do Sistema Nacional de Unidades de Conservação (SNUC). Segundo Mileski et al., (2006, p. 46), o parque possui uma área formada por floresta primária de terra firme sobre solo arenoso e vegetação de campinarana, com rica diversidade de Bromeliaceae e Orquidaceae.

d) O RGS é um bairro proveniente do Programa do Governo Federal Minha Casa Minha Vida, inaugurado em 2014, com 180 moradias, com famílias com renda de até $\mathrm{R} \$ 1,6$ mil. Está localizado próximo à diversas

Figura 2. Resultados das invasões, Foto: Andreia Oliveira, Abr. 2017

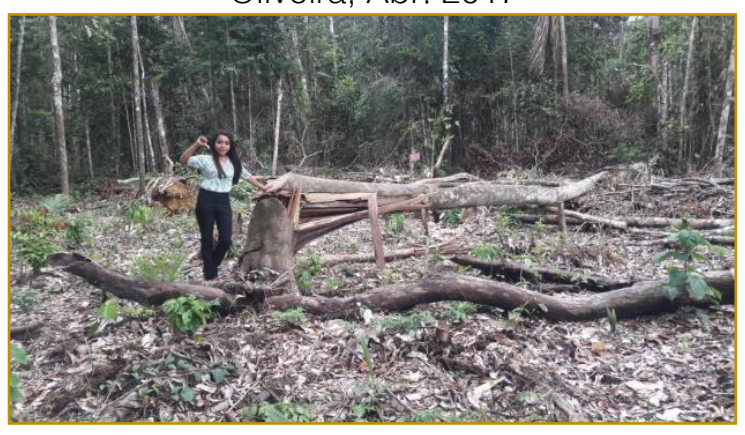

áreas verdes, inclusive a aproximadamente $150 m$ do PNMCO. Alguns imóveis já sofreram modificações nas suas estruturas originais com fim de atender aos negócios dos próprios moradores, que conseguem sua renda sem sair de casa. Fatores socioeconômicos influenciaram na escolha dos moradores do RGS. Essa escolha deu-se a partir de um levantamento socioeconômico e ambiental através de uma ação conjunta entre as Secretarias Municipais de Meio Ambiente e Sustentabilidade e a Secretaria de Ação Social e Defesa Civil. Os perfis dos moradores são: pessoas idosas; pessoas deficientes; mulheres que são chefes de famílias; pessoas que residiam em áreas de riscos ou insalubre ou desabrigadas; e, pessoas que moravam em casas alugadas.

\subsection{MÉTODO DE VALORAÇÃO ECONÔMICA AMBIENTAL: DISPOSIÇÃO A PAGAR}

a) A princípio foram realizadas algumas visitas na área de estudo, especialmente nas áreas das UCs mais próximas ao RGS, para a identificação e a caracterização dos problemas ambientais que estão sofrendo atualmente - as invasões. Ora, o município de Presidente Figueiredo, apesar de ser um município novo com apenas 36 anos de existência, já sofre com problemas relacionados às invasões. Como exemplo, são as invasões recentes incorridas no entorno do RGS, onde estão localizados os dois Parques Municipais e a APA (G1 AM, 2017). A invasão contou com a participação de mais de 2.000 pessoas. Os invasores (alguns do próprio RGS) demarcavam os locais utilizando plaquinhas com os nomes dos supostos donos, parte da vegetação presente nas áreas foi devastada (Figuras 2, 3,4 e 5).

Figura 3. Resultados das invasões, Foto: Andreia Oliveira, Abr. 2017

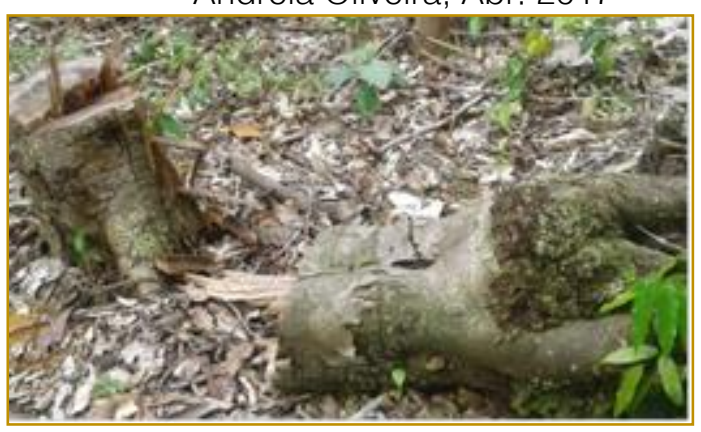


Figura 4. Reintegração de posse, Foto: Portal Urubuí, Jan. 2017.

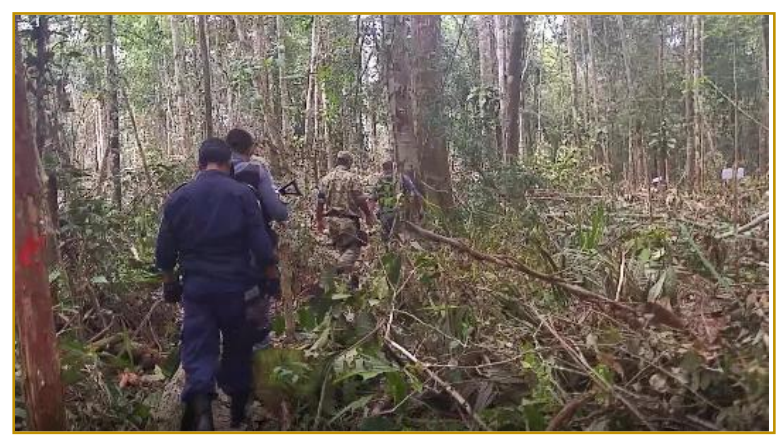

b) Entrevistas semiestruturadas foram realizadas com aplicação de 50 (cinquenta) questionários. Utilizou-se amostragem não probabilística, uma vez que a representatividade exata da população investigada no RGS não era necessária para obtermos uma percepção da disposição a pagar pela conservação dos recursos nas UCs supracitadas. O questionário capturou informações em 03 (três) subtemas: dados socioeconômicos; dados da percepção dos moradores do RGS sobre as UCs; e, dados sobre a DAP pela conservação das UCs PNMCO e PNMGS. As questões relativas à DAP foram elaboradas a partir de dois questionamentos: i) valor máximo que o morador estaria disposto a pagar para visitar e se tornar um agente direto responsável pela conservação da Cachoeira das Orquídeas ou de outros recursos naturais das UCs; ii) valor fixo inserido na conta de luz ou de água ou de IPTU que o morador do RGS estaria disposto a pagar pela conservação dos recursos das UCs.

c) O método de valoração contingente permite determinar o valor monetário dos recursos naturais a partir das preferências dos usuários. Segundo May (1995), uma das
Figura 5. Resultados das invasões, Foto: Portal Urubuí, Jan. 2017.

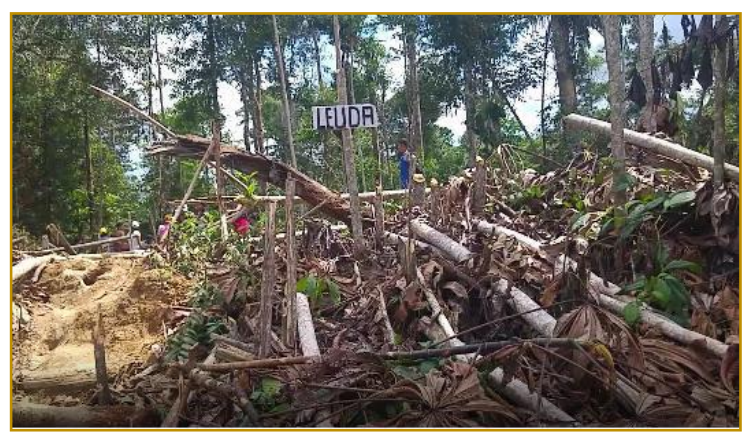

vantagens desta metodologia é justamente em produzir estimativas de valores que não poderiam ser obtidos por outros meios; o método é indicado em situações na qual não existem valores de mercado. Motta (1998) argumenta que o objetivo dela é observar as preferências dos consumidores através da revelação da disposição a pagar pelo recurso ambiental. Ainda segundo Motta (1998), utilizou-se nessa pesquisa para definir a DAP o método referendo (escolha dicotômica).

\section{RESULTADOS E DISCUSSÃO}

O objetivo desse artigo é analisar a percepção material dos moradores do RGS quanto à disposição a pagar para conservar os recursos ambientais das UCs PNMCO, PNMGS e a APACM, os Parques estão inseridos dentro desta APA.

\subsection{SOCIOECONOMIA DO RGS}

O perfil dos entrevistados foi $74 \%$ do gênero feminino e $26 \%$ do gênero masculino, sendo que a idade média dos moradores do RGS é entre 35 a 49 anos (Gráfico 1).

Gráfico 1: perfil dos entrevistados do RGS

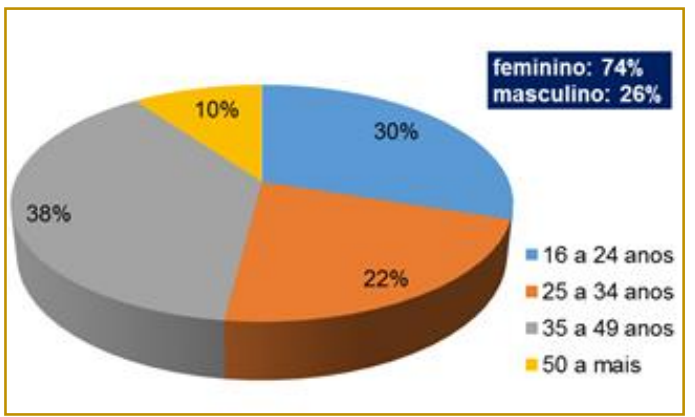

Fonte: resultado da pesquisa. 
O grau de instrução dos moradores concentrava-se no ensino médio (50\%); mas, o nível superior alcançava $28 \%$ de todos os entrevistados (Gráfico 2).

Gráfico 2: grau de instrução do RGS

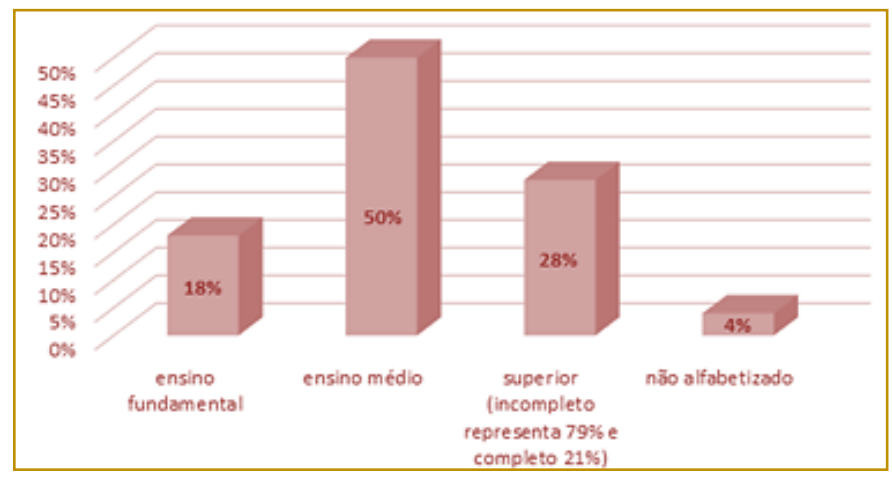

Fonte: resultado da pesquisa.

O número de residentes por domicílio alcança $54 \%$ de 4 a 6 pessoas (Gráfico 3).

Gráfico 3: Participação do número de indivíduos por domicílio do RGS

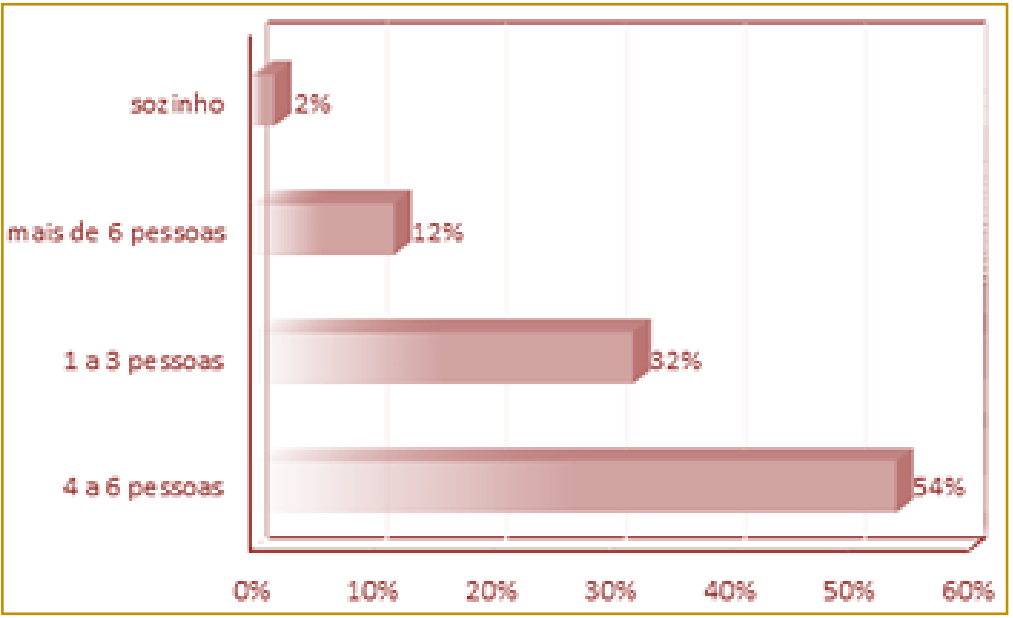

Fonte: resultado da pesquisa.

Quanto à ocupação dos moradores do RGS, $66 \%$ estavam empregados na ocasião da pesquisa e $34 \%$ estavam desempregados ou sem exercer atividade remunerada; sendo que dos empregados $24 \%$ trabalhavam por conta própria (autônomos) e 21\% eram servidores públicos diversos, 18\% exerciam atividades no comércio, $9 \%$ eram empregados domésticos e 3\% eram pedreiros/pensionistas/agricultores (Gráfico 4). 
Gráfico 4: ocupação dos moradores do RGS

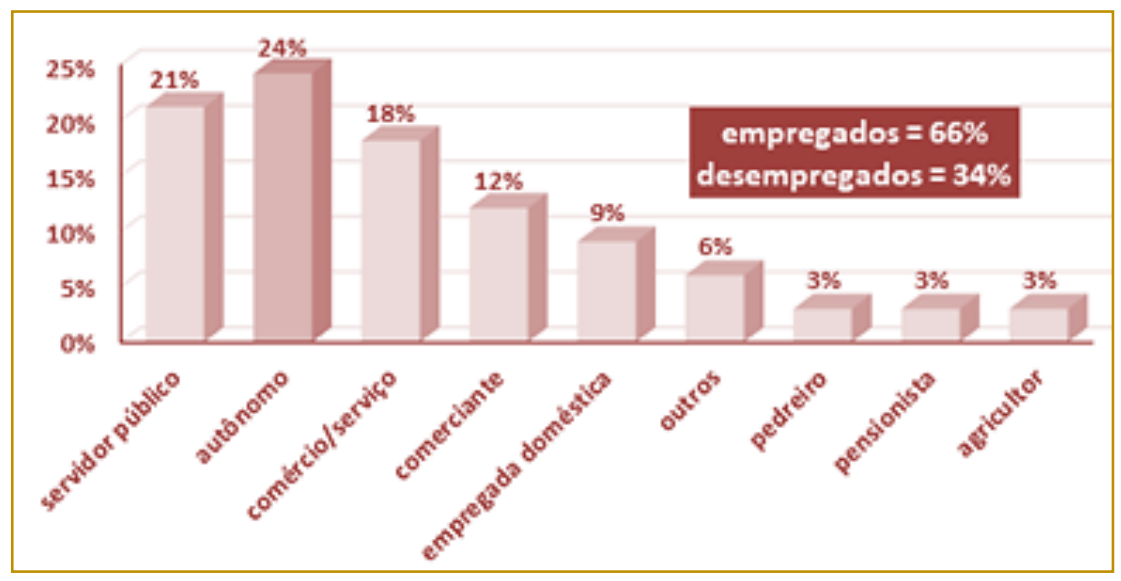

Fonte: resultado da pesquisa.

Em relação à renda média familiar dos moradores do RGS, 44\% detinham renda entre 1 a 2 salários mínimos ( $R \$$ 954,00 a $\mathrm{R} \$ 1.908,00), 26 \%$ detinham renda entre 2 a 3 salários mínimos $(R \$ 1.908,00$ a $R \$ 2.862,00)$, $22 \%$ detinham renda entre $1 / 2$ até 1 salário ( $R \$ 477,00$ a $R \$ 954,00$ ) (Gráfico 5).

Gráfico 5: renda média familiar dos moradores do RGS

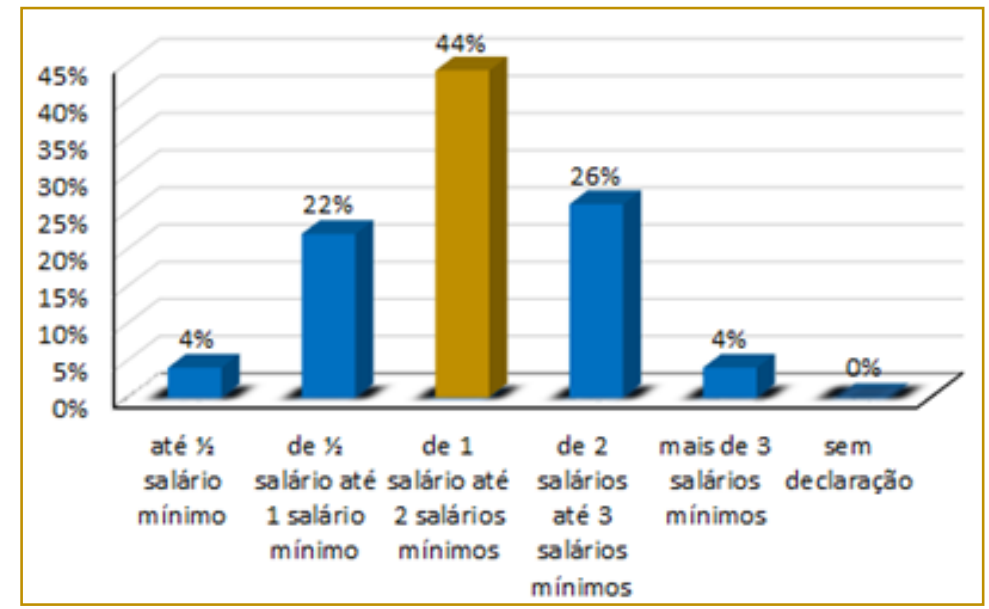

Fonte: resultado da pesquisa.

\subsection{PERCEPÇÃO DOS MORADORES DO RGS QUANTO ÀS UCS: PNMCO E PNMGS}

A Tabela 1 mostra a percepção dos moradores do RGS sobre os recursos ambientais inseridos nas UCs estudadas. 
Tabela 1: percepção dos m oradores do RGS sobre as UC's

\begin{tabular}{|c|c|c|c|c|c|c|}
\hline \multicolumn{7}{|c|}{ Percepção sobre as UC's PN MG S e PNMCO - Percentual (\%) } \\
\hline Resposta & $\begin{array}{l}\text { Sabe o } \\
\text { que é } \\
\text { uma UC? }\end{array}$ & $\begin{array}{c}\text { Sabia que o RGS } \\
\text { está entre o } \\
\text { PNMGS/PNM CO } \\
?\end{array}$ & $\begin{array}{l}\text { Já visitou } \\
\text { os } \\
\text { Parques? }\end{array}$ & $\begin{array}{c}\text { É importante } \\
\text { preservar as } \\
\text { áreas naturais? }\end{array}$ & $\begin{array}{c}\text { Sabe o que é } \\
\text { uma Zona de } \\
\text { Amortecimento } \\
?\end{array}$ & $\begin{array}{c}\text { O RGS pode } \\
\text { ser um a Zona } \\
\text { de } \\
\text { am orte cim ento? }\end{array}$ \\
\hline $\operatorname{sim}$ & 34 & 78 & 100 & 88 & 20 & 76 \\
\hline กล̃o & 68 & 22 & - & 12 & 80 & 24 \\
\hline total & 100 & 100 & 100 & 100 & 100 & 100 \\
\hline
\end{tabular}

O que é interessante é que, apesar de 100\% dos entrevistados já terem visitado um dos Parques Municipais, os moradores não possuem conhecimento sobre o que significa uma UC (66\%), muito embora $78 \%$ deles tenham percepção que o RGS está localizado entre os Parques. Durante as entrevistas, notou-se que após ser discutido que os parques naturais, eram UCs, os entrevistados compreenderam parcialmente o significado de UC, visto que alguns designavam como: áreas naturais, áreas destinadas à proteção de animais, etc. Porém nem todos compreendiam o significado real das UCs, e que suas funções vão além de apenas conservar árvores e proteger animais.

Isto é preocupante porque essas UCs têm sido alvos de invasões, especialmente nas proximidades dos Parques Municipais Cachoeira das Orquídeas e Galo da Serra. As invasões ocasionaram: desmatamento demasiado; árvores de anos derrubadas; perda da biodiversidade; poluição, ocasionada pelos descartes incorretos de resíduos sólidos na floresta, como placas, Ionas, garrafas; efeitos climáticos, pois as florestas contribuem fornecendo umidade para o ambiente.

Contudo, para os moradores do RGS, $88 \%$ dos entrevistados consideram importante preservar as áreas naturais dos Parques. E, mesmo não tendo conhecimento do significado real do que é uma zona de amortecimento, $76 \%$ dos moradores consideram que o RGS pode vir a ser uma zona de amortecimento para impedir alterações das características originais dos recursos naturais existentes nesses parques, como: no caso do PNMCO pode haver a preservação do volume das águas da cachoeira; e, no caso do PNMGS pode haver a preservação do galo-da-serra.

A questão é que outros problemas podem surgir caso a sociedade não reconheça o devido valor dos recursos naturais. Antigamente no PNMCO havia muitas orquídeas, porém grande parte foi suprimida, muitas vezes os próprios visitantes "levavam" algumas espécies. Praticando 0 que chamamos de biopirataria. No PNMGS, existe uma espécie endêmica muita rara, o galo-daserra (Rupícola rupícola) que por causa dos impactos ambientais podem ser extintos do Parque, tais impactos como: biopirataria das espécies - onde filhotes são capturados; excesso de visitas, uma vez que o pássaro costuma viver solitário, e barulhos faz com que se mude.

- Portanto, o RGS pode contribuir para que esses impactos possam ser evitados ou até minimizados. Os moradores desse Projeto habitacional de grande escopo do Governo Federal - Minha Casa Minha Vida - são fundamentais nesse processo de conservação ambiental dos recursos inseridos nessas UCs, pois todos os recursos encontrados ali são bens de grande valor ambiental.

Os entrevistados questionavam que na entrada dos Parques poderia estar mais claro o que pode, e o que não pode fazer nos parques, fornecendo orientações adequadas aos visitantes, argumentavam que por vezes não é esclarecido o motivo pelo qual não pode fazer determinadas ações dentro dos parques. O que seria muito relevante, para que as pessoas compreendessem os problemas ambientais ocasionados por atitudes equivocadas, levar uma espécie de orquídea do PNMCO, por exemplo, 
futuramente isso pode ocasionar a extinção da espécie.

\subsection{DISPOSIÇÃO A PAGAR PELA CONSERVAÇÃO DAS UCS PARQUE NATURAL MUNICIPAL CACHOEIRA DAS ORQUÍDEAS E PARQUE NATURAL MUNICIPAL GALO DA SERRA}

Talvez a única forma de garantir a existência e conservação da Cachoeira das Orquídeas ou dos pássaros galo-da-serra - localizados no PNMCO e no PNMGS - seria permitir a visitação controlada, onde seria cobrado um valor destinado a Secretaria de Meio Ambiente ou Órgão competente para evitar invasões, degradações, etc e manter esses recursos para as futuras gerações. Então, nessas condições, qual o valor máximo que os moradores do RGS estariam dispostos a pagar para visitar e se tornar um agente direto responsável pela conservação da Cachoeira das Orquídeas ou de qualquer outro recurso natural ali encontrado.

A pesquisa apontou que $40 \%$ dos moradores do RGS estavam dispostos a pagar um valor entre $R \$ 1$ a $R \$ 2$ para manter as UCs conservadas, assim como $36 \%$ estavam dispostos a pagar entre $R \$ 3$ a $R \$ 5,16 \%$ estavam dispostos a pagar até $R \$ 10$, e $4 \%$ mais de $\mathrm{R} \$ 10$ (Gráfico 6).

Gráfico 6: DAP pelo moradores do RGS

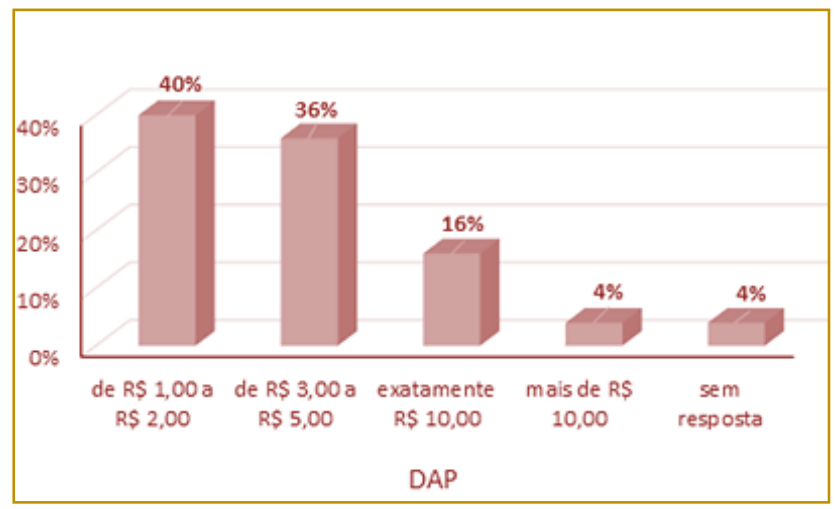

Fonte: resultado da pesquisa.

Nota-se no gráfico 6 que 96\% dos entrevistados estavam dispostos a pagar para entrar nos parques, pois, acreditam que isso pode contribuir para que as pessoas compreendam o valor dos parques, Outros argumentavam que isso possibilitaria melhoras nas trilhas, para que pessoas idosas e pessoas com deficiência pudessem visitar as UCs. Permitiria também a construção de uma sala de orientação, para que os visitantes pudessem conhecer a biodiversidade dos parques e sua importância.
Os moradores do RGS revelaram que se tivessem a plena certeza que um imposto ou uma taxa fossem destinados para a conservação e manutenção dos parques no sentido de preservar as espécies de orquídeas e pássaros galo-da-serra que ainda existem lá, estariam dispostos a pagar um valor fixo em uma de suas contas: de luz, de água ou de IPTU. Essa disposição pode ser avaliada no Gráfico 7, logo abaixo. 
Gráfico 7: DAP na conta d e energia/água/IPTU pelos moradores do RGS

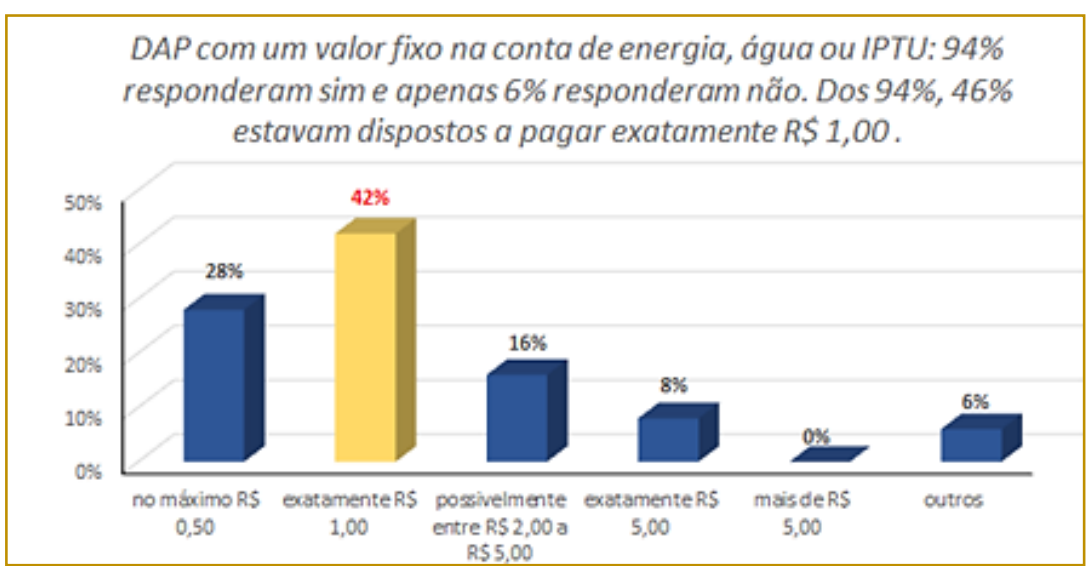

Fonte: resultado da pesquisa.

É interessante que $42 \%$ dos moradores optaram ou aceitaram em pagar uma taxa fixa em sua conta de luz/água/IPTU em exatamente $R \$ 1,00$ para que os Parques fossem conservados. Isto demonstra o valor material e perceptivo que os moradores do RGS possuem das UC, muito embora tenham pouco conhecimento sobre o verdadeiro significado desse conceito.

\section{CONSIDERAÇÕES FINAIS}

O desenvolvimento do presente artigo possibilitou estimar o valor de recursos ambientais inseridos em Unidades de Conservação do município de Presidente Figueiredo. Um estudo acerca de seus benefícios e dos problemas que enfrentam.

O artigo analisou a percepção material dos moradores do Residencial Galo da Serra quanto à disposição a pagar para conservar os recursos ambientais presentes nas UCs: PNMCO e PNMGS. Ao revelarem que estariam dispostos a pagar uma taxa para a conservação e manutenção dos parques, os entrevistados requerem políticas públicas concretas de melhoria e proteção para as UCs. Tal resultado confirmou a importância e - valor dessas áreas protegidas para a população do residencial. Apesar de não apresentarem uma boa renda mostraram disposição em colaborar financeiramente com a conservação dos ativos ambientais em análise.

O questionário conseguiu capturar a disposição dos moradores do residencial em conservar ou não os recursos ambientais presentes nas UCs, através de um texto no subtema: Disposição a pagar pela conservação das UCs, que expunha sobre as invasões nos parques e sobre suas biodiversidades.

Estudos posteriores devem procurar uma amostragem maior, abrangendo uma porção significativa da população de Presidente Figueiredo, envolvendo os frequentadores e os não frequentadores dos ativos, E deste modo estimar o valor total dessas UCs, com a finalidade de averiguar se existem diferenças relevantes entre as preferências dos usuários e não usuários.

Portanto, valorar os recursos ambientais viabiliza a formulação de políticas públicas voltadas para meios mais sustentáveis de desenvolvimento. A disposição a pagar pela conservação de UCs permite subsídios importantes para seus órgãos gestores, permitindo que estes demonstrem o valor desses bens ambientais para a população de seu entorno, proporcionando uma gestão participativa, que contribui para sua proteção.

\section{REFERÊNCIAS}

[1] Brasil. Lei Federal № 9.985, de 18 de julho de 2000. Regulamenta o art. 225, § 10, incisos I, II, III e VII da Constituição Federal, institui o Sistema Nacional de Unidades de Conservação da
Natureza e dá outras providências. Disponível em: $<$ http://www.planalto.gov.br/ccivil_03/leis/L9985.ht m>. Acesso em: 18 jun. 2017. 
[2] Cirino, Jader Fernandes; LIMA João Eustáquio de. Valoração contingente da Área de Proteção Ambiental (APA) São José - MG: um estudo de caso. Rev. Econ. Sociol. Rural Brasília, vol. 46, no 03, p. 647-672, set 2008. Disponível em: $<$

http://www.scielo.br/scielo.php?script=sci_arttext\& pid=S0103-20032008000300004 >. Acesso em: 22 mar. 2018

[3] G1, Amazonas. Polícia realiza reintegração de posse em Presidente Figueiredo, no AM, 22 mar. $2017 . \quad$ Disponível em:<http://g1.globo.com/am/amazonas/noticia/201 7/03/policia-realiza-reintegracao-de-posse-empresidente-figueiredo-no-am.html>. Acesso em: 22 jun. 2017.

[4] Hassler, Márcio Luís. A importância das Unidades de Conservação no Brasil. Uberlândia: Sociedade \& Natureza. V. 17, n. 33, p.79-89. 2005. Disponível em:<http://www.redalyc.org/articulo. oa?id=321327187006 > . Acesso em: 17 jun. 2017.

[5] Hildebrand, Elisabeth; Graça, Luiz Roberto; Hoeflich, Vitor Afonso. "valoração contingente" na avaliação econômica de áreas verdes urbanas. Revista Floresta, Curitiba - PR. p.121-132. 2002. Disponível em: <http://revistas.ufpr.br/floresta/article/view/2353/196 7>. Acesso em: 12 abr. 2018.

[6] Ibge - Instituto Brasileiro de Geografia e Estatística. Cidades. 2010. Disponível em: <http://www1.ibge.gov.br/cidadesat/painel/painel.p hp?lang=_ES\&codmun=130353\&search=amazona slpresidente-figueiredolinfograficos:-dados-geraisdo-municipio>. Acesso em: 22 de jun. 2017.

[7] Kahn, James R.; Rivas, Alexandre. Abordagens para a valoração econômica ambiental. IN: Economia e valoração de serviços ambientais: utilizando técnicas de preferências declaradas. RIVAS, Alexandre (Org.). Manaus: EDUA, 2014. 304 p.

[8] Maia, Alexandre Gori; Romeiro, Ademar Ribeiro; Reydon, Bastiaan Philip. Valoração de recursos ambientais - metodologias e recomendações. Texto para Discussão, Instituto de Economia/UNICAMP, Campinas. p. 2-38, mar. 2004

Disponível em:<http://www.eco.unicamp.br/docprod/downarq. php?id=1833\&tp=a> . Acesso em: 14 mar. 2018

[9] May, Peter. Aplicação de técnicas de avaliação econômica ao ecossistema manguezal. IN: Economia ecológica: aplicações no Brasil. Rio de Janeiro: Campus, 1995.

[10] Mileski, Edison; Olivera, Ronne Flávio Vieira; Torres Manoel Haroldo Coutinho et al. Cenário Analítico: Plano Diretor Participativo do
Município de Presidente Figueiredo. Presidente Figueiredo- AM. p. 1-180. 2006.

[11] Mota, José Aroudo. Valoração de ativos e serviços ecossistêmicos. IN: Economia e valoração de serviços ambientais: utilizando técnicas de preferências declaradas. RIVAS, Alexandre (Org). Manaus: EDUA, 2014. 204 p.

[12] Motta, Ronaldo Seroa da. Manual para valoração econômica de recursos ambientais. Brasília: Ministério do Meio Ambiente, dos Recursos Hídricos e da Amazônia Legal, 1998. 218 p.

[13]

Ortiz, Ramon Arigoni. Valoração econômica ambiental. IN: Economia do meio ambiente: teoria e prática. MAY, et al. (ORGs). Rio de Janeiro: Elsevier, 2003. 6aㅡ reimpressão. 318 p.

[14] Pearce, David; Moran, Dominic. O valor económico da biodiversidade. Instituto Piaget, 1994.

[15] Peixer, Janice; Giacomini, Henrique Corrêa; JúNIOR, Miguel Petrere. Valoração Ambiental da Cachoeira de Emas. IN: Economia e valoração de serviços ambientais: utilizando técnicas de preferências declaradas. Rivas, Alexandre (Org.). Manaus: edua, 2014. 304 p.

[16] Reis, João Rodrigo Leitão. Gerenciamento ambiental de atributos naturais da APA Caverna do Maroaga, Presidente Figueiredo-AM. 2010. $231 \mathrm{f}$. Dissertação (Mestrado) - Curso de Ciências Florestais e Ambientais, Universidade Federal do Amazonas Faculdade de Ciências Agrárias, Manaus, 2010. Cap. 1. Disponível em: <http://tede.ufam.edu.br/bitstream/tede/2997/1/Diss ertação - João Rodrigo Leitão dos Reis.pdf>. Acesso em: 23 jun. 2017

[17] Semmas/PF - Secretaria Municipal de Meio Ambiente e Sustentabilidade de Presidente Figueiredo. 2017.

[18] Serra, Maurício A. et al. A valoração contingente como ferramenta de economia aplicada à conservação ambiental: o caso da estrada parque pantanal. IPEA - Instituto de Pesquisa Econômica Aplicada. Brasil. p.193-212. $2004 . \quad$ Disponível em: <http://www.ipea.gov.br/ppp/index.php/PPP/article/ view/55>. Acesso em: 15 mar. 2018.

[19] Silva, Rubicleis Gomes da; Lima, João Eustáquio de. Valoração contingente do parque "Chico Mendes": uma aplicação probabilística do método Referendum com bidding games. Rev. Econ. Sociol. Rural, Brasília, v. 42, n. 4, p. 685-708, Dec. 2004.

Disponível em:<http://www.scielo.br/scielo.php?script=sci_artt ext\&pid=S0103-20032004000400008 . . Acesso em: 22 mar. 2018 


\section{Gapítulo 13}

\section{PROGRAMA BOLSA VERDE E INCLUSÃO: A EXPERIENCIA DAS FAMILIAS AGROEXTRATIVISTAS NA RESEX MEDIO PURUS, LÁBREA (AM)}

\section{Silvânia Queiroz e Silva}

\section{Elenise Faria Scherer}

Resumo: O artigo trata das politicas socioambientais desenvolvidas na região amazônica pelo Estado brasileiro e tem como problema central analisar o modelo de desenvolvimento sustentável promovido para inclusão produtiva. O recorte de análise foi o Programa Bolsa Verde (PBV) do governo federal com o objetivo de identificar as principais implicações dessa política no trabalho e nas condições de vida das famílias na Reserva Agroextrativista Médio Purus, localizada no rio Purus, município de Lábrea (AM). A pesquisa fundamenta-se na perspectiva qualitativa, foram realizadas entrevistas narrativas por meio de esquema auto gerador junto as família beneficiárias do PBV no período de 2014 a 2016. Os resultados indicam que a inclusão produtiva proposta pelo PBV apresenta dificuldades de se efetivar, sendo necessário possibilitar a ampla participação dos agroextrativistas e promover sua maior autonomia na gestão da Resex Médio Purus, bem como integrar as ações do PBV à implementação de políticas públicas que possibilitem o acesso aos serviços de cidadania.

Palavras Chave: inclusão produtiva, programa bolsa verde e agroextrativismo 


\section{INTRODUÇÃO}

As iniciativas governamentais que buscam articular desenvolvimento econômico e conservação ambiental implicaram, no âmbito regional, nacional e global, em políticas que vislumbram, de modo integrado, promover melhorias nas condições de vida, a partir da erradicação da pobreza e inclusão produtiva da sociedade, por meio da construção de territórios e novos mercados que visem a sustentabilidade ambiental dos ecossistemas, especialmente no território amazônico.

Conhecer essa dinâmica é relevante para compreender o ambiente e a racionalidade ecológica e social de resistência dos povos tradicionais que garantem a sustentabilidade dos complexos ecossistemas das Unidades de Conservação Federais frente as estratégias de integração social, política e econômica dessas unidades às novas dinâmicas socioeconômicas do país.

Com este objetivo, este artigo apresenta o resultado da investigação do desenvolvimento do Programa Bolsa Verde (PBV) e sua contribuição para a inclusão produtiva das famílias agroextrativistas da comunidade Cassianã, localizada na Resex Médio Purus,
Lábrea (AM), interior do estado do Amazonas, como estratégia política de desenvolvimento com sustentabilidade econômica, social e ambiental.

A Resex Médio Purus foi criada no ano de 2008, a partir da luta do movimento social de lideranças comunitárias, organizadas por meio da Associação dos Trabalhadores Agroextrativistas do Médio Purus (ATAMP), no anseio de sair do isolamento espacial e político e garantir seus direitos territoriais e de cidadania. Compreende uma área de 604.290 $\mathrm{Km}^{2}$ (Figura 1), sendo composta por 97 comunidades, localizadas tanto em ecossistemas de várzea como em terra firme. A comunidade Cassianã é uma das comunidades da Resex que compõe o ecossistema de várzea, distante "quatro praias" da sede municipal de Lábrea, cidade com a qual possui relação de intensas trocas econômicas e socioculturais. É comum os moradores de Lábrea se referirem às praias para medir a distância entre a sede do município e as comunidades da área rural, sejam elas localizadas nas várzeas ou em terras firmes. Retomo essa expressão no capítulo 3 para melhor explicação.

Figura 1 - Localização da Resex Médio Purus e indicação da comunidade Cassianã

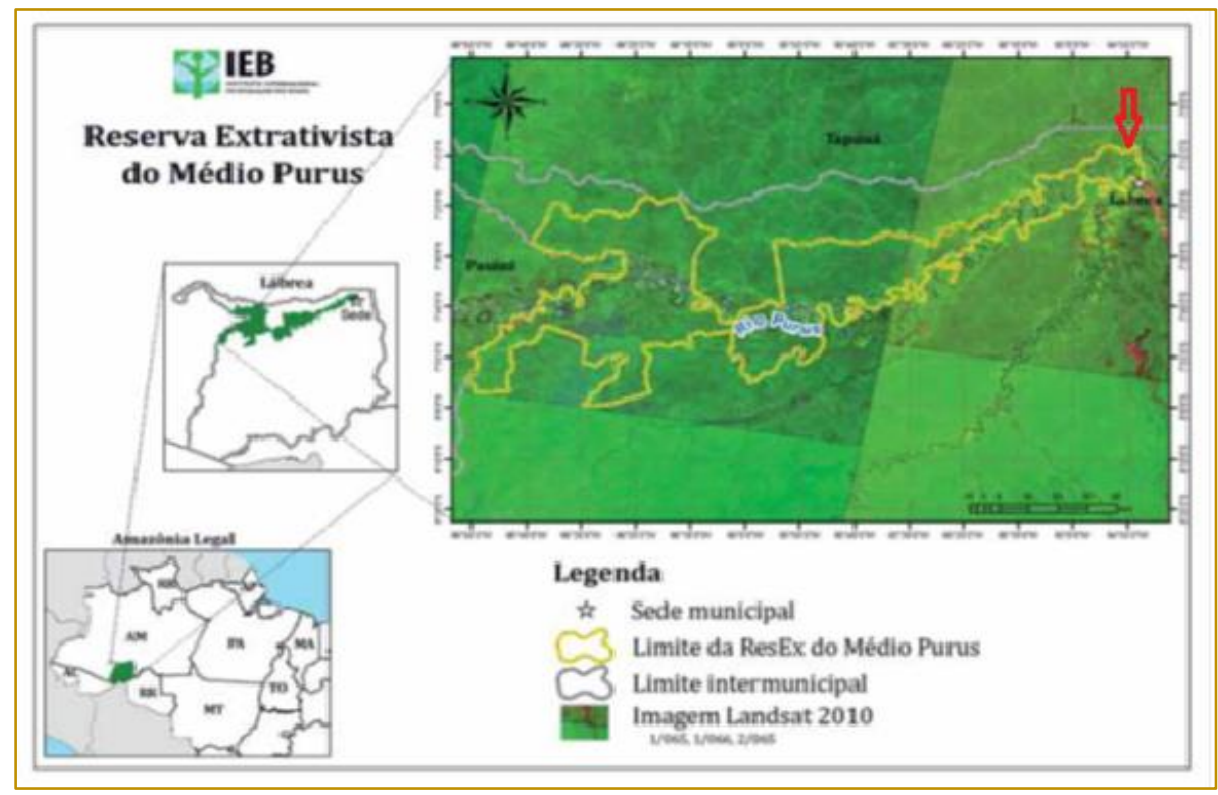

Fonte: IEB

O Programa Bolsa Verde foi implementado na comunidade no ano de 2012. Antes de sua implementação, a ATAMP realizou um levantamento de campo para elaboração do perfil socioeconômico e cadastramento, no
CadÚnico, das mais de 900 famílias da Resex Médio Purus. Essa ação teve o objetivo de que as famílias aderissem ao Programa Bolsa Verde e a outros programas sociais do Governo Federal, a fim de promover o acesso 
a bens e serviços de cidadania, além de incentivar a inclusão produtiva rural, através do manejo dos diversos recursos naturais da Resex.

Até abril de 2016, 597 famílias da Resex Médio Purus eram atendidas pelo Programa Bolsa Verde (MMA, 2016). Desde 2012, a comunidade Cassianã é a que possui maior número de famílias da Resex cadastradas ao PBV, com aproximadamente 20 famílias inseridas, até o ano de 2015.

A metodologia utilizada na pesquisa pauta-se na perspectiva da hermenêutica dialética, uma vez que buscamos a interpretação e a compreensão dos sentidos da realidade social investigada. A pesquisa é qualitativa por estudar um fenômeno no local em que ele ocorre, procurando o sentido e os significados dados a ele pelas pessoas. Utilizamos como instrumento formulário de entrevista narrativa aplicado junto às famílias e os resultados analisados a partir de técnica de análise de conteúdo segundo Bardin (1977).

A análise apresenta as implicações das ações do Programa Bolsa Verde na comunidade, tendo como ponto de partida os objetivos propostos pelo Programa. Nesse sentido, buscamos verificar o impacto das ações do programa no perfil socioeconômico das famílias, no potencial de consumo, nas atividades produtivas e nas relações sociais das famílias atendidas. As percepções e considerações feitas pelas famílias indicam elementos importantes a serem avaliados no programa. Dentre eles, a efetiva interação com outras ações públicas, com vista a promover a inclusão produtiva e a cidadania, paralelas às ações de valorização ambiental e inserção dos produtos da agricultura familiar num circuito de produção que seja adaptável ao ciclo produtivo agroextrativista de várzea e viável econômica, social e ambientalmente para os agroextrativistas, sem destruição de sua identidade sociocultural.

\subsection{INCENTIVO À CONSERVAÇÃO AMBIENTAL ENQUANTO MANUTENÇÃO E USO SUSTENTÁVEL DO ECOSSISTEMA}

Segundo a lei que instituiu o PBV como Programa de Apoio à Conservação Ambiental, a conservação ambiental é entendida como "a manutenção e uso sustentável dos ecossistemas"(Lei n. 12.512/2011, Art. 1‥ alínea | ). Essa noção dá indícios de que a principal condicionalidade para garantir a conservação seria a imposição de limites a determinadas atividades de exploração e extração dos recursos naturais, entre as quais se destaca o não desmatamento.

Para Silva (2012), essa condicionalidade se trata de uma limitação extremamente técnica que objetiva racionalizar o uso dos recursos naturais e possui a tendência de escamotear as determinações sociais da questão ambiental e a lógica destrutiva do capital. Dessa forma, transfere para os trabalhadores e povos tradicionais da floresta a culpa pela degradação da natureza sem, no entanto, levar em consideração as relações de poder e de exploração construídas em torno da luta pelo domínio e exploração dos recursos naturais nos territórios.

Ao conceber a conservação como manutenção e uso sustentável dos ecossistemas, o PBV toma como critério a existência efetiva dos planos de manejo ou de utilização que regulam o acesso e o uso dos recursos naturais em determinados territórios, sejam eles unidades de conservação ou áreas rurais.

As regulações dos planos de manejo do PBV são consideradas pactos entre o Governo Federal e as famílias atendidas, a fim de garantir o uso sustentável dos recursos naturais. Logo, a criação de áreas protegidas ganhou o rótulo de concessão territorial do Estado à sociedade civil (MARTINS, 2002) e não de conquista da luta social dos povos tradicionais e grupos de trabalhadores rurais. Tal perspectiva não põe em evidência os conflitos que permeiam as reais condições de vida e nem as determinações das desigualdades a que são submetidos os agroextrativistas. Dessa maneira, tenta, na verdade, compensar a destrutividade ambiental e social dos empreendimentos do capital e da globalização da economia.

No âmbito da Resex Médio Purus, o plano de manejo de diversos recursos naturais ainda se encontra em processo de formulação e implementação. O Plano de Utilização ${ }^{1}$ da Resex regula e orienta os critérios, limites e proibições de atividades de trabalho e subsistência dos ecossistemas das comunidades, nos lagos e florestas do perímetro da reserva. Esse plano proíbe a extração da madeira para comercialização e

${ }^{1}$ Portaria $n^{\circ} .126$ de 08/11/2012 do ICMbio, conforme já sinalizamos. 
restringe seu uso para atividades de subsistência das famílias ou uso comunitário, por exemplo, a retirada de lenha somente para construção de casas, canoas, casa de farinha, móveis, dentre outros. O plano também prevê o controle da venda e da pesca de peixes e de "bicho de casco", que durante muito tempo constituiu importante fonte de renda das famílias.

As condicionalidades previstas no Plano de Utilização e atreladas ao Programa Bolsa Verde tornaram apenas o "morador" da Resex como potencial transgressor das regras estabelecidas, além de possibilitar a aplicação de advertências e penalidades aos mesmos, o que pode causar forte impacto nas condições de sobrevivência das famílias, dado o seu perfil de baixa renda.

De forma contraditória, o Plano de Utilização, apesar de elaborado pelos agroextrativistas, não contempla a aplicação de penalidades a atores externos à reserva que praticarem exploração ou depredação dos recursos naturais, em especial da madeira. Costumeiramente, esses atores agenciam os moradores da reserva em atividades de exploração dos recursos madeireiros e em consequência, somente os agroextrativistas serão punidos. Assim, verifica-se que o Plano de utilização atua como um instrumento de "biopoder" sob o controle da ação e do comportamento das pessoas, permitindo a constante vigilância nas relações sociais na Resex. (FOUCAULT, 1993)

De modo geral, o uso conservacionista dos recursos naturais da comunidade Cassianã se identifica com os seguintes princípios: uso dos recursos naturais pela geração presente; prevenção do desperdício e o uso dos recursos naturais para benefício da coletividade (DIEGUES, 2004). Essa relação com a natureza garante a manutenção das principais fontes de sustento das famílias, através do rio, da floresta e da terra. Nessa estrutura, os agroextrativistas desenvolvem a conservação ambiental, diferente das relações estabelecidas pelos princípios do

\footnotetext{
2Para Foucault (1993), o biopoder se refere ao poder que exerce o Estado de regulamentar normas e submeter a população à elas, regendo formas de comportamentos. Desse modo, o autor apresenta a biopolítica como aquelas ações que buscam obter a subjugação de comportamentos e controle.
}

desenvolvimento sustentável que acabam sendo a eles incorporados devido à relação estabelecida entre o Estado, a sociedade e o mercado.

$\mathrm{Na}$ perspectiva do desenvolvimento sustentável, o uso ambientalmente correto dos recursos naturais é pautado por regulamentações técnicas coercitivas. A viabilidade econômica prevista nessa perspectiva indica a mercantilização dos bens ambientais como compensação à degradação promovida pelas grandes empresas. Entretanto, a justiça socioambiental implica ações que favorecem o consumo e não políticas que possam garantir o acesso aos direitos e serviços de cidadania.

Já a perspectiva da sustentabilidade promovida pelos agroextrativistas, não prevê a conservação pela via da vigilância e punição, mas sim, a partir da relação material e simbólica estabelecida com a natureza. Nesse cenário, os limites de sobrevivência do homem encontram consonância com a dinâmica da natureza, através de uma relação de equilíbrio, em que ambos possam se reproduzir, mesmo frente às determinações dos modos de vida exploratórios dos centros urbanos e da organização técnica do trabalho e da indústria.

Sob esse prisma, as políticas que se pretendem ser socioambientais evidenciam sua natureza complexa e contraditória. Isso é perceptível nas políticas emergentes que expressam a consciência de classe e a organização política da luta social e étnica dos diversos segmentos organizados dos trabalhadores rurais. Bem como, materializam os conflitos socioambientais no jogo de forças entre projetos societários distintos, através da apropriação pelo capital que visa dar viabilidade e legitimação à modernização conservadora.

A regulamentação do uso dos recursos naturais em áreas protegidas tem origem na determinação preservacionista, que foi referenciada na perspectiva norte americana de contemplação da natureza. Essa compreensão apresenta-se como um equívoco quando dissemina as condicionalidades do PBV às famílias, pois as Reservas Extrativistas requerem o uso dos recursos naturais de forma sustentável, não a simples proibição do uso dos recursos. Esse processo pode ser observado no incentivo ao desmatamento zero como condição de atendimento pelo PBV, o que implica proibir 
atividades socioculturais essenciais do modo de vida das famílias residentes nas Unidades de Conservação como o manejo madeireiro e a realização de roças nas atividades agrícolas.

Além disso, a compreensão errônea dos modos de conservação é capaz de gerar conflitos na relação de solidariedade e na identidade coletiva dos grupos sociais. Dessa forma, há urgência na formulação e implementação dos planos de manejo para atender as realidades vivenciadas em cada UC. É necessário definir estratégias que, baseadas na participação comunitária efetiva, visem equilibrar o uso dos recursos na unidade e não apenas proibi-los. $\mathrm{Na}$ comunidade Cassianã, a proibição da extração comercial da madeira, a não realização de roças em áreas de várzea da floresta e a limitação de 2 hectares/família para área de cultivo causaram impactos nas atividades de trabalho e, principalmente, mudanças nas relações sociais da comunidade.

Dessa maneira, assim como no modelo de alta tecnologia da organização da produção nos chãos de fábrica, os agroextrativistas passaram a desempenhar o papel de vigilantes uns dos outros, fragilizando suas relações de solidariedade e de identidade coletiva, as quais constituem a comunidade, como por exemplo, a divisão de praias entre as famílias. Diante dessas questões, novas configurações passaram a nortear as territorialidades das famílias agroextrativistas.

Diante desse contexto e das narrativas dos agroextrativistas, verifica-se que o objetivo de incentivar a sustentabilidade e a conservação ambiental do PBV, mediado através do Plano de Utilização da Resex Médio Purus, é distante da realidade vivenciada pelas famílias da comunidade Cassianã. Pois, a proibição e limitação das atividades já desenvolvidas pela comunidade, sem inibição dos atores externos que mais causam o desmatamento e depredação do ambiente, causa um intenso dissenso entre as famílias agroextrativistas em relação à regularização dos critérios previstos no Plano de Utilização e disseminados como condicionalidade do Programa Bolsa Verde.

\section{O AUMENTO DA RENDA E A SAÍDA DAS FAMÍLIAS DA SITUAÇÃO DE EXTREMA POBREZA}

O segundo objetivo do Programa Bolsa Verde é a saída das famílias da situação de extrema pobreza por meio da transferência de renda e, corresponde ao primeiro eixo de atuação proposto no Plano Brasil Sem Miséria. Essa política causa um aumento da renda das famílias, porém não o suficiente para o atendimento de suas necessidades.

$\mathrm{Na}$ concepção das famílias agroextrativistas, a renda se constitui de recursos financeiros advindos de diversas fontes, como do trabalho, seja ele na pesca, agricultura ou extrativismo; das políticas sociais, como o Programa Bolsa Família, Bolsa Verde, Seguro Defeso, etc. e das aposentadorias ou benefícios previdenciários e eventuais como auxílio doença e salário maternidade.

O valor da renda advinda do trabalho agroextrativista depende da quantidade e qualidade da produção, além da dinâmica dos ecossistemas regionais ao longo do ano. A renda advinda da Política do Seguro Desemprego ao Pescador Artesanal (PSDPA), conhecido popularmente como Seguro Defeso, ocorre no período anual de reprodução dos peixes (com duração de até cinco meses). A renda advinda do Programa Bolsa Verde chega às famílias trimestralmente. E por fim, mensalmente, a aposentadoria (para aqueles que a possui) e o Programa Bolsa Família que, para algumas famílias, chega a constitui a única fonte de renda do mês, de acordo com as mudanças do período produtivo.

Cabe destacar que, para as famílias agroextrativistas, as principais fontes de sobrevivência não se resumem apenas a rendas pecuniárias, mas também ao trabalho com a pesca, agricultura e extrativismo, pelo qual é possível garantir o acesso a bens materiais e simbólicos de reprodução sem a mediação do dinheiro. Desse modo, a concepção de renda e fonte de sustento dos entrevistados se distingue por sua origem e temporalidade, devido aos elementos culturais e simbólicos que dão sentido e significado ao trabalho agroextrativista como práxis de produção e reprodução social, cultural e ambiental de seu sistema produtivo.

Essa observação é importante porque, ao informar a renda mensal as famílias consideraram seu cálculo a partir do valor médio que necessitam para garantir sua 
reprodução material e a manutenção de seus meios e instrumentos de trabalho. Esses valores corresponderam ao mínimo de $R \$ 200,00$ (duzentos reais) e ao máximo de $\mathrm{R} \$ 1.448,00$ (um mil quatrocentos e quarenta e oito reais) por família, ou seja, menor que um salário mínimo e no máximo dois salários mínimos ${ }^{3}$.

Segundo dados da pesquisa de campo, 53\% das famílias da comunidade sobrevivem com renda mensal menor que um salário mínimo, composta principalmente pelos recursos oriundos do Programa Bolsa Família e Bolsa Verde. Cerca de 35\% possui renda mensal de até um salário mínimo, composta pela combinação dos recursos dos mesmos programas, acrescido do trabalho remunerado não agrícola, identificados como "bicos" na prestação de serviços diversos na comunidade e na sede do município de Lábrea. Os outros 12\% compõem renda de até dois salários mínimos, composta da combinação de recursos advindos de trabalhos esporádicos ou por contratos, aposentadorias, e dos programas sociais.

Devemos ainda considerar que, a depender da quantidade de membros das famílias, mesmo aquelas que possuem renda maior que um salário mínimo podem ser inseridas na condição de extrema pobreza, devido ao cálculo de critério de renda per capita por família. Segundo o Ministério de Desenvolvimento Social (MDS), considera-se em situação de extrema pobreza a família com renda per capita menor ou igual $1 / 4$ do salário mínimo, ou seja, $\mathrm{R} \$ 77,00$ (setenta e sete reais) por pessoa. As famílias consideradas pobres são as que possuem renda per capita entre $R \$ 77,01$ (setenta e sete reais e um centavo) e $R \$ 154,00$ (cento e cinquenta e quatro reais) e aquelas com a renda acima desse valor não são consideradas pobres, portanto, não são atendidas pelos programas sociais.

Essa abordagem, a partir de parâmetros micro e individualizados, em detrimento do caráter universal da política como direito social, é contrária à concepção coletiva das famílias que residem na Resex. Isso constitui, na comunidade Cassianã, um dos elementos geradores do conflito referente,

\footnotetext{
${ }^{3}$ Considerando o valor base do salário mínimo de $\mathrm{R} \$ 724,00$, no ano de 2014, quando iniciamos as atividades de pesquisa de campo.
}

principalmente, à derrubada florestal, pois, uma vez que todos os residentes na reserva compartilham da responsabilidade de cumprir com as regras do Plano de Utilização, deveriam ter garantia de acesso ao Programa Bolsa Verde, independente de sua renda per capita familiar.

Nesse ínterim, segundo Lustosa (2012), políticas compensatórias de combate à pobreza são desenvolvidas, em detrimento do direito ao trabalho e, no meio rural, em detrimento às políticas de reforma agrária que é a forma de garantir o direito à terra, trabalho e produção dos agricultores, fazendo assim expandir a desigualdade no campo, mesmo diante do aumento do acesso à renda, pois, para a autora, o capitalismo, além de seletivo é absolutamente contrário à autonomia de trabalho. (Lustosa, 2012, p. 235)

Nesse contexto, os dados do IPEA mostram que a renda per capita média do município de Lábrea cresceu 49,85\% no período entre 1990 e 2010. Porém também indicam o aumento da concentração de renda, por meio da elevação do Índice de Gini ${ }^{4}$ entre 1991(0,63) e 2000 $(0,66)$ o que revela a má distribuição de renda e o aumento da pobreza nesse período. Já em 2010 houve redução da desigualdade de renda, com Îndice de Gini caindo para 0,59.

Observa-se, portanto, que, entre 1991 e 2010, a situação de extrema pobreza aumentou e posteriormente reduziu, indicando a flutuação da renda familiar constatada na comunidade Cassianã, devido às diferentes temporalidades que permitem a combinação de rendas advindas de políticas sociais ou do trabalho agroextrativista.

Desse modo, o aumento da renda não constitui o único elemento ou pelo menos não é o suficiente, para retirar e manter as famílias fora da situação de extrema pobreza e proporcionar melhores condições de vida. Entretanto, resulta no atendimento às necessidades de sobrevivência do mercado, uma vez que permite maior poder de

\footnotetext{
4 Segundo o IPEA o índice de Gini é um instrumento usado para medir o grau de concentração de renda. Ele aponta a diferença entre os rendimentos dos mais pobres e dos mais ricos. Numericamente, varia

de 0 a 1 , sendo que representa a situação de total igualdade, ou seja, todos têm a mesma renda, e o 1 significa completa desigualdade de renda, ou seja, se uma só pessoa detém toda a renda do lugar.
} 
consumo. Essa trama também se trata de um processo político e econômico contraditório que tem por dilema atender às necessidades sociais com recursos escassos, inserido em uma lógica capitalista, segundo a qual a riqueza deve ser gerada cada vez mais por meio de atividades economicamente rentáveis (PEREIRA, 2013)

Tabela 1: Renda, Pobreza e desigualdade - Lábrea (AM)

\begin{tabular}{|c|c|c|c|}
\hline \multicolumn{4}{|c|}{ Renda, Pobreza E Desigualdade - Lábrea - Am } \\
\hline & 1991 & 2000 & 2010 \\
\hline Renda per capita (em R $\$$ ) & 151,90 & 136,22 & 227,62 \\
\hline$\%$ de extremamente pobres & 45,84 & 51,67 & 33,28 \\
\hline$\%$ de pobres & 78,77 & 75,67 & 52,41 \\
\hline Índice de Gini & 0,63 & 0,66 & 0,59 \\
\hline
\end{tabular}

Por isso, o aumento da renda das famílias devido ao acesso ao Programa Bolsa Verde atende a duas tendências do capital contemporâneo: a mercantilização da natureza e o incentivo ao consumo, ambos como vetores do crescimento econômico local para inclusão no mercado globalizado.

A pesquisa de campo corrobora que o recurso monetário do Programa Bolsa Verde contribui para o sustento da família e é utilizado basicamente para compra de produtos alimentícios que não são produzidos em suas atividades agroextrativistas como açúcar, arroz, café, biscoitos, sal e óleo de cozinha. Na narrativa da Sra. Maria Inês, o dinheiro advindo do Programa Bolsa Verde:

\section{Contribui para o nosso sustento. Porque só com o Bolsa Família é muito pouco para a gente fazer as compras. Antes desse dinheiro [Bolsa Verde] a pessoa passava o verão todinho sem pegar num centavo. Depois que começou o Bolsa Família aí todo mês nós recebemos dinheiro e com o Bolsa Verde ficou mais fácil, mas antes se passava o verão todinho e só pegava em dinheiro quando vendia o feijão (Maria Inês Veiga, 29 anos, agroextrativista, jan/2014)}

Os relatos expressam a importância dos recursos do Programa Bolsa Verde e do Programa Bolsa Família para garantir a sobrevivência alimentar das famílias. Nessa reflexão, questões acerca do trabalho agroextrativista podem ser levantadas, primeiro quanto à condição progressiva de diminuição dos recursos naturais na área de reserva, como a redução do pescado no rio Purus e, por último, a mobilização da força de trabalho para atividades não agrícolas.

Nesse contexto, dados do IPEA de 2010 revelam que $51,12 \%$ da população de Lábrea, acima de 18 anos, exercia alguma atividade no setor agropecuário ${ }^{5}, 0,00 \%$ na indústria extrativa, $3,78 \%$ na indústria de transformação, 4,14\% no setor de construção, 0,5\% nos setores de utilidade pública e 9,31\% no comércio. A partir da análise dos dados, é perceptível o não investimento no potencial extrativista do município e a dificuldade em construir uma cadeia produtiva de inserção dos produtos da reserva, a fim de investir e valorizar o trabalho dos povos tradicionais. Todavia, percebe-se que, nos últimos anos há maior investimento na expansão agropecuária, tornando contraditório o objetivo do Programa Bolsa Verde quanto ao incentivo às atividades de uso sustentável e à conservação ambiental.

Identifica-se, portanto, a ênfase da economia local por meio de investimento na modernização conservadora que em consequência aumenta a dependência das famílias por políticas sociais de transferência de renda que permitem o acesso ao mercado interno de bens e serviços essenciais (YAZBECK, 2012). Nesse ínterim, a transferência de renda como incentivo à conservação ambiental não possibilita a construção de uma rota produtiva de legitimação do trabalho e valorização dos produtos agroextrativistas, mas vai ao encontro das formas de provisão social que o

\footnotetext{
${ }^{5}$ Como verificado no Plano de Utilização da Resex Médio Purus a agropecuária é uma atividade pouco desenvolvida pelas famílias agroextrativistas na Resex devido as condições geográficas, a viabilidade econômica para as famílias uma vez que a atividade requer investimento alto de recursos e criação de grandes pastos. Essa atividade é geralmente desenvolvida na região de Lábrea por grandes Fazendeiros ou empresas agropecuárias.
} 
Estado brasileiro assumiu como medida de enfrentamento às expressões da questão social e ambiental. Contudo não altera as estruturas da desigualdade, proporcionando apenas o acesso cada vez maior ao consumo.

Sobre as recentes políticas governamentais, conforme argumenta Silva (2010), evidenciam a tendência do capitalismo, no século XXI, de integrar as ações a fim de atender a um complexo sistema de acumulação financeira, que articula e lidera diversas esferas da vida social. Com isso, visam garantir a reprodução do capital, por meio da reforma neoliberal, da reestruturação produtiva e da naturalização dos conflitos socioambientais, assim, redefinem as bases do processo de acumulação, mesmo que seja necessária a crescente prevalência da dilapidação da natureza e da exacerbação da exclusão.

Mota (2012) ainda destaca que o acesso à renda no Brasil está intimamente atrelado a uma política econômica de ajustes fiscais de modo a promover a cidadania pela via do consumo, o que legitima o modelo econômico concentrador e homogeneizador dos sistemas de produção socioculturais.

Em relação à região amazônica, o atual processo homogeneizador é um forte elemento que impede a realização da sustentabilidade, pois não considera as especificidades sociais, políticas, econômicas e culturais da região, muito menos a diversidade dos ecossistemas e os insere na lógica destrutiva a altos custos socioambientais. Desse modo, o Programa Bolsa Verde, em sua dualidade, se constitui como avanço da conquista de uma política socioambiental nacional por reconhecer e valorizar os sistemas produtivos dos povos tradicionais na materialização das Unidades de Conservação, especialmente na Amazônia. Entretanto, também é acompanhado de uma estratégia de legitimação do poder econômico, ao não considerar as complexidades e particularidades da diversidade dos ecossistemas no propósito da inclusão produtiva.

Corroboramos então com o estudo de Pfeifer (2014), ao inferir que a inclusão social via consumo de massa configura um modelo de política social como fator de crescimento econômico interno. Nessa política, a inclusão pretendida não diz respeito ao acesso a bens e serviços públicos e gratuitos na esfera do Estado, uma vez que o Estado também deixa de ser provedor dos serviços sociais, para consumi-los da esfera privada, a inclusão a ser alcançada refere-se à inclusão no mercado de consumo, fortalecendo a configuração do cidadão consumidor. Esse movimento, além de favorecer a acumulação do capital, promove a responsabilização de indivíduos e famílias pelo acesso mercantil para garantir o acesso às condições de sobrevivência.

É nessa conjuntura que as lutas sociais travadas pelos povos tradicionais da região amazônica a favor da conquista de direitos socioambientais - como a regularização fundiária, valorização da cultura e identidade, direito ao trabalho digno, domínio de seus territórios e manutenção de seus modos de vida - esbarraram nos interesses do capital e na morosidade tendenciosa do Estado que, muitas vezes, atuou por meio da violência, implementando uma "justiça às avessas", favorecendo empresários, políticos, grileiros e fazendeiros.

É nessa estrutura que o PBV está inserido e, até $O$ presente momento, se mostra insuficiente, uma política complexa e contraditória. Para a presente pesquisa, o Programa representa e materializa a institucionalização da ambientalização das demandas socioambientais dos povos tradicionais, estabelecidos em Unidades de Conservação e, devido a sua essência funcionalista ao capital não permite o atendimento real das necessidades de sobrevivência das famílias atendidas, dada a sua alternância temporal. Além disso, não valoriza adequadamente o "acordo" que estabelece as condicionalidades ambientais do programa e institui uma cultura moralista e de vigilância entre os agroextrativistas, em detrimento do cumprimento das responsabilidades governamentais de fiscalização adequada em nome de um bem ambiental comum.

\section{CAPACITAÇÃO SOCIOAMBIENTAL E ASSISTÊNCIA TÉCNICA PARA A INCLUSÃO PRODUTIVA}

O terceiro objetivo do Programa Bolsa Verde diz respeito ao incentivo à participação do público-alvo em ações de capacitação socioambiental, técnica e profissional. Essa medida é articulada às ações do Programa de Fomento às Atividades Produtivas Rurais (PFPR), gerido pelo Ministério do Desenvolvimento Agrário. 
As ações do PFPR serão executadas por meio da transferência de recursos financeiros não reembolsáveis e da disponibilização de serviços de Assistência Técnica e Extensão Rural (ATER) aos agricultores familiares, com a finalidade potencializar a produção agrícola de base familiar, por meio da capacitação técnica e incentivo às organizações associativas de produtores rurais (BRASIL, 2011)

O PFPR pode ser somado ao Programa Bolsa Verde e oferecer aos agricultores familiares o acesso a uma linha de crédito no valor de $\mathrm{R} \$ 2.400,00$ (dois mil e quarenta reais) por família, que devem ser utilizados para subsidiar as atividades produtivas. O acesso ao crédito é por demanda espontânea, porém adota como critérios de atendimento, a situação de extrema pobreza e inscrição na base de dados do Cadúnico, portanto, é uma política seletiva e focalizada.

A família interessada em participar do Programa de Fomento deve assinar um Termo de Adesão, no qual se compromete a utilizar o recurso em favor da produção e a participar da ATER. Também receberá as orientações de um técnico agrícola e fornecerá informações acerca de seus saberes tradicionais.

As famílias da comunidade Cassianã tiveram acesso a essa linha de crédito e utilizaram-na para aquisição de instrumentos de acesso aos meios de produção, como forno de farinha, motor de polpa ou bomba d'água. A respeito da disponibilidade de assistência técnica para qualificação dos processos produtivos, os quais devem ser disponibilizados pelas instituições regionais de desenvolvimento da política rural, as famílias sinalizam que foi um serviço corriqueiramente oferecido nos últimos dois anos.

O serviço de ATER contextualiza a emergência da extensão rural como uma das estratégias técnicas do processo de expansão e modernização da fronteira agrícola, engrenado nos anos 60, para o desenvolvimento da Amazônia (BECKER, 2005). Esse processo implicou mudanças econômicas, políticas e culturais que favoreceram a reprodução capitalista na região e a expropriação e exploração da população rural, incluindo os povos tradicionais, visando, não só a ocupação e integração regional, mas a articulação da região à dinâmica do desenvolvimento agrícola nacional e internacional.

As políticas governamentais de desenvolvimento, que pautam a expansão agrícola na Amazônia sofrem alterações, a partir do contexto da expansão do Vetor Tecno-ecológico (VTE) identificado por Becker (2005). No âmbito dos serviços da ATER, convencionalmente estruturada para transferir conhecimentos tecnológicos aos produtores familiares, a fim de homogeneizar a produção agrícola para o mercado, a adoção dos princípios da sustentabilidade ambiental reestrutura o direcionamento das ações de extensão rural que devem privilegiar:

- potencial endógeno das comunidades e territórios, resgatar e interagir com os conhecimentos dos agricultores familiares e demais povos que vivem e trabalham no campo em regime de economia familiar, e estimular o uso sustentável dos recursos locais. Ao contrário da prática extensionista convencional, estruturada para transferir pacotes tecnológicos, a nova Ater pública deve atuar partindo do conhecimento e análise dos agroecossistemas e dos ecossistemas aquáticos, adotando um enfoque holístico e integrador de estratégias de desenvolvimento, além de uma abordagem sistêmica capaz de privilegiar a busca de equidade e inclusão social, bem como a adoção de bases tecnológicas que aproximem os processos produtivos das dinâmicas ecológicas. (Política Nacional de Assistência Técnica e Extensão Rural, 2007)

A partir dessa perspectiva é que os objetivos da ATER se interligam com os objetivos do Programa Bolsa Verde, o que requer a integração institucional e operacional das ações. No contexto de Lábrea, a instituição responsável pela disponibilidade da ATER é o Instituto de Desenvolvimento Agropecuário e Florestal Sustentável do Estado do Amazonas (IDAM), onde os serviços prestados têm por finalidade conectar a pesquisa, o conhecimento científico, o desenvolvimento de tecnologias e as políticas públicas com a agricultura familiar e outras atividades produtivas rurais (MDA, 2014). Esse objetivo deve ser alcançado seja por meio da atuação direta de técnicos qualificados junto às famílias para crescentes melhorias da produção rural ou pela construção de cadeias produtivas que garantam a inclusão dos agroextrativistas com mais valorização dos 
produtos e das práticas tradicionais, assegurando ainda a conservação ambiental.

Observamos que a modernização dos serviços de extensão rural, na perspectiva de promover a agricultura familiar com fins de conservação ambiental, se insere no rol de reordenamentos das políticas que caracterizam a modernização conservadora das perspectivas de desenvolvimento para a Amazônia e não alteram as estruturas geradoras da desigualdade social, mas se redirecionam para as vias produtivas. Dessa maneira, são agora voltadas a um modelo produtivista agroecológico (WANDERLEY, 2011), que tem nos serviços ambientais, na produção de base familiar e tradicional, na pluriatividade do trabalho e na renda no meio rural as formas dialéticas e potencializadas de exploração e subordinação do trabalho, bem como de concentração de propriedade, escamoteando as questões que permeiam e perpetuam a pobreza rural.

Neste estudo, essas questões emergem através da reprodução e reestruturação das relações de poder, caracterizadas em seus elementos materiais e simbólicos pela construção histórica do território de Lábrea e expressam os conflitos socioambientais entre as famílias agroextrativistas e os que exercem o poder político e econômico na região. Esse cenário é visto na renovação do sistema de escravidão pela dívida nos grandes e pequenos comércios e é viabilizado pelo acesso ao crédito ou garantia de pagamento, por meio de recursos das políticas sociais. Além da concentração de propriedade que se relaciona também ao domínio de mercado, dificultando a inclusão dos produtos agroextrativistas numa cadeia produtiva em que os esses possam ser economicamente valorizados.

A valorização econômica dos produtos da agricultura familiar e tradicional, assim como os produtos agroextrativistas, de que trata o estudo, se apresenta como um princípio complexo na promoção da inclusão produtiva das famílias nas Unidades de Conservação. Isso porque, a noção de território e territorialidade adotada pelas políticas governamentais ${ }^{6}$ se diferencia da adota pelos

\footnotetext{
${ }^{6}$ Castro (2012) enfatiza que a lógica das políticas governamentais concebem o território como espaço desconectado de valores e tradições, sendo gerido apenas por relações econômicas e políticas em que o tempo e o espaço devem
}

povos tradicionais da Amazônia. Nesse contexto, conforme Castro e Pinton (1997), para os povos tradicionais a construção de um território é regida por uma ordem social de tempo e espaço que legitima o direito de posse e acesso aos recursos naturais pelo trabalho, ancorado no mundo da vida e da cultura e não mediatizado pelo mercado, de modo que se realiza por meio do controle do uso dos recursos naturais e a partir de sua disponibilidade no tempo.

Assim, as estruturas produtivas requeridas pelas políticas de mercado não encontram consonância com a dinâmica produtiva tradicional. Os diferentes projetos de desenvolvimento inseridos nessa perspectiva de conceber os territórios como mercados implicam processos de construção de diferentes territorialidades e territorializações. A ruptura com as raízes culturais e tradicionais se apresenta como um desafio para as empresas agroindustriais e até mesmo para o Estado, uma vez que as políticas favorecem o mercado industrial (CASTRO, 2012, p. 48)

Diante disso, o serviço da ATER busca promover a inclusão de técnicas científicas comprovadas para potencializar a produção agrícola e assim materializar a tentativa de homogeneizar e dominar o modo de produção familiar. No entanto, também capacita os agricultores familiares, a fim de adequá-los à nova economia de produção agrícola, cujo principal objetivo é o de abastecimento interno do mercado, além de transformar os conhecimentos tradicionais dos povos em serviços de grandes possibilidades à produção de commodities com facilidade de escoamento para o mercado mundial (CASTRO, 2012)

Na proposta do Plano Brasil sem Miséria, a integralidade das ações para inclusão produtiva pressupõe a operacionalização das ações de forma paralela, para garantir a sua eficiência. Entretanto, conforme Castro (2012), a integralidade das políticas governamentais atuais se realiza a partir de sua uniformidade com o projeto de desenvolvimento nacional e internacional que visa a acumulação do capital.

Segundo Mello (2014), o acompanhamento por meio do serviço da ATER junto às famílias é constituído por visitas individuais e

ser aproveitados ao máximo pelos sistemas produtivos. 
atividades coletivas, também prevê a elaboração de um projeto produtivo de acordo com a realidade, potencialidade e necessidade de cada família ou comunidade. Essas medidas devem ser realizadas por equipes multiprofissionais, a partir de um cronograma de atividades, no qual está previsto o diagnóstico inicial e a elaboração de estratégias de avanço do projeto para aumentar a capacidade produtiva das famílias. Até o fechamento dessa pesquisa, esse serviço não tinha sido prestado por meio dessas estratégias, como descrito também nas narrativas, resumindo-se à distribuição de sementes e abordagens educativas de transmissão de conhecimentos.

Nesse contexto, verifica-se que o PBV e os demais programas de cunho socioambiental cometem erros comuns, principalmente no que se refere à capacidade de articular e integrar, de forma efetiva o investimento financeiro, capacitação e educação dos povos tradicionais em conjunto com a valorização e potencialização de seus conhecimentos. Dessa maneira, há dificuldades para promover as ações de qualificação e de conservação nos ecossistemas, uma vez que o PBV não permite o protagonismo dos usuários e não considera as relações comerciais estabelecidas nas regiões.

Uma das principais perspectivas apresentadas pelas famílias agroextrativistas em relação ao PBV foi quanto à possibilidade de capacitação e o acompanhamento profissional para melhor desenvolverem suas atividades agrícolas. Os agroextrativistas acreditam que a capacitação voltada para a realidade de seus modos de produção, articulada ao Programa Bolsa Verde permitiria uma melhor valorização de seus produtos, especialmente no que se refere ao cultivo do feijão, produto de maior capacidade comercial na comunidade Cassianã.

Verifica-se então que a dinâmica com que as ações são desenvolvidas no âmbito da promoção da inclusão produtiva não atende aos interesses das famílias agroextrativistas, por não produzirem melhorias no processo trabalho e na qualidade de seus produtos. Ademais, as famílias desenvolvem seu trabalho agrícola a partir de relações coletivas, enquanto o Programa de Fomento realiza ações individualizadas como o incentivo ao crédito limitado que não permite a ampliação das relações coletivas de trabalho, uma vez que adquirir instrumentos e maquinários para mecanização de algum processo produtivo só e possível por meio dos financiamentos individuais e, frente ao alto valor dos equipamentos de maior capacidade produtiva, o credito disponível torna-se insuficiente.

Essa realidade retifica que o acesso às políticas de transferência de renda tem contribuído para o consumo em massa de mercadorias, no atendimento às necessidades primárias e não garante o direito efetivo a melhores condições ou mesmo o direito ao trabalho.

Esses argumentos sinalizam a complexidade de desenvolver uma agricultura sustentável no contexto das contradições da organização social do capitalismo brasileiro e suas incompatibilidades com a sustentabilidade social que se apresentam, principalmente, no âmbito da integração das políticas governamentais. Enquanto isso, as famílias agroextrativistas são submetidas à um processo de inclusão desigual no sistema produtivo rural. Pois, as propostas de conservação ambiental são aplicadas, erroneamente, sob a ideologia preservacionista, que impõe limites e proibições às atividades culturais e produtivas das famílias agroextrativistas, sem apresentar alternativas adequadas aos seus modos de vida pelo próprio desconhecimento da dinâmica de seus sistemas produtivos.

Martins (2002) recorda que os trabalhadores rurais possuem certa independência por serem donos de seus meios de trabalho e produtos, porém suas vidas estão residualmente articuladas à trama das relações do mercado, uma vez que necessitam vender os seus produtos, para que se tornem dinheiro. O autor ainda alerta que se o operário necessita produzir trabalho excedente na lógica do mercado, o trabalhador rural precisa ter produto excedente para ser inserido na mesma lógica. É nesse sentido, que as determinações econômicas impõem a produção de monoculturas, proletarizando o trabalho rural, - que resulta na divisão de trabalho no campo.

Observa-se que a inclusão das famílias aos mercados se dá por via dessa relação entre mercado e produto e, por meio dela, se estabelece a relação das famílias com o capital (MARTINS, 2002). O incentivo a essa relação é objetivado pelas ações engrenadas no Programa Bolsa Verde, por meio de sua 
articulação com o Programa de Aquisição de Alimentos (PAA), desenvolvido sob a responsabilidade do MDS.

O PAA visa a compra direta de produtos da agricultura familiar, dispensando procedimento licitatório pelas esferas dos estados e municípios para aquisição de alimentos destinados às ações de segurança alimentar e nutricional (Art. 16 e 18 da Lei $n^{\circ}$. 12.512 de 14/10/2011). Assim, forma as cadeias produtivas para inclusão da população rural no mercado que, conforme expressam as narrativas dos agroextrativistas, trata-se de uma ação ainda não desenvolvida no contexto da comunidade Cassianã.

O PAA foi regulamentado em 2003 para articular as ações de incentivo à produção agrícola familiar aos serviços assistenciais do governo. Em 2011 o Programa foi interligado ao PBV com objetivo de expandir os canais de comercialização da produção familiar e garantir que seja pago ao produtor um preço justo por sua produção, conforme a referência estabelecida regionalmente (SANTOS, 2015). A ação desse Programa ainda não alcançou as famílias da comunidade Cassianã diretamente, mas sim por meio da ASPAK, associação pela qual é realizada a comercialização do feijão.

Observa-se, desse modo, a ausência das ações do PAA na comunidade Cassianã, pois as famílias sinalizaram que, há mais de 5 anos, o preço do feijão comercializado para a associação continua o mesmo. Nesse sentido, confirmamos a análise de Noda (2012) acerca da situação da agricultura familiar na região do Purus e sua articulação com as políticas públicas:

A agricultura familiar nesta região não é apoiada de maneira eficaz pelas políticas públicas nem vista como uma forma sustentável de geração de renda e sobrevivência. As políticas de fomento à produção agropecuária tem incentivado a produção de malva, arroz e criação bovina, que representam modalidades de manejo desvinculadas dos ecossistemas associados e de sua dinâmica, sem considerar critérios de sustentabilidade ecológica, econômica e social. A existência de políticas agrícolas ineficientes, onde há falta de serviços de assistência técnica e extensão rural, problemas nos programas de financiamento e crédito, fazem com que os agricultores não melhorem suas condições de vida e muitas vezes contribuam inadvertidamente para acelerar processos de degradação ambiental. [...] As prioridades para a assistência técnica tem sido direcionadas para as áreas de terra firme. (NODA, 2012, p. 70)

A realidade descrita por Noda (2012) corresponde em muitos pontos àquela vivenciada pelas famílias na comunidade Cassianã, no que tange à agricultura familiar. Após a criação da Resex Médio Purus, as famílias viram chegar algumas políticas governamentais, às quais só os proprietários de terras tinham acesso, enquanto a maior parte da população era obrigada a desenvolver modos adaptativos de vida às margens dos rios. Porém, mesmo com maior alcance das políticas governamentais mediante sua estratégia de focalização, sua desvinculação das diversas realidades desses povos tornam frágeis as possibilidades de sustentabilidade para além da proteção ambiental.

Martins (2002) afirma que, no contexto de modernização do Estado, o mercado é usado para viabilizar a modernização das instituições políticas, visíveis na inauguração dos modelos de governança participativa. Nesse sentido, possibilita importante espaço para que, inseridos nas discussões, os verdadeiros movimentos sociais possam compreender o alcance das mudanças em processo.

Isso requer, dentre outros elementos, a construção da consciência social de classe e dos processos de qualificação e capacitação dos agroextrativistas com base política e crítica. Esse ponto de vista decorre da necessidade de reforma agrária para atender aos interesses dos agricultores familiares. Tal processo, porém, tem se mostrado complexo, pois o Estado vem promovendo a retomada do senhorio do território, devolvendo-o em forma de prestação de serviço à sociedade civil (MARTINS, 2002, p. 179), ao criar as áreas de proteção ambiental, contudo, sem possibilitar sua efetiva implementação sustentável, exercendo apenas o controle sobre $\mathrm{o}$ uso do território conforme seus interesses.

Nesse sentido, verificamos que a presença do Estado, a partir da criação da Resex Médio Purus vem consolidando as tendências do capitalismo contemporâneo à inclusão no mercado por meio do consumo em massa. No entanto, as ações para promover a sustentabilidade não se efetivam, pois apresentam resultados reduzidos, 
desarticulados e descontinuados nas dimensões ambientais, sociais e econômicas.

Como apresentado ao longo dessa pesquisa e tendo como referência a comunidade Cassianã, as atuais ações governamentais que visam a proteção ambiental na Resex estão longe de combater a degradação, devido, especialmente, à falta de fiscalização competente. A sustentabilidade social está sendo direcionada ao consumo, descaracterizando as conquistas da luta social dos agroextrativistas, o exercício de sua cidadania e as ações de viabilidade da sustentabilidade econômica tem se resumindo a distribuição precária de sementes e a distribuição do acesso ao crédito.

O acordo realizado entre a ATAMP e a ASPAK, apesar de aparentemente representar uma conquista da ATAMP para os produtores agroextrativistas, não se articula ao PAA ou outra política governamental de incentivo à agricultura familiar, mas, supostamente, com empresas e indústrias do agronegócio, para o abastecimento comercial das principais capitais da região como Manaus, Porto Velho e Rio Branco, o que torna ainda mais urgente uma ação de valorização dos produtos agroextrativistas frente à exploração de seu produto na atual cadeia produtiva.

Retomando as considerações de Santos (2015) sobre a inclusão produtiva proposta no PBSM, verificamos que o PBV articulado ao PFAPR e ao PAA como estratégia de integração política para promover a inclusão produtiva rural precisa qualificar suas ações e efetivar sua integração, estabelecendo um cronograma de atividades que permita a complementariedade das ações e não o seu isolamento.

O Programa Bolsa Verde se apresenta, então, a partir de um hibridismo de políticas de conservação ambiental, mínimos sociais e incentivo ao trabalho, que corresponde à lógica estratégica da política de governo engrenada no contexto da crise do capital e das mudanças na sociedade. Essas políticas públicas de abrangência social tendem a acentuar traços de improvisação e inoperância, com funcionamento ambíguo e impotência na universalização dos acessos a serviços sociais delas provenientes, permanecendo, assim, como políticas casuísticas, fragmentadas, sem regras estáveis e com risco de uma grave regressão de direitos sociais (YAZBEK, 2012, p. 31)
Acrescente-se ainda, a responsabilização por danos causados ao ambiente pelas instituições capitalistas às populações locais e povos tradicionais como detentoras, no caso da região amazônica, do título de "guardiãs da floresta".

Cabe destacar que, mesmo incorporadoras às lógicas e ideologias desenvolvimentistas governamentais, as políticas que se caracterizam por objetivos socioambientais, especialmente aquelas voltadas para Unidades de Conservação e de uso sustentável na Amazônia, expressam o processo de ambientalização das lutas políticas e sociais dos povos tradicionais, a partir da evidência dos conflitos socioambientais que permeiam a trama do jogo de forças pelo domínio dos territórios e dos recursos naturais.

Nesse processo, os povos tradicionais galgaram importantes espaços de participação democrática como forma de resistência à dominação do capital verde e garantia de vitalidade e significação de seus modos de vida.

Os desafios para garantia de melhorias na qualidade de vida e a oportunidade efetiva de exercer a cidadania, se apresentam aos povos tradicionais de formas complexas e diversas. Um desses desafios é superar a invisibilidade e o desconhecimento das experiências sociais e do campo de trocas, materiais e simbólicas que marcam as relações e a dinâmica da vida, a partir da relação entre os homens e a natureza em regiões e ecossistemas específicos (CASTRO, 2012).

O presente estudo buscou, não só possibilitar o conhecimento dessa realidade à academia e à sociedade, mas, a partir da evidência das implicações e das não implicações das políticas governamentais na vida das famílias agroextrativistas do Resex Médio Purus, ser mais um instrumento de lutas dessas famílias por acesso aos seus direitos de proteção social, trabalho digno, respeito cultural e equilíbrio ambiental, substanciadas em melhoria das suas condições de vida e como exercício de sua cidadania.

\section{CONSIDERAÇÕES FINAIS}

A noção de inclusão produtiva incutida nas políticas socioambientais tem por objetivo potencializar a capacidade produtiva presente nas Unidades de Conservação de 
uso sustentável para disposição dos serviços ambientais no mercado internacional, uma vez que essa noção, construída historicamente e desenvolvida para atender aos ditames da economia globalizada, no contexto do enfrentamento da questão ambiental, visa maior integração econômica dos mercados.

Trata-se, portanto, de um conjunto combinatório de ideologias burguesas para cooptação e conformidade com a situação de pobreza perante a pauperização exponencial de milhares de brasileiros, posto que a manutenção da ordem capitalista, sem pobreza absoluta, deve se transformar no ideário social comum a todos.

Nesse contexto, evidencia-se que o Programa Bolsa Verde (PBV), como política compensatória de cunho socioambiental, é resultado da evidência dos conflitos socioambientais no contexto de resistência e luta política pelo território, ao mesmo tempo em que se apresenta como estratégia governamental inovadora para integração de políticas, com vistas ao desenvolvimento do país.

Como política socioambiental, O PBV apresenta equívocos conceituais $\mathrm{e}$ metodológicos. Conceituais, por mostrar-se, no discurso político, como política de pagamento por serviço ambiental (MMA, 2014; VIANA, 2014; VIANA 2013) sem, no entanto, esclarecer as condições e os atores envolvidos. A partir de suas características, o programa se aproxima conceitualmente, como política do tipo compensatória (PEREIRA, 2009), dos povos tradicionais, a fim de incentivar a conservação ambiental, a saída da situação de extrema pobreza, além de possibilitar o acesso a bens e serviços para potencializar sua capacidade produtiva e inserção nos mercados.

Metodológicos, porque, apesar de teoricamente estar integrado a outros programas e ações governamentais e à estratégia de focalização que determina a seleção para o atendimento no PBV, as ações não se articulam no tempo e no espaço. O acesso aos meios produtivos, como abastecimento de água e energia elétrica, para possibilitar a viabilidade de sistemas de produção sustentáveis também se encontram desarticulados às ações do PBV, assim como às políticas públicas redistributivas de garantia dos direitos sociais, além da transferência de renda.
Esses equívocos dificultam a própria compreensão acerca do PBV e sua implementação, pois suas condicionalidades são disseminadas sob a perspectiva preservacionista. No âmbito da Resex Médio Purus, o PBV é operacionalizado pelos próprios agroextrativistas que desenvolvem a gestão da Resex, ocupando cargos de gestores e conselheiros e passam a ser incumbidos da vigilância e controle do uso dos recursos naturais da Resex, mediante o cumprimento do Plano de Utilização com poucos recursos. A isso, soma-se um mercado local pautado na exploração indiscriminada dos recursos naturais, dificultando a compreensão e a viabilidades de usos manejados, inerentes ao modo de vida dos povos residentes nas Unidades de Conservação de Uso Sustentável.

Desse modo, a efetiva implementação da Resex e a construção de seu Plano de Manejo ainda se encontra em processo de elaboração e torna permanente a luta dos agroextrativistas pelo domínio do território, evidenciando conflitos internos e externos à Resex, mediante a ausência de fiscalização efetiva pelas instituições competentes do Estado, relegando essa responsabilidade às famílias agroextrativistas.

O atendimento do PBV às famílias agroextrativistas da comunidade Cassianã apresenta limites e possibilidades, verifica-se que o acesso à renda por meio do Programa contribui significativamente para o sustento e sobrevivência material das famílias. O recurso permite a ampliação do acesso ao mercado na compra de bens materiais e alimentícios de necessidades primárias. Porém, pouco contribui para a qualificação das atividades produtivas desenvolvidas pelas famílias, através da agricultura, pesca e extrativismo, uma vez que as ações de fomento viabilizadas pelo Programa de Fomento às Atividades Produtivas Rurais ainda são incipientes, inadequadas e se resumem ao acesso ao crédito individual e à distribuição de sementes sem o devido acompanhamento, sendo as ações de Assistência Técnica de Extensão Rural pouco viabilizadas no processo de qualificação do sistema produtivo agroextrativista, além de não atender à diversidade das atividades produtivas desenvolvidas pelas famílias.

A construção de cadeia produtiva, por meio de aquisições e inclusão dos produtos agroextrativistas, numa relação de comercialização favorável para as famílias, 
ainda apresenta-se distante e constitui um grande desafio para o Programa de Aquisição de Alimentos, diante da forte rede de comercialização instituída em Lábrea, que culturalmente demanda a exploração intensiva dos recursos naturais presentes na Resex Médio Purus.

Nesse sentido, o incentivo à conservação ambiental, promovido pelo PBV e seus programas correlatos, tende a individualizar as relações sociais, em detrimento do fortalecimento da coletividade e da solidariedade das relações sociais dos ecossistemas amazônicos. Pois, tais programas desenvolvidos e implementados no contexto da crise e das mudanças atuais da sociedade, sem regras estáveis, com funcionamento ambíguo e inoperante apresentam-se como regressão dos direitos sociais e das lutas sociais dos povos tradicionais pela visibilidade das particularidades dos modos de vida e produção. A cidadania desses povos tem sido negada nos contextos locais e nacionais e o seu reconhecimento requer o atendimento às suas particularidades sociais, políticas, econômicas e culturais.

Por fim, é importante sinalizar que a construção de políticas socioambientais de caráter compensatório, tais como o Programa Bolsa Verde precisam não só estar integradas institucionalmente, mas também estar temporalmente articuladas à ampliação do acesso às políticas públicas adequadas às realidades vivenciadas pelos povos tradicionais. Para isso, o programa precisa possibilitar que os agroextrativistas sejam ouvidos e suas reinvindicações consideradas nas tomadas de decisões.

\section{REFERÊNCIAS}

[1] Bardin, L. Análise de Conteúdo. Lisboa: Edições 70, 1977.

[2] Becker, Bertha K. Amazônia: geopolítica na virada do III milênio. Garamond. Rio de Janeiro, 2005.

[3] Brasil. Decreto n. 7.572, de 8 de setembro de 2011. Regulamenta dispositivos da Medida Provisória no 535, de 2 de junho de 2011, que tratam do Programa de Apoio à Conservação Ambiental - Programa Bolsa Verde. Disponível em http://www.planalto.gov.br/ccivil_03/_Ato20112014/2011/Decreto/D7572.htm. Acesso: 20/10/13.

[4] Brasil. Ministério do Meio Ambiente. Programa de Apoio à Conservação Ambiental Bolsa Verde: erradicar a extrema pobreza e
Nesse sentido, é necessário ainda que as políticas socioambientais permitam, por meio de uma metodologia criativa, identificar os conflitos socioambientais e ampliar as negociações. Criar novas políticas e adequar as já existentes às realidades e territorialidades desenvolvidas pelos povos tradicionais da Amazônia. Isso requer ousadia e fortalecimento da luta desses povos para que sua cidadania amadureça, amplie e, enfim as famílias agroextrativistas possam ter acesso à melhores condições de vida.

De certo, a emergência e o alcance das políticas de caráter socioambiental já são conquistas de suas lutas, cabe agora ao poder público efetivá-las de maneira adequada e para além da legalidade, ampliando as condições e as possibilidades de autonomia na gestão da Resex Médio Purus, não apenas como repasse de responsabilização aos agroextrativistas por meio de sua institucionalização, mas com os efetivos e necessários recursos estruturais, materiais e humanos.

A análise dessa realidade nos permitiu verificar que ainda há muitos aspectos a serem pesquisados, a fim de contribuir para a construção de uma cadeia produtiva que contribua para o manejo dos ecossistemas de uma Resex, pois a diversidade das relações sociais e do sistema de produção e trabalho ali presentes são processos em permanente construção que, por meio da dinâmica de conflitos socioambientais, unem memórias do passado, divergências do presente e perspectivas de um futuro sustentável.

conservar o meio ambiente, histórico, gestão e monitoramento, balanço geral. Disponível em http://www.mma.gov.br/estruturas/201/_arquivos/ap resentao_bolsa_verde_201.pdf. Acesso em 10/03/2015

[5] Castro, Edna; Pinton, Florence. Faces do trópico úmido: conceitos e novas questões sobre desenvolvimento e meio ambiente. Belém: Cejup: UFPA-NAEA, 1997

[6] A expansão da fronteira: megaprojetos de infraestrutura e integração sul americana. Caderno $\mathrm{CRH}$. Salvador, v. 25, n. 64, p, 45-61, jun/abr 2012;

[7] Diegues, Antônio C. Santa. O mito moderno da natureza intocada. São Paulo: Hucitec; 
Núcleo de Apoio à Pesquisa sobre Populações Humanas e Áreas Úmidas Brasileiras, USP, 2004.

[8] Foucault, Michel. Vigiar e Punir: nascimento da prisão. Trad. Lígia M. Ponde Vassalo. Petrópolis: Vozes, 1993

[9] Lustosa, Maria das Graças Osório P. Reforma agrária à brasileira: política social e pobreza. São Paulo: Cortez, 2012

[10] Martins, José de Souza. A sociedade vista do abismo: novos estudos sobre exclusão, pobreza e classes sociais. Petrópolis, RJ: Vozes, 2002.

[11] Mello, Neli Aparecida de. Políticas Territoriais na Amazônia. São Paulo: Annablume, 2006.

[12] Mota, Ana Elizabete (org.). Desenvolvimentismo e construção da hegemonia: crescimento econômico e reprodução da desigualdade - São Paulo: Cortez, 2012.

[13] Noda, Sandra do Nascimento; NODA, Hiroshi et all. Arranjos e usos dos recursos naturais na agricultura do povo Deni. In: revista Tellus, ano 3, n. 4, p. 37-55, abril de 2003, Campo grande MS. Disponível em: http://www.tellus.ucdb.br/index.php/tellus/article/vie w/61. Acesso em 12/01/2016.

[14] Pereira, P. A. P. Necessidades humanas: subsídios à crítica dos mínimos sociais. São Paulo: Cortez, 2007.

[15] Discussões conceituais sobre política social como política pública e dirieto de cidadania. IN Boschetti, Ivanete (org). Política social no capitalismo: tendências contemporâneas. 2 ed. São Paulo: Cortez, 2009.

[16] SANTOS, Laura Meneghel dos. Inclusão produtiva no combate à pobreza: possibilidades e limites do Plano Brasil Sem Miséria. Dissertação de Mestrado apresentada ao Programa de PósGraduação em Políticas Públicas, Estratégias e Economia da Universidade Federal do Rio de Janeiro, 2015.

[17] Scheneider, Sergio; Fialho, Marco Antônio Verardi. Pobreza rural, desequilíbrios regionais e desenvolvimento agrário no Rio Grande do Sul. Teoria e Evidencia Econômica, Passo Fundo - RS, v. 8, n. 15 , p. 117-149, 2000.

[18] Viana, Virgílio. Bolsa Floresta e Bolsa Verde: diferenças, semelhanças e desafios. In: Revista Virtual Página 22. Julho,2011. Disponível em:

http://www.pagina22.com.br/index.php/2011/10/bol sa-floresta-e-bolsa-verde-semelhancas-diferencase-desafios/. Acesso em: maio de 2013.

[19] Viana, João Paulo. Dois anos de Bolsa verde: seria uma meta alcançável? In: 2017 texto para discussão do Instituto de Pesquisa Econômica Aplicada- Brasília. Rio de Janeiro: IPEA, 2014.

[20] Wanderley, Maria de Nazareth Baudel. Um saber necessário: os estudos rurais no Brasil. Campinas: Unicamp, 2011. 152 p. 


\title{
BAPÍTULO 14
}

\section{OBSERVATÓRIO DA EDUCAÇ̃O DO CAMPO NO ALTO SOLIMÕES - OBECAS: DA IMPLEMENTAÇÃO AOS PRIMEIROS RESULTADOS}

\author{
Jarliane da Silva Ferreira
}

Maria Auxiliadora dos Santos Coelho

Eu quero uma escola do campo que tenha a ver com a vida, com a gente querida e organizada e conduzida coletivamente; Eu quero uma escola do campo que não enxergue apenas equações que tenha como "chave mestra" o trabalho e os mutirões; Eu quero uma escola do campo que não tenha cerca, que não tenha muros, onde iremos aprender a sermos construtores do futuro; Eu quero uma escola do campo onde o saber não seja limitado, que agente possa ver, o todo e possa compreender os lados; Eu quero uma escola do campo onde esteja o ciclo da nossa semeia, que seja como a nossa casa, que não seja como a casa alheia. (Letra da música- Construtores do Futuro/Gilvan Santos)

Resumo: Nos últimos anos, avanços foram verificados no campo das políticas públicas e de pesquisas nas universidades que focalizam como objeto de estudo a educação em contextos rurais, formação do educador do campo, escolas multisseriadas e afirmação cultural dos grupos sociais que habitam a área rural do país. Um dos exemplos é a criação de vários observatórios que possibilitam a inserção da temática da nova política da educação do campo, bem como o conhecimento da realidade da educação escolar desenvolvida em contextos rurais/ribeirinhos. Assim, surge a proposta de criação do Observatório Educação do Campo no Alto Solimões, como um programa, envolvendo extensão e pesquisa, implementado desde 2014, no âmbito da PROEXTI, com apoio financeiro, no ano de 2014, do MEC/SEsu. O programa visa a consolidação deste observatório por meio de ações e discussões que favoreçam a formação/ assessoramento participativo aos professores rurais, bem como a implementação da Educação do campo no Alto Solimões. A metodologia adotada é pautada na pesquisa-ação, por meio de reuniões e encontros interdisciplinares; formação continuada com professores do campo; oficinas pedagógicas; seminários ou fóruns; diagnósticos participativos. As temáticas guardam coerência com os princípios da indissociabilidade entre Ensino, Pesquisa e Extensão e da interdisciplinaridade, conforme pressupõem os Projetos Pedagógicos dos Cursos - PPC's e o PDI da UFAM. Assim, o presente artigo focalizará apenas as diretrizes e princípios da execução do programa, historicizando brevemente a implementação do programa, seus objetivos e os primeiros resultados.

Palavras-chave: Observatório. Educação do Campo. Alto Solimões. Primeiros resultados. 


\section{INTRODUÇÃO}

O programa Observatório da Educação do Campo no Alto Solimões surgiu como uma proposta que objetivou, dentre outros aspectos, desenvolver estudos visando superar a escassez de produções acadêmicas acerca da educação do campo no Alto Solimões; e promover ações compartilhadas com profissionais da educação básica que atuam em escolas rurais, por meio de metodologias participativas na região (FERREIRA, 2014).

Entende-se que são lacunas a serem preenchidas, pela possibilidade de revelar dados, de problemáticas existentes que precisam ser compreendidas, diagnosticadas e superadas mediante a implementação de políticas públicas de qualidade. Isso significa conjugar esforços que obriguem o Estado a assumir seu papel tanto de garantir a equidade, quanto de reafirmar o direito público subjetivo dos cidadãos no processo de desenvolvimento do ensino com qualidade social, nos espaços rurais e urbanos da região.

O interesse em educação do campo foi impulsionado por mais de uma década a partir de vivências e estudos de temática referentes ao contexto em questão. Inicialmente, deve-se computar a participação em projetos pastorais da Igreja católica em comunidades rurais. Além dessas experiências conta também a atuação profissional como professora da zona rural e coordenadora de programas de formação de professores rurais nos municípios de Benjamin Constant, Atalaia do Norte e Santo Antônio do Içá, no Alto Solimões. A partir dessas experiências realizou-se a pesquisa no mestrado em educação, cujo objeto de estudo referiu-se a formação de professores e currículo em escolas rurais/ribeirinhas. Atualmente, dá-se continuidade a produção de conhecimento a partir desta temática, também no âmbito do Doutorado.

Cabe salientar que a formação da equipe de execução do programa pauta-se na possibilidade de trabalho acadêmico interdisciplinar, desenvolvendo atividades de ensino, pesquisa e extensão relacionadas às temáticas propostas. Logo, a proposta caracteriza-se por ser interdisciplinar dada a experiência e formação da equipe de trabalho. São profissionais da área da Educação, Ciências Agrárias e Letras, envolvendo ainda outras instituições parceiras neste processo. ${ }^{7}$

Atualmente a educação do campo vem sendo regulamentada no âmbito das políticas públicas e discutida em instituições de ensino superior do país. Nesse processo, surgem novas concepções de educação que (re) conhecem a historicidade, identidade étnica, educação escolar diferenciada e afirmação e pluralidade cultural dos grupos sociais que compõem o campesinato brasileiro.

Nesse sentido, as novas concepções de educação para os contextos rurais têm superado perspectivas autoritárias, ruralistas graças aos vários movimentos sociais os quais têm assumido como bandeira de luta a educação voltada aos interesses e ao desenvolvimento sociocultural e econômico dos povos que habitam e trabalham no meio rural (FERREIRA, 2010).

Apesar destes progressos, de forma contraditória, no chão desses espaços ruraisconstituído por populações que vivem e trabalham ao longo dos rios, igarapés, assentamentos, florestas, várzeas, terrasfirmes - na maioria das vezes ainda prevalece o tratamento periférico dado historicamente às pessoas que aí sobrevivem. Pesquisas e estudos são realizados mostrando índices que demonstram a negação do pleno usufruto dos direitos conquistados constitucionalmente pelos sujeitos desses contextos, dentre os quais o direito à educação significativa e de qualidade.

A região do Alto Solimões, constituída por nove (09) municípios, configura-se como um dos espaços de negação desse direito. Esta região apresenta índices preocupantes

\footnotetext{
${ }^{7}$ No ano de 2014 o diagnóstico participativo foi em parceria com a ISCOS. No I Seminário realizado em 2015 pode-se firmar parceria com várias instituições como: Universidade Federal do Para (UFPA), Empresa Brasileira de Pesquisa Agropecuária (EMBRAPA), Fundacion Caminos de Identidad (FUCAI), Universidade Nacional da Colômbia (UNAL), Instituto de Desenvolvimento Agropecuário e Florestal Sustentável do Amazonas (IDAM), Associação para o desenvolvimento agrosustentavel do Alto Solimões (AGROSOL), secretarias municipais de Atalaia do Norte, Tabatinga, Amaturá, São Paulo de Olivença, Benjamin Constant. Foi importante ainda a contribuição do Instituto Federal de Educação, Ciência e Tecnologia do Amazonas (IFAM) e do Projeto de Desenvolvimento Sustentado do Alto Solimões (PRODESAS), em 2014, na capacitação em georreferenciamento e agricultura familiar.
} 
retratando a ausência e pouca atuação do Estado na garantia de serviços sociais já conquistados. Por exemplo, o município de Benjamin Constant/AM apresenta Índice de Desenvolvimento Humano igual a 0,64, que comparado ao do país, retrata as condições precárias vivenciadas pelos cidadãos destas localidades. Apresenta o IDI-Índice de Desenvolvimento Infantil igual a 0,396 segundo os dados da UNICEF. Este dado reflete mais fortemente em áreas rurais do município que também possuem uma das maiores taxas de analfabetismo, dentre a população a partir de 15 anos (27,8\%), apresentando nota inferior a quatro pontos em muitas escolas públicas no Alto Solimões no ano de 2011.

Esses dados refletem as condições precárias em que os trabalhos pedagógicos são desenvolvidos, mostrando a necessidade de processos de formação continuada específica aos profissionais da educação que atuam em escolas rurais/ribeirinhas. Dessa forma, o projeto justifica-se pela escassez de extensões, pesquisas, publicações e trabalhos com professores, comunitários, por meio de metodologias participativas na região que envolva as temáticas da Educação do campo, escolas multisseriadas, metodologias e projetos pedagógicos próprios para atender as populações rurais da região.

\section{FUNDAMENTAÇÃO TEÓRICA}

\subsection{ALGUMAS CONCEPÇÕES EDUCAÇÃO DO CAMPO}

Os últimos anos do século XX e início do XXI são marcados principalmente por movimentos sociais que contestam as formas de dominação e lutam a favor de uma escola mais democrática e com qualidade social para todos. Exemplo dessas lutas tem sido efetivado pelas populações campesinas. Esses movimentos sociais; protagonizados pelos camponeses, intelectuais, pesquisadores do campo; têm implementado novas discussões acerca do papel da escola, o projeto pedagógico da Educação Básica e a formação de seus professores.

Neste contexto, considera-se que outros projetos e novos currículos sejam construídos e abertos à consciência de mudança. Esse movimento deve fortalecer a especificidade do direito à educação, garantindo que os sujeitos do campo tenham acesso aos conhecimentos produzidos historicamente e, sobretudo, acesso aos conhecimentos produzidos pelos movimentos sociais, possibilitando entender as formas de produção, as estruturas de poder, trabalho e resistência Isso significa pensar em outros currículos que fortaleçam as culturas, memórias, identidades, universos simbólicos dos educandos do campo, indígenas, quilombolas, trabalhadores da cidade (ARROYO, 2013). Os trabalhadores do campo sempre produziram, pela prática, os seus conhecimentos e, esses, não podem, simplesmente, ser desprezados pelo saber acadêmico e científico.

Nessa perspectiva, os processos de formação de professores e a própria escola não podem mais seguir perpetuando a velha e fraca educação rural ${ }^{8}$ (ARROYO, 2013). Esse antigo modelo, historicamente reproduzido no campo, já mostrou a que veio. Veio trazer constantes reprovações de estudantes do campo, veio inferiorizar as práticas e saberes do homem camponês, trouxe ideias presentes no ruralismo pedagógico e ainda desqualificou a vida no meio rural. Como sabemos na história da educação do país houve uma constante desvalorização do ensino no meio rural. Pesquisas mostraram que muitos professores que atuam em área rural têm baixa qualificação e salários inferiores aos da zona urbana, além de sobrecarga de trabalho, alta rotatividade e dificuldades de acesso à escola (ALMEIDA,

\footnotetext{
8 Nos estudos recentes há distinção acerca das concepções presentes na educação rural e a educação do campo. As concepções pautadas na educação dita rural há prevalência de precariedade no processo de manutenção e desenvolvimento do ensino. Já as concepções da nova política da educação protagonizado pelos movimentos sociais, defendem princípios e procedimentos para construir uma identidade das escolas do campo definida pela sua vinculação a questões inerentes à sua realidade, temporalidade, saberes próprios dos grupos socioculturais, memória coletiva, bem como à rede de ciência e tecnologia. (FERREIRA, 2010).

9 No entender de Calazans (1993), o ruralismo pedagógico utilizava a escola rural como um "aparelho educativo organizado em função da produção" (p. 26). Para Paiva (2003), "o ruralismo pedagógico foi a tentativa de fazer o homem do campo compreender o sentido rural da civilização brasileira e de reforçar os seus valores a fim de prendê-lo à terra; para tanto era preciso adaptar os programas e currículos ao meio físico e à cultura rural" (p. 137).
} 
2005; FERREIRA, 2010; BRASIL, 2015; AVELINO e FERREIRA, 2014).

O Instituto Nacional de Pesquisas - INEP realizou importante levantamento por região do país no qual demonstrou:

Apenas 21,6\% dos professores atuam no ensino fundamental de $1^{\underline{a}}$ a $4^{\underline{a}}$ série, têm formação superior, enquanto nas escolas urbanas esse contingente representa $56,4 \%$ dos docentes. O que é mais preocupante, no entanto, é a existência de 6.913 funções docentes sendo exercidas por professores que têm apenas o ensino fundamental e que, portanto, não dispõem da habilitação mínima para o desempenho de suas atividades. A maioria desses professores leigos atua nas Regiões Nordeste e Norte (INEP/MEC, 2007, p 35).

Os dados contidos no Plano Nacional de Educação (triênio 2011- 2020) mostram que a realidade de professores que atuam sem formação mínima para o exercício do magistério ainda é desafiadora. De acordo com o diagnóstico os Municípios, Estados e União, em regime de colaboração tem o prazo até 2020 para formar os profissionais da educação básica em nível superior e garantir que $50 \%$ estejam com pós-graduação lato e stricto sensu. Há muito o que fazer quando essa realidade mostra que dos 1.977.978 professores da Educação Básica de todo país, 12.480 tinham apenas o ensino fundamental e 139.974 tinham ensino médio. A mesma pesquisa mostrou que em 2007, $68 \%$ dos professores tinham nível superior e em 2008 este índice decaiu apresentando $67 \%$ de professores com formação em nível superior. Em 2009 a mesma porcentagem de $68 \%$ retorna (BRASIL, 2011).

Na região do Alto Solimões, a exemplo do município de Benjamin Constant (dados coletados no ano de 2014) esses dados também são preocupantes de 294 professores que atuam no campo, 203 trabalham em regime temporário e apenas 91 são efetivos mediante concurso público. Desse universo 104 são graduados; 66 têm formação em nível médio; 09 possui magistério; 19 são especialistas e 96 estão cursando graduação ${ }^{10}$.

10 Levantamento realizado pelo programa Observatório da Educação do Campo no Alto Solimões, em 2014, a partir dos documentos cedidos pela Secretaria Municipal de Educação.
Até quando a escola do campo será apenas uma escola agrícola e não necessariamente vinculada à cultura, à memória, luta, resistência e trabalho do povo campesino? (ARROYO, 2013). Como podemos perceber historicamente, a precariedade prevaleceu no processo de manutenção e desenvolvimento do ensino e implementação de políticas de formação e valorização de professores do campo. Essas discussões precisam avançar para além do debate teórico. Se assim seguir pode-se correr o risco de acumular análises de alta radicalidade política e teórica, continuar desenvolvendo um corpo avançadíssimo de reflexão política e, ainda permanecer nas fracas práticas pedagógicas em precárias escolinhas rurais, regida por um currículo pobre em conhecimento, cultura e medíocres em repassar habilidades primaríssimas de leitura-escrita, contas, noções de ciência (ARROYO, 2013).

\subsection{A ESCOLA DO RURAL/RIBEIRINHA E SEUS SUJEITOS}

As comunidades rurais são constituídas por sujeitos que têm suas vidas inseridas num modo peculiar de viver, trabalhar e construir saberes. Este modo de vida é marcado por uma cultura diferenciada, caracterizada principalmente pelo contato com as águas, terras e floresta (FERREIRA, 2010). São esses homens e mulheres que decidem o que manter, criar e desenvolver em cada ecossistema nos assentamentos rurais, por meio de um conjunto de recursos, técnicas e ricas estratégias (AMÂNCIO, 2000), eles são camponeses amazônicos possuidores de uma vasta experiência na utilização e conservação da biodiversidade e da ecologia dos ambientes onde vivem e trabalham (BARREIRA, 2007).

A implementação dos diversos programas/projetos são resultados das reivindicações de suas populações e de movimentos sociais organizados (Movimento Rural Ribeirinho, Organizações Indígenas Tikunas, Sindicatos de Pescadores, Madeireiros, Agricultores, Mulheres Indígenas, Associações de Professores, dentre outros) que lutam por melhores condições de vida. A exemplo dessas lutas está no campo da educação a partir da implantação de programas de formação de professores como Metodologia da Escola Ativa, Pró-várzea, dentre outros que contribuem para o fortalecimento da cultura do campo, respeito 
às formas de vida, produção, tecnologia e cultura, aumentado a possibilidade de continuidade de vida nestes contextos (FERREIRA, 2014).

Isto quer dizer que se trata de pensar a educação (política e pedagógica) desde os interesses sociais, políticos, culturais de um determinado grupo social; ou trata-se de pensar a educação (que é um processo universal) desde uma particularidade, ou seja, desde os sujeitos concretos que se movimentam dentro de determinadas condições sociais de existência em dado tempo histórico. A educação do campo assume sua particularidade, que é o vínculo com sujeitos sociais concretos, e com um recorte específico de classe, mas sem deixar de considerar a dimensão da universalidade [...] (CALDART, 2004, p. 17). A mesma autora discute que este momento é uma novidade histórica com a discussão e implementação da nova Política da Educação do Campo que representa a possibilidade efetiva dos homens e mulheres que residem e trabalham em espaços rurais assumirem a condição de sujeitos de seu próprio projeto educativo.

As Diretrizes Operacionais para a Educação Básica nas Escolas do Campo, 2008) estabelece princípios e procedimentos para construir uma identidade das escolas do campo definida pela sua vinculação a questões inerentes à sua realidade, temporalidade, saberes próprios dos grupos socioculturais, memória coletiva, bem como à rede de ciência e tecnologia, superando nessa perspectiva o ruralismo pedagógico.

No entanto, Victória (2008) acena em sua pesquisa que a cultura e 0 mundo rural/ribeirinho frequentemente, não é valorizada e nem consideradas no currículo escolar. O currículo das escolas ribeirinhas necessita contemplar elementos de compreensão dessa realidade. Trata-se de uma escola que tem suas diferenças, suas características, sua organização, suas marcas, e que precisa ser respeitada enquanto "escola que abriga um outro modo de viver as relações pedagógicas e cujo currículo precisa voltar-se para suas necessidades cotidianas" (p. 77).

Para o autor, as escolas rurais/ribeirinhas possuem "elementos importantes de cultura como a indígena e cabocla, que tanto têm a nos ensinar" (VICTÓRIA, 2008, p. 77). Para Santomé (1998), o mundo rural e ribeirinho costuma ser silenciado nas intenções e ações pedagógicas.

Uma característica da escola rural, segundo Souza (2005) é a forma diferenciada de organização do ensino, denominado sala multisseriada, com atuação de professores/as multidisciplinar; sem formação continuada específica para esta realidade; atuando em espaços inadequados, com escassez de materialdidático-pedagógico, enfrentando as idas e vindas dos fatores climáticos e a inviabilização de políticas públicas de valorização do magistério.

Nesse sentido, a realização de diagnósticos sócio-educacionais, assessoramento na elaboração de projetos pedagógicos e de produção de materiais didático envolvendo os interesses, conhecimentos, ciência e tecnologia das populações tradicionais, tornase essencial para a discussão "pró-educação ribeirinha" e a efetivação de uma política da educação do campo no Alto Solimões.

\section{METODOLOGIA DE TRABALHO}

O programa desenvolve suas ações com base na abordagem qualitativa (STAKE, 2011), na qual considera os seus sujeitos em seus reais contextos. Este tipo de abordagem embasam as atividades realizadas, pois, entendemos que todo o resultado depende de uma postura metodológica que considera os sujeitos, suas crenças, convicções, visões de mundo.

Assim, adota-se a metodologia da pesquisaação, a partir de instrumentos metodológicos já experienciados, possibilitando o envolvimento em processos de responsabilidades compartilhadas, promovendo a troca de saberes e experiências, pela participação sistemática dos sujeitos envolvidos.

As atividades incluem parceiros institucionais ligados ao trabalho participativo em comunidades rurais/ribeirinhas a fim de consolidar ações de formação/ assessoramento participativo a partir de realidades dos profissionais da educação do campo/ rurais-ribeirinhos que atuam nesses contextos diferenciados.

A metodologia da pesquisa-ação (THIOLLENT, 2007) adotada envolve o "diagnóstico participativo" (FERREIRA; SILVA, 2009) e após essa etapa são realizadas processos de formação continuada, por meio 
de oficinas pedagógicas multitemáticas para reflexão e assessoramento ao planejamento escolar e elaboração de projeto pedagógico próprio que atenda a realidade dos sujeitos que trabalham e residem no campo. Nesse processo, ainda é considerado a produção de materiais didáticos e sua aplicação no contexto das escolas multisseriadas, incluindo um amplo processo de análise, avaliação e assessoramento/ formação de professores na perspectiva participativa.

Como instrumentos de trabalho utiliza-se coleta de depoimentos, nos Grupos de Trabalho - GT's, nas próprias comunidades durante o desenvolvimento do diagnóstico participativo. Trabalha-se com cinco (05) GT: Educação; Saúde; Setor Primário; Cultura e Infraestrutura, a fim de coletar informações para posterior intervenção, conforme exposto no item seguinte.

\section{PRIMEIROS RESULTADOS:}

As atividades iniciaram-se no ano de 2014 no Instituto de Natureza e Cultura-INC/UFAM. Primeiramente foi selecionado um grupo de 10 (dez) bolsistas para o cumprimento da carga horária de 20 horas semanais. 0 processo seletivo se deu a partir de entrevista com base em documentos solicitados aos acadêmicos.

Os documentos foram histórico escolar, cópia dos documentos pessoais. $\mathrm{Na}$ entrevista foram levados em consideração aproximação temática da educação do campo, experiência na área e principalmente levou em consideração os marcadores sociais de diferença (etnia, classe social) e, dentre os grupos socialmente vulneráveis, priorizando estudantes indígenas e ribeirinhos.

Assim, foram selecionados dois bolsistas indígenas, dentre eles um ribeirinho residente em uma comunidade rural de Benjamin Constant.

Figura 1 e 2: Estudos nos Grupos de Trabalho- GT's, 2014 (Arquivo do OBECAS).
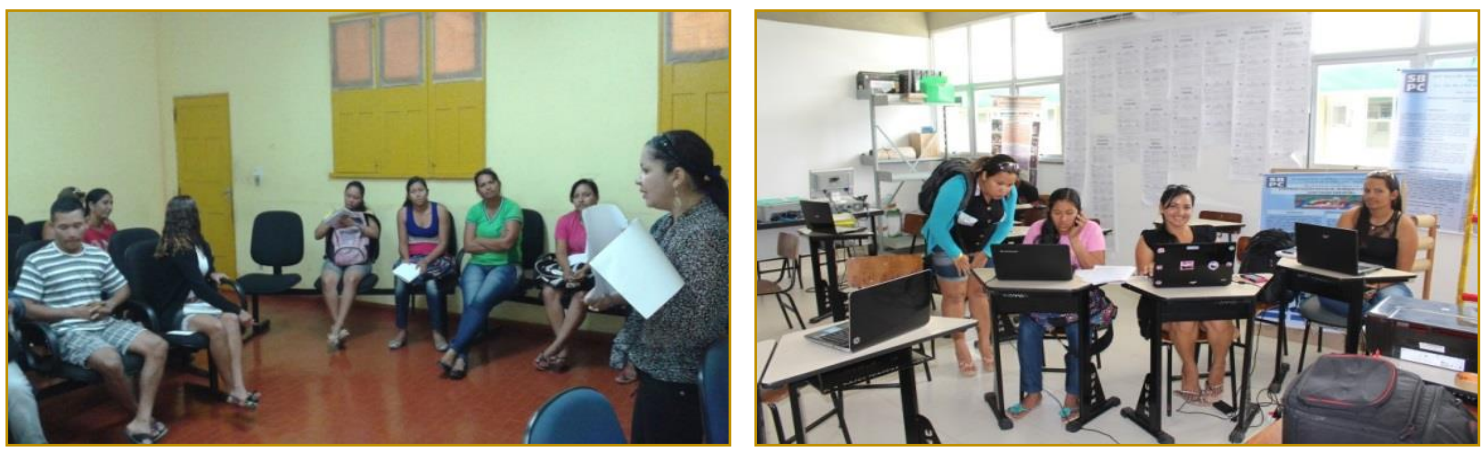

As atividades iniciaram-se com formação de grupos de estudos.

Foram inseridos inicialmente textos tais como: Diretrizes Operacionais da Educação do Campo (2001); Os sujeitos da Amazônia (FRAXE, 2007); Ecologia dos saberes (SANTOS, 2010); Movimentos sociais do campo e afirmação do direito a educação: pautando 0 debate sobre as escolas multisseriadas na Amazônia paraense (Hage, 2006).

O objetivo desta metodologia de trabalho, a partir de grupos de estudo, possibilitou a inserção da política da educação do campo, a partir da formação de uma equipe interdisciplinar com participação de professores dos diferentes cursos do INC e

ainda com participação de alunos também dos diferentes cursos. Nesse sentido formaram-se três grupos de trabalho GT- 01 . Projeto pedagógico e escolas do campo. 02. Educação multisseriada e formação de professores. 03. Educação, cultura e trabalho, e posteriormente com a inserção de dois novos professores do curso de Ciências Agrárias do INC foi criado o GT Agroecologia.

A fim de atingir objetivo de mapear e diagnosticar as escolas rurais dos municípios envolvidos na proposta elaborou-se um roteiro para buscar entender a realidade da educação escolar no espaço rural. Os municípios de Atalaia do Norte, Benjamin Constant e Tabatinga forneceram todos os dados solicitados para este primeiro trabalho de levantamento da área rural. 
Inicialmente esses dados foram quantitativos com base no roteiro: número de escolas da área rural; quantidade de escolas indígenas e não indígenas; localização; entidade mantenedora; número de alunos e professores; quantidade de turmas multisseriadas; formação de professores. A partir do roteiro cada GT foi encaminhado a um município para obter as informações a fim de conhecer a realidade da educação rural nos municípios do Alto Solimões, para a partir dessas informações fazer o planejamento para iniciar os trabalhos de campo. Os dados desse primeiro levantamento estão sendo sistematizados e analisados para posterior publicação.

Figura 3: Início das práticas de campo, 2014 (Acervo do OBECAS).

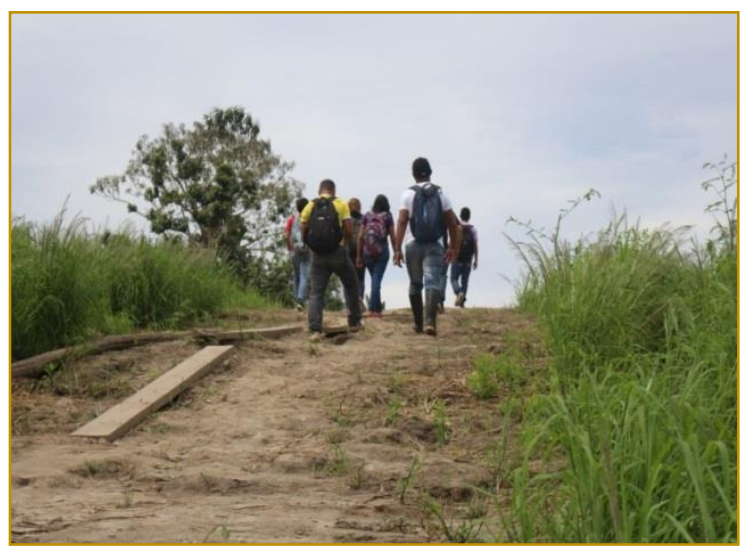

O trabalho de diagnóstico participativo foi realizado até 0 momento em duas comunidades ribeirinhas do Alto Solimões: uma pertencente ao município de Benjamin Constant e outra pertencente à Atalaia do Norte, esta última por ocasião da prática de campo organizada na disciplina Educação do Campo do Curso de Ciências Agrárias do INC.

A prática de diagnóstico participativo (FERREIRA e SILVA, 2009) já havia sido testada anteriormente em minicurso realizado no INC. Esta ação se mostrou eficaz para o desenvolvimento de trabalho coletivo, facilitando a articulação da academia e comunidade. Então, optou-se por realizar este trabalho antes de qualquer ação nas comunidades envolvidas. Este trabalho visa considerar o maior número de informações do local onde o programa se concentra a fim de subsidiar novas ações, principalmente a formação continuada de professores do campo em atenção à produção de materiais didáticos.

Antecipadamente foram lidos e discutidos textos para preparação às práticas como o texto de Carlos Rodrigues Brandão (2007) Reflexões sobre como fazer práticas de campo e o texto e Ver, ouvir e escrever de autoria José Cardoso de Oliveira (2000). Ainda nos concentramos em preparar um roteiro para as entrevistas semi-estruturadas para facilitar a coleta de dados nos grupos, além de disponibilizar TCLE- Termos de Consentimento para comunitários que aceitaram participar das ações desenvolvidas e gerar informações para o programa.

Assim, são formados cinco grupos de trabalho com relatores e animadores para coordenar os trabalhos. Neste processo organiza-se desde os equipamentos necessários à alimentação para a prática de campo. Para a realização das atividades do diagnóstico é necessário um conjunto de materiais que devem facilitar a ação: Kit pedagógico para diagnóstico participativo: papel cartão, papel madeira, pinceis, tesouras, barbante, cartolina. Equipamentos: data show, notebook, microfone, caixa amplificada, tarrafa, corda para dinâmica, CD músicas da Educação do campo, letras das músicas. Instrumento de coleta de dados: roteiro para Grupos de Trabalho (GT's: 1. Educação; 2. Saúde; 3. Setor primário; 4. Cultura e; 5. Infraestrutura) gravador de voz, filmadora. Kit oficina de desenho com as crianças "A escola do campo dos meus sonhos": pinceis, giz cera, papel A4, barbante, cola, tesoura.

Primeiramente, já na comunidade, organiza-se - grupão entorno de cinco eixos: 1. Educação; 2. Saúde; 3. Setor primário; 4. 
Cultura e; 5. Infraestrutura. Cada grupo tem em média duas horas para debater o tema, levantar problemáticas e potencialidades e registrar para posterior apresentação em plenária. Após os debates nos grupos é escolhido um ou dois representantes para exposição das questões levantadas no GT. Após as apresentações das problemáticas de cada GT uma equipe organiza todas os cartazes dos grupos em um espaço dedicado a esse momento denominado: "Nó das Lamentações", local onde agrupamos todos os cartazes com os pontos fracos de cada setor. É importante neste momento que cada grupo eleja como representante deles um morador da comunidade, possibilitando dar voz aos comunitários, importante para o seu processo de empoderamento.

Figura 4: GT expondo seu cartaz contendo as problemáticas, 2014 (Acervo do OBECAS).

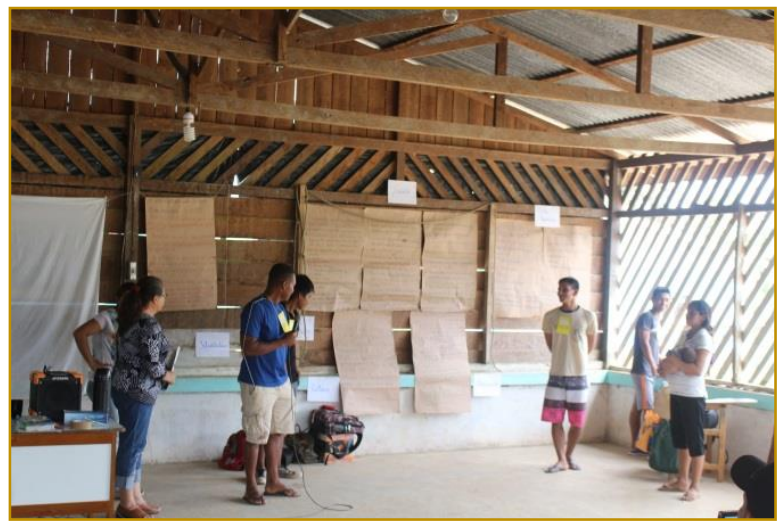

Após apresentações de todos os GT's é discutido possíveis alternativas como meio de superação das lamentações/ problemáticas citadas. Cada participante, neste momento, fica a vontade para expor suas ideias que é automaticamente registrada na "Tarrafa dos Sonhos da Comunidade". Essa dinâmica é interessante, pois todos têm a liberdade de colocar seus pensamentos dando sugestões.

Figura 5: Tarrafa dos sonhos, 2014 (Acervo do OBECAS).

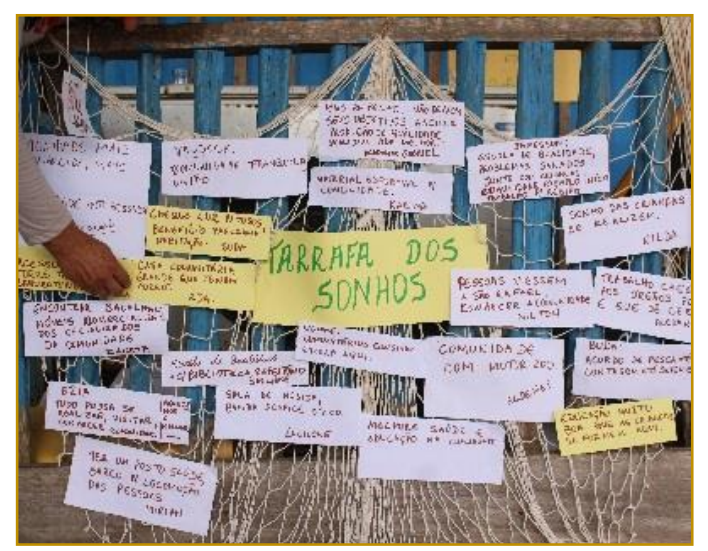

O grupo extensionista no momento do diagnóstico participativo precisa ter muita sensibilidade para saber até onde ir, pois este momento é forte na comunidade, expõe pessoas, pontos de vista, questões mal resolvidas. O jogo de poder, as opressões e as altas investidas de questões partidárias na comunidade são revelados, mostrando muitas mazelas e intrigas. É preciso saber lidar com estes riscos. Pois esse momento não pode ser mais um para contribuir para aumentar as problemáticas da localidade. O diálogo nesse momento deve ser claro, preciso e honesto, a fim de não criar falsas expectativas nos 
comunitários e tomar para o grupo questões que não poderá resolver, pois é muito comum, as populações rurais, pelo peso do esquecimento que historicamente sofreu, tender a esperar soluções de todos que ali forem realizar qualquer trabalho. Os objetivos da ação devem ser expostos de forma franca e clara a fim de não ser um impedimento para continuidade do trabalho.

No GT Educação reúnem-se integrantes na maioria professores, alunos, agentes pastorais e demais comunitários que se interessam e tenham envolvimento com o tema. De lá saem muitas questões com base em um roteiro que pode ser alterado: estrutura e infraestrutura escolar; recursos didáticos; formação de professores; alimentação e transporte escolar; conteúdos de ensino e outros.

No GT Saúde reuniram principalmente agentes de saúde, agentes pastorais, comunitários. Esse GT geralmente aponta para questões sobre a qualidade da água, esgoto sanitário, lixo, principais doenças que afligem a comunidade, posto de saúde, escassez de medicamentos, profissionais da saúde e deslocamento de doentes graves.

O GT Setor Primário aponta para as produções animal e vegetal e as dificuldades enfrentadas pela comunidade que vão desde a plantação ao escoamento, além de ausência de profissionais qualificados no acompanhamento às comunidades. O GT Cultura expõe sobre as datas comemorativas da comunidade, além das dificuldades em fortalecer a produção do artesanato. O GT Infraestrutura direciona as discussões para as condições das instituições mantidas na comunidade, como a escola, a igreja, a casa de farinha, casa de reunião e as condições de saneamento básico.

Resumidamente elencamos as primeiras ações desenvolvidas no programa entre os anos de 2014 e 2015:

- Realização do I Seminário da Educação do Campo no Alto Solimões, realizado em junho de 2015, com ampla participação da sociedade, movimentos sociais do campo, autoridades e professores do Alto Solimões, acadêmicos dos diferentes cursos do INC, comunitários das diferentes comunidades rurais/ribeirinhas. Assim, este seminário foi a possibilidade de implementação das concepções da nova política de educação do campo na universidade e região do Alto.

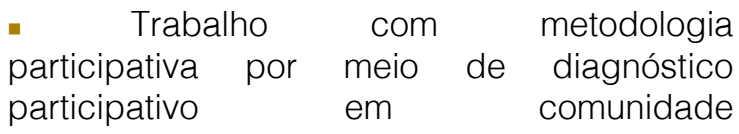
rurais/ribeirinhas;

- Processos de assessoramento/ formação de professores rurais: A I Formação Continuada de Professores do Campo, com o tema: "Planejamento e produção de materiais didáticos: reflexões e práticas a partir do chão da escola do campo", foi um momento significativo do OBECAS. A formação foi destinada a educadores que atuam em escolas rurais com classes multisseriadas do ensino fundamental. Contou com a forte participação de professores de diferentes comunidades, que reuniram durante uma semana na própria comunidade pólo de Guanabara III onde foi realizado o primeiro diagnóstico participativo do programa. Nesse sentido, a concepção do grupo é que não apenas coleta-se informações na comunidade e nada oferecem como retorno. Então, conforme foi apontado no diagnóstico, a ausência de formação continuada de professores é constante. Nesse sentido, o primeiro foco de ação priorizado pelo OBECAS foi a formação continuada de professores. Assim, a ação priorizou a produção de material didático a partir da realidade das populações do campo.

- Mapeamento da realidade da educação no meio rural em municípios do Alto Solimões: Articulação com as secretarias de educação dos municípios envolvidos para fins de levantamento de dados quantitativos acerca da educação do campo;

- Capacitação em georreferenciamento e agricultura familiar;

- Produção de artigos científicos e participação de alguns participantes em congressos em Rio Branco/AC, Manaus/AM e Santa Maria/RS. Apresentação dos primeiros resultados do OBECAS em eventos da região como Mesa Redonda do IFAM e INC.

\section{ALGUMAS CONSIDERAÇÕES:}

Assim, o programa implementado e em andamento converge com aquilo que 0 Projeto de Desenvolvimento Institucional da UFAM (PDI) enfatiza, pois assume uma tarefa histórica referente à criação de condições para produção de conhecimentos, materiais e metodologias diferenciadas que reconheçam as riquezas que advêm de ecossistemas, da sociobiodiversidade, mas, que considerem 
ainda os marcadores sociais de pobreza, violências, discriminações, desigualdades sócio educacionais apresentadas pelo IDH, IDEB.

As ações do programa refletem o grau de comprometimento de uma equipe de trabalho envolvendo professores, pesquisadores, alunos e voluntários externos à instituição que desbravaram comunidades distantes das sedes de seus municípios. Um grupo que vivenciou a subida e descida das águas, acompanhou o cotidiano de escolas por meio de observações participantes, uma equipe que pode constatar as precariedades de uma educação escolar que solicita auxílio, acompanhamento e sobretudo fiscalização, por exigir os direitos de uma população infantil que tanto espera de uma dívida social e pedagógica histórica (FERREIRA E COELHO, 2015).

Um grupo que viajou por beiradões, em canoas, barcos de linha e viu, ouviu e escreveu sobre os anseios e potencialidades das populações que sobrevivem e trabalham em espaços das florestas, das matas, dos igarapés, lagos, terra firme, assentamentos da região. Ouviu grupos de crianças que com seus desenhos mostraram a escola de seus sonhos, solicitando aquilo que é direito, uma escola com mínimo de qualidade em sua infraestrutura, como condições de ter um banheiro, refeitório, água potável, energia elétrica e principalmente uma escola que Ihes

\section{REFERÊNCIAS:}

[1] ALMEIDA, Dóris Bittencourt. A educação rural como um processo civilizador. In: Histórias e Memórias da Educação no Brasil. vol. III: Século XX. Petrópolis, RJ: Vozes, 2005.

[2] AMÂNCIO, Robson. Gestão em assentamento e poder público. Lavras: UFLA/FAEPE, 2000.

[3] ARROYO, Miguel G. Os Movimentos sociais e a construção de outros currículos. Educar em Revista (Impresso), v. 55, p. 47-68, 2013.

[4] BARREIRA, César. Prefácio. In: WITKOSKI, Antônio Carlos. Terras, florestas e águas de trabalho: os camponeses amazônicos e as formas de uso de seus recursos naturais. Manaus: Editora da Universidade do Amazonas, 2007.

[5] Diretrizes Complementares para a Educação Básica nas Escolas do Campo. Conselho Nacional de Educação/Câmara de Educação Básica. Brasília, 2008. dê possibilidade de continuidade em seus estudos em sua própria comunidade. Uma equipe que viu sorrisos, tristezas, descontentamentos, esperanças de dias melhores, e que luta por uma educação que respeite a cultura, as tradições, os saberes, os modos de produção, os rios de um povo que vive em contextos rurais amazônicos.

Nesse sentido, o grupo percebe o grau de interesse dos comunitários e necessidade de continuar com as ações vinculadas ao programa principalmente com realização de diagnósticos participativos a fim de entender e propor novas atividades e parcerias, mesmo que o programa não tenha tido aprovação de recursos para sua execução para o ano de 2015, continuou realizando suas ações.

Porém, ainda é muito a ser feito, considerando a natureza da proposta apresentada e a vastidão do campo da educação do campo no Alto Solimões, prioriza-se para esta nova etapa ciclos de palestras envolvendo a temática, bem como continuidade nos grupos de estudo em educação do campo. O grupo se propõe a continuar realizando os diagnósticos participativos nas comunidades rurais dos municípios, ampliando para outras comunidades e outros municípios. Espera-se realizar novas ações com base nos objetivos propostos e em atenção aos interesses dos povos do campo, além de poder cativar novos profissionais extensionistas e pesquisadores preocupados com a temática apresentada.

[6] Diretrizes Operacionais para a Educação Básica nas Escolas do Campo. Conselho Nacional de Educação/Câmara de Educação Básica. Brasília, 2001.

[7] PNE: Triênio 2011- 2020. MEC, 2011

[8] Instituto Nacional de PesquisaINEP. MEC, 2007.

[9] MADALENA, M. M. R. Valorizar docentes para atuar no campo? Formação, luta e condições de trabalho em contextos rurais no município de Benjamin Constant. Trabalho de Conclusão de Curso. Orientação: Profa. Jarliane da Silva Ferreira, 2015.

[10] CALAZANS, Maria Julieta Costa. Para compreender a educação do Estado no meio ruraltraços de uma trajetória. In.: THERRIEN, Jacques e DAMASCENO, Maria Nobre (Coord). Educação e Escola no Campo. Campinas: Papirus, 1993.

[11] CALDART, R. S. Elementos para a construção do PPP da Educação do campo. IN: 
Por uma educação do campo: contribuições para a construção de um projeto de educação do campo. Vol. 5. Brasília, 2004.

[12] FABRÉ, Nidia Noemi, et AL (Org.). Sociobiodiversidade e conservação da várzea amazônica. Manaus: PYRÁ, 2007.

[13] FERREIRA, Jarliane da Silva. E o rio, entra na escola? Cotidiano de uma escola ribeirinha no município de Benjamin Constant/AM e os desafios da Formação de seus Professores. (Dissertação de Mestrado em Educação)- Manaus: Universidade Federal do Amazonas, 2010.

[14] Proposta de Projeto apresentado a PROEXTI- MEC-Sesu, 2014.

[15] FERREIRA, J. S. SILVA, A. L. M da. Minicurso em Educação do campo e desenvolvimento sustentável. IN: Semana de atividades complementares do curso de Pedagogia do INC, 2009.

[16] FERREIRA, J. S.; COELHO, M. A. S. Relatório final do I Seminário de Educação do Campo no Alto Solimões: INC/UFAM. Benjamin Constant, 2015

[17] FRAXE, Therezinha J. P. Cultura cabocla ribeirinha: mitos, lendas e transculturalidade. São Paulo: Annablume, 2004.

[18] FRAXE, Therezinha J. P. Os sujeitos da Amazônia. IN: FRAXE, Therezinha J. P.; PEREIRA, H. S.; VITKOSK, A. C. (Orgs.). Comunidades ribeirinhas amazônicas: modos de vida e usos dos recursos naturais. Manaus: EDUA, 2007.

[19] HAGE, S. M. Movimentos sociais do campo e afirmação do direito a educação: pautando o debate sobre as escolas multisseriadas na Amazônia paraense. IN: Revista Brasileira de Educação, 2006.
[20] PAIVA, Vanilda. História da Educação Popular no Brasil: educação popular e educação de adultos. 6. ed. São Paulo: Edições Loyola, 2003.

[21] PAULA, M. D. A. FERREIRA, J. S. Educação do Campo no Alto Solimões: Um Estudo sobre a Política de Formação e Valorização de Professores que atuam em Comunidades Rurais/Ribeirinhas no Município de Benjamin Constant. Relatório Final do Programa de Iniciação Científica - PIBIC/UFAM, 2014

[22] SATKE, R. E. Pesquisa qualitativa: estudando como as coisas funcionam. Porto Alegre: Penso, 2011. p. 11- 45.

[23] SANTOMÉ, Jurjo Torres. Globalização e interdisciplinaridade: o currículo integrado. Trad. Cláudia Schilling. Porto Alegre: Editora Artes Médicas Sul Ltda., 1998.

[24] SANTOS, B. S. Ecologia dos saberes. IN: A gramatica do tempo: para uma nova cultura politica. 3. ed. são Paulo: Cortez, 2010.

[25] SOUZA, M. F. Currículo das águas: vida, escola e formação ribeirinha no município de Nova Olinda do Norte-AM. Dissertação de Mestrado no PPGE-UFAM, 2005.

[26] OLIVEIRA, R. C. O trabalho antropológico. 2. ed. Brasília: Paralelo 15; São Paulo: Editora UNESP, 2000.

[27] THIOLLENT. M. Metodologia da pesquisa ação. São Paulo: Cortez, 2007.

[28] VICTORIA, C. G. de. Desafios do cotidiano na formação e práxis dos educadores de uma escola ribeirinha no município do Carreiro-AM. Manaus: Dissertação de Mestrado- PPGE-UFAM, 2008 


\section{Bapítulo 15}

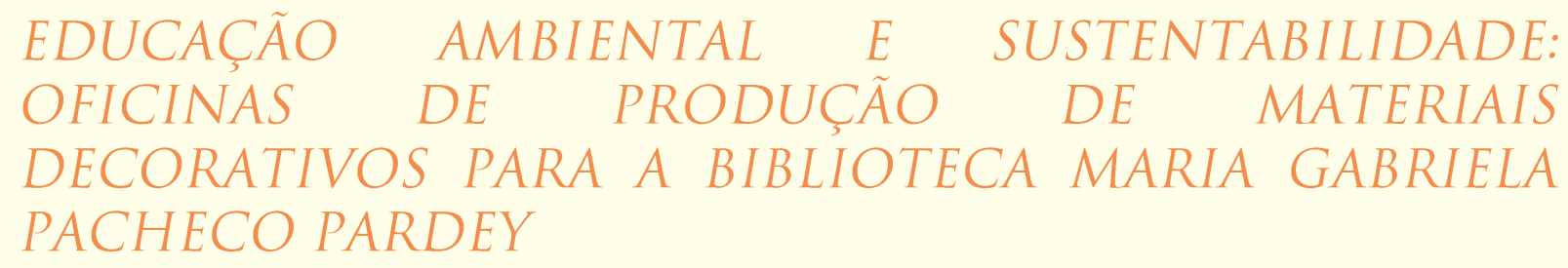

Maraína Souza Medeiros

Pedro Henrique Pereira e Moreira

Rosiane Gonçalves de Lima

Patrícia Michele Ribeiro

Resumo: Com o passar dos anos e o avanço tecnológico foi possível observar o quanto o ser humano tem interferido na qualidade do meio ambiente. Nesse sentido, muitos pesquisadores têm buscado meios para mitigar tais impactos ambientais, assim como dar um novo sentido aos resíduos sólidos urbanos descartados a princípio. Assim, neste trabalho objetivou-se promover a conscientização de alunos em uma palestra sobre Educação Ambiental (EA) e Sustentabilidade na Biblioteca Maria Gabriela Pacheco Pardey (IFG - Câmpus Itumbiara), e desenvolver oficinas para a produção de materiais decorativos a partir da reutilização de materiais coletados na instituição de ensino e doados pelos alunos. O projeto foi desenvolvido na Semana do Meio Ambiente e contou com a participação de 12 alunos inscritos, uma vez que no dia do evento estavam acontecendo outras atividades de cunho ambiental na instituição de ensino. Notouse que tanto os alunos quanto os idealizadores do projeto estavam bastante empenhados antes e durante a realização das oficinas de reciclagem. Entretanto, a composição química e os efeitos nocivos do copo descartável impactaram os alunos durante a palestra. Com base nos resultados é possível inferir que a palestra e as oficinas em conjunto podem ser uma importante estratégia para provocar mudanças comportamentais nos alunos e que, consequentemente, melhorem a qualidade ambiental.

Palavras-chave: Meio Ambiente; Palestra; Reciclagem; Biblioteca; Decoração. 


\section{INTRODUÇÃO}

Considerando o novo modelo de vida propagado pelo avanço tecnológico percebese que à medida que o ser humano satisfaz suas necessidades, aumenta-se significativamente a problemática dos resíduos gerados de diversas atividades cotidianas (CANDITO; STEFFANI, 2013; SCUPINO, KAICK, 2017). Pensando nessa realidade, Roos e Becker (2012) afirmam que "ou o ser humano muda a sua forma de explorar os recursos naturais e, assim, pratique ações sustentáveis, ou todo Planeta Terra perecerá brutalmente e emersa em seus próprios resíduos produzidos". Portanto, a implementação de projetos que ressaltem a importância da EA, por exemplo, pode ser uma estratégia que leve a mudança comportamental das pessoas, bem como permite o desenvolvimento humano e da natureza em equilíbrio.

No nosso dia-a-dia, a maioria dos resíduos sólidos que descartamos ou que precisa ser descartado não é perigoso, isto é, não oferece riscos ao ser humano (lixo comum) (BAIRD; CANN, 2011). No entanto, a questão do lixo é um problema que vem se agravando com o passar dos anos e com o aumento populacional. No contexto escolar, o tema "resíduos sólidos urbanos" permite trabalhar conhecimentos científicos de forma contextualizada, assim como desenvolve nos alunos um pensamento crítico quanto a esse problema de cunho social e ambiental (SANTOS et al., 2011).

Nessa perspectiva, este projeto entende a necessidade da realização de trabalhos educativos envolvendo o espaço da Biblioteca Maria Gabriela Pacheco Pardey (IFG - Câmpus Itumbiara), uma vez que mostra à comunidade escolar que este ambiente não deve ser padronizado apenas para leitura e estudos, mas sim como um local que integre aluno, professor e livros com propostas educativas diferenciadas e motivadoras.

Portanto, o objetivo desse trabalho foi de unir a teoria (palestra) com a prática (oficinas de reciclagem) de forma a despertar no aluno mudanças de hábito e comportamentais frente às questões ambientais relacionadas ao reaproveitamento de resíduos sólidos descartados cotidianamente na instituição de ensino.

\section{METODOLOGIA}

Inicialmente, foi trabalhado com os participantes assuntos como EA e Sustentabilidade (palestra), de forma a prepará-los para o desenvolvimento das oficinas. Para a confecção dos materiais decorativos, foram utilizados itens de uso comum - em sua maioria reaproveitados - e ferramentas necessárias para manipulá-los. Ambos foram adquiridos por meio de coleta, compra ou já eram objetos pertencentes ao patrimônio do setor.

Na manufatura dos quadros (Oficina I), foram aproveitados papéis de revista e fita adesiva, para a construção dos canudos responsáveis pelo efeito de texturização do artigo, e papéis do tipo color set na cor preta, fundamentais para o sustento do quadro e aquisição da forma desejada. Além disso, foram utilizados estilete e tesoura, importantes para o corte do contorno das imagens nas folhas de papel color set. Durante a montagem, os participantes das oficinas, com o uso da cola quente, colaram os canudos sobre uma das folhas e, por fim, a folha recortada foi colada sobre os canudos. O processo foi repetido três vezes para a obtenção de quatro quadros ao final.

Para a construção das bolas (Oficina II) foram utilizados copos descartáveis de $200 \mathrm{ml}$ e de $50 \mathrm{ml}$, além de tintas guache nas cores amarelo e verde e pincéis utilizados na pintura. As cores foram escolhidas por serem predominantes na bandeira do Brasil, sendo sugeridas devido à proximidade da Copa do Mundo. Como os copos eram transparentes, eles foram pintados externamente sem que houvesse prejuízo do efeito da coloração e, posteriormente, foram unidos por grampos, por meio do uso de grampeador de mesa. Por fim, foram feitas duas bolas grandes utilizando os copos de $200 \mathrm{ml}$ e quatro bolas pequenas, com o uso dos copos de $50 \mathrm{ml}$. A definição da quantidade de bolas por cor foi guiada pela quantidade de material disponível para construção.

$\mathrm{Na}$ confecção da bandeira (Oficina III) foram gastos um banner em estado ocioso e copos descartáveis de $200 \mathrm{ml}$ pintados de verde, amarelo e azul, da mesma forma com que foram pintados para a construção das bolas. Para uma melhor orientação em como fixar os copos, foram desenhadas as figuras geométricas da bandeira em um dos lados do banner. Em seguida, os participantes da 
oficina, com o uso da cola quente, anexaram os copos à parte lisa do banner, começando com o círculo azul no centro da bandeira.

Além da elaboração de artigos utilizando materiais reutilizados, foram produzidas peças decorativas para a Festa Junina, como as bandeirinhas. A produção foi realizada utilizando folhas de papel seda nas cores amarela e verde, doadas pelos alunos, barbante e papel crepom também nas cores amarela e verde. $O$ corte das bandeirinhas foi realizado com um molde único e com o auxílio da guilhotina, instrumento de corte de papeis. Dessa forma, foi priorizada a economia de tempo e evitou-se o desperdício de material, já que todo o papel seda foi utilizado. Por fim, as bandeirinhas - intercaladas com uma faixa de papel crepom - foram anexadas à faixa de barbante com grampos, por meio do uso de grampeador de mesa.

\section{RESULTADOS E DISCUSSÃO}

O projeto foi desenvolvido com o intuito de dar destino criativo a alguns tipos de resíduos gerados na própria instituição de ensino, especialmente os copos descartáveis utilizados e descartados na maioria dos setores administrativos. Embora no IFG Câmpus Itumbiara tenha coleta seletiva ao longo dos corredores de acesso da instituição, houve a ideia por parte dos servidores da Biblioteca em reaproveitar seus próprios resíduos gerados e transformá-los em objetos decorativos para o setor. Além dos servidores coletarem resíduos para utilizá-los nas oficinas, os alunos também se sensibilizaram com a causa coletando resíduos e doando outros tipos de materiais para o projeto da Biblioteca.

Na palestra inicial percebeu-se que os alunos ficaram impactados com algumas informações, tais como a data oficial escolhida para a comemoração do meio ambiente e a composição química do copo descartável. Percebeu-se um grande envolvimento e curiosidade dos participantes na produção dos quadros com folhas de revistas velhas (Figura 1), pois eles não imaginavam que os rolinhos de revistas produziriam um efeito interessante nos moldes das figuras utilizadas. Segundo Lopes e Nunes (2010), a confecção de materiais educativos a partir de materiais recicláveis promove o desenvolvimento dos alunos de forma responsável e consciente, bem como melhora a interação dos mesmos durante as atividades.

Figura 1: Educadora ambiental e participante montando um quadro com rolos de revistas velhas (à esquerda) e alguns dos quadros produzidos na 'Oficina l' (à direita).

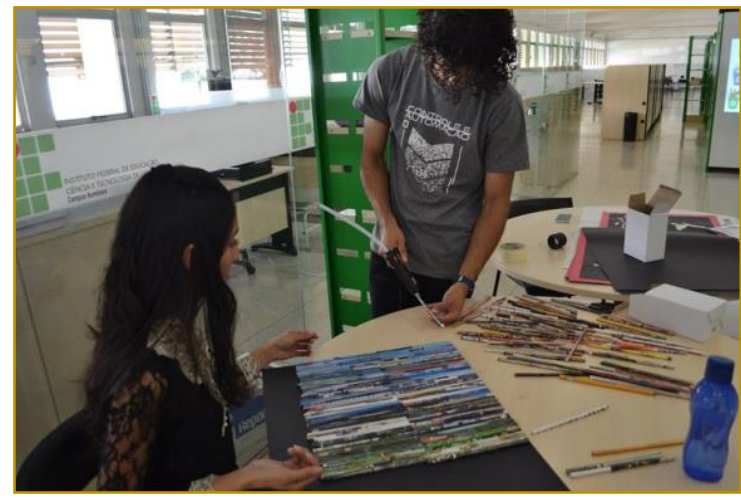

Já nas Oficinas de produção de bolas suspensas (Figura 2) e da bandeira oficial do Brasil (Figura 3) foi um momento em que os alunos puderam desenvolver materiais decorativos a partir da temática da Copa

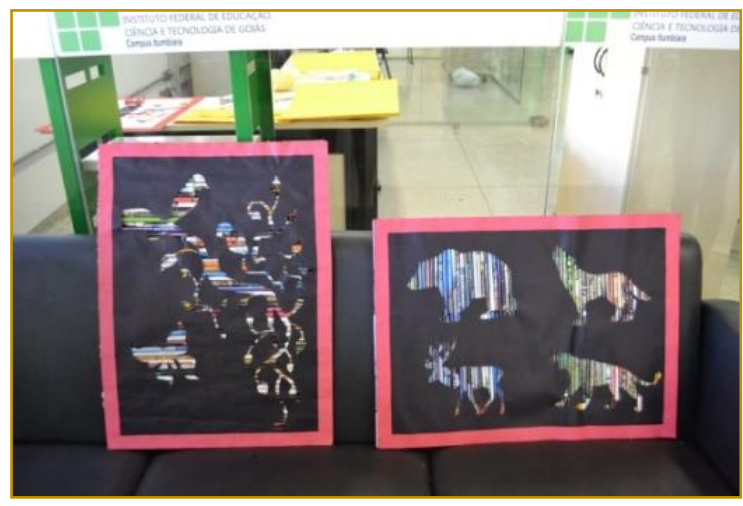

Mundial 2018 aliada à sustentabilidade. As bolas e a bandeira foram colocadas no espaço da Biblioteca, juntamente com bandeirinhas juninas nas cores verde e amarela (Figura 3). 
Figura 2: Alunos participando da 'Oficina II' (à esquerda) e Educadora ambiental instruindo os alunos nessa mesma oficina (à direita).
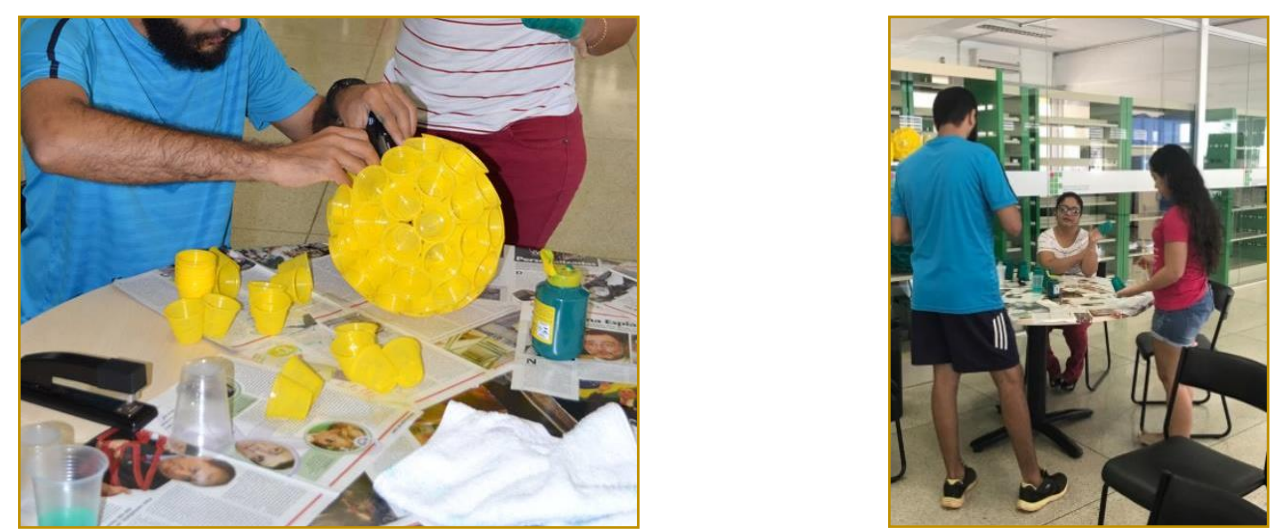

Figura 3: Educador ambiental instruindo a aluna na Oficina III (à esquerda) e Bandeira Oficial do Brasil finalizada pelos alunos (à direita).

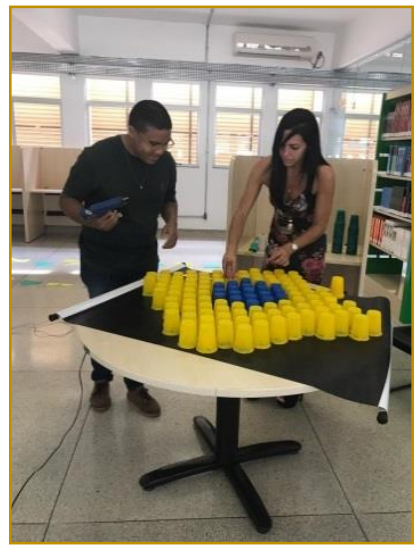

Já os quadros produzidos na Oficina I compuseram a decoração do Arraiá IFest 2018 do IFG - Câmpus Itumbiara, uma vez que este evento também trabalhou com o tema sustentabilidade. Este evento foi uma oportunidade de divulgar os trabalhos

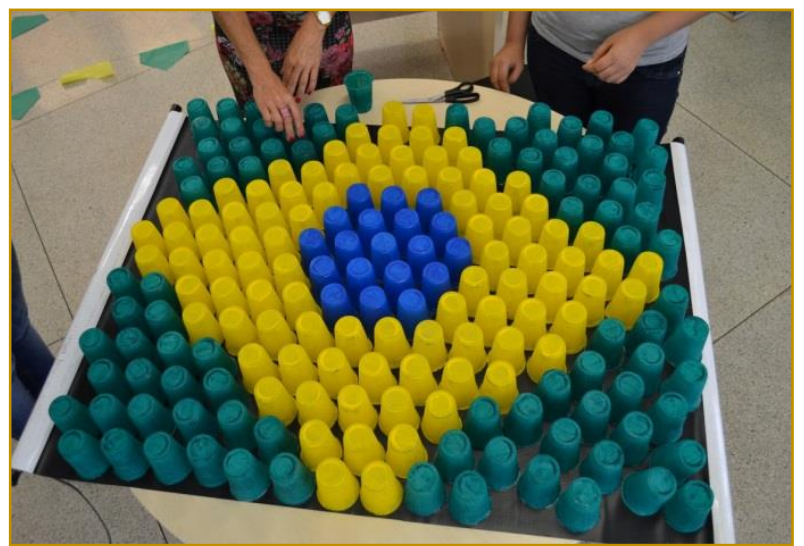

desenvolvidos pela Biblioteca, assim como alertar toda a comunidade acadêmica sobre a necessidade de se repensar novos destinos para os resíduos produzidos pela instituição de ensino. 
Figura 4: Educadora ambiental realizando a palestra inicial (à esquerda) e decoração da Biblioteca após a finalização dos materiais decorativos (à direita).

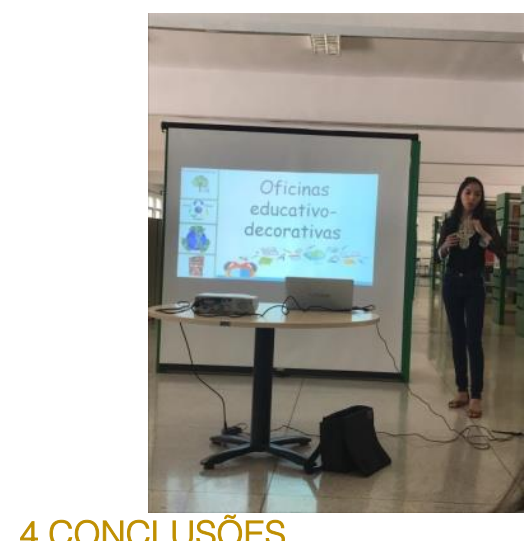

Pode-se inferir com as atividades realizadas de que é possível sim desenvolver projetos educacionais pautados na EA e sustentabilidade dentro de uma Biblioteca, principalmente quando estão relacionados à própria realidade dos alunos e servidores de uma instituição de ensino técnico e tecnológico. Ademais, tais atividades não comprometem o calendário acadêmico em vigor, assim como podem incentivar os alunos a participarem mais ativamente da solução dos problemas ambientais locais e do mundo.

\section{REFERÊNCIAS}

[1] Baird, C.; Cann, M. Química ambiental. 4 $4^{\underline{a}}$ ed., Porto Alegre: Bookman, 2011. 844p.

[2] Candito, V.; Steffani, E. A reciclagem como instrumento da conscientização e preservação ambiental. TCC de especialização, Universidade Federal de Santa Maria - RS, 2013. 15p.

[3] Lopes, F. M.; Nunes, A. N. Reutilização de materiais recicláveis para incentivo à Educação Ambiental e auxílio ao ensino didático de ciências em um colégio estadual de Anápolis-GO. Revista de Educação, v. 13, n. 15, p. 87-103, 2010.

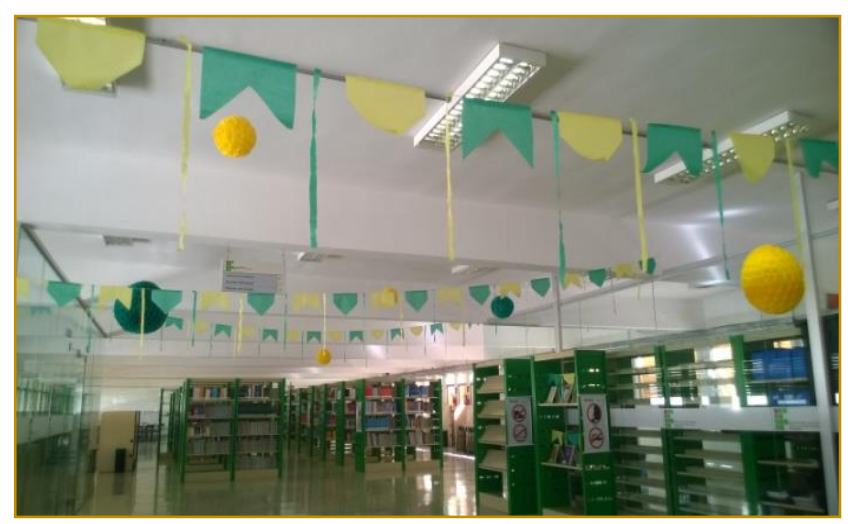

O mau gerenciamento dos resíduos gerados e os efeitos nocivos destes ao ser humano e a natureza foram assuntos que impactaram os alunos durante a realização da palestra. Portanto, abordar o tema deste projeto em uma Biblioteca pública faz-se pertinente ao passo que valoriza e movimenta o setor, faz com que o aluno em formação reveja seus conceitos e posturas com relação aos seus próprios resíduos gerados, e incentiva professores a desenvolverem atividades educativas nesse espaço com enfoque interdisciplinar.

[4] Roos, A.; Becker, E. L. S. Educação ambiental e sustentabilidade. Revista Eletrônica em Gestão, Educação e Tecnologia Ambiental, v. 05, n. 05, p. 857-866, 2012.

[5] Santos, P. T. A. et al. Lixo e reciclagem como tema motivador no ensino de química. Ecl. Quím., São Paulo, v. 36, n. 01, p. 78-92, 2011.

[6] Scupino, F.; Kaick, T. S. V. Avaliação de programas de educação ambiental voltados para a gestão de resíduos sólidos em escolas municipais de Pinhais/PR. Pesquisa em Educação Ambiental, v. 12, n. 01, p. 71-84, 2017. 


\section{Bapítulo 16}

\section{EDUCAÇÃO AMBIENTAL E A SUSTENTABILIDADE DOS RECURSOS HIDDICOS}

\section{Roberta Borges de Medeiros Falcão}

Patrícia Freire Chagas

Cinthya Antonia Vieira Gurgel

Resumo : Nos últimos anos, a constatação de que a água doce disponível é, na realidade, um recurso limitado e que seus reservatórios naturais vêm sendo dramaticamente degradados com o crescimento desordenado das demandas trouxe à tona a tese da "crise da água" como um grave problema ambiental. Nesse sentido, a Companhia de Águas e Esgotos do Rio Grande do Norte (CAERN), através da Gerência de Qualidade do Produto e Meio Ambiente (GQM) iniciou um Projeto Agentes do Saneamento, que consistiu na capacitação dos Agentes Comunitários de Saúde na Zona Norte de Natal/RN, especificamente o Distrito Sanitário Norte II, através de um curso de Sensibilização em Recursos Hídricos de 20 horas. O curso visou contribuir na sensibilização sobre recursos hídricos a fim de que os agentes comunitários de saúde possam mudar seus hábitos negativos em relação à água, tornando-se agentes multiplicadores das informações recebidas, desenvolvendo ações de educação ambiental nas localidades que residem e trabalham. A metodologia consistiu em um conjunto de ações interligadas cuja metodologia deu ênfase na abordagem participativa buscando desenvolver conhecimentos teóricos e práticos através de interações, trocas, debates. Como principais resultados, os Agentes Comunitários de Saúde realizaram uma série de ações educativas nos bairros tais como: ministração de palestras em escolas, visitas domiciliares e fixação de cartazes. Como conclusão podemos tirar que, quando um trabalho é realizado tendo como base a relação sujeito/sujeito no processo educativo há uma mudança de comportamento ambiental fazendo com que a pessoa sinta a sua importância e assuma seu papel na sustentabilidade dos recursos hídricos.

Palavras-chave: Capacitação; agentes comunitários de saúde; educação. 


\section{INTRODUÇÃO}

A água, por ser essencial ao homem e ter reservas limitadas, é cada vez mais estratégica e tem provocado debates em vários organismos internacionais. Discute-se o seu uso racional, a sua temida e inevitável escassez em várias regiões do mundo e a degradação dos mananciais hídricos, pois dela depende a qualidade de vida no planeta.

Somente poderá haver futuro com qualidade de vida se existir uma educação para o desenvolvimento sustentado, isto é, se conseguir criar um equilíbrio na relação entre o homem com o seu semelhante e com seu meio ambiente. É necessário criar um novo conjunto de valores, de regras de convívio com os outros e com o meio ambiente de maneira justa, democrática, participativa e crítica, em direção a uma cultura diferente, com base no respeito, solidariedade, justiça e sustentabilidade.

Segundo Medina (2002), a Educação Ambiental apresenta-se como uma das alternativas de transformação da Educação, no âmbito de um novo paradigma em construção, e de novas formas de pensar, de interpretar e de agir no mundo, capaz de possibilitar a superação da visão positivista, instrumental e tecnocrática que caracteriza a civilização contemporânea e que se manifesta através da crise global e generalizada deste início de século.

Nesse sentido, a Companhia de Águas e Esgotos do Rio Grande do Norte (CAERN), através da Gerência de Qualidade do Produto e Meio Ambiente (GQM) vem realizando uma série de ações de Educação Ambiental e uma delas foi a implementação do Projeto Agentes do Saneamento, que consistiu na capacitação dos Agentes Comunitários de Saúde (ACS) na Zona Norte de Natal/RN, especificamente no Distritito Sanitátio Norte II, através de curso de Sensibilização em Recursos Hídricos com carga horária de 20 horas.

A escolha em realizar um trabalho de educação ambiental na Região Norte da capital potiguar, deveu-se a um problema crítico de diminuição do volume de água no reservatório de abastecimento, o qual obrigou a Caern a realizar rodízio no abastecimento para 70\% dos bairros da Zona Norte de Natal.

Associado ao rodízio, foi imprescindível a realização de um amplo trabalho de educação ambiental junto à população, objetivando informar sobre o problema hídrico, mostrando a necessidade do uso racional e preservação dos mananciais. Entre as ações realizadas, o Projeto Agentes do Saneamento realizou dois cursos de vinte horas (20h) com os Agentes Comunitários de Saúde da Zona Norte de Natal abrangendo sete (07) bairros, loteamentos e conjuntos com um número de setenta e quatro (74) participantes no ano de 2017.

Dessa forma, objetivou-se com esse trabalho capacitar os Agentes Comunitários de Saúde do Distrito Sanitário Norte II da Secretatira Municipal de Saúde da cidade do Natal/RN, sensibilizando-os sobre os recursos hídricos de maneira a estimulá-los no desempenho do seu papel mediador entre os saberes técnicos e populares de maneira que transformasse 0 conhecimento em prática, em mudança de comportamento. O trabalho corpo a corpo dos ACS, com as visitas às casas, possibilita criar junto à população um relacionamento profissional e afetivo, tornando-os em agentes multiplicadores de conhecimento com potencial de mudanças de valores, atitudes e comportamentos para a preservação dos recursos hídricos.

\section{METODOLOGIA}

A Educação Ambiental tem sido colocada como uma importante ferramenta para o processo de mudança de comportamento; sendo eficaz para a formação de uma consciência pública crítica e participativa. $\mathrm{Na}$ compreensão de Phillipi \& Peliconi (2000), a humanidade necessita de uma nova concepção científica, de um novo projeto civilizatório que leve em consideração a questão da universalidade do ser humano dentro de um processo histórico onde necessariamente se deve estabelecer a ética da promoção da vida, o que exige reflexões e ações sobre as desigualdades, sobre a pobreza, sobre a exclusão da maioria ao acesso a bens e serviços, sobre as práticas e relações de consumo. Isso impõe a reconstrução de paradigmas e das relações do homem com a natureza, como também uma reflexão a partir da sua ação.

As propostas de Educação Ambiental pretendem aproximar a realidade ambiental das pessoas e conseguir que elas passem a perceber o ambiente como algo próximo e importante nas suas vidas; e verificar, ainda, que cada uma tem um importante papel a cumprir na preservação e transformação do ambiente em que vivem (MEDINA, 2000). 
A metodologia adotada teve por base a relação sujeito/sujeito no processo educativo, pois a mudança de comportamento ambiental só ocorrerá se a pessoa sentir a sua importância e assumi-la. Desta maneira, a metodologia contou com trabalhos coletivos, interações, trocas, debates.

O curso teve como ementa: Os recursos hídricos: usos consuntivos e não consuntivos; ciclo da água; caracterização de bacia hidrográfica. Disponibilidade hídrica mundial, nacional e regional. Usos múltiplos dos recursos hídricos. Impactos ambientais negativos. Sistema de Gestão Ambiental e seus Instrumentos. Doenças de veiculação hídrica. Estação de Tratamento de Água. As aulas foram ministradas de maneira expositiva, com dinâmicas de grupos, debates, discussões utilizando recursos como projeção via data-show, músicas, atividades práticas e exibição de vídeos, entre outros (figuras 1 e 2), além de uma aula prática conhecendo uma miniestação de água (vide figuras 3 e 4 ).

\section{RESULTADOS E DISCUSSÃO}

O projeto Agentes do Saneamento com a realização do curso de Sensibilização em Recursos Hídricos contemplou o conhecimento cientifico, teórico, e o conhecimento empírico, além das experiências de trabalho e percepções que cada Agente Comunitário de Saúde traz sobre o tema. É como afirma Phillipi \& Peliconi (2000), a educação ambiental deve repensar a prática a partir da teoria discutida e trabalhar a teoria à luz da prática vivida. Através da educação são trabalhados conhecimentos que possam elaborar uma nova visão de mundo capaz de direcionar ações no sentido da sustentabilidade.

Os Agentes Comunitários de Saúde envolveram-se no projeto de maneira voluntária e entusiasta, o que favoreceu o trabalho de Educação Ambiental, que devido à complexidade e pluralidade da questão necessita, igualmente, de abordagens também múltiplas.

Assim, o trabalho educativo partiu de uma ação conjunta, agregando e cruzando informações, inserindo estratégias que vislumbrassem o envolvimento de comportamentos responsáveis e participativos.

Em trabalhos de educação ambiental, é extremamente importante saber emocionar, pois sensibilizar é cativar o indivíduo para que ele seja receptivo às informações e aprenda a ser um agente multiplicador, transmitindo as informações assimiladas em seus ambientes familiares.

A cada aula, os agentes eram estimulados a implementar ações educativa para serem realizadas em seus bairros e localidades. Os agentes fixaram cartazes em cinquenta e nove (59) pontos estratégicos como estabelecimentos comerciais, instituições de ensino, Unidade Básicas de Saúde (figuras 5 e 6); distribuição de material educativo à população (figuras 7 e 8); ministração de dezenas de palestras em escolas e Unidades de Saúde (figuras 9 a 12), e elaboraram vídeo ambiental.

Após as conclusões dos cursos foram realizadas avalições escritas e orais nas quais foram coletados alguns depoimentos. Quanto a didática uma agente comunitária declarou: "a didática do curso foi bastante dinâmica e proveitosa. Só temos a agradecer por essa oportunidade de adquirir mais conhecimento sobre esse bem universal", outro "Gostamos da dinâmica da aula, pois foram utilizadas músicas, vídeos, além da clareza da palestrante".

Um outro agente Comunitário de Saúde afirmou "Na categoria de Agente Comunitário de Saúde, esses conhecimentos sobre água nos levaram a melhorar nosso procedimento de levar a população o dever e cumprimento de grandes melhorias. Deixou esclarecimento. Tudo que nos foi capaz de ser observado é para a melhoria da área de trabalho como a economia de água". Outra participante nos informou: "O curso nos trouxe um novo olhar em relação a algo vital em nossas vidas. Conscientizando-nos e nos dando conhecimento de como tratar os recursos hídricos, não só nosso Estado, mas um olhar geral". 
Figuras 1 e 2 - Aulas teóricas em sala de aula
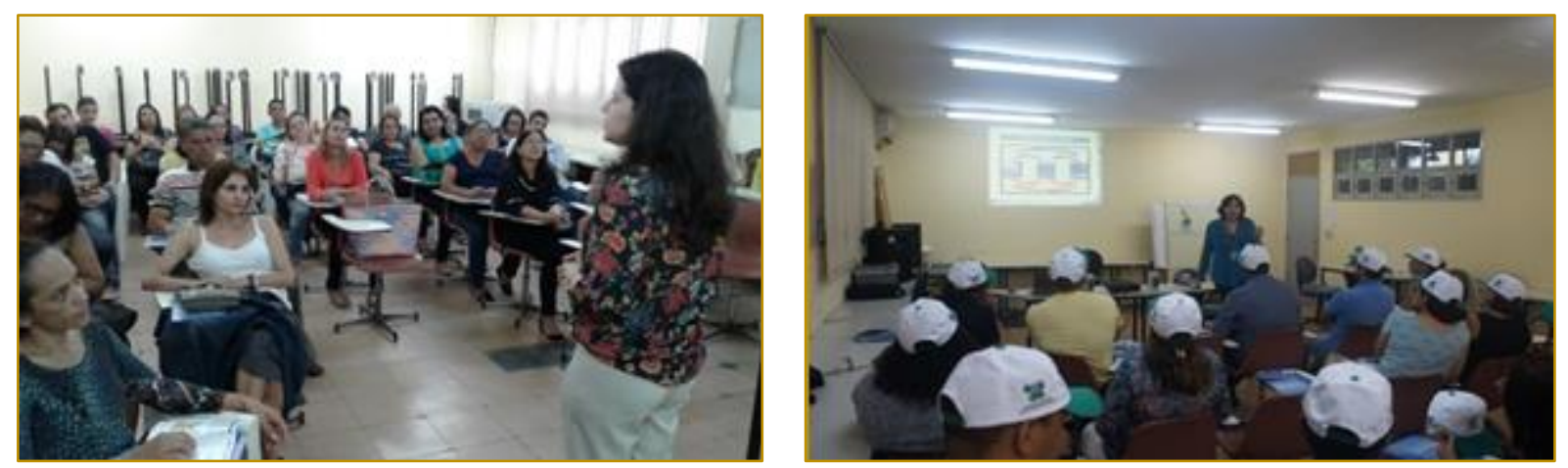

Figuras 3 e 4 - Aula prática (conhecendo uma mini estação de tratamento de água)
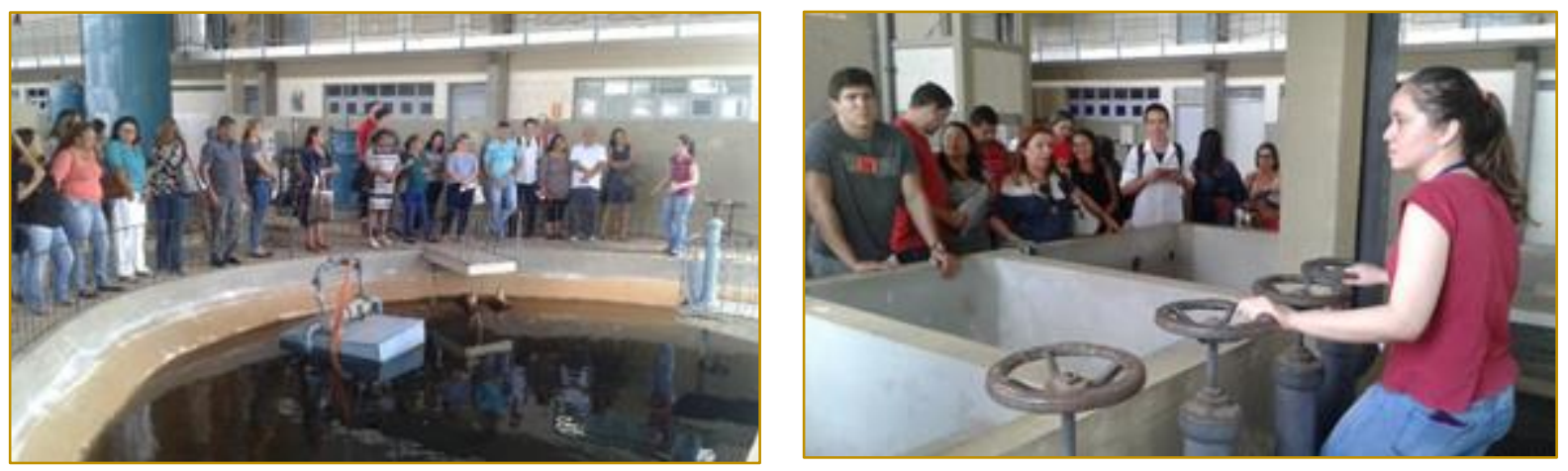

Figuras 5 e 6 - Fixação de cartazes em pontos estratégicos das localidades
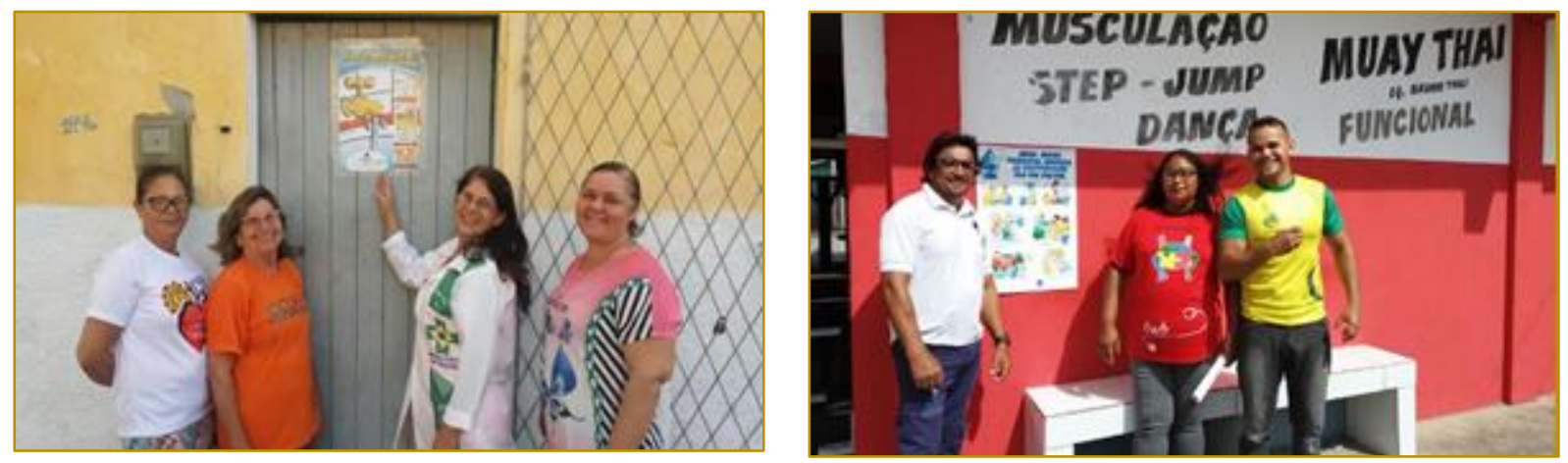
Figuras 7 e 8 - Distribuição de material educativo
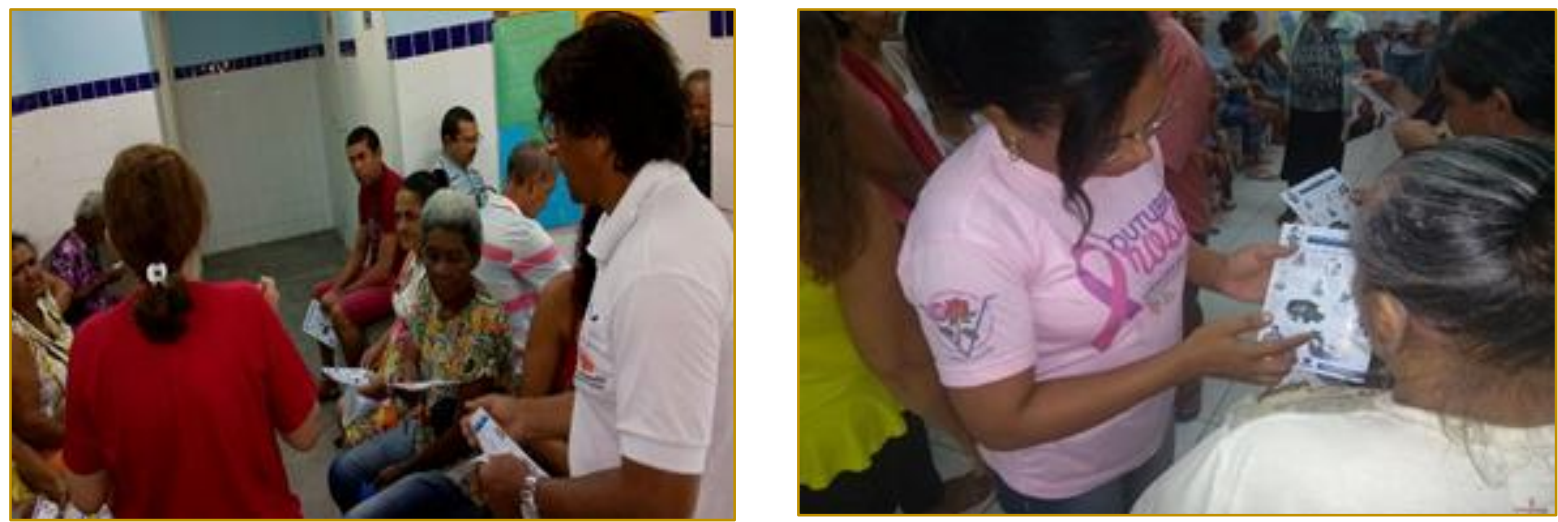

Figuras 9 e 10 - Palestras educativas em Unidades Básicas de Saúde
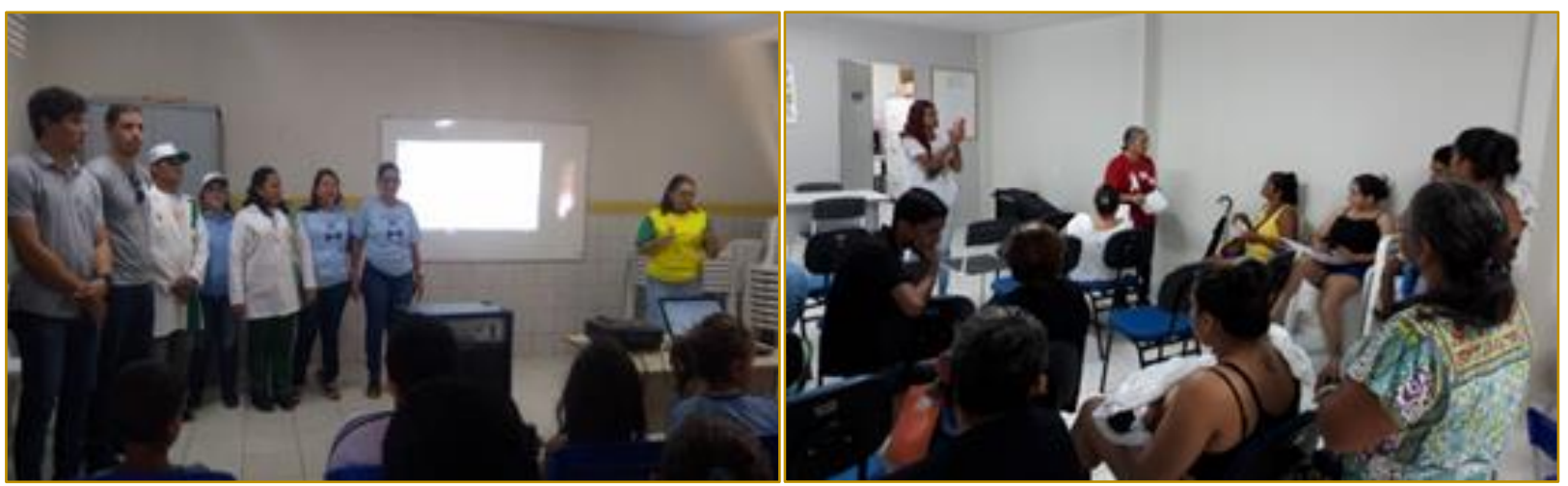

Figuras 11 e 12 - Palestras educativas em escolas da localidade
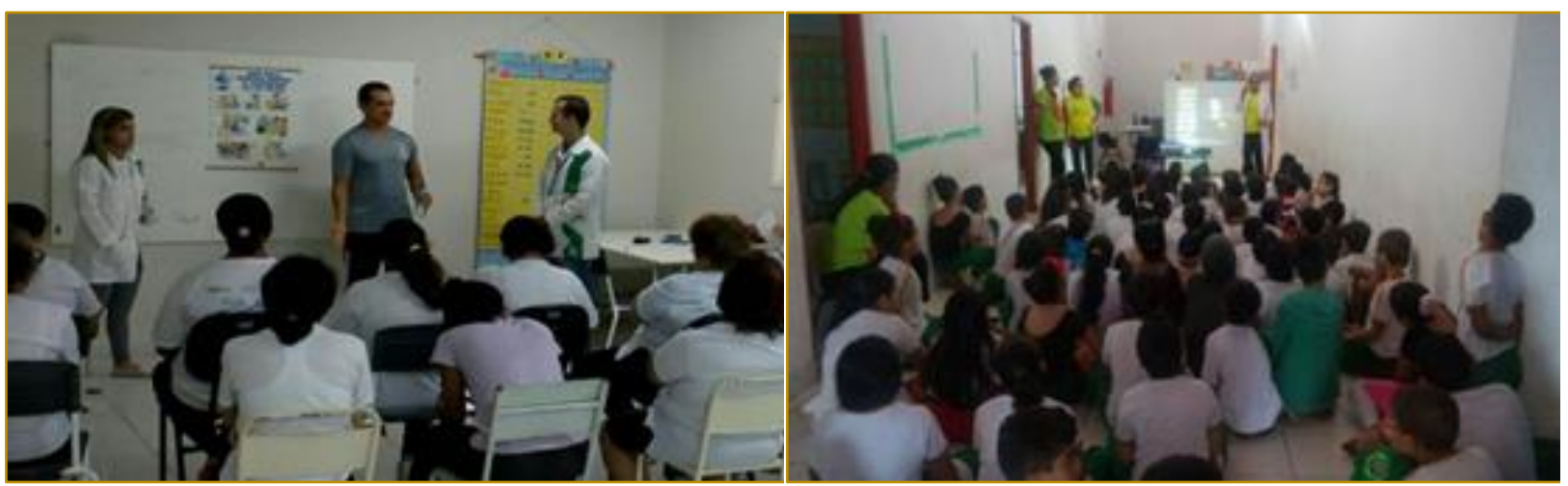

\section{CONCLUSÕES}

A CAERN buscou a participação dos profissionais de maneira que garantisse, a partir da sensibilização dos ACS, que as ações fossem implementadas. Desde o início, o projeto estabeleceu parceria com a Regional de Saúde da Zona Norte para maximizar o alcance das ações e serviços a serem proporcionados à comunidade e aumentar a probabilidade que os mesmos pudessem ser sustentáveis a longo prazo. O desenvolvimento desse trabalho buscou possibilidades de envolver os Agentes
Comunitários de Saúde para que eles começassem a formar ou aprimorar em suas mentes os princípios de cidadania e de preservação ambiental.

A motivação e o interesse dos ACS diante das diversas atividades realizadas na rotina de seus trabalhos vêm comprovar, apenas, o sucesso do objetivo a que se propunha que era sensibilizar os Agentes Comunitários de Saúde para os problemas da água na Zona Norte de Natal. 


\section{AGRADECIMENTOS}

Agradecemos a Companhia de Águas e Esgotos do Rio grande do Norte (CAERN) pela valorização e incentivo do trabalho de

\section{REFERÊNCIAS}

[1] Medina, N. M. Os Desafios da Formação de Formadores para a Educação Ambiental In: Phillipi, A. J. \& Peliconi, M. C. (editores) Educação Ambiental: Desenvolvimento de Cursos e Projetos, Universidade de São Paulo, São Paulo, Faculdade de Saúde Pública Núcleo de Informações em Saúde Ambiental: Signus Editora, 2000.
Educação Ambiental, proporcionando a capacitação de agentes multiplicadores e assim, contribuindo para a formação de uma sociedade pautada nos preceitos da sustentabilidade.

[2] Philippi, A.J.; Pelicioni, M.C. Recursos Humanos em Educação Ambiental: O Papel da Faculdade de Saúde Pública da Universidade de São Paulo In: PHILIPPI, Arlindo Júnior \& Medina, N. M. O Contrato Social da Ciência, unindo saberes na Educação Ambiental. Petrópolis, Vozes, 2002. 


\section{Gapítulo 17}

\section{EDUCADOR \\ AMBIENTAL \\ E SUA \\ FORMAÇÃO PROFISSIONAL}

\section{Debora Regina Marochi de Oliveira}

Terezinha Corrêa Lindino

Resumo: Cada vez mais, a relação entre meio ambiente e educação torna-se desafiadora, exigindo novos conhecimentos para compreender os processos sociais cada vez mais complexos e riscos ambientais que se intensificam. $\mathrm{O}$ debate atual sobre a Educação Ambiental adentra escolas, universidades, organizações governamentais e não governamentais. Mas as recomendações da Conferência de Tbilisi (1977) atribuem à escola um papel determinante na marcha progressiva da Educação Ambiental em transformar atitudes e comportamentos para que todos os membros da comunidade tenham consciência das suas responsabilidades na concepção, elaboração e aplicação de programas relativos ao Meio Ambiente. Compreende-se ser a escola espaço propício e privilegiado para construir conhecimentos, valores e práticas que possam ser reproduzidos nos contextos sociais. Atribui-se a ela e seus integrantes a necessidade de estarem preparados para abordarem de maneira satisfatória essa temática. Assim, por meio da revisão sistemática proposta (referenciais bibliográficos e documentais), procura-se indicar a necessidade de o Educador Ambiental desenvolver práticas ambientais adequadas e um novo modelo de Educador Ambiental Formal, cuja característica principal seja o perfil transformador de sua própria prática. Independentemente do público-alvo, cabe ressaltar que capacitar o Educador Ambiental Formal é levar o indivíduo a repensar a sua relação com o meio, a fim de garantir mudanças de atitudes em prol da melhoria da qualidade de vida de sua sociedade. Essa capacitação deve visar ao Educador Ambiental a segurança para inovar e reformular suas práticas, incorporando a questão ambiental ao programa escolar.

Palavras-chave: Educação Ambiental Formal, Vertentes da EA, Transformação Social. 


\section{INTRODUÇÃO}

O processo formativo da educação ambiental vem se formando e reformando dentro de um movimento histórico de diálogos e disputas diante da manifestação da humanidade e da produção de pensamentos significativos sobre a relação da sociedade com a natureza, relatando vários e possíveis caminhos epistemológicos sobre sua operacionalidade. As diferentes concepções relacionadas ao conceito de meio ambiente tendem a expressar práticas pedagógicas e discursos complementares ou, às vezes, antagônicos dos educadores ambientais (MORALES, 2009). Por isso, ao longo do tempo, estes educadores foram se dando conta de que há diferentes concepções de natureza, meio ambiente, sociedade e educação, oportunizando a exclusão do ponto de vista da prática pedagógica monolítica e, em seu lugar, assumir diversas possibilidades de expressões (LAYRARGUES; LIMA, 2011).

Acredita-se que a escola e os professores são considerados como um dos principais mediadores na criação de métodos e práticas educativas as quais contribuem para uma educação ambiental sustentável e transformadora. Implantar a temática ambiental, em todos os níveis de ensino, visa fortalecer a formação de valores e princípios importantes na capacitação dos indivíduos ao exercício pleno da cidadania. Porém, a área ambiental, ainda não é vista como parte integrante da educação geral e, não tem recebido a atenção que necessita ao que se refere à formação profissional. Sendo o educador ambiental, o principal responsável por trabalhar essa temática, sua formação profissional necessita constantemente aperfeiçoar métodos e conteúdo; um saber adaptado às condições variáveis do Meio Ambiente.

Neste contexto, algumas perguntas são necessárias: Que tipo de Educador Ambiental está presente em nossas escolas? Estes contemplam as necessidades exigidas entre a Educação Ambiental e o ambiente escolar? Quais características devem ser estruturantes na formação do seu perfil profissional?
Para tanto, objetiva-se com este estudo delimitar um perfil profissional para a Educação Ambiental no ambiente escolar, tendo como base as características elencadas nas legislações pertinentes. Esta necessidade se justifica visto que a Educação Ambiental ainda hoje carece de uma conceituação mais elaborada e, portanto, não há consenso sobre qual perfil é o mais adequado para o Educador Ambiental Formal.

Sabe-se que muitas são as possibilidades de entendimento dos conceitos associados à Educação Ambiental e que derivam de diferentes perspectivas pedagógicas inerentes a sua prática (LOUREIRO, 2004).

\section{METODOLOGIA}

A presente pesquisa adota o caráter bibliográfico e documental, caracaterizando-a como qualitativa de cunho exploratório e tendo como objetivo compreender a necessidade de uma inovação educativa voltada à capacitação do educador ambiental na educação fundamental, bem como propiciar a este condições técnicas e metodológicas para a construção de novas pedagogias a serem desenvolvidas no ambiente escolar. Ela fundamenta-se na importância que a Educação Ambiental apresenta nos tempos atuais, na qual a necessidade de reflexão e construção de novos saberes e valores despontam como estratégias para minimizar os danos ambientais causados pelo modelo de produção, consumo e serviços adotados pela sociedade contemporânea.

Para a realização desta pesquisa foram utilizados referenciais teóricos e documentais como articuladores de respostas. As duas técnicas tiveram o objetivo de sintetizar informações importantes e relevantes para a compreensão da história da Educação Ambiental, os princípios e as leis que a fundamentam e as principais vertentes que a regem (Gráfico 1). 
Gráfico 1. Amostragem da bibliografia utilizada (Total 155 artigos)

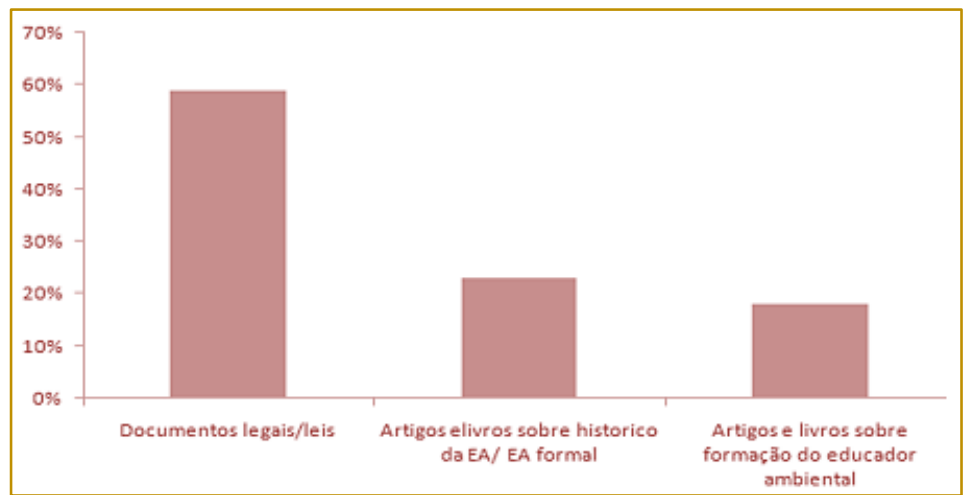

Fonte: elaborado pelas autoras com base na literatura e legislação utilizada (2018).

Para o referencial teórico utilizou-se a pesquisa em livros relacionados à temática ambiental procurando contemplar os principais autores envolvidos neste universo. Também se utilizou da pesquisa eletrônica em sites como Scielo e Portal de Periódicos Capes com o propósito de selecionar artigos, dissertações e teses que viessem a contribuir com a pesquisa. Já a pesquisa documental foi realizada a partir das leis existentes e dos Projetos Políticos Pedagógicos dos estabelecimentos de ensino, os quais foram obtidos por meio de pesquisa eletrônica (site oficial da escola) ou fornecidos via e-mail após contato com o responsável pela escola.

Nestes documentos, explorou-se a relação que a escola tem com a Educação Ambiental com base na perspectiva apresentada pelas vertentes da Educação Ambiental, visto que elas promovem diferentes concepções que visam ampliar as maneiras de percepção e práticas da EA no sistema escolar. Assim, procura-se desenhar o perfil do Educador Ambiental Formal, com base na multiplicidade de vertentes, conceitos, práticas e metodologias próprias que a Educação Ambiental abrange (CARVALHO, 2004).

Acredita-se que a falta de apropriação pelos educadores ambientais de um subsídio teórico que "[...] sustente a compreensão da complexidade da questão socioambiental leva a práticas simplistas e reducionistas de Educação Ambiental, práticas estas incapazes de contribuir no processo de transformação da realidade socioambiental" (DIB-FERREIRA, 2010, p.18). Com isso, tornase urgente investir na formação e desenvolvimento profissional de professores, proporcionando-lhes o confronto de suas ações cotidianas com as produções teóricas, para que transformem sua prática a partir da ampliação de sua consciência e da própria prática" (UNESCO, 2004, p. 17).

A partir de então, pensa-se ser possível uma Educação Ambiental emancipatória e transformadora e que contribua para a transformação da sociedade e da sua relação com a natureza. Porém, longe de se constituir em um método, uma fórmula pronta e acabada, propõe-se o aprofundamento de linhas de "[...] pensamento para a ação, as quais devem ser ainda amplamente debatidas, discutidas, estudadas, praticadas, remodeladas, testadas no sentido de se fortalecer o caminho já iniciado por diversos pesquisadores" (DIB-FERREIRA, 2010, p.20).

Ao buscar na literatura dados e informações relevantes que contribuam para a compreenção desta temática, adota-se conjuntamente ao método qualitativo a pesquisa de cunho exploratório, pois pretende-se, segundo Gil (2002, p. 41), "[...] proporcionar maior familiaridade com o problema, com vistas a torná-lo mais explícito ou a construir hipóteses". Desta forma, como a pesquisa qualitativa e exploratória baseia-se na adoção dos métodos desenvolvidos pela pesquisa bibliográfica e documental destacase que a partir da utilização das técnicas de levantamentos de informações sobre a Educação Ambiental, foi possível levantar conceitos, pressupostos e legislações que caracterizam um perfil profissional do Educador Ambiental Formal.

A abordagem qualitativa se aprofunda no mundo dos significados. Portanto, segundo Minayo (2010, p.22), "[...] quando bem trabalhados, produzem riquezas de informações, aprofundamento e maior fidedignidade interpretativa". Logo, o uso deste tipo de pesquisa é altamente 
recomendado por auxiliar nas respostas a questões muito particulares, "[...] atuando em um nível da realidade que não pode ou não deve ser quantificado, trabalhando com o universo dos significados, motivos, aspirações, crenças, valores e atitudes" (MINAYO, 2010, p. 21).
Do total de 155 fontes da literatura abordadas, as apresentadas no quadro 03 foram as principais estruturantes desta pesquisa, sendo as demais um complemento para o enriquecimento das informações.

Quadro 1. Artigos selecionados, por meio da revisão da literatura, para a pesquisa (2018)

\begin{tabular}{|c|c|}
\hline Referência & Assunto abordado \\
\hline $\begin{array}{l}\text { Educação Ambiental: o desafio da construção de } \\
\text { um pensamento crítico, complexo e reflexivo } \\
\text { (JACOBI, 2005) }\end{array}$ & $\begin{array}{l}\text { Degradação ambiental e o papel do educador ambiental } \\
\text { formal para transformar hábitos e práticas sociais. }\end{array}$ \\
\hline $\begin{array}{l}\text { Uma cartografia das correntes em EA (SAUVÉ, } \\
\text { 2005b) }\end{array}$ & Diferentes maneiras de conceber e praticar a EA. \\
\hline $\begin{array}{l}\text { Os caminhos da Educação Ambiental nos Espaços } \\
\text { formais de Ensino-Aprendizagem: qual o papel da } \\
\text { política nacional de Educação Ambiental? } \\
\text { (FURTADO, 2009) }\end{array}$ & $\begin{array}{l}\text { A forma como o ensino formal vem articulando-se com a } \\
\text { Educação Ambiental em suas práticas de ensino- } \\
\text { aprendizagem. }\end{array}$ \\
\hline $\begin{array}{l}\text { Processo de institucionalização da Educação } \\
\text { Ambiental: tendências, correntes e concepções } \\
\text { (MORALES, 2009). }\end{array}$ & $\begin{array}{l}\text { Analisar a narrativa da EA, focando suas tendências, } \\
\text { correntes e concepções que permeiam o discurso dos } \\
\text { profissionais educadores ambientais. }\end{array}$ \\
\hline $\begin{array}{l}\text { Mapeando as macro-tendências político- } \\
\text { pedagógicas da EA contemporânea no Brasil } \\
\text { (LAYRARGUES; LIMA 2011). }\end{array}$ & $\begin{array}{l}\text { Macro-tendências que definem a atual diferenciação do } \\
\text { campo da EA: conservadora, pragmática e crítica. }\end{array}$ \\
\hline $\begin{array}{l}\text { Educação Ambiental: a formação do sujeito } \\
\text { ecológico (CARVALHO, 2012). }\end{array}$ & $\begin{array}{l}\text { Discute e contribui para a formação de indivíduos } \\
\text { capazes de ler e interpretar o mundo em transformação. }\end{array}$ \\
\hline $\begin{array}{l}\text { O Aspecto Ambiental respaldado por Lei } \\
\text { (TOFFOLO; FRANCISCHETT, 2012). }\end{array}$ & $\begin{array}{l}\text { Analisa a Constituição Federal de } 1988 \text { e a Lei 9597/99 e } \\
\text { suas contribuições para o processo de EA. }\end{array}$ \\
\hline $\begin{array}{l}\text { Para onde vai a Educação Ambiental? O cenário } \\
\text { político-ideológico da Educação Ambiental } \\
\text { brasileira e os desafios de uma agenda política } \\
\text { crítica contra hegemônica (LAYRARGUES, 2012). }\end{array}$ & $\begin{array}{l}\text { Problematizar a questão da categorização das correntes } \\
\text { de pensamento no Campo Social da Educação } \\
\text { Ambiental, }\end{array}$ \\
\hline $\begin{array}{l}\text { A Educação Ambiental em debate (MOURA; } \\
\text { HIRATA, 2013) }\end{array}$ & $\begin{array}{l}\text { A trajetória da EA baseada no histórico e na legislação } \\
\text { pertinente visando a formação para uma sociedade } \\
\text { sustentável. }\end{array}$ \\
\hline $\begin{array}{l}\text { As macrotendências político-pedagógicas da } \\
\text { Educação Ambiental brasileira (LAYRAR-GUES; } \\
\text { LIMA, 2014). }\end{array}$ & $\begin{array}{l}\text { Macrotendências que definem a atual diferenciação do } \\
\text { campo da EA no Brasil, interpretadas por meio do } \\
\text { diálogo com a literatura da área. }\end{array}$ \\
\hline
\end{tabular}

Fonte: elaborado pelas autoras (2018).

Ainda, por meio da legislação sintetizada, foi possível obter informações a respeito da legalidade da EA, sua importância e diretrizes para sua implantação no ambiente formal, bem como os norteadores para a formação do Educador Ambiental. 
Quadro 2. Legislações selecionadas por meio da revisão documental

\begin{tabular}{|c|c|}
\hline Legislação & Assunto abordado \\
\hline Lei 6938/81- PNMA & $\begin{array}{l}\text { Estabelece a necessidade da inclusão da EA em todos os níveis de } \\
\text { ensino nacional, estadual e municipal. }\end{array}$ \\
\hline Constituição Federal 1988 & $\begin{array}{l}\text { Delega a responsabilidade ao Poder Público promover a EA em } \\
\text { todos os níveis de ensino. }\end{array}$ \\
\hline Lei 9394/96- LDB & $\begin{array}{l}\text { Define que a Educação tem como uma de suas finalidades, a } \\
\text { preparação para o exercício da cidadania. }\end{array}$ \\
\hline $\mathrm{PCN}$ & $\begin{array}{l}\text { Primeira tentativa de trabalhar a EA no ensino formal de forma } \\
\text { interdisciplinar. }\end{array}$ \\
\hline Lei 9795/99 & $\begin{array}{l}\text { Dispõe como a EA deve estar presente na Educação Formal e Não } \\
\text { Formal, seus princípios, objetivos e sobre a PNEA. }\end{array}$ \\
\hline Lei $17.505 / 13$ & $\begin{array}{l}\text { Estabelece os aspectos operacionais das DCNEA a serem } \\
\text { cumpridos na educação básica e ensino superior, prevê a criação de } \\
\text { espaços sustentáveis. }\end{array}$ \\
\hline Diretrizes Curriculares Nacionais da EA & $\begin{array}{l}\text { Prevê a formação de profissionais com ênfase na visão ética e } \\
\text { humanística; propõe trabalho didático pedagógico relacionado à } \\
\text { realidade vivencial do educando. }\end{array}$ \\
\hline
\end{tabular}

Fonte: elaborado pelas autoras (2018).

Os documentos elencados trazem para a discussão elementos importantes na busca das respostas das questões já mencionadas. Desta forma, a seleção dos referenciais teóricos e documentais proporcionou a varredura da temática e, que a partir desta, desenvolver-se-á uma interpretação das informações.

Esta pesquisa se propõe trazer uma síntese, em termos teóricos e a partir dos dados coletados (pesquisa bibliográfica e documental) a respeito do Educador Ambiental Formal, suas características, inserção legal e o perfil deste para o século $X X I$. As técnicas adotadas para o desenvolvimento deste trabalho foram baseadas na descrição analítica, com ênfase na Análise do Conteúdo de Bardin que, segundo a autora, torna-se um conjunto de técnicas de análise das comunicações que utiliza procedimentos sistemáticos e objetivos de descrição do conteúdo das mensagens (BARDIN, 2009).

A Análise de Conteúdo nos permite interpretar o conteúdo expresso na comunicação, sua mensagem e seus indicadores. O objetivo desta técnica é, portanto, "[...] explicar e sistematizar o conteúdo da mensagem e o significado desse conteúdo, por meio de deduções lógicas e justificadas, tendo como referência sua origem (quem emitiu) e o contexto da mensagem ou os efeitos dessa mensagem" tendo como objetivo final da análise de conteúdo o fornecimento de indicadores aos objetivos da pesquisa (OLIVEIRA et al., 2003, p.04-05).

Pensa-se com isso, que área ambiental ainda não é vista como parte integrante da educação geral e não tem recebido a atenção que realmente merece ao que se refere à formação profissional. Logo, esta situação resulta na crença de que o educador ambiental não necessita de formação específica ou a formação deste pode ser realizada de qualquer forma ou quando houver tempo e condições hábeis para que isso se concretize.

\section{RESULTADOS E DISCUSSÃO}

Após varredura da temática e coleta das informações pertinentes realizou-se a leitura e interpretação das informações com o objetivo de formular hipóteses que resultaram em categorias de interpretação dos dados e apresentação de conceitos, resultados e comparações pertinentes ao objeto deste estudo, designando este o perfil do Educador Ambiental.

Dentre os 155 artigos encontrados, estimouse uma amostra, onde desta, 59\% referem-se a documentos legais e leis que discutem sobre: a) as contribuições para o processo de EA; b) a necessidade da inclusão da EA em todos os níveis de ensino nacional, estadual e municipal; c) a finalidade da Educação como a preparação para o exercício da cidadania; 
d) a tentativa de trabalhar a EA no ensino formal de forma interdisciplinar; e) como a Educação Ambiental deve estar presente na Educação Formal e Não Formal, seus princípios, objetivos e sobre a PNEA ${ }^{11}$; f) os aspectos operacionais das Diretrizes Curriculares Nacionais da Educação Ambiental a serem cumpridos na educação básica e ensino superior e a criação de espaços sustentáveis; g) as realidades locais para a elaboração das Políticas e Programas estaduais de Educação Ambiental; h) a formação de profissionais com ênfase na visão ética e humanística e enfoque didático pedagógico relacionado à realidade vivencial do educando; e, i) a maneira que a EA vem sendo trabalhada no ambiente escolar.

Contribuindo para o enfoque da pesquisa, $18 \%$ dos artigos e livros selecionados referem-se à degradação ambiental; à formação de indivíduos capazes de ler e interpretar o mundo em transformação; ao papel do educador ambiental formal para transformar hábitos e práticas sociais; e a categorização das correntes de pensamento no Campo Social da Educação Ambiental e 23\% destes fomentam e conceituam a forma como o ensino formal vem articulando a EA nas suas práticas de ensino-aprendizagem; a trajetória da EA baseada no histórico e na legislação pertinente visando à formação para uma sociedade sustentável; a atual diferenciação do campo da EA no Brasil, interpretadas por meio do diálogo com a literatura da área; análise da narrativa da EA, focando suas tendências, correntes e concepções que permeiam o discurso dos profissionais educadores ambientais.

Vale destacar também que essas literaturas indicam que a formação do Educador Ambiental implica uma reformulação metodológica, conceitual e curricular. O perfil desejado deveria assumir o conhecimento como um processo dialético resultante da interação entre o sujeito e o objeto do conhecimento, a dimensão afetiva, a visão da complexidade, a contextualização dos problemas ambientais, pois, a metodologia de ensino deve recorrer ao conflito cognitivo, visando à reconstrução conceitual. Isso quer dizer que o Educador Ambiental Formal tornar-se-ia um profissional com qualificação que desvinculasse o mito de "[...] apenas pela boa vontade ou por um voluntariado idealista, mas sim um docente que se nutrisse do geral

11 Política Nacional de Educação Ambiental e também das especificidades que a habilitação como formação sistemática requer" (SATO, 2001, p. 10).

O relatório da UNESCO (2004) enfatiza que a preparação de Professores/ Educadores Ambientais para atuarem como agentes de conscientização e mudanças têm sido consideradas prioridade para as nações em todas as regiões do mundo. $\mathrm{E}$, de acordo com Tristão (2013, p. 854), muito se tem argumentado sobre o encantamento provocado pela educação ambiental, pela sua conectividade com uma razão sensível em que a natureza é encarnada na produção de subjetividades.

Porém, a autora adverte que a ideia que perpassa entre os professores/educadores ambientais é: sei da sua importância, reconheço, mas não sei muito bem como fazer. Por isso, para atingir resultados positivos neste processo é preciso que a formação destes profissionais seja eficiente, pautada na realização de ações que visem à formação de cidadãos conscientes de seus valores em relação à preservação do Meio Ambiente (SANTOS, 2016).

Sabe-se que ainda não há um modelo universal de Educador Ambiental; mas a necessidade de se estudar este profissional pode ser a chave para renovar os valores sociais, desenvolvendo o comprometimento de mudança desde as pequenas atitudes individuais até o envolvimento na resolução dos problemas mundiais. $\mathrm{Na}$ visão de Carvalho (2004), o Educador Ambiental poderia cultivar ideias e sensibilidades ecológicas em sua prática educativa. Acrescemos a esta visão que o Educador Ambiental Formal não deve ser considerado como uma pessoa ou grupo de pessoas completamente ecológicas. Na verdade, a esse profissional exigem-se características pessoais e coletivas.

A formação de um sujeito capaz de ler seu ambiente $e$ interpretar as relações, os conflitos e os problemas neles presentes se enquadra como a primeira ideia de sujeito ecológico que podemos ter. Assim, como sujeitos ecológicos, podem transformar a natureza em cultura, ou seja, transformar tudo que nos é dado por meio dos recursos naturais em ensinamentos capazes de nos guiar por meio de valores éticos (LOUREIRO, 2007, p. 41).

Jacobi (2005) defende que os Educadores Ambientais devem desenvolver práticas de 
Educação Ambiental promovendo uma transformação de hábitos e práticas sociais além da formação de cidadania ambiental, pois para este autor, o papel deste é primordial para impulsionar as transformações de uma educação que precisa também levar em consideração a questão do desenvolvimento sustentável. E, sob este mesmo viés, Saviani (2005) ratifica a importância da junção da teoria com a prática e acredita que, para o Educador Ambiental buscar o enfrentamento do estado das coisas e dos problemas encontrados no cotidiano é importante buscar fundamentos a partir da filosofia da práxis.

\section{CONCLUSÃO}

Desta forma, este estudo defende a ideia de que o papel do Educador Ambiental se torna essencial para a transformação de valores e práticas sociais desejados. Contudo, podemos concluir que ainda é necessário ampliar seu envolvimento por meio de iniciativas que aumentem o seu nível de preocupação com o meio ambiente, pois, em

\section{REFERÊNCIAS}

[1] Carvalho, I. C. M. Educação Ambiental Crítica: nomes e endereçamentos da educação. In: Layrargues, P. P. Identidades da educação ambiental brasileira. Brasília, 2004.

[2] Jacobi, P. R. Educação Ambiental: o desafio da construção de um pensamento crítico, complexo e reflexivo. Educ. Pesqui. [online]. 2005, vol.31, n.2, pp. 233-250.

[3] Layrargues, P. P.; Lima, G. F. C. Mapeando as macro-tendências políticopedagógicas da Educação Ambiental contemporânea no Brasil. In: VI Encontro Pesquisa em Educação Ambiental: A Pesquisa em Educação Ambiental e a Pós-Graduação no Brasil, Ribeirão Preto, 2011, p. 1-15.

[4] Loureiro, C. F. B. Educar, participar e transformar em Educação Ambiental. Revista brasileira de Educação Ambiental. Brasília: Rede Brasileira de Educação Ambiental, nov. 2004.

[5] Educação e Meio Ambiente. Tocantins: Fundação Universidade do Tocantins Unitins/Empresa de Educação Continuada Ltda Educon. Palmas, 2007.

[6] Morales, A. G. M. Processo de institucionalização da Educação Ambiental: tendências, correntes e concepções. Revista Pesquisa em Educação Ambiental, vol. 4, n. 1 - pp. 159-175, SIBI, 2009. conformidade com a Lei 9798/1999, para que a Educação Ambiental Formal apresente características próprias esta necessita ser desenvolvida por meio da capacitação das pessoas envolvidas.

A reflexão sobre a prática do professor pode, portanto, contribuir para a superação de práticas educativas ambientais que se mostram deficientes na medida em que legitimam o pensamento hegemônico da sociedade atual. Por conseguinte, concordamos com Tristão (2004), que é fundamental que o Educador Ambiental se reconheça como parte integrante do trabalho, se sensibilize com os problemas e se sinta responsável por eles; entendendo os conceitos que regem a sua dinâmica poderá agir de forma efetiva. Mais ainda, que sejam eles participantes do processo de construção dos saberes ecológicos e responsabilizem-se na formação de novas subjetividades de seus alunos. Mediante a isso, o Educador assume o papel de mediador e transmissor do conhecimento, necessitando este estar devidamente capacitado, informado e preparado para fazê-lo.

[7] $\mathrm{Sa}$ ntos, M. F. P. Educação Ambiental e seus Reflexos para a Comunidade Escolar. In: (org) Carvalhêdo, J. L. P; Portela, J. L. Educação Ambiental: Ensino, formação e práticas educativas. Teresina: EDUFPI, 2016.

[8] Sato, M. Formação em Educação Ambiental - da escola à comunidade. In: Panorama da Educação Ambiental no ensino fundamental. Secretaria de Educação Fundamental. Brasília: MEC; SEF, 2001.

[9] Saviani, D. Pedagogia histórico-crítica. 9. ed. Campinas: Autores Associados, 2005.

[10] Tristão, M. A educação ambiental na formação de professores: A educação ambiental na formação de professores redes de saberes. São Paulo/Vitória: Annablume/ Facitec, 2004.

[11] Uma abordagem filosófica da pesquisa em educação ambiental. Revista Brasileira de Educação, Vitória, ES: Universidade Federal do Espírito Santo v. 18 n. 55, Brasil, out.dez. 2013.

[12] Unesco. O Perfil dos professores brasileiros: o que fazem, o que pensam, o que almejam - São Paulo: Moderna, 2004. 


\section{Gapítulo 18}

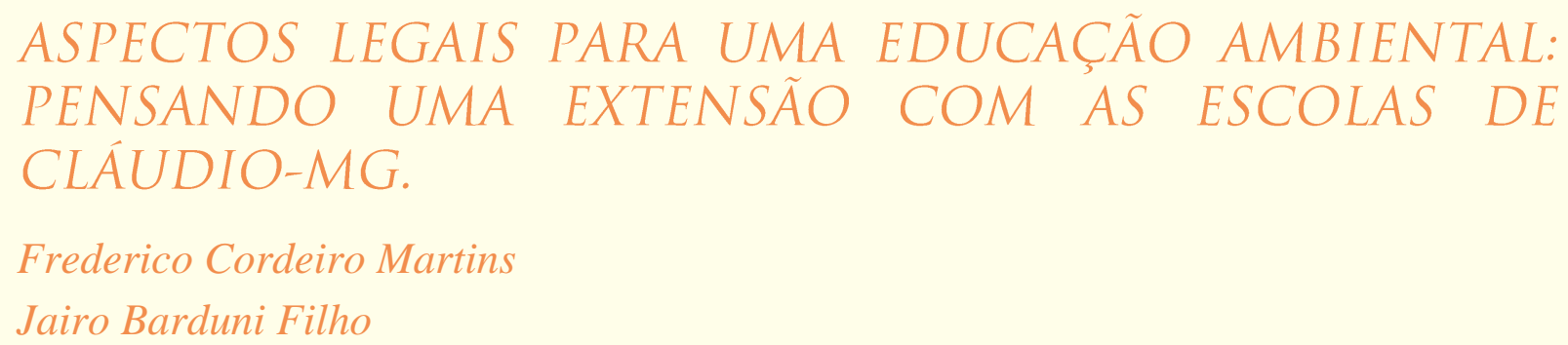

Márcio Pereira

Resumo: Nos últimos anos a sociedade vem acompanhando verdadeiros desastres ambientais, se por um lado o discurso se concentra no que se convencionou chamar de aquecimento global, sabemos que esse aquecimento e parte de um conjunto de outros problemas produzidos pelo capital no desejo de sua reprodução acelerada e para sua manutenção sem nenhuma preocupação com o meio ambiente. O meio ambiente, além de sofrer com os impactos de ações climáticas, tem sido deteriorado historicamente pelo descarte incontrolado do lixo residual doméstico e industrial. O projeto de tratamento de resíduos sólidos em sua vertente educacional possui o objetivo de diagnosticar e pensar a implementação de ações nas escolas do município de Cláudio-MG, no intuito de concretizar o desejo tanto do poder administrativo local quanto institucional, Universidade Estadual de Minas Gerais - UEMG-Cláudio bem como da Faculdade de Políticas Públicas (FAPP) de Belo Horizonte de tornar existente o cuidado com o descarte do lixo neste município. As ações educativas são o foco de nossas ações extensionistas tendo em vista a importância de diagnosticar e agir neste campo como sendo um dos responsáveis pelo processo de conscientização de preservação do meio ambiente. Pretendemos acionar através de uma rede institucional e com diferentes protagonistas um fazer ambiental, no qual a formação, a preservação e a conservação se apresentam como elementos centrais de realização a curto, médio e longo prazo. Assim a ideia principal é que possamos, no âmbito da Educação Ambiental, diagnosticar e gestar possibilidades de atividades extensionistas para as escolas do município de Cláudio-MG. 


\section{INTRODUÇÃO}

A ideia de construção de pesquisa cientifica interdisciplinar e interinstitucional surge de uma concepção contemporânea de produção de conhecimento, onde a reciprocidade se torna presente entre os pesquisadores e instituições, envolvendo trabalho em grupo, colaboração e parceria na busca de uma investigação detalhada através do compartilhamento de experiências, objetivos e problemas. Segundo Veiga (2009):

"A pesquisa interinstitucional entre professores-pesquisadores e alunos de diferentes instituições de educação superior tem surgido como resposta às transformações sociais, políticas, culturais e tecnológicas que colocam em discussão as formas conservadoras e individualistas de produção de conhecimento e desenvolvimento profissional de professores." (p.3)

A interdisciplinaridade na pesquisa busca a correta contextualização de certas realidades marcadas pela complexidade, pois na maioria das vezes não podem ser explicadas por uma única disciplina.

\section{Conforme cita Maranhão (2010):}

"A prática interdisciplinar de pesquisa ocorre em meio a diversos contextos no âmbito da história e consiste num empreendimento coletivo (e controverso) para conhecer as realidades2. Tal contexto, caracterizado pela complexidade (Baumgarten, 2006; Floriani, 2006; Zellmer et al, 2006), indica a necessidade de novas explicações científicas multidimensionais de médio e longo alcance (Baumgarten, 2006: 16-17), principalmente quando se investigam objetos complexos, que escapam às explicações de uma única disciplina (Floriani, 2006: 72)."

Diante da complexidade de que se trata o tema meio ambiente, encontra-se na cooperação científica entres pessoas e instituições de diversas áreas de conhecimento, a correta investigação das prováveis soluções para os problemas advindos do uso de recursos naturais.

Com este espirito de cooperação e troca de experiências surgiu a ideia de desenvolvimento do projeto de tratamento de resíduos sólidos do município de Cláudio-MG, pela Universidade Estadual de Minas Gerais UEMG, Unidades Cláudio e Faculdade de Políticas Públicas (FAPP) de Belo Horizonte, contemplando as áreas de conhecimento de ambas. Um primeiro momento de troca de informações sobre as necessidades já conhecidas do município quanto às politicas públicas de gestão ambiental foi o ponto chave da união interinstitucional e interdisciplinar.

Estabelecido o grupo inicial de trabalho, o projeto foi provisoriamente intitulado de "Gestão de Resíduos Sólidos - Projeto Cidade de Cláudio", estabelecidas as diretrizes de pesquisa pautadas nos temas: Política e Estrutura Legal; Arranjo Institucional (Governança Corporativa); Gestão Operacional; Tecnologias Apropriadas Gestão Financeira e Orçamentária; Participação e Conscientização Pública e Educação, que se apresenta neste artigo como o primeiro trabalho oriundo deste macro projeto.

A educação neste caso seria uma vertente do projeto que visa a conscientização tanto dos alunos das escolas de Cláudio quanto de suas famílias, entendendo que o processo de extensão poderá se estender as famílias bem como até mesmo aos próprios catadores da cidade de Cláudio.

\section{METODOLOGIA}

A investigação que está em seu começo partiu de uma revisão bibliográfica sobre o assunto - Educação ambiental e, após esta primeira etapa que será melhor apresentada na análise e discussões, partimos para gestar um plano futuro de diagnóstico com as escolas do município de Cláudio-MG para saber como as escolas deste município pensam e trabalham com o tema em suas ações pedagógicas.

Assim, a investigação que projetamos para começar no segundo semestre de 2018, ocorrerá com as escolas da rede pública de educação da cidade de Cláudio, por meio da análise da pesquisa documental, no caso, análises de conteúdo (livros didáticos, Plano Político Pedagógico (PPP) e currículo escolar). Paralelamente serão realizadas algumas entrevistas/conversas com os sujeitos (alunos) no intuito de saber deles o que têm visto e apreendido na escola sobre o assunto meio ambiente.

Entende-se a entrevista como sendo um gênero discursivo no qual se pode pensar nas redes de significados, interações, invenções infantis e a importância dada ao tema do Meio Ambiente que certamente pode ser 
evidenciada na relação entre o interlocutor e o destinatário. Logo, as entrevistas irão fornecer base para a análise de conteúdo que seria o método de estudo dos conteúdos em comunicação, ou seja, da presença de determinadas palavras, das verdades contidas nestas, em suas repetições etc.

É de conhecimento do desenvolvimento de um projeto, informação dita pela secretaria do meio ambiente da prefeitura de Cláudio, Maria Helena Gonçalves Mitre Amorim, que as escolas, em parceria com a secretaria, já trabalham com o tema meio ambiente, duas vezes ao ano, no sentido de conscientização deste conteúdo nas escolas. Assim, a proposta é a de diagnosticar este trabalho. Como ele é feito? De que modo é desenvolvido? O que se tem produzido desta ação? O objetivo é saber se, de fato, esta conscientização é algo possível de ser mensurada pelas entrevistas e se os alunos e alunas possuem compreensão do tema.

\section{RESULTADOS E DISCUSSÕES}

Até o presente momento, já houveram três reuniões do projeto de tratamento de resíduos sólidos do município de Cláudio, a primeira aconteceu na cidade de Belo Horizonte, na Faculdade de Políticas Públicas (FAPPUEMG). Naquele momento, estiveram presentes os representantes da Unidade da UEMG-Cláudio para definirmos em conjunto com os professores da FAPP os eixos de extensão.

\section{Imagem 1 (Encontro de professores da UEMG-Cláudio com os professores da Faculdade de Políticas Públicas (FAPP) em Belo Horizonte em junho de 2018).}

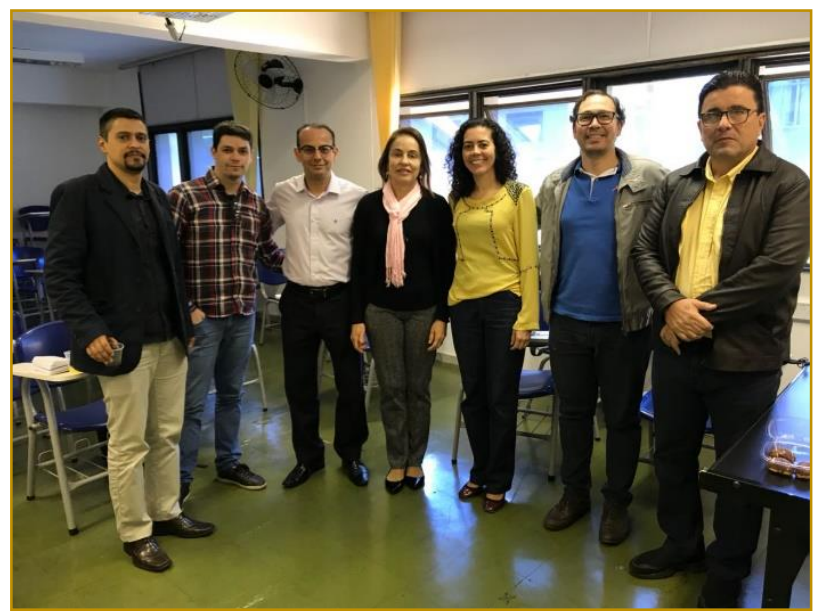

A segunda reunião ocorreu na prefeitura da cidade de Cláudio, a reunião contou com a presença dos catadores, a equipe da UEMGCláudio, do prefeito, da secretaria do meio ambiente e vereadores da cidade. O objetivo do encontro foi de conversar com os catadores na tentativa de convencimento para a associação de catadores, saímos da reunião com uma expectativa boa de adesão dos catadores. 
Imagem 2 (Encontro da equipe UEMG com os catadores, secretaria do meio ambiente, vereadores e outros convidados em julho de 2018).

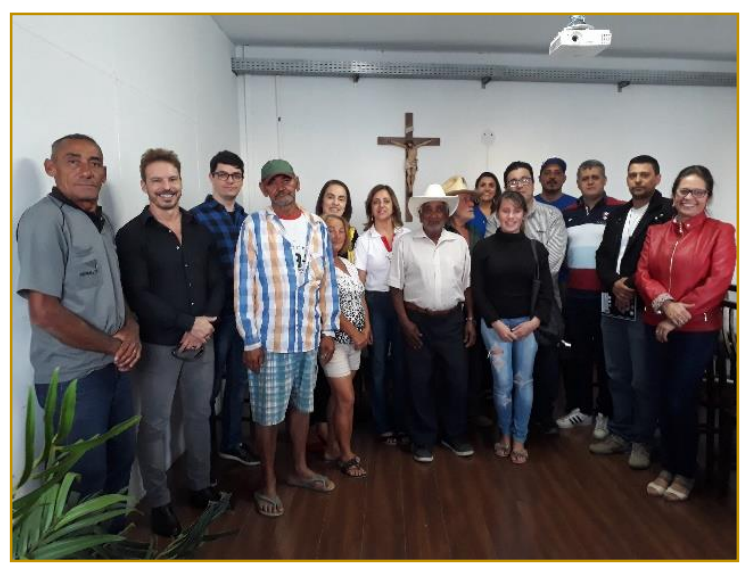

Contudo, no terceiro encontro que ocorreu entre os catadores e vereadores para que a conversa avançasse no sentido de ouvi-los para que o processo ocorresse de acordo com a demanda deles, ficamos sabendo que apenas três catadores compareceram. A próxima reunião está marcada para o dia 01 de agosto na cede da UEMG-Cláudio.

Para a próxima reunião, pedimos a presença de uma representante da Secretaria de Educação para tentarmos articular um modo de diagnosticar como o trabalho em prol da educação ambiental tem sido praticado pelas escolas e se tem ocorrido essa extensão de conscientização nas famílias dos educandos.

\subsection{BREVE CONTEXTO DA EDUCAÇÃO AMBIENTAL E A DIFÍCIL TAREFA DE TRABALHAR EM PROL DO COLETIVO.}

O processo de industrialização e o estilo de vida capitalista trouxeram mudanças profundas para o modo como nos relacionamos com a natureza e com o outro. Apesar de ainda enxergarmos a questão ambiental como algo fora de nós, que trata do impacto da ação do homem sobre a natureza e como essa tem se reorganizado para resistir a essa intervenção, é fato que o homem é parte da natureza, toda e qualquer ação que venha a afetá-la de algum modo, vai determinar mudanças também na sociedade.

A Educação Ambiental tem sido sujeito de pesquisas onde se procura compreender e questionar as metodologias aplicadas em suas atividades com objetivo de construir diferentes possibilidades de interações sociais. As ações da Educação Ambiental são pensadas a partir de um olhar voltado para um fazer ambiental, no qual a formação, a preservação e a conservação se apresentam como centrais. Trata-se de pensar o meio ambiente enquanto sendo o cuidado de si e do outro, cuidando do meio ambiente eu cuido de mim e do outro que também é parte deste coletivo. Além disso, a educação ambiental é uma intervenção no mundo, uma forma de desmascarar a ideologia dominante de evolução que confunde o senso comum em discursos romanceados de um capitalismo destituído de sua responsabilidade social. Segundo Freire (2013): "É uma imoralidade, para mim, que se sobreponha, como se vem fazendo, aos interesses radicalmente humanos, os do mercado" (p.98).

Freire (2017) ainda nos fala que: “(...) através de sua ação sobre ele (o mundo), o homem se encontra marcado pelos resultados de sua própria ação" (p.26), isso nos faz refletir sobre a necessidade do uso sustentável dos recursos naturais e da terra, e principalmente sobre a maneira como as relações humanas são afetadas em todo esse processo.

No Brasil o Movimento Ecológico vai ganhar força em plena ditadura, na década de 1970. Em um país em que o manejo racional dos recursos naturais nunca foi uma tradição, a industrialização e a abertura da economia ao capital estrangeiro tiveram consequências devastadoras.

No país foi criada em 1973 a Secretaria Especial do Meio Ambiente, aparentemente mais por pressão do Banco Mundial e de organizações voltadas para a questão ambiental que por interesse real no tema. 
Propôs que as instituições governamentais de Educação no Brasil deveriam promover a Educação Ambiental, mas, diante do quadro político vigente desfavorável (...) a Educação Ambiental foi vista como um processo de natureza revolucionário-subversiva e foi devidamente congelada. (...) os interesses políticos e econômicos das nações mais ricas poderiam ser "afetados" por um tipo de educação que poderia proporcionar às pessoas uma nova visão de mundo.

Realizado em 1975, na Iugoslávia, a Conferência de Belgrado estabeleceu no documento conhecido com Carta de Belgrado os princípios e orientações para um programa de Educação Ambiental, com características multidisciplinares, baseadas nas diferenças regionais e com foco nos interesses nacionais, por se tratar de um dos mais fundamentais elementos de enfrentamento das questões ambientais com possibilidade de desenvolvimento de novas habilidades, competências, atitudes e valores para a melhoria da qualidade de vida das pessoas, suas relações com a ecologia e, principalmente das pessoas entre si. Uma das mais importantes metas é a formação de uma população consciente e preocupada com o meio ambiente e com os problemas associados, e que tenha conhecimento, aptidão, atitude, motivação e compromisso para trabalhar individual e coletivamente na busca de soluções para os problemas existentes e para prevenir novos.

A própria Carta de Belgrado estabelece que a Educação Ambiental deve considerar o ambiente em sua totalidade - natural e criado pelo homem, ecológico, econômico, tecnológico, social, legislativo, cultural e estético, como processo contínuo, permanente, tanto dentro como fora da escola e deve adotar um método interdisciplinar.

Uma das conferências mais importantes sobre o meio ambiente ocorreu em Tblisi na Geórgia em 1977, esta conferência representou um momento de entendimento do que vem a ser educação ambiental, algo, aliás, apropriado pelo Ministério da Educação em sua posição signatária deste encontro, pois, mesmo não tendo participado do encontro, o Brasil produziu inspirado nas discussões do encontro o primeiro documento oficial para a educação ambiental do país.

Deste modo, como aponta Bovo (2007), no Brasil, ocorreu a promulgação da primeira lei que instrumentaliza a educação ambiental, lei
(Lei federal 6.938/81). Este instrumento legal versa sobre as escolas precisarem trabalhar o tema da EA integrada aos programas educacionais.

Ainda de acordo com Bovo (2007), no viés de movimento pró meio ambiente, temos os efeitos da Rio-92 que, por exemplo, lançou a carta da terra, que entre outros pontos que versam esse documento, é apontado o direito que todo cidadão possui de ter uma vida saudável e ter uma vida saudável é viver em um ambiente cuidado, com o lixo devidamente tratado. Um ambiente no qual tanto as indústrias se tornariam instituições preocupadas com o meio ambiente como os cidadãos ordinários, nossos vizinhos, nossos parentes, nossos professores e amigos da escola.

A Educação Ambiental, ao ser destacada pela Rio-92, com a realização da Conferência das Nações Unidas sobre o Meio Ambiente e Desenvolvimento (CNUMAD), propôs um padrão de desenvolvimento conciliando métodos e práticas ambientais com objetivos de promover a justiça social com eficiência econômica.

Além desse evento, foi realizada a primeira jornada internacional de educação ambiental e o workshop sobre educação ambiental, organizado pelo MEC, dando origem a três documentos - Agenda 21, carta brasileira para a educação ambiental e o tratado de Educação Ambiental sociedades sustentáveis e responsabilidade global. Ações que, fortalecidas pelo grupo de trabalho para a educação ambiental no âmbito do MEC e pela elaboração dos parâmetros Curriculares Nacionais (PCN's) que sugerem 0 meio ambiente como um dos temas transversais.

De fato, um dos documentos legais de maior impacto no currículo escolar, os (PCN's), instituídos pela Secretaria de Ensino Fundamental, do Ministério da Educação, em seus temas transversais de 1997, passam a orientar metodologicamente a implantação do tema nas escolas. Logo depois, a Lei no 9.795, de 27 de abril de 1999, criou a Política Nacional de Educação Ambiental. De acordo com Bovo (2007):

Os parâmetros Curriculares Nacionais sugerem que o tema Meio Ambiente seja trabalhado transversalmente na Educação, ou seja, propõem que as questões ambientais permeiam os objetivos, conteúdos e orientações didáticas em todas as disciplinas, no período da escolaridade obrigatória. Ao 
mesmo tempo, na perspectiva da nova Lei de Diretrizes e Bases (Lei 9.394/96) há indicação de mudanças curriculares no ensino formal; a Educação Ambiental pode ser apresentada em outros níveis de ensino. (p.6).

Em 2002 se instituiria uma política nacional de educação ambiental que a institucionaliza, localiza seus princípios e apregoa a necessidade de interação entre os sistemas educacionais e os setores públicos e privados. (GONÇALVES e DIAS, 2018). O que se espera é que a Educação Ambiental escolar seja desenvolvida mediante práticas que integram humanidade e ambiente num processo prazeroso e lúdico em que as interações educativas estão relacionadas com aspectos bióticos e abióticos do meio.

Os adultos de hoje não sabem administrar a herança deixada pela era industrial e, como não conseguem limpar a casa, a esperança fica com a próxima geração, aquela que ainda frequenta os bancos escolares. A sociedade mostra que educação ambiental não se aprende (ou não é ensinada) em casa. É só observar por alguns minutos o trânsito fluir numa rua e contar quantos papéis e de cigarros são jogados na mesma. Ou ir à praia e ver onde os banhistas jogam o lixo. Então, dê uma olhada no cesto de lixo de sua casa e repare como você também não separa o seu próprio lixo, ou seja, falta que nos apliquemos o $A B C$ da reciclagem. Bom, você dirá que a prefeitura não tem nenhum programa sério de reciclagem. $O$ fato é que quem se omite e lava as mãos na frente dos filhos, hoje, formará mais um adulto porcalhão daqui há pouco tempo. A questão do lixo doméstico não é a única, nem é o mal maior se considerarmos a poluição industrial, os resíduos químicos despejados nos córregos, rios etc.

Se a escola pretende estar em consonância com as demandas atuais da sociedade, é necessário que trate de questões que interferem na vida diária, contribuindo para a formação e pleno reconhecido, ou seja, a educação ambiental deve ser um processo permanente, no qual a sociedade deve tomar e adquirir conhecimentos, valores, habilidades, experiências e determinação que nos tornem aptos a agir em prol do cuidado com o meio ambiente. Para isso, é preciso que o currículo, um dispositivo de poder no ambiente educacional contemple a discussão de Meio Ambiente em diálogo com as disciplinas escolares e não apenas aparecendo a discussão duas vezes por ano.
Por último, não poderia deixar de apontar para a reforma da Base Nacional Comum Curricular que parece ser $\mathrm{o}$ assunto do momento nas escolas, o documento é o que define o que os alunos aprenderão como aprendizagens essenciais a todos os alunos da educação básica além de ser uma referência obrigatória para formulação dos currículos, de acordo com o documento, seria uma reforma para direcionar na educação brasileira a formação integral do aluno e a construção de uma sociedade justa, democrática e inclusiva. São diversos os pontos de vistas em relação a este documento, e, em visita a duas escolas públicas de Cláudio-MG, por ocasião do estágio obrigatório das alunas da Pedagogia, pude ouvir de duas diretoras que as escolas já estão se preparando para tal mudança. Em fala de uma delas, o documento a nível fundamental preconiza o trabalho com valores o que a escola já faz, me parece que seria um reforço dos valores humanos, democráticos e inclusivos.

$E$, se a Base preconiza os valores, a integralidade da formação, então o trabalho com os temas tidos como transversais, no caso, o meio ambiente deve se tornar um dos temas a serem trabalhados pedagogicamente pela professora independente se a escola possui dia de trabalho comemorativo do meio ambiente. A Base Nacional Comum Curricular recebido por uma das diretoras da Secretaria de Educação foi gentilmente cedido a mim nesta visita, e, aponta para dez competências gerais para cumprir com as dimensões cognitiva, social, emocional, cultura e física, entre os dez, o sétimo me chamou atenção, este diz assim:

Argumentar com base em fatos, dados e informações confiáveis, para formular, negociar e defender ideais, pontos de vista e decisões comuns que respeitam e promovam os direitos humanos, a consciência socioambiental e o consumo responsável em âmbito local, regional e global, com posicionamento ético em relação ao cuidado de si mesmo, dos outros e do planeta. (BASE NACIONAL COMUM CURRICULAR, 2018 p.9)

Assim, é possível que com esta competência em destaque, as escolas trabalhem concretamente o tema da preservação do meio ambiente, isso, claro, entendo que se trata de uma letra prescritiva, ou seja, no plano ideal já que é preciso esse olhar averiguador para nos certificarmos esta ação acontecendo. 
Também é algo interessante de se observar, é se os livros didáticos, com a nova base, irão se adequar a esse tema de modo a trazê-lo como protagonista da aprendizagem. Contudo, como já foi dito, muitas são as críticas e desconfianças do impacto desta política atual do MEC. Uma delas foi feita pelo professor Freitas (2017) ao dizer que:

Antes da BNCC os editores (e professores) tinham uma margem de manobra maior na questão do conteúdo, agora, além dos conteúdos definidos (baseados em competências) terão ainda definido o próprio sequenciamento dos conceitos envolvidos nos conteúdos. E de quebra, a questão das habilidades socioemocionais. Acabou a fase da "criatividade", agora é material padronizado, para o ensino padronizado e que deve apoiar uma avaliação padronizada. Tudo voltado para aumentar a nota do IDEB. No conceito de educação do MEC, nota mais alta é sinônimo de boa educação, e se você quer melhorar o desempenho nos exames, deve-se ensinar aquilo que cai na prova. Portanto, é preciso estreitar o ensino nas habilidades esperadas e que serão avaliadas. A consequência para os editores e professores era esperada. Para os estudantes, a consequência é o estreitamento curricular e o treino para os testes. (p.1)

\section{REFERÊNCIAS}

[1] Brasil. Base Nacional Comum Curricular disponível em: http://basenacionalcomum.mec.gov.br/wpcontent/uploads/2018/02/bncc-20dez-site.pdf acesso em: 29 de jun de 2018.

[2] Brasil. Secretaria de Educação Fundamental: Parâmetros Curriculares Nacionais: meio ambiente/ saúde. Brasília. 128p. Disponível em:

http://portal.mec.gov.br/seb/arquivos/pdf/livro091.p df

[3] Bovo, Marcos Clair. Desenvolvimento da educação ambiental na vida escolar: avanços e desafios. Disponível em: http://www.urutagua.uem.br/013/13bovo.htm acesso em 27 de junho de 2018.

[4] Cnumad. Agenda 21. Brasília: Senado Federal/Subsecretaria de Edições Técnicas, 1997.

[5] Freire, Paulo. Extensão ou comunicação. Disponível em: http://www.emater.tche.br/site/arquivos_pdf/teses/Li
Logo, o que vai acontecer na prática com o ensino é algo que nos interessa observar enquanto professores e pesquisadores da educação e do direito e, no tocante a este cenário em mudança, saber como temas como meio ambiente tido como transversal pelos Parâmetros Curriculares Nacionais irão compor não apenas o novo livro didático, mas, quais as estratégias pedagógicas as escolas irão se valer para o trabalho com o conhecimento deste tema visando a conscientização do coletivo para a Educação Ambiental durante o ano letivo?

\section{CONCLUSÕES}

Podemos falar que até o momento as primeiras impressões são de que o trabalho em prol do coletivo não será fácil de ser praticada entre os sujeitos catadores e que esperamos que com as escolas não haja a mesma resistência por parte dos gestores e professores para a execução do projeto. Contudo, entendemos que a oportunidade da UEMG-Cláudio participar da construção do projeto de resíduos sólidos é uma realidade e que o trabalho será de longo prazo, o que trazemos nesta escrita é apenas as primeiras impressões fruto de nosso "diário de bordo" da pesquisa que acaba de iniciar.

vro_P_Freire_Extensao_ou_Comunicacao.pdf acesso em 25 de mai de 2017.

[6] Freire, Paulo. Pedagogia da Autonomia: saberes necessários à prática educativa. $47^{\circ}$ ed Rio de Janeiro: Paz e Terra, 2013.

[7] Gonçalves, A, C, G. Dias, Cleuza Maria Sobral. Práticas Educativas no Contexto Escolar e as Manifestações dos Princípios da Educação Ambiental. GT Educação ambiental $n^{0} 22$. Disponivel em: http://arquivos.ambiente.sp.gov.br/cea/cea/Praticas _Educativas.pdf acesso em 28 de junho de 2018.

[8] Maranhão, Tatiana de P. A. Produção Interdisciplinar de Conhecimento Científico no Brasil: temas ambientais. Revista Sociedade e Estado - Volume 25 Número 3 Setembro/Dezembro 2010

[9] Veiga, IIma Passos Alencastro. Pesquisa Interinstitucional Em Parceira: um espaço de possibilidades formativas. Rev. Diálogo Educ., Curitiba, v. 9, n. 26, p. 47-59, jan./abr. 2009. 


\section{Bapítulo 19}

\section{A EFETIVAÇÃO DA EDUCAÇ̃̃O AMBIENTAL CRITICA NO ENSINO SUPERIOR, MINISTRADO NA MODALIDADE À DISTÂNCIA}

\section{Leandro Costa Fávaro \\ Sérgio Ricardo Silva Magalhães \\ Letícia Rodrigues da Fonseca}

Resumo : O presente resumo expandido deriva da observação sistemática relativa à efetivação de uma prática pedagógica voltada para a aplicação da Educação Ambiental Crítica ou Emancipatória inter-relacionada com a introdução do aluno universitário EaD no universo da Pesquisa. Objetivou-se, nesta pesquisa, descrever a experiência vivenciada pela Universidade Vale do Rio Verde - UninCor em seus cursos de graduação, ministrados na modalidade à distância: Pedagogia, Letras, Arquitetura, Engenharia Civil e Administração, referente ao ano de 2017. O conceito de Educação Ambiental, enquanto área do conhecimento, passa a ser desenvolvido em meados de 1965, e, desde então, vem sofrendo inúmeras modificações, subdividindo-se em diversas correntes, em decorrência da forma com que os seres humanos se compreendem em relação ao planeta. Nos últimos anos, a temática passou a ser compreendida com extremada significância, tornando a Educação Ambiental um direito previsto em legislações específicas, e garantido aos diferentes níveis de ensino. Porém, continua sendo um desafio para as instituições, principalmente, para o ensino superior, fazer com que as discussões ocorram de forma efetiva e eficaz entre seus estudantes. Nessa perspectiva, observa-se que a prática descrita apresenta um norteamento de ações pedagógicas que possibilitou a apropriação do conhecimento a respeito da Educação Ambiental Crítica ou Emancipatória, a partir da associação com o universo da pesquisa, tendo sido efetivada por meio da oferta de uma disciplina denominada "Projeto Integrador: Responsabilidade Social e Meio Ambiente", comprovando a possibilidade das universidades flexibilizarem-se, criando adequações aos cenários educacionais, a fim de atingirem as demandas relativas aos debates planetários sobre o Meio Ambiente.

Palavras-chave: Educação Ambiental; Educação Ambiental Crítica; Educação Ambiental Emancipatória (EAE). 


\section{INTRODUÇÃO}

Os séculos $X X$ e XXI foram marcados pela divulgação de problemas ambientais decorrentes de procedimentos históricos evolutivos que revelaram a utilização inapropriada dos recursos naturais, conforme afirmam Ana Maria Ferreira e Yolanda Shizue Aoki (2010).

Dessa forma, debates e reflexões foram sendo desencadeados em busca de processos de ressignificação e interação entre o homem e o ambiente, originando $O$ conceito de Educação Ambiental (EA), que se tornou, de fato, conhecido a partir de 1965. Layrargues e Lima (2014) referem-se à EA como sendo um termo usual para designar todos os processos educativos que visam ao contexto ambiental como o motivador da ação pedagógica.

No entanto, Pádua e Tabanez (1997) ressaltam que, após a Conferência de Estocolmo, é que a EA passa a ser vista como um campo de atuação pedagógica de relevância e vigência internacional. Desde então, foi sendo desenvolvida timidamente, mantendo caráter experimental, por meio de metodologias distintas e propostas variadas.

Passadas décadas, estudiosos chegaram a uma concepção de EA, em que o meio ambiente é visto a partir de uma estrutura complexa, posicionando o homem como parte intrínseca de uma rede conectada por múltiplas vertentes. A essa concepção, Carvalho (2004) se refere utilizando a nomenclatura de EA Crítica, frisando que também é conhecida como emancipatória ou popular. Loureiro (2004) apresenta como características o estímulo ao questionamento às abordagens comportamentalistas, reducionistas e dualistas no entendimento da relação cultura-natureza.

Assim, ao mesmo tempo que a EA sofreu essas transformações, as estruturas educacionais modificaram-se. Por consequência, a sociedade passou a ter modelos e cenários educacionais distintos coexistindo, sendo que muitos deles representam verdadeiros desafios para a aplicabilidade da EA Crítica. Um exemplo é a Educação à Distância (EaD), que de acordo com o Censo realizado pela Associação Brasileira de Educação à Distância - ABED (2016), atende, aproximadamente, 33\% dos estudantes regularmente matriculados no ensino superior. Alves (2011) diz que, globalmente, é cada vez mais crescente a oferta de cursos formais e informais nessa modalidade.

Portanto, evidencia-se a existência de um número expressivo de estudantes que deve vivenciar as discussões relacionadas à EA, por meio de procedimentos e métodos que sejam adaptados para atender as especificidades presentes em seu contexto.

Objetiva-se com o este trabalho realizar a descrição de uma experiência de Educação Ambiental Emancipatória - EAE, vivenciada pela Universidade Vale do Rio Verde UninCor, em seus cursos de graduação, ministrados na modalidade EaD, como sendo uma possibilidade real de empoderamento de seus estudantes em relação aos debates ambientais.

\section{METODOLOGIA}

A pesquisa foi realizada em parceria com a Universidade Vale do Rio Verde - UninCor, Três Corações - MG. Optou-se pela abordagem qualitativa, apresentando natureza aplicável, sendo classificada como descritiva em relação aos seus objetivos e tendo como procedimento de estudo a observação sistemática. De acordo com Baker (2006), Marroun e Young (2017), esse método proporciona a compreensão do funcionamento de determinada atividade ou tarefa, criando condições para que se conheçam as etapas, os procedimentos, as ferramentas e os resultados obtidos.

É importante ressaltar que a pesquisa objetivou a descrição de uma proposta metodológica de efetivação da EAE. Foi direcionada a partir de uma estrutura sequencial, em que se propôs a observar e descrever as condições preliminares existentes nos cursos; a execução e a avaliação da proposta. Tal atividade exigiu a inserção do pesquisador na instituição, ao longo do primeiro semestre de 2017, registrando as observações pela construção do Diário de Campo Descritivo, conforme proposto por Falkembach (1997).

\section{RESULTADOS E DISCUSSÃO}

A UninCor propôs-se a trabalhar a EAE, por meio da disciplina denominada "Projeto Integrador: Responsabilidade Social e Meio Ambiente", presente em todas as matrizes curriculares, com carga horária total correspondente a 80 horas, sendo 
disponibilizada pela plataforma Moodle, com interface própria denominada EaD+. É acompanhada por um professor, que desenvolve a função de conteudista e mediador, possuindo formação na área ambiental e titulação correspondente ao mestrado.

A disciplina ofertada apoia-se em 35 itens, que foram estruturados a partir de uma lógica de construção da aprendizagem, visando provocar o contínuo questionamento e reflexão dos estudantes acerca dos problemas ambientais vivenciados no contexto em que se encontram inseridos, conforme indica a imagem 1. Didaticamente, o material e o processo podem ser subdivididos em três momentos específicos: introdução, pesquisa e conclusão.

Imagem 1 : Estrutura da Disciplina "Projeto Integrador: Responsabilidade Social e Meio Ambiente".

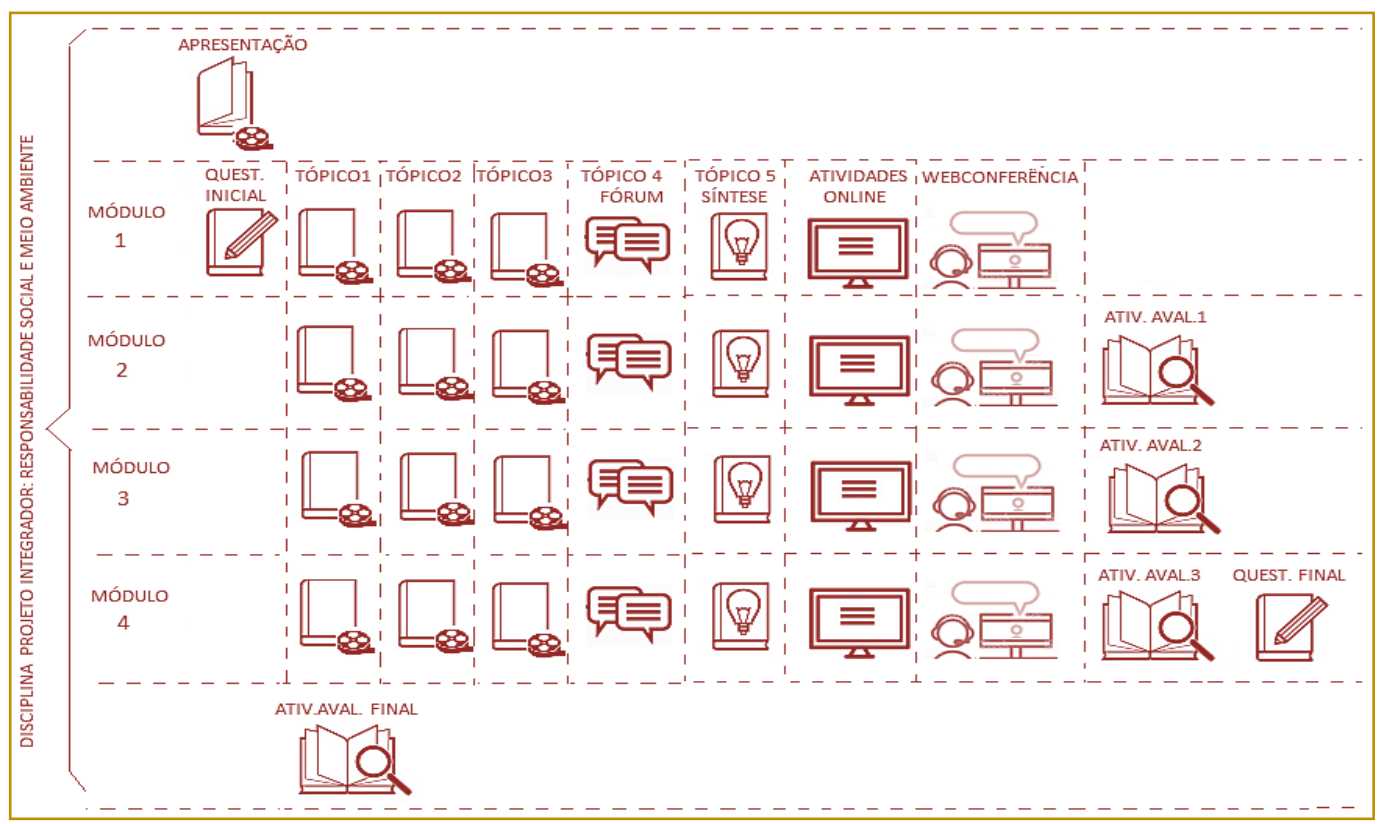

Fonte: Próprio autor (2018).

A primeira etapa, composta pelos itens "Apresentação" e "Módulo 1", destina-se a introduzir os estudantes nas propostas da disciplina, conduzindo-os à efetivação de um processo diagnóstico. Para isso, faz-se o uso da aplicação do "Questionário inicial", contendo 40 questões objetivas e 10 discursivas. Também estabelece discussões relacionadas aos princípios da pesquisa, a partir dos conteúdos apresentados nos "tópicos 1, 2 e 3", "fórum", "Atividades online" e "webconferência". Essa etapa é disponibilizada para os estudantes logo no início do período letivo, tendo duração aproximada de 25 dias letivos, e propicia ao professor relatórios, descrevendo os problemas ambientais existentes no contexto dos estudantes, de forma que a produção das demais etapas passa a ter um norteamento claro e objetivo.

No segundo momento, representado pelos "Módulos 2, 3 e 4", os estudantes são expostos aos debates científicos relacionados às questões anteriormente levantadas. Utilizam-se, para isso, recursos variados, como textos, vídeos, links e atividades online, distribuídos ao longo dos "Tópicos 1, 2 e 3", além de serem estimulados a adentrarem na pesquisa, pela construção e execução de um projeto que reflita as discussões estabelecidas. É importante ressaltar que, durante essa etapa, o professor assume uma postura de orientação, estando disponível por meio dos canais de comunicação existentes na plataforma.

Ao término do "Módulo 2", os estudantes encaminham ao professor o "projeto de pesquisa" finalizado (Atividade Avaliativa 1), e iniciam a execução da pesquisa, tendo o prazo aproximado de 40 dias para a total efetivação. A pesquisa ocorre, necessariamente, por ações desenvolvidas em campo.

No final do "Módulo 3", os estudantes entregam parte dos resultados encontrados 
(Atividade Avaliativa 2), possibilitando ao professor a efetivação de ponderações e reflexões, para que se dê continuidade às atividades. Espera-se que, ao terminar o "Módulo 4", a pesquisa tenha sido encerrada e que os estudantes possam encaminhar 0 Painel Científico - banner (Atividade Avaliativa 3), contendo os resultados mais significativos para a devida divulgação.

A última etapa pressupõe a autoavaliação do estudante, utilizando-se do "Questionário final", contendo 30 questões objetivas e 10 discursivas, estando relacionadas às possíveis mudanças posturais ocasionadas pela vivência da disciplina.

O processo avaliativo é feito de forma contínua e reflexiva, pela participação nas atividades online e nas interações existentes. Todavia, $60 \%$ da nota é atribuída às atividades avaliativas do final dos "Módulos 2, 3 e 4", correspondendo às etapas da pesquisa.

É notória a existência de projetos que extrapolam os muros institucionais, provocando modificações sociais por meio da ressignificação da interação com o meio ambiente.

\section{REFERÊNCIAS}

[1] Alves, Lucineia. Educação a distância: conceitos e história no Brasil e no mundo. Revista Associação Brasileira de Educação A Distância, São Paulo, v. 10, n. 1, p.83-92, 1 jan. 2011.

[2] Baker, Lynda. Observation: a complex research method. Library Trends, Chicago, v. 55, n. 1, p.171-189, 1 jul. 2006.

[3] Brasil. Decreto no 5.622, de 19 de dezembro de 2005. Regulamenta o artigo 80 da Lei no 9.394, de 20 de dezembro de 1996, que estabelece as diretrizes e bases da educação nacional. Diário Oficial [da] República Federativa do Brasil. Brasília, DF, 20 dez. 2005.

[4] Falkembach, Elza Maria Fonseca. Diário de campo: um instrumento de reflexão. Contexto e Educação, ljuí, v. 2, n. 7, p.19-24, 1 jul. 1987.

[5] Ferreira, Ana Maria; AOKI, Yolanda Shizue. Educação ambiental e a problemática do uso da

\section{CONCLUSÕES}

Mediante a pesquisa, torna-se evidente que a efetivação de uma proposta de EAE, destinada à modalidade EaD, vem representando um grande desafio para os Institutos de Educação Superior, mesmo a comunidade acadêmica estando ciente das legislações e das orientações sobre a importância dos debates interdisciplinares, que foquem a temática ambiental sob uma perspectiva da tríade do ensino, da pesquisa e da extensão.

Entretanto, é significativo verificar, a partir da descrição da experiência vivenciada pela UninCor, que a flexibilização e a adequação de processos metodológicos tornam possível a concretização da EAE, propiciando modificações sociais que extrapolam a dimensão institucional, conforme as considerações apresentadas por Carvalho (2004) e Loureiro (2004), destacando-se o cuidado em encaminhar a disciplina de forma crítica e reflexiva, a partir da realidade apresentada pelos estudantes.

Sugere-se a continuidade do estudo, possibilitando a descrição de outras práticas, voltadas para o ensino superior, destinadas aos mesmos propósitos educacionais.

água: conhecer para cuidar. Caderno Pde, São Paulo, p.2-32, 2016.

[6] Layrargues, Philippe Pomier; LIMA, Gustavo Ferreira da Costa. As macrotendências político-pedagógicas da educação ambiental brasileira. Ambiente \& Sociedade, São Paulo, v. 17, n. 1, p.23-40, jan. 2014. Trimestral.

[7] Loureiro, Carlos Frederico B.; Layrargues, Philippe Pomier; Castro, Ronaldo Souza de. Educação ambiental: repensando o espaço da cidadania. São Paulo: Cortez, 2002.

[8] Marroun, Sana; Young, Louise. Multimethod Systematic Observation: Theory and Practice. Collaborative Research Design: Working with Business for Meaningful Findings, Singapore, v. 55, n. 1, p.195-211, 28 set. 2017.

[9] Pádua, Susana Machado; Tabanez, Mariene Francisca. Educação Ambiental: Caminhos Trilhados no Brasil. Brasília: Fnma/lpe, 1997. 


\section{Bapítulo 20}

\section{EDUCAÇÃO AMBIENTAL NA ESCOLA: CONCEITOS E PRÁTICAS PLASTICBANK}

Gregorio Augusto Marciaga Teófilo

Juan Franc's Lima de Moura

Gesiane Oliveira da Trindade

Resumo: A Educação Ambiental (EA) mostra-se como uma série de técnicas que visam libertar a sociedade de atividades ambientalmente inadequadas, provocando mudanças significativas nos hábitos dos indivíduos que dela fazem parte de modo a torná-los seres humanos mais sensíveis e conscientes de suas ações e seus impactos no planeta Terra. Este trabalho teve como objetivo promover o desenvolvimento sustentável a partir da relação teoria e prática no ambiente escolar e comunitário, efetivando-a mediante conceitos básicos sobre sustentabilidade e a prática de atividades lúdicas no meio ambiente escolar. Primeiramente, foram apresentados os conceitos básicos de Sustentabilidade e Meio Ambiente acoplados às disciplinas do núcleo comum escolar, seguidos da apresentação do aplicativo PlasticBank. A Plastibank trata-se de uma organização que atua no meio socioambiental, proporcionando à conversão de resíduos plásticos em moedas, contribuindo desta forma, para a retirada do plástico do meio ambiente e dando poder aquisitivo á populações de baixa renda, fundada no ano de 2015 em Vancouver-CA por David Katz e Shaun Frankson, o Plasikbank. A utilização deste aplicativo entrou como mecanismo inovador na coleta de materiais plásticos na comunidade para, posteriormente, encaminhá-los aos catadores de resíduos recicláveis do município. Em um segundo momento, foram trabalhadas atividades lúdicas em forma de oficinas de reciclagem de papel, reutilização de papelão e pets. Por fim, ocorreu a apresentação dos trabalhos realizados pelos estudantes à comunidade de Açailandia-MA durante o evento "I Mostra de Artes Recicladas" feito em parceria com a Escola Municipal Mário Cabral de Melo e com a Secretaria Municipal do Meio Ambiente. Desta forma, implantou-se a EA como prática para o desenvolvimento sustentável, ou seja, execução de atividades geradoras de renda, conservação ambiental e equidade social e, com isso, contribuiu para a aproximação entre o IFMA e a comunidade Açailandense, configurando assim, a extensão acadêmica e prática do técnico em Meio Ambiente.

Palavras-chave: Desenvolvimento Sustentável; Açailândia-MA; Educação Ambiental; Plasticbank. 


\section{INTRODUÇÃO}

Segundo Dias, Marques e Dias (2016) os diferentes impactos ambientais ocorrem principalmente em função do tipo de relação que o ser humano estabelece com o meio ambiente. Contudo, a Educação Ambiental está intimamente ligada ao indivíduo como ser social, portanto é importante a percepção individual como elemento da prática ou disseminação da Educação Ambiental sob os olhares de cada ator do espaço social.

Como metodologia contrária ao desequilíbrio ambiental causado por ações antrópicas, a Educação Ambiental (EA) mostra-se como uma série de técnicas que visam sensibilizar a sociedade de atividades ambientalmente inadequadas, provocando mudanças significativas nos hábitos dos indivíduos que dela fazem parte de modo a torná-los seres humanos mais conscientes de suas ações e seus impactos no planeta Terra.

A educação ambiental assume cada vez mais uma função transformadora, na qual a coresponsabilização dos indivíduos torna-se um objetivo essencial para promover um novo tipo de desenvolvimento, o desenvolvimento sustentável (JACOBI, 2003). A influência da tecnologia tem um importante impacto no meio social, através de ideais inovadores e como fonte principal de economia na valorização do plástico, o aplicativo PlasticBank atua como ferramenta para a conscientização dos princípios sustentáveis, além de promover a mobilização social através da reciclagem e reutilização da garrafa pet, fornecendo aliança política entre comerciantes e contribuintes, movimentando um grande setor econômico em busca de equidade social além de estabelecer a construção de indivíduos ecologicamente corretos.

O termo "desenvolvimento sustentável" surgiu a partir de estudos da Organização das Nações Unidas sobre as mudanças climáticas, como uma resposta para a humanidade perante a crise social e ambiental pela qual o mundo passava a partir da segunda metade do século XX (BARBOSA, 2008). Segundo Brundtland (1987), desenvolvimento sustentável é desenvolvimento que satisfaz as necessidades do presente sem comprometer a capacidade das futuras gerações satisfazerem as suas próprias necessidades.

Assim, o presente trabalho teve como objetivo geral promover o desenvolvimento sustentável a partir da relação teoria e prática no ambiente escolar e comunitário. Os objetivos específicos foram: a) debater noções teóricas sobre sustentabilidade e meio ambiente; $b$ ) promover atividades lúdicas voltadas a temática do desenvolvimento sustentável e c) atribuir valor econômico ao plástico através do aplicativo plasticbank.

\section{METODOLOGIA}

Para a realização do projeto foram elencadas algumas etapas de execução, que nos possibilitaram a construção de ação social de caráter qualitativo, a saber: introdução dos conceitos básicos de sustentabilidade e meio ambiente a partir de palestras junto ao corpo discente. Nesta ocasião, foram realizadas atividades em que os alunos demonstraram suas visões acerca do conceito de meio ambiente (desenhos) e gestão de resíduo (elaboração de lixeiros seletivos, a partir do estudo das respectivas cores e seus significados); oficinas de reutilização de papelão, pets e reciclagem de papel; evento e momento de confraternização e divulgação junto à comunidade próxima da escola; a culminância deste projeto deu-se durante realização da "I Mostra de Artes Recicladas"; e por fim, houve também a doação das garrafas plásticas coletadas, aos catadores independentes de resíduos recicláveis do lixão municipal de Açailândia, haja vista, a inexistência de cooperativa ou associação na cidade.

A utilização do aplicativo plasticbank entrou como mecanismo inovador na coleta de materiais plásticos na comunidade para utilizá-los como matéria prima das oficinas e encaminhá-los aos catadores. A idéia difundida originada pelo aplicativo, viabilizou a troca de garrafas pets, por tickets com função monetária que foram utilizados na compra de produtos, atribuindo assim, valor econômico ao plástico e, consequentemente, promovendo o desenvolvimento sustentável. Foram estabelecidos dois pontos de coleta, sendo um deles a Escola Municipal Mario Cabral de Melo onde se concentraram as atividades de educação ambiental e um segundo ponto localizado em um comércio local. Estes dois pontos de coleta se responsabilizaram pela recepção do material e pela distribuição do ticket a cada dez garrafas plásticas.

O evento denominado "I Mostra de Artes Recicladas" consistiu na exposição dos 
trabalhos desenvolvidos pelos alunos do terceiro e quarto ano (06 a 14 anos) do ensino fundamental da escola municipal Mario Cabral de Melo à comunidade açailandense. A mostra deu-se através de obras teatrais com temáticas ambientais utilizando fantoches confeccionados nas oficinas e exposição dos quadros feitos à base de papelão e papel reciclado. Nesta ocasião, ocorreram as trocas dos tickets do plasticbank por diversos produtos, tais como: alimentos não perecíveis, produtos de limpeza; roupas e sapatos patrocinados por comerciantes locais. O evento ocorreu no dia 25 do mês de maio do ano vigente, e reuniu um grande contingente de alunos, pais e professores da escola municipal Mario Cabral de Melo, assim como a turma florestas 1 do IFMA, e comunitários. Havendo também a cobertura da imprensa local.

\section{RESULTADOS E DISCUSSÃO}

Em Açailândia-MA, a carência de programas de educação ambiental, tem gerado uma sociedade insensível da importância do seu papel na conservação do meio ambiente. Dessa forma, o trabalho foi desenvolvido nos bairros Barra Azul e Vila Flávio Dino, perímetro onde localiza-se a escola municipal Mario Cabral de Melo.

Ressalta-se que o perfil socioeconômico dessas comunidades é formado por população de baixa renda, uma vez que estão localizadas na periferia urbana, próximas ao lixão municipal. Essa população vivencia diariamente os problemas causados pela má destinação dos resíduos sólidos, falta de acesso a informações construtivas e aos seus direitos básicos de moradia, segurança, transporte e saúde pública, fatores que estão diretamente ligados ás más condições socioambientais.

Ao debater noções teóricas sobre sustentabilidade e meio ambiente com os alunos, foi possível observar que os mesmos possuem conhecimentos prévios acerca do conceito de meio ambiente e sobre as práticas insustentáveis. Nesse sentido, as palestras serviram para ampliar esses conhecimentos e ratificar a importância de uma cultura pautada na educação ambiental.

Foi realizada a prática da educação ambiental como exercício para o desenvolvimento sustentável, ou seja, execução de atividades geradoras de renda, feita através da implementação do aplicativo plasticbank. Nesta etapa, foi realizada a apresentação da ideia central do plasticbank ao corpo estudantil da escola municipal Mario Cabral de Melo e ás comunidades Vila Flávio Dino e Barra Azul, dando início a coleta das garrafas plásticas.

Através da realização da I Mostra de Artes Recicladas, foi possível perceber a necessidade de atividades lúdicas, onde sejam incentivados os debates coletivos, baseados na importância do exercício da cidadania e na busca pelo desenvolvimento sustentável. Portanto, proporcionar este evento contribuiu para a valorização das atividades socioambientais realizadas na comunidade.

Nessa ocasião, foi possível movimentar a comunidade em geral pelo propósito de retirar resíduos plásticos do ambiente comunitário e transformá-los em uma inovadora fonte de renda para o consumo de produtos básicos, que no evento foram fornecidos por patrocinadores do setor comercial local. Ressalta-se também que a feira foi um momento de socialização entre alunos, pais, professores, comunitários, representantes do poder público municipal (Secretaria Municipal do Meio Ambiente) e alunos do IFMA.

Contudo, deu-se a cessão do material plástico adquirido pelo programa plasticbank aos catadores independentes de resíduos recicláveis do lixão municipal de Açailândia, onde se evidenciou na entrega, a facilitação do trabalho dos catadores e menor exposição dos mesmos, aos riscos no ambiente insalubre. Tendo em vista que a cidade não possui sistema de coleta seletiva, aterro sanitário, unidade de tratamento e triagem dos resíduos. Observou-se, assim a necessidade da criação de cooperativas e associações, para efetuar as atividades de separação e encaminhamento dos resíduos de forma a integrar os setores de recolhimento e disposição final no município, garantindo assim, melhores condições de trabalho.

\section{CONCLUSÕES}

Este trabalho teve como finalidade desenvolver técnicas de ensino e pratica da educação ambiental de forma a proporcionar o desenvolvimento sustentável e fortalecer a integração do IFMA com a comunidade externa, além de assimilar a tecnologia como 
fonte de sustentabilidade socioeconômica, com o uso do aplicativo plasticbank. Tendo em vista que o projeto contribui para a formação de futuros cidadãos ecologicamente conscientes e sensíveis de seus atos, durante a finalização do projeto surgiu a possibilidade, juntamente com a Secretaria Municipal do Meio Ambiente de Açailândia, em dar continuidade ao projeto, rodando-o de forma

\section{REFERÊNCIAS}

[1] Barbosa, G. S. O desafio do desenvolvimento sustentável. Desenvolvimento Sustentável. Revista Visões 4aㅡ Edição, №4, Volume 1 - Jan/Jun 2008.

[2] Brundtland, G. H. (Inglaterra) (Ed.). Nosso Futuro Comum. Oxford: Oxford University Press, 1987. 383 p. sequencial nas escolas municipais, levando ações práticas de Educação Ambiental aos estudantes de ensino fundamental. Ressaltase que tal parceria será importante tanto para firmar ações proativas afim de incentivar desenvolvimento sustentável, quanto para criar alternativas e possibilidades de estágios supervisionados para os estudantes do curso técnico em Meio Ambiente do IFMA.

[3] Dias, L. S; Marques, M. D.; Dias, L. S. Utilização do Acervo Educacional de Ciências Naturais da Unoeste para a Educação Ambiental. 2016. 


\section{Gapítulo 21}

\section{ESPAÇOS EDUCACIONAIS SUSTENTÁVEIS}

\section{Jaqueline Fernanda Meireles \\ Terezinha Corrêa Lindino}

Resumo: A geração dos resíduos sólidos aumentou exponencialmente nos últimos anos, dificultando a sua destinação final. O tema tem atraído à atenção de agências de desenvolvimento e de cooperação internacional, de autoridades públicas e de Organizações Não Governamentais (ONGs) que trabalham com gestão ambiental e desenvolvimento urbano. Vários autores vêm destacando em suas pesquisas os problemas enfrentados no que tange a gestão de resíduos sólidos, ressaltando que a preocupação mundial em relação ao volume de geração de resíduos por pessoa. O que reforça a urgência da revisão dos padrões de produção, consumo e descarte ou a implantação de um sistema eficaz de gestão dos resíduos sólidos. Esta preocupação deu origem a diversos eventos ambientais que discutiram maneiras de mitigar os danos ambientais e evidenciou-se a importância da Educação Ambiental (EA) como uma das saídas para este enfrentamento. Desta forma, o Programa Municípios Educadores Sustentáveis viabilizou a implantação de espaços coletivos para desenvolvimento de Projetos de Educação Ambiental capazes de mudar a realidade local. Sendo assim, por meio de levantamento bibliográfico e documental, procura-se debater as características dos Espaços Educadores Sustentáveis existentes na literatura que corroboram a necessidade da Educação Ambiental na Gestão dos Resíduos Sólidos em Associações de Recicladores Ambientais. Este estudo está em andamento, mas até o momento pode-se defender que as características pertencentes ao EES somam forças para inserir a EA em todas as esferas da sociedade, mas não agem como um espaço com forte intenção pedagógica capaz de transformar a realidade local.

Palavras-chave: Programa Municípios Sustentáveis; Educadores Ambientais; Educação Ambiental. 


\section{INTRODUÇÃO}

A indicação de que o homem deveria perceber os recursos naturais como finitos fez que com as questões ambientais ganhassem forças na sociedade e, de acordo com Jacobi (2003), a partir da Conferência sobre Educação Ambiental, em 1977, realizada em Tbilisi, inicia-se um amplo processo em nível global para criar condições de uma nova tomada de decisão sobre o valor da natureza. Esta conferência foi o marco inicial, na qual começou a discutir-se oficialmente a importância da Educação Ambiental (EA) como ferramenta para despertar a responsabilidade ambiental, vinculada às mudanças no modo de produção, comportamento e atitudes.

Após a realização desses eventos, a contribuição da Educação Ambiental para o enfrentamento dos problemas ambientais ocasionados pela ação humana ganha força e exige mudanças nas inter-relações existentes na formação da personalidade social e do como o homem enxerga e interage com a natureza. Diante desse cenário, em 2010, a Lei 12.305 institui a responsabilidade dos geradores e do poder público pela destinação inadequada dos resíduos. Esta lei definiu instrumentos para a gestão dos resíduos sólidos, sugerindo a organização de espaços educadores que possam ampliar os benefícios ambientais, sociais e econômicos para a sociedade (BRASIL, 2010).

Assim, ao considerar uma associação a reunião de pessoas físicas ou jurídicas com objetivos comuns, visando superar dificuldades e gerar benefícios para os seus associados, as Associações de Recicladores Ambientais surge para responder as necessidades da sociedade e do mercado (SEBRAE, 2014). Logo, as Associações de Recicladores Ambientais nasceram com 0 objetivo de responder às necessidades de gestão dos resíduos sólidos urbanos, visto que ela se mostrava como modelo de organização social prevalente e disposto a adaptar-se ao consumo promovido pelos seres humanos.

Estima-se que no Brasil existem mais de 1.100 organizações (cooperativas e associações) de catadores de materiais recicláveis em funcionamento (BESEN et al, 2014). Desta forma, os dados da Associação Brasileira de Empresas de Limpeza Pública Especial (ABRELPE) mostram que os setores industriais de alumínio, papel e plástico possuem considerável participação nas atividades de reciclagem, apresentando evolução anual dos índices, reintroduzindo os materiais reciclados no processo produtivo e diminuindo a sobrecarga nos ecossistemas (ABRELPE, 2016).

Desta forma, este trabalho tem o objetivo de identificar e definir o que é um Espaço Educador Sustentável na literatura e a importância da utilização da Educação Ambiental na Gestão dos Resíduos Sólidos em Associações de Recicladores Ambientais.

\section{METODOLOGIA}

A metodologia escolhida nessa pesquisa fundamentou-se na pesquisa qualitativa (GIL, 2002). Assim, foi realizada a revisão sistemática de literatura em bases de dados como SciElo, banco de arquivos da Revista REMEA, Revista Gestão e Sustentabilidade, sites do Ministério do Meio Ambiente, ABRELP, CEMPRE, IBGE, SEBRAE, Banco de Dados de Dissertações da Unioeste e site do Planalto Central, em três etapas: 1) pesquisa aleatória sobre o assunto, 2) filtração dos artigos por meio de palavras-chave e 3) separação do material para leitura e fichamento. A escolha pelo corpus bibliográfico possibilitou a aquisição de informações e auxiliou a definição do quadro conceitual que envolve o objeto desse estudo e o critério de corte para a seleção do material foi à data de publicação (20 anos para documentos oficiais e leis; dez anos para livros e cinco para artigos, informativos).

Com o uso da técnica de levantamento bibliográfico desenvolveu-se uma base de dados a partir de artigos científicos, livros e documentos publicados e socialmente difundidos sobre a relação entre o sistema socioeconômico capitalista e as questões ambientais; conceituação de EA e suas origens; ontologia e desenvolvimento do conceito de Resíduo sólido urbano, Gerenciamento de Resíduos Sólidos (coleta, transporte, transbordo, tratamento, destinação e disposição final dos rejeitos), Gestão compartilhada, Manejo e a destinação final ambientalmente adequada dos resíduos sólidos, Crescimento econômico versus desenvolvimento sustentável, Sustentabilidade e Papel dos catadores.

Durante a realização da pesquisa, foram encontradas 169 literaturas entre artigos, livros, informativos, leis e documentos. Do 
Tabela 1. Principais referências bibliográficas que subsidiaram a pesquisa

\begin{tabular}{|c|c|}
\hline Referências & Assuntos Abordados \\
\hline ABNT NBR 10004/2004 & $\begin{array}{l}\text { Critérios de classificação e identificação dos resíduos de acordo com as } \\
\text { suas características (perigosos e não perigosos). }\end{array}$ \\
\hline ABRELPE (2016) & $\begin{array}{l}\text { Aponta o crescimento na geração de resíduos sólidos, panorama da coleta } \\
\text { seletiva no Brasil e da destinação final e reciclagem. }\end{array}$ \\
\hline ASSIS; RUTKOWSKI (2016) & $\begin{array}{l}\text { Indica a aplicação da gestão ambiental para diminuir os impactos } \\
\text { ambientais. }\end{array}$ \\
\hline BATISTA (2014) & $\begin{array}{l}\text { Cita as características do perfil dos catadores e as atividades atribuídas a } \\
\text { eles. }\end{array}$ \\
\hline BOFF (2012) & $\begin{array}{l}\text { Conceituam e desmistificam termos como sustentabilidade, } \\
\text { desenvolvimento sustentável e desenvolvimento econômico. }\end{array}$ \\
\hline BRASIL (2005) & $\begin{array}{l}\text { Traz os conceitos, criação e evolução de Espaços Educadores } \\
\text { Sustentáveis. }\end{array}$ \\
\hline BRASIL (2014) & $\begin{array}{l}\text { Traz a discussão sobre a EA na construção de sociedades sustentáveis, } \\
\text { empoderamento das pessoas, por meio da autonomia, respeito às } \\
\text { diferenças culturais. Também, a aplicação da EA na gestão dos resíduos } \\
\text { sólidos. }\end{array}$ \\
\hline BRASIL (2017) & $\begin{array}{l}\text { Definição de salas verdes, organização e estruturas, diferenciação de salas } \\
\text { verdes de espaço educador. }\end{array}$ \\
\hline CBO (2012) & Apresenta o papel dos catadores na gestão dos resíduos e na reciclagem. \\
\hline CEMPRE (2014) & Informações sobre gerenciamento de resíduos sólidos e reciclagem. \\
\hline FELICORI et al. (2016) & Destinação final ambientalmente adequada. \\
\hline FERNANDES; CABRAL (2017) & $\begin{array}{l}\text { Traz a discussão sobre crescimento econômico, desenvolvimento } \\
\text { sustentável e o triple bottom line, no contexto de uma associação de } \\
\text { catadores. }\end{array}$ \\
\hline FOSTER; ROBERTO; IGARI (2016) & $\begin{array}{l}\text { Apresenta informações sobre o aumento de consumo, em consequência a } \\
\text { mudanças no modo de produção e as dificuldades de uma destinação final } \\
\text { adequada. }\end{array}$ \\
\hline FROTA et al. (2015) & $\begin{array}{l}\text { Trata da geração e gerenciamento de resíduos sólidos, classificação, } \\
\text { destinação final, reciclagem e coleta seletiva. }\end{array}$ \\
\hline GABIRA; CASTILHO; VALÊNCIA (2017) & Debate sobre a EA na construção de sociedades sustentáveis. \\
\hline LAYRARGUES; LIMA (2014) & $\begin{array}{l}\text { Apresenta as macrotendências de EA: conservacionista, pragmática e } \\
\text { crítica. }\end{array}$ \\
\hline LEI 12.305/2010 & Política Nacional de Resíduos Sólidos. \\
\hline LEI 9.795/1999 & Política Nacional de Educação Ambiental. \\
\hline LIBÂNEO (2005) & Definição de educação, educação formal e não formal. \\
\hline LIMA; ARAUJO; RODRIGUES (2011) & $\begin{array}{l}\text { Contextualização, conceitos, profissionalização e perfil dos catadores, } \\
\text { atividades atribuídas aos catadores, o seu papel na gestão dos resíduos e } \\
\text { na reciclagem. }\end{array}$ \\
\hline MATAREZI (2005) & $\begin{array}{l}\text { Traz a definição e a criação de EES enquanto promotores de aprendizagem } \\
\text { e práticas de sustentabilidade. }\end{array}$ \\
\hline MENDES (2016) & $\begin{array}{l}\text { Diferencia crescimento econômico, desenvolvimento sustentável e } \\
\text { ecodesenvolvimento. }\end{array}$ \\
\hline NASCIMENTO et al. (2015) & Reflexões sobre o panorama dos resíduos sólidos no Brasil. \\
\hline NOBRE; ANELLO (2017) & $\begin{array}{l}\text { EA na construção de sociedades sustentáveis, por meio da autonomia e } \\
\text { respeito as diferenças culturais na gestão dos resíduos sólidos. }\end{array}$ \\
\hline OLIVEIRA; TONSO (2012) & $\begin{array}{l}\text { Discute sobre a criação e a evolução de EES, por meio de práticas de } \\
\text { sustentabilidade. }\end{array}$ \\
\hline SABEDOT; PEREIRA NETO (2017) & $\begin{array}{l}\text { Apresenta o perfil dos catadores e suas atividades na gestão dos resíduos } \\
\text { e na reciclagem. }\end{array}$ \\
\hline SAUVÉ (2005) & Discorre sobre 15 correntes de educação ambiental. \\
\hline SILVA (2014) & $\begin{array}{l}\text { Apresenta o EES como espaços promotores de aprendizagem e práticas de } \\
\text { sustentabilidade. }\end{array}$ \\
\hline SORRENTINO (2005) & $\begin{array}{l}\text { Discute sobre o enfrentamento da crise civilizatória, melhoria da qualidade } \\
\text { de vida, EA como filosofia de vida. }\end{array}$ \\
\hline TRISTÃO (2013) & Debate e analisa a melhoria da qualidade de vida, sob o aspecto da EA. \\
\hline ZANATTA (2017) & $\begin{array}{l}\text { Traz a importância de incluir a gravidade dos problemas ambientais na } \\
\text { cultura organizacional das empresas, bem como a importância da gestão } \\
\text { ambiental empresarial e os benefícios que a implantação sugere. }\end{array}$ \\
\hline
\end{tabular}

Fonte: Elaborado pelas autoras (2018). 
As bibliografias elencadas trazem para a discussão elementos importantes na busca das respostas das questões já mencionadas. A seleção dos referenciais teóricos proporciona a varredura da temática e, que a partir desta, desenvolver-se-á uma interpretação das informações.

Portanto, esta análise não se trata de uma leitura plural na qual um sujeito multiplica os pontos de vista possíveis para melhor se reconhecer. Mas sim, de uma leitura na qual o sujeito é, ao mesmo tempo, despojado e responsável pelo sentido que lê.

Quanto mais o sujeito reconhecer o que fala e como se organiza sua estrutura de pensamento, melhor será a compreensão do como seu discurso infere em si e no outro.

\section{RESULTADOS E DISCUSSÃO}

Do material encontrado, 29\% são documentos oficiais e leis, que trazem discussões sobre classificação e identificação dos resíduos de acordo com as suas características; sobre o crescimento na geração de resíduos sólidos, panorama da coleta seletiva no Brasil e da destinação final e reciclagem; sobre a EA na construção de sociedades sustentáveis, empoderamento das pessoas, respeito às diferenças culturais e sua aplicação na gestão dos resíduos sólidos; definem o que são salas verdes $e$ as diferenciam dos espaços educadores; e sobre o papel dos catadores na gestão dos resíduos e na reciclagem.

Ainda, $13 \%$ são artigos que conceituam e desmistificam termos como sustentabilidade, desenvolvimento sustentável e desenvolvimento econômico; discutem o crescimento econômico, o desenvolvimento sustentável e o triple bottom line no contexto de uma associação de catadores; apresentam informações sobre o aumento de consumo, em consequência a mudanças no modo de produção e as dificuldades de uma destinação final adequada; e diferenciam crescimento econômico, desenvolvimento sustentável e ecodesenvolvimento. Também, $10 \%$ são artigos indicam a aplicação da gestão ambiental para diminuir os impactos ambientais; tratam das formas de geração e gerenciamento de resíduos sólidos, classificação, destinação final ambientalmente adequada.

Os que citam as características do perfil dos catadores e as atividades atribuídas a eles são 6\% artigos. Esses artigos discorrem sobre a contextualização, os conceitos, a profissionalização, o perfil dos catadores, bem como as atividades atribuídas a eles e o seu papel na gestão dos resíduos e na reciclagem.

Dentro do montante total, conseguiu-se separar $16 \%$ dos artigos que debatem sobre a EA na construção de sociedades sustentáveis; que apresentam as macrotendências de EA: conservacionista, pragmática e crítica; que distinguem a diferença entre a educação, a educação formal e a educação não formal; que discutem a EA na construção de sociedades sustentáveis, por meio da autonomia e respeito às diferenças culturais na gestão dos resíduos sólidos; e discorrem sobre as 15 correntes existentes na Educação Ambiental.

Em relação aos Espaços Educadores Sustentáveis, $6 \%$ são materiais que definem a criação desses espaços, como promotores de aprendizagem e práticas de sustentabilidade; discutem ainda as práticas de sustentabilidade como forma de evolução de Espaços Educadores Sustentáveis. E 10\% trazem reflexões sobre o panorama dos resíduos sólidos no Brasil; apresentam o perfil dos catadores e suas atividades na gestão dos resíduos e na reciclagem; e defende o EES como espaço promotor de aprendizagem e práticas de sustentabilidade.

O Programa Municípios Educadores Sustentáveis (MES) considera como espaços educadores aqueles capazes de demonstrar alternativas viáveis para a sustentabilidade, estimulando as pessoas a desejarem realizar ações conjuntas em prol da coletividade e reconhecerem a necessidade de se educarem. Logo, Matarezi (2005) relaciona estritamente as palavras espaço e esperança com a educação, pois todo ato educativo, aprendizado e construção de conhecimento traz esperança e ocupa um determinado espaço.

Por meio da publicação do livro intitulado Salto para o Futuro, o conceito de Espaços Educadores Sustentáveis foi originado. Neste sentido, sua definição é:

Locais que transformam os hábitos e sua lógica de funcionamento que reduz os impactos ambientais e se torna referência de vida sustentável para sua comunidade, ampliando seu escopo de ação, um espaço pode ser educador sem ser sustentável e ser sustentável sem, necessariamente, ser 
educador (SALTO PARA O FUTURO, 2011, p. 06).

O caminho para promover a transformação de posturas e atitudes, construindo cidades sustentáveis, passa por este tipo de espaço. Ressaltando que cidades sustentáveis engloba uma série de ações e metas que promovem a sustentabilidade e melhoria na qualidade de vida na população, priorizando a participação da comunidade local na tomada de decisões, no que tange a preservação dos recursos naturais, a equidade social, ordenamento do território e a mobilidade urbana. Os prefeitos têm a oportunidade de influenciar comportamento sociais $e$ individuais no sentido da sustentabilidade, por meio da educação (Cidades Sustentáveis, 2018).

Para Borges (2011), nas cidades encontra-se uma gama de oportunidade de espaços educadores (praças, jardins, ruas). Neste contexto, a cidade será educadora quando reconhecer, exercer e desenvolver para além de suas funções tradicionais. Logo, a EA praticada nesses espaços tem o papel de promover mudanças no cotidiano de indivíduos e instituições (OLIVEIRA; TONSO, 2012).

Gráfico 1. Panorama do material encontrado na literatura.

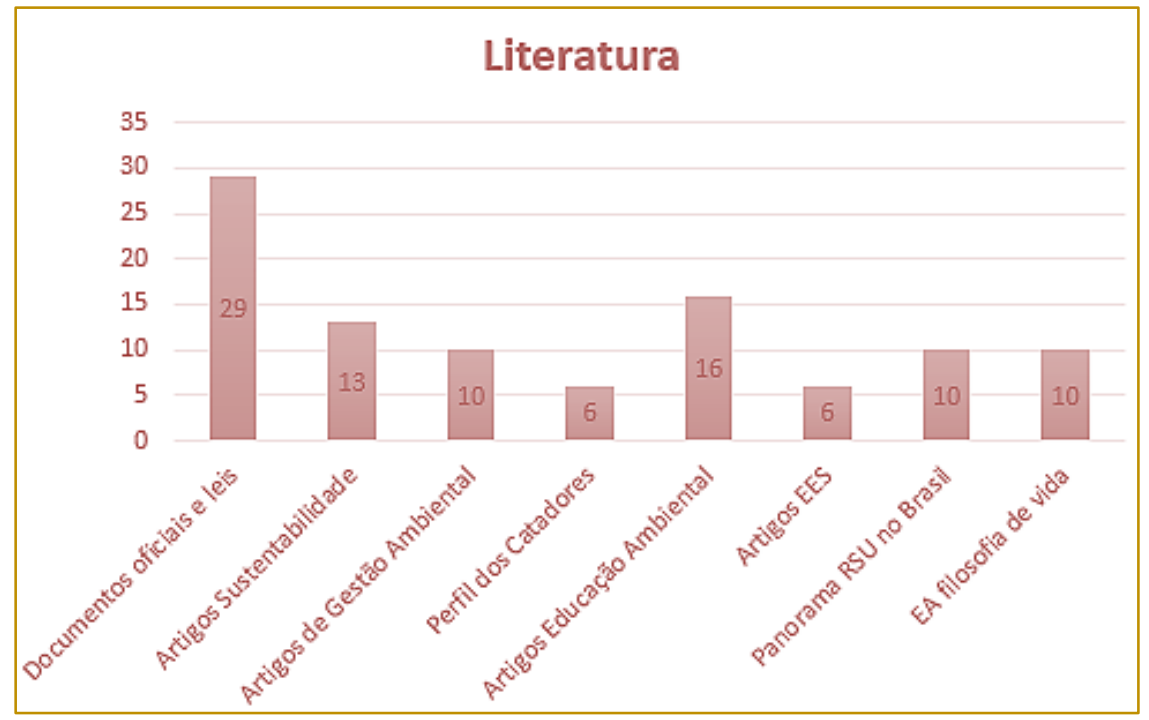

Fonte: Elaborado pelas autoras (2018).

A união destes assuntos e autores indica a veracidade da afirmação de que a Educação Ambiental tende a contribuir pra uma nova concepção de Meio Ambiente, na qual inclui não somente o Meio Ambiente enquanto recurso natural, mas também como sistema que promova fortaleça o sentimento de pertencimento. Ela se torna uma educação que promove o desenvolvimento econômico,
Oliveira (2012) considera que os espaços educadores proporcionam para as pessoas uma série de descobertas e eventos. Nestes espaços não acontecem relações e vivências ao acaso, mas sim relações construídas de forma a atingir objetivos propostos, de forma participativa, resultando em experiências repletas de valores.

O resultado concreto da implantação dos EES em escolas integra ações educativas ao gerenciamento do consumo. Do mesmo modo, os EES precisam ser referências do que ensinam. Mas, cabe ressaltar que para ensinar conceitos de sustentabilidade, primeiro é necessário pratica-la.

Por fim, 10\% dos artigos discutem sobre o enfrentamento da crise civilizatória, melhoria da qualidade de vida, EA como filosofia de vida; discorrem sobre a importância de incluir a gravidade dos problemas ambientais na cultura organizacional das empresas, bem como a importância da gestão ambiental empresarial e os benefícios que a implantação sugere; e debatem sobre a melhoria da qualidade de vida, sob o aspecto da EA, o gráfico 1 apresenta o panorama do material encontrado na literatura. 
Sob este prisma, Tristão (2013) defende que a EA deve ser compreendida como uma filosofia de vida e não como uma disciplina obrigatória. Ela deveria ser organizada como uma orientação para conhecer e compreender a complexidade da natureza e da realidade socioambiental.

De tal modo, deveria ser apresentada em diferentes abordagens ou ideologias ambientais, sustentadas pela premissa da interdisciplinaridade, e contemplar a natureza intacta, preservando os recursos naturais, usufruindo de serviços ecossistêmicos considerada pela autora como estilo de vida adotado por pessoas sensíveis, responsáveis e solidárias. E, nesta perspectiva, a EA surge como uma das possíveis estratégias para o enfrentamento da crise civilizatória de dupla ordem: a cultural e social, buscando mudanças individual e coletiva intrinsicamente interligados (SORRENTINO et al2005).

Também defende a visão que o planeta está passando por uma crise ambiental diretamente vinculada aos valores culturais e econômicos, estimulando a mudança de hábitos e principalmente rever os padrões de consumo. Os autores acreditam ainda que a EA tem por finalidade abrir Espaços Educadores Ambientais que possam contribuir para a melhoria da qualidade de vida dos humanos e de todas as espécies, construindo uma cultura ecológica. Para isso, torna-se necessário desenvolver diálogos com todos os envolvidos no processo, enfatizando a importância das inter-relações e conexões.

Igualmente, entender quem são os envolvidos no processo para que juntos possam construir uma nova cultura, priorizando o respeito ao Meio Ambiente. Desta forma, o fortalecimento da organização produtiva dos catadores em associações representa a atuação desta categoria profissional na implantação da PNRS e, com isso, a implantação da Educação Ambiental revitaliza os objetivos da cadeia produtiva da reciclagem, por meio das

\section{REFERÊNCIAS}

[1] Abrelpe, Associação Brasileira de Empresas de Limpeza Pública e Resíduos Especiais. Panorama dos Resíduos Sólidos no Brasil. São Paulo, 2016.

[2] Besen, R.G. et al. Coleta Seletiva na Região Metropolitana de São Paulo: Impactos da Política Nacional de Resíduos Sólidos. Ambiente \& Sociedade. São Paulo. v. XVII, n. 3. p. 259-278, jul.set. 2014. oportunidades de geração de renda e de negócio e, especialmente na inclusão social dos catadores, ressaltando a contribuição da classe na gestão dos resíduos sólidos e preservação dos recursos naturais por meio da reciclagem.

Tornando-se, assim, evidente a contribuição da EA seja no ensino formal ou não formal, como a praticada nos espaços educadores, para o enfrentamento da crise ambiental também considerada como uma crise de civilização, de forma que colabore com a construção de novos valores e quebras de paradigmas priorizando o respeito ao meio ambiente e suas interações.

\section{CONCLUSÃO}

No Brasil, a reciclagem é realizada por meio dos catadores de materiais recicláveis. Analisando a trajetória dos catadores de material reciclável, concordamos com Sabedot e Pereira Neto (2017) quando afirmam que esses catadores têm participado dos sistemas de gerenciamento de resíduos sólidos das cidades e são considerados operários terceirizados da reciclagem, pois conseguem reconstituir valor sobre determinado resíduo e inseri-lo novamente na cadeia produtiva.

Neste sentido, este trabalho defende que, por meio da implantação de ações voltadas para a formalização de um Espaço Educador Sustentável, a partir de ações de teóricopráticas de Educação Ambiental. Contudo, a maior dificuldade para atingir este objetivo é a ausência de um Educador Ambiental nestes espaços, cuja função é de transpor conhecimentos que possibilitem a mudança da cultura ambiental dos associados e desenvolver uma nova percepção socioambiental em suas práticas diárias, de modo a tornar viáveis as práticas de sustentabilidade sugeridas neste tipo de espaço.

[3] Borges, C. Espaço Educadores Sustentáveis. In: Espaços Educadores Sustentáveis. Boletim 07, TV escola/Salto para o Futuro. Rio de Janeiro. 2011.

[4] Brasil, Ministério do Meio Ambiente. Programa Município Educadores Sustentáveis. 2 ed. Brasília, 2005.

[5] Política Nacional de Resíduos Sólidos. Lei n. 12.305 de 02 de agosto de 2010. Brasília, 2010. 
[6] GIL, C. A. Como Elaborar Projetos de Pesquisa. 4를 ed. São Paulo: Editora Atlas S.A. 2002.

[7] Jacobi, P. Educação Ambiental, Cidadania e Sustentabilidade. Cadernos de Pesquisa, n. 118, p. 189-205. março/ 2003.

[8] Matarezi, J. Estruturas e espaços educadores: quando estruturas e espaços se tornam educadores. In: Ferraro, L. A. (org.). Encontros e caminhos: formação de educadoras (es) ambientais e coletivos educadores. Brasília: MMA, Diretoria de Educação Ambiental, 2005. p. 161-173.

[9] Oliveira, A. Espaço Educador: Um Conceito em Formação. Dissertação (Mestrado em Tecnologia). Universidade Estadual de Campinas, SP. 2012.

[10] Oliveira, A.; Tonso, S. Espaço Educador: Um Conceito Em Formação. VI Encontro Nacional da Anppas 18 a 21 de setembro de 2012. Belém/PA - Brasil.
[11] Programa Cidades Sustentáveis, disponível em: https://www.cidadessustentaveis.org.br/ acessado em 10 de setembro de 2018.

[12] Sabedot, S.; Pereira Neto, J.T. Desempenho ambiental dos catadores de materiais recicláveis em Esteio (RS). Eng. Sanit. Ambient. v.22 n.1, jan/fev 2017. p. 103-109

[13] Salto para o Futuro. Espaços Educadores Sustentáveis. Tv escola o canal da educação. Ano XXI Boletim 07 - Junho 2011.

[14] Serviço Brasileiro de Apoio as Micros e Pequenas Empresas - Sebrae. Associação. Série Empreendimentos Coletivos. Brasília, 2014.

[15] Sorrentino, M.; Trajber, R.; Mendonça, P.; Ferraro, L.A.J. Educação ambiental como política pública. Educação e Pesquisa, São Paulo, v. 31, n. 2, p. 285-299, maio/ago. 2005.

[16] Tristão, M. Uma abordagem filosófica da pesquisa em educação ambiental. Revista Brasileira de Educação. v. 18, n. 55. out-dez. 2013. 


$$
\text { Alutary }
$$




\section{FABIANE DOS SANTOS TOLEDO (Organizadora)}

Mestre em geografia pela Universidade Federal de Uberlândia, na área de planejamento ambiental, atuante em geociências, com ênfase em ambiental - áreas verdes, índice de áreas verdes, espaços públicos livres e parques urbanos. Possui graduação em Geografia (Licenciatura e Bacharelado) pela Universidade Federal de Uberlândia, mestrado em geografia pela Universidade Federal de Uberlândia. Tem experiência na área de Geociências, com ênfase em Geografia ambiental, atuando principalmente nos seguintes temas: áreas verdes, índice de áreas verdes, espaços públicos livres e parques urbanos.

\section{ADMILSON ÍRIO RIBEIRO}

Bacharel em Engenharia Agrícola pela Universidade Federal de Lavras, Mestre e Doutor Engenharia Agrícola pela Faculdade de Engenharia Agrícola FEAGRI UNICAMP e Pós-Doutor em Environmental Science, Department of Environmental Science - University of CaliforniaRiverside. Atualmente é Professor Assistente na UNESP-Sorocaba, ministrando disciplinas de Estudos de Impacto Ambiental e Recuperação de Áreas Degradadas para o Curso de Graduação em Engenharia Ambiental do Instituto de Ciência tecnologia da UNESP-Sorocaba e nos Programas de Pós-Graduação em e Ciências Ambientais UNESP/Sorocaba.

\section{AMANDA FIALHO}

Professora designada na Universidade do Estado de Minas Gerais, unidade Ituiutaba. Realizou o Pós Doutorado no Departamento de Biologia/Setor ecologia UFLA. Doutora em Entomologia pela Universidade Federal de Lavras/UFLA em março de 2014_ MG, Brasil. Com realização de parte do Doutorado no Exterior - PDSE, no INECOL, Xalapa, VC (Estágio Internacional) México (outubro de 2012 a junho 2013). Mestre em Ciências Agrárias/Área de Concentração em Agroecologia (UFMG). Graduada em Agronomia, pela Universidade Federal de Viçosa/UFV, em 2006

\section{ANA CRISTINA DE ALMEIDA RIBEIRO}

Possui Curso Técnico Em Saneamento, Pelo Centro Federal De Educação Tecnológica De Goiás(CEFET), Graduanda em Licenciatura em Biologia Pela Universidade Federal De Mato Grosso-Campus Barra do Garças(UFMT), tem Experiências: Área Ambiental, Cadastro Técnico Urbano. Bolsista- Pibid- Programa de Iniciação À Docência que atua Desenvolvendo Projetos em Sala de Aula, auxiliando o Trabalho do Docente. Fazendo Com Que, os Discentes consigam suas Capacidades de Relacionar a Prática e Teoria.

\section{ANA LUCY CAPRONI}

Possui graduação em Engenharia Florestal pela Universidade José do Rosário Vellano (1984), mestrado em Agronomia (Fitotecnia) pela Universidade Federal de Lavras (1991) e doutorado em Agronomia Fitotecnia pela Universidade Federal Rural do Rio de Janeiro (2001), Pós doutorado pela Universidade de Buenos Aires (2004). Atualmente é professora Associada II do Departamento de Gestão Ambiental do Campus de Guajará Mirim da Universidade Federal de Rondônia. Foi Chefe do depto de Agronomia (2008/2009), criou o curso de Engenharia Florestal e foi chefe deste Departamento em 2010 e Diretora Pro Tempore do Campus de Rolim de Moura (2010/2011). Tem experiência na área de Sementes Florestais, Silvicultura, Paisagismo, Agroecologia, Sistemas Agroflorestais, diversidade, fma, areas degradadas, ecologia do solo, Trabalho de Conclusão de Curso e Metodologia de Pesquisa. 


\section{ANA PAULA MARTINAZZO}

Possui graduação em Engenharia Agrícola pela Universidade Estadual do Oeste do Paraná, mestrado em Engenharia Agrícola pela Universidade Federal de Viçosa e doutorado em Engenharia Agrícola pela Universidade Federal de Viçosa. Atualmente é Professora Associada II no curso de graduação em Engenharia de Agronegócios, nos cursos de mestrado em Engenharia de Biossistemas e Tecnologia Ambiental da Universidade Federal Fluminense. Tem experiência na área de Engenharia Agrícola, com ênfase em Engenharia de Processamento de Produtos Agrícolas. Tem atua junto a outros pesquisadores em estudos envolvendo os temas: secagem, armazemamento e pós-colheita de plantas medicinais e grãos; logística reversa de resíduos

\section{ANDREIA OLIVEIRA DOS SANTOS}

Tecnóloga em Gestão Ambiental, pelo Núcleo de Ensino Superior de Presidente Figueiredo, Universidade do Estado do Amazonas (NESPF/UEA).

\section{ANDREZA DA SILVA MELO}

Graduanda do Curso em Licenciatura em Ciências Biológicas e Técnica em Enfermagem na Saúde Pública.

\section{CARLOS EDUARDO DE SOUZA TEODORO}

Possui graduação em Engenharia Agronômica pela Universidade Federal Rural do Rio de Janeiro(1997), mestrado em Produção Vegetal pela Universidade Estadual do Norte Fluminense Darcy Ribeiro(1999) e doutorado em Biociências e Biotecnologia pela Universidade Estadual do Norte Fluminense Darcy Ribeiro(2004). Atualmente é Professor adjunto da Universidade Federal Fluminense e Revisor de periódico da Revista Brasileira de Engenharia Agricola e Ambiental. Tem experiência na área de Bioquímica. Atuando principalmente nos seguintes temas:ATPase Vacuolar, Pirofosfatase, transporte de prótons, leveduras, plantas.

\section{CAROLINA BITTENCOURT DE SOUZA DOS SANTOS}

Graduada pela Fatec Americana em Tecnologia da Produção Têxtil. Atua na área de design de superfície.

\section{CINTHYA ANTONIA VIEIRA GURGEL}

Técnica em Controle Ambiental pelo Instituto Federal de Educação, Ciência e Tecnologia do Rio grande do Norte (IFRN/campus Natal-cental), bacharel em Ciências e Tecnologia com ênfase em Tecnologia Ambiental pela Universidade Federal do Rio grande do Norte (UFRN/Natal) e Engenheira Ambiental pela Universidade Federal do Rio grande do Norte (UFRN/Natal). Atua como Técnica em Controle Ambiental na Companhia de Águas e Esgotos do Rio grande do Norte (CAERN) com experiências nas áreas de Tratamento de Água, Monitoramento da Qualidade de Águas e Educação Ambiental.

\section{DANYLLA PAULA DE MENEZES}

Graduanda em engenharia agronômica. Pela Universidade do Estado de Minas GeraisUEMG (2015-2019). Pesquisadora na área de sementes orgânicas e convencionais, reflorestamento entre outras, produção de mudas, biodiversidade de coleópteros, desenvolvimento de projetos sociais, entre outros. Trabalhou como analista de laboratório de controle de qualidade na empresa BP. 


\section{DAYANNE DE SOUZA CARVALHO}

Possui graduação em Engenharia Ambiental pela Universidade Federal do Amazonas (2016). Mestranda em Ciências Ambientais pela Universidade Federal do Amazonas.

\section{DEBORA REGINA MAROCHI DE OLIVEIRA}

Mestranda em Ciências Ambientais pela Universidade do Oeste do Paraná (Unioeste, Toledo-PR), Especialista em Docência no Ensino Superior (Faculdade Unipan, Cascavel- PR) e Bióloga Licenciada e Bacharel pela Universidade Paranaense (Unipar, Cascavel- PR). Pesquisadora na área de Educação com ênfase na formação do Educador Ambiental.

\section{DIANA SUZETE NUNES DA SILVA}

Engenheira Florestal pela Universidade do Estado de Mato Grosso (UNEMAT, campus de Alta Floresta-MT), Mestre e Doutora em Engenharia Florestal pela Universidade Federal de Lavras (UFLA). Licenciada em Letras pela União das Faculdades de Alta Floresta (UNIFLOR). Foi Professora Assistente substituta, disciplina de Silvicultura, no curso de Agronomia da UNEMAT, campus de Alta Floresta. Trabalhou também como Analista de Meio Ambiente no Sindicato das Indústrias Madeireiras do Norte de Mato Grosso (SINDUSMAD, em Sinop-MT); como Analista de Meio Ambiente na Secretaria de Estado do Meio Ambiente (SEMA/MT).

\section{DORALICE LURO BALAN}

Graduada em Ciências Biológicas pela UFSCar - São Carlos - SP; Mestre em Imunologia pela Unicamp - Campinas - SP; Doutora em Microbiologia Aplicada pela Unesp - Rio ClaroSP (1998); Especialista em Ciências da Educação pela Università Ca'Foscari Venezia- Itália (2012); Especialista em Educação a Distância - Implantação, Gestão e Docência pelo Centro Universitário Claretiano - Campinas - SP (2014).Desde 1998 concentra atividades de Ensino e Pesquisa no CPS - Faculdade de Tecnologia de Americana, Instituição Pública do Estado de São Paulo, na área de Gestão Ambiental e Sustentabilidade.

\section{DOUGLAS WILLIAN NOGUEIRA DE SOUZA}

Mestre em Ensino de Ciências e Humanidades na Universidade Federal do Amazonas com enfoque em Fundamentos e Metodologias para o Ensino das Ciências Naturais e Matemática. Pesquisador na área de Educação Estatística. Possui graduação em Ciências: Matemática e Física pela Universidade Federal do Amazonas (2016), atuando principalmente nas seguintes áreas: Educação Estatística, Ensino de Ciências e Matemática.

\section{ELANE CONCEIÇÃO DE OLIVEIRA}

Professora adjunta, Escola Superior de Ciências Sociais da Universidade do Estado do Amazonas (ESO/UEA). Líder do Grupo de Pesquisa do CNPq Desenvolvimento Regional e Sustentabilidade (GDERS). Pesquisadora no Programa UNIVERSAL AMAZONAS, da Fundação de Amparo à Pesquisa do Estado do Amazonas (FAPEAM/AM).

\section{ELENISE FARIA SCHERER}

Possui mestrado em Serviço Social pela Pontifícia Universidade Católica de São Paulo (1988), Doutorado - bolsa sanduiche - em Politica Social - Universidad Autonoma de Barcelona (1995) e doutorado em Serviço Social pela Pontifícia Universidade Católica de São Paulo (1997). É pós-doutora pelo Intitut des Hautes Etudes de IAmerique Latine - Université Paris III - Sorbonne Nouvelle (2008). É Professora Titular da Universidade Federal do Amazonas. Seus estudos e pesquisas estão concentrados na análise das Políticas Sociais, Mundo do Trabalho,desemprego, cidadania e exclusão. Atualmente tem se dedicado, também, ao estudo das políticas públicas, território sociais e ambiente na Amazônia. 


\section{ELIAS DE SÁ FARIAS}

Engenheiro Florestal (2011), Mestre em Ciência e Tecnologia da Madeira (2013) e Doutor em Engenharia Florestal (2017), pela Universidade Federal de Lavras. Participou de trabalhos científicos sobre nutrição mineral de espécies florestais nativas e exóticas em solo e hidroponia, conservação genética de espécies arbóreas, seleção de espécies florestais e madeira de florestas plantadas. Tem experiência em geoprocessamento, adequação ambiental de propriedades rurais, implantação de viveiros e povoamentos florestais, fertilidade do solo, nutrição mineral de plantas e análise não destrutiva da madeira. Atuou como docente do Pronatec/IFMG, como professor substituto no Centro Federal de Educação Tecnológico - CEFET, MG e professor mediador no Curso Técnico em Meio Ambiente, NEAD CEFET. Tem experiência profissional como engenheiro autônomo e integrante da Empresa Terra Jr., com trabalhos técnicos realizados nas regiões leste, sudoeste, sudeste e sul de Minas Gerais.

\section{FABRICIO CAMILLO SPERANDIO}

Doutorado em andamento - Ciências Ambientais pela Universidade Estadual Paulista - Júlio de Mesquita Filho (UNESP) de Sorocaba. Graduação em Geografia - Uni São Luís de Jaboticabal (2008); Pós-graduação Lato senso em Gestão Ambiental pelo Centro Universitário Claretiano (CEUCLAR) de Batatais (2012); Mestrado em Ciências Ambientais pela Universidade Estadual Paulista - Júlio de Mesquita Filho (UNESP) de Sorocaba (2017).

\section{FELIPE HASHIMOTO FENGLER}

Possui graduação em Engenharia Ambiental pela Universidade Estadual Paulista Júlio de Mesquita Filho (2011), mestrado em Agricultura Tropical e Subtropical pelo Instituto Agronômico de Campinas (2014) e doutorado em Ciências Ambientais pelo programa de pós-graduação em Ciências Ambientais da Universidade Estadual Paulista Júlio de Mesquita Filho Campus Sorocaba.

\section{FRANKLIN DOS SANTOS AMARAL}

Graduando do curso de Bacharelado em Gestão Ambienta na Universidade Federal de Rondônia - Campus de Guajará-Mirim, no Departamento Acadêmico de Ciências Sociais e Ambientais. Possui experiência em microbiologia do solo.

\section{FREDERICO CORDEIRO MARTINS}

Doutorando em Sistemas de Informação e Gestão do Conhecimento pela Universidade FUMEC. Possui graduação em Direito pelo Centro Universitário de Sete Lagoas (2003) e mestrado em Turismo e Meio Ambiente pelo Centro Universitário UNA (2011). Assessor Judiciário - Tribunal de justiça de Minas Gerais entre 2006 a 2011. Atualmente atua como Advogado. Tem experiência na área de Direito, com ênfase em Direito Ambiental, Direito do consumidor, Direito Penal e Processual Penal. Possui experiência em docência, já tendo lecionado no Centro Universitário UNA de 2006 a 2009, nas disciplinas de Direito do Consumidor, Direito Tributário, Direito Ambiental e Ética e em orientação de alunos e acompanhamento de audiências no núcleo de prática jurídica do UNI-BH de 2004 a 2005. Lecionou no Centro Universitário - UNIBH, de 2012 a 2015, nas disciplinas de Direito e Legislação em Engenharia, Certificação Ambiental, Fundamentos de Direito e Direito Empresarial. Atualmente leciona na UEMG - Universidade do Estado de Minas Gerais, Unidade Cláudio, nas disciplinas de Direito Tributário, Direito Previdenciário, Direito do Trabalho, Direito Comercial e Empresarial, Direito Previdenciário e Ciências Políticas. Exerce a função de Coordenador de Pesquisa e Extensão na UEMG - Universidade do Estado de Minas Gerais, Unidade Cláudio. É editor, avaliador e revisor do periódico Ciências Gerenciais em Foco da UEMG - Universidade do Estado de Minas Gerais, Unidade Cláudio. 


\section{GABRIEL CESTARI VILARDI}

Possui graduação em Bacharelado e Licenciatura em Ciências Biológicas (2007) pela Universidade Estadual Paulista \&quot;Júlio de Mesquita Filho\&quot; (UNESP), mestrado em Ecologia e Recursos Naturais (2010) e doutorado em Ciências, Área de Concentração em Ecologia e Recursos Naturais (2015) pela Universidade Federal de São Carlos (UFSCar). Atualmente é Professor de Magistério Superior Efetivo/Adjunto I da Fundação Universidade Federal de Rondônia (UNIR).

\section{GABRIEL RONDINA PUPO DA SILVEIRA}

Doutorando em Agronomia/Energia na Agricultura pela FCA/UNESP/Botucatu-SP. Mestre em Agronomia/Energia na Agricultura pela FCA/UNESP/Botucatu-SP (2016). Engenheiro Agrônomo pela FCA/UNESP/Botucatu-SP. Atualmente é professor do Centro Universitário Sudoeste Paulista (UniFSP/ Avaré- SP). É membro do Grupo de Estudos e Pesquisas em Geotecnologias, Geoprocessamento e Topografia (GEPEGEO) do Departamento de Engenharia Rural da FCA/UNESP/ Botucatu-SP. Realiza atividades de pesquisa na área de Topografia e Geoprocessamento, com ênfase no estudo de Preservação Ambiental, Capacidade de Uso do Solo e Manejo de Bacias Hidrográficas, utilizando Sistemas de Informação Geográfica (SIG) e outras Geotecnologias.

\section{GERSON ARAÚJO DE MEDEIROS}

Possui graduação em Engenharia Agrícola, Mestrado e Doutorado em Engenharia de Água e Solo pela Universidade Estadual de Campinas (UNICAMP); Especialista em Drenagem e Gerenciamento de Bacias Hidrográficas pela Universidade de Taubaté (UNITAU). Em 2015, para reforçar a inserção internacional, desenvolveu estudos em nível de pós-doutorado sobre aspectos econômicos dos serviços ecossistêmicos na Faculdade de Ciências Agrárias em Vida e Meio Ambiente pela Universidade de Alberta em Edmonton, Canadá. Desde 2011 é professor do Instituto de Ciência e Tecnologia de Sorocaba (ICTS) da Universidade Estadual Paulista - Júlio de Mesquita Filho (UNESP) de Sorocaba, pelo curso de pós-graduação em Ciências Ambientais e curso de graduação em Engenharia Ambiental

\section{GESIANE OLIVEIRA DA TRINDADE}

Possui graduação em geografia pela Universidade Federal do Pará (2013) e mestrado em Desenvolvimento Sustentável do Trópico Úmido pela Universidade Federal do Pará (2015). Atualmente é professor de geografia do Instituto Federal do Maranhão, atuando principalmente nos seguintes temas: amazônia, centralidade politica, centralidade econômica e cidade média.

\section{GIOVANNA FREDERICI DE MELLO}

Mestre em Ciências Ambientais (2015) pela Universidade Estadual Paulista - Júlio de Mesquita Filho (UNESP) de Sorocaba; Graduação em Ciências Biológicas, modalidade Bacharelado (2012) pela Universidade Júlio de Mesquita Filho, UNESP, campus de Assis. Licenciada em Ciências Biológicas (2013) pela Universidade Júlio de Mesquita Filho, UNESP, campus de Assis. Técnica em Meio Ambiente pela ETEC, Centro Paula \& Souza; Doutoranda do Programa de Ciências Ambientais, oferecido pela UNESP de Sorocaba.

\section{GREGORIO AUGUSTO MARCIAGA TEÓFILO}

Técnico em Meio Ambiente pelo Instituto Federal do Maranhão - Campus Açailândia. Possui experiência nas áreas de educação ambiental, ecologia geral e aplicada. 


\section{HELENA CAROLINA ALVES BARRETO}

Bolsista do Programa de Apoio á Iniciação Cientifica do Amazonas PAIC - Universidade Federal Do Amazonas. Graduando em Engenharia Florestal pela Universidade Federal Do Amazonas.

\section{ÍSIS RIBEIRO DO NASCIMENTO}

Graduanda em Engenharia Ambiental na Universidade Federal do Amazonas, campus Humaitá. Diretora de Pesquisa e Extensão na Executiva Nacional dos Estudantes de Engenharia Ambiental - ENEEA - gestão 2018/2019. Presidente do Centro Acadêmico de Engenharia Ambiental - CAEAMB - gestão 2017/2018. Representante discente no Colegiado de Engenharia Ambiental. Membro do Grupo de Pesquisa em Interação Biosfera Atmosfera na Amazônia - GPIBA.

\section{JAIRO BARDUNI FILHO}

Professor da Universidade Estadual de Minas Gerais (UEMG). Doutor em Educação pela Universidade Federal de Juiz de Fora - UFJF. Doutorado Sanduíche na Universidade de Barcelona (UB). Mestre em Extensão Rural pela Universidade Federal de Viçosa/MG. Graduado em Pedagogia pela Universidade Federal de Viçosa/MG. Interesses de pesquisa: Masculinidades; Cotidiano Escolar; Teoria do currículo; Escola Família Agrícola, Gênero e Sexualidades; Didática e Estágios supervisionados.

\section{JANAÍNA PAOLUCCI SALES DE LIMA}

Possui graduação em Zootecnia pela Universidade Federal Rural do Rio de Janeiro (2002), mestrado em Ciências Agrárias pelo Instituto Nacional de Pesquisas da Amazônia (2005) e doutorado em Biotecnologia pela Universidade Federal do Amazonas (2012). Atualmente é professor Adjunto III da Universidade Federal do Amazonas. Tem experiência na área de Quimioterapia, com ênfase em Química de Produtos Naturais, atuando principalmente nos seguintes temas: investigação de metabólitos secundários bioativos de interesse medicinal e agronômico.

\section{JAQUELINE FERNANDA MEIRELES}

Mestranda em Ciências Ambientais pela Universidade Estadual do Oeste do Paraná UNIOESTE, bolsista CAPES.

\section{JARLIANE DA SILVA FERREIRA}

Professora pesquisadora do Instituto de Natureza e Cultura - INC/UFAM. Experiência na Educação Básica e Superior. Formação em Pedagogia (UFAM), Mestre em Educação (UFAM) e Doutora pelo Programa Sociedade e Cultura na Amazônia - PPGSCA/UFAM. Desenvolve extensão e Pesquisa acerca da temática da educação do campo, da floresta e das águas; Educação de Jovens e Adultos; Formação de professores indígenas e não indígenas; Escolas multisseriadas. Coordena o programa Observatório da Educação do Campo no Alto Solimões - OBECAS/INC. Orienta pesquisas de TCC e PIBIC sobre a temática da educação do campo, EJA, Histórias e memórias de processos educativos na região do Alto Solimões.

\section{JOÃO FAUSTINO MUNGUAMBE}

Doutor em Engenharia Florestal na Universidade Federal de Lavras (UFLA), Brasil. Mestre pela mesma Instituição (2012). Engenheiro Florestal pela Universidad Pinar del Rio, Cuba (2001). Atua na área de silvicultura do Ministério da Defesa Nacional de Moçambique. Tem experiência na área de Recursos Florestais e Engenharia Florestal, com ênfase em 
Silvicultura, Florestamento, Reflorestamento, Recuperação de Áreas Degradadas, Nutrição Mineral de Espécies Florestais.

\section{JOSÉ RODOLFO DANTAS DE OLIVEIRA GRANHA}

Possui graduação em Engenharia Florestal pela Universidade Federal Rural do Rio de Janeiro (1994), mestrado em Agronomia (Ciências do Solo) pela Universidade Federal Rural do Rio de Janeiro (1998) e doutorado em Agronomia pela Universidade Federal do Rio de Janeiro (2003). Foi professor do curso de pós graduação de Ciência do Solo e Ambiente, atualmente é Professor Adjunto do curso de Graduação de Gestão Ambiental da Fundação Universidade Federal de Rondônia (UNIR). Tem experiência em Fertilidade do Solo, Nutrição Mineral de Plantas, Solos Florestais, Desenvolvimento Sustentável, Manejo e Conservação do Solo, Física, Ecologia Geral e Biologia do Solo, atuando principalmente nos seguintes temas: Ecologia matemática, diversidade, ecossistemas brasileiros, manejo e conservação dos solos, classificação dos solos, biologia do solo, fauna do solo e micorrizas.

\section{JOSEF GASTL FILHO}

Graduando em Agronomia pela Universidade do Estado de Minas Gerais, Unidade Ituiutaba. Técnico em Agroindústria pelo Instituto Federal do Triângulo Mineiro (IFTM). Foi bolsista de Iniciação Científica Júnior do CNPq (2016-2017) na área de Ciência e Tecnologia dos Alimentos no setor de Agroindústria do IFTM. Foi bolsista de bolsista de iniciação científica do PAPq/UEMG (2017) na área de Recursos Naturais, Ciências e Tecnologias no Departamento de Ciências Agrárias da UEMG. Atualmente é bolsista de iniciação científica PIBIC/FAPEMIG (2018/2019) na área de Melhoramento Vegetal no Departamento de Ciências Agrárias da UEMG. Possui experiência na área de Ciência e Tecnologia de alimentos com ênfase em tecnologia de bebidas, na Área de Agronomia com ênfase em qualidade fisiológica de sementes, enraizamento de estacas nativas, genética e melhoramento vegetal.

\section{JUAN FRANC'S LIMA DE MOURA}

Técnico em Meio Ambiente pelo Instituto Federal do Maranhão - Campus Açailândia.

\section{KATYA KAVUYA JEANNOT}

Professor na Universidade Livre dos País de Grandes Lagos, República Democrática do Congo. Doutor em Ciências Florestais e Mestre em Engenharia Florestal. Possui graduação em Engenharia Florestal na Universidade de Kisangani (2010). Tem experiência na área de Ecologia, com ênfase em Ecologia de Ecossistemas, atuando principalmente no seguinte tema: Agrobiodiversidade, Gestão de unidades de conservação e Ecoturismo.

\section{LARISSA CARVALHO GATO}

Acadêmica de Engenharia Ambiental na Universidade Federal do Amazonas - Campus Vale do Rio Madeira em Humaitá Amazonas.

\section{LEANDRO COSTA FÁVARO}

Graduado em Matemática com pós-graduação lato sensu em Educação Matemática, Psicopedagogia Institucional e Clínica , Gestão Escolar/ Administração e Supervisão , encontra-se em fase de finalização da pós-graduação stricto sensu, Mestrado Profissional em Sustentabilidade em Recursos Hídricos. Exerceu a Docência, Supervisão, Coordenação Pedagógica e gestão da educação básica, perpassando por todos os níveis de ensino, incluindo a Rede Pública e Privada. Atualmente é docente e coordenador pedagógico do ensino superior, atuando na graduação e pós-graduação em especial na modalidade à distância - EaD. Atua principalmente nos seguintes temas: educação, visão holística, teoria da complexidade, sustentabilidade ambiental e engenharia civil. 


\section{LETÍCIA RODRIGUES DA FONSECA}

Graduada em Ciência da Computação e Administração. Especialista em Gestão de Tecnologias da Informação. Mestra e Doutora em Administração. Professora do Curso de Mestrado Profissional em Sustentabilidade em Recursos Hídricos da Universidade Vale do Rio Verde (UNINCOR). Membro do Comitê de Avaliadores da Revista Gestão \& Tecnologia. Membro do Grupo de Pesquisa \&quot;Controladoria e Finanças\&quot; do Conselho de Pesquisa e Pós-Graduação da UFMS. Áreas de Pesquisa: aprendizagem; aprendizagem contínua; gestão do conhecimento; melhoria do processo de software; gestão de projetos; gestão de tecnologias da informação; gestão da sustentabilidade; estratégia em organizações sustentáveis.

\section{LINCOLN GEHRING CARDOSO}

Engenheiro Agrônomo pela FCA/UNESP/Botucatu-SP (1980), Mestre em Agronomia, (1986), Doutor em Agronomia (1988) pela FCA/UNESP/Botucatu-SP. Professor Titular do Departamento de Engenharia Rural da FCA/UNESP/Botucatu-SP, atuando na área de Topografia e Sensoriamento Remoto. Sua linha de pesquisa e de seus orientados abrange principalmente os seguintes temas: Uso de imagens orbitais (satélite) e imagens não orbitais (fotografias aéreas) em estudos de alterações da paisagem e de redes de drenagem ; Topografia Clássica ; Sistema de Posicionamento Global.

\section{LUNDOI TOBIAS LEE}

Possui Licenciatura em Ciências Biológicas pela Universidade Federal do Rio de Janeiro. Mestre em Tecnologia Ambiental pela Universidade Federal Fluminense, pesquisa desenvolvida durante o mestrado análise da atividade antifúngica de óleos essenciais sobre fungos filamentosos que acometem grãos em armazenamento. Doutoranda em Microbiologia Agrícola pela Universidade Federal de Lavras, atualmente investiga o controle de fungos patogênicos em cogumelos comestíveis (champignon) utilizando óleos essenciais como alternativa natural, substituindo compostos químicos.

\section{MARAÍNA SOUZA MEDEIROS}

Possui mestrado em Meio Ambiente e Qualidade Ambiental pela Universidade Federal de Uberlândia - UFU/Câmpus Umuarama (2015 a 2017). Possui curso de aperfeiçoamento em "Técnicas aplicadas ao Meio Ambiente" pelo Centro de Estudos e Formação (2014). É Licenciada em Química pelo Instituto Federal de Educação, Ciência e Tecnologia de Goiás IFG Câmpus Itumbiara (2010 a 2013). Atuou como Petiana bolsista no Programa de Educação Tutorial (PET) vinculado à SEsu/MEC e denominado "PET Química: Educação, Ambiente e Sociedade" (2013 a 2014). Trabalhou como auxiliar de laboratório (estagiária) no laboratório de Controle de Qualidade de Águas da Companhia de Saneamento Básico do Estado de Goiás - Saneago S/A, regional de Itumbiara - GO (2011 a 2013). Atualmente, é auxiliar de biblioteca no Instituto Federal de Goiás, Campus Itumbiara (IFG) desde outubro de 2017.

\section{MÁRCIO PEREIRA}

Possui graduação em Psicologia pela Fundação Educacional de Divinópolis (1995), graduação em Administração pela Faculdade de Ciências Econômicas de Divinópolis (1990), graduação em Pedagogia pela Faculdade de Educação Regional Serrana (2015), graduação em Matemática pelo Instituto Superior de Educação Elvira Dayrell (2016) e mestrado em Mestrado Em Educação pelo Centro Universitário Salesiano de São Paulo (2003). Atualmente é professor teoria existencial-humanista da Faculdade de Nova Serrana, professor de curso de pós-graduação lato sensu - CONSULCAP - Consultoria e Capacitação, orientador estágio supervisionado psicologia da Universidade do Estado de Minas Gerais, prof. psicologia da educação da Universidade do Estado de Minas Gerais, prof. conteúdo e metodologia. de matemática i da Universidade do Estado de Minas Gerais, prof. fundamentos da educação 
p/a diversidade da Universidade do Estado de Minas Gerais, coordenador do curso de pedagogia da Universidade do Estado de Minas Gerais, prof. psicologia do excepcional da Universidade do Estado de Minas Gerais, prof. métodos e técnicas de pesquisa em psic. da Universidade do Estado de Minas Gerais e prof. psicologia e ensino da Universidade do Estado de Minas Gerais. Tem experiência na área de Educação, com ênfase em Educação Especial - Atendimento Educacional Especializado, atuando principalmente nos seguintes temas: inclusão, conflitos, dever de casa, aprendizagem e acompanhamento familiar.

\section{MARCOS ANDRÉ BRAZ VAZ}

Professor Adjunto na Universidade Federal do Amazonas no Instituto de Educação, Agricultura e Ambiente do Campus Vale do Rio Madeira, Humaitá-AM. Possui graduação em Agronomia pela Universidade Federal da Grande Dourados (2010), mestrado em Estatística e Experimentação Agronômica pela Universidade de São Paulo, Escola Superior de Agricultura Luiz de Queiroz (2012) e doutorado em Zootecnia pela Universidade Federal de Santa Maria (2016).

\section{MARIA AUXILIADORA DOS SANTOS COELHO}

Mestranda no Programa de Pós-Graduação em Educação da Universidade Federal do ParáUFPA. Graduada em Licenciatura Plena em Pedagogia pela Universidade Federal do Amazonas - UFAM (2011). Especialização Lato Sensu em educação infantil e ensino fundamental pela Faculdade Integrada do Brasil- FAIBRA (2014). Professora do Instituto de Natureza de Natureza e Cultura - INC/UFAM no Curso de Pedagogia. Participa o Observatório da Educação do Campo no Alto Solimões (OBECAS). Tem experiência na área de Educação, atuando principalmente nos seguintes temas: Educação do campo/ ribeirinha; Diversidade cultural; Práticas pedagógicas; Estágios Supervisionados, Orientação de TCC, Fundamentos da alfabetização, Princípios e Métodos da Educação Infantil, Artes na Educação Infantil e ensino fundamental, Práticas da Pesquisa Pedagógica; A criança e a linguagem oral, escrita e visual e Metodologia da Alfabetização.

\section{MARTA DE SOUZA DA SILVA}

Estudantes do curso de Gestão Ambiental do Campus de Guajará-Mirim da Universidade Federal de Rondônia. Participa de projetos de pesquisa referente ao PIBIC.

\section{MAURICIO JOSÉ BORGES}

Possui graduação em Agronomia pela Universidade Estadual Paulista Júlio de Mesquita Filho (1984), mestrado em Conservação e Manejo de Recursos pela Universidade Estadual Paulista Júlio de Mesquita Filho (2001) e doutorado em Agronomia (Producao Vegetal) pela Universidade Estadual Paulista Júlio de Mesquita Filho (2005).

\section{NELSON VENTURIN}

Professor Emérito da UFLA. Possui graduação em Recursos Florestais e Engenharia Florestal pela Universidade Federal do Paraná(1965), mestrado em Silvicultura pelo Centro Agronomico Tropical de Investigacion y Ensenanza(1971) e doutorado em Ciência do Solo pela Universidade de São Paulo(1978). Atualmente é Professor Senior, bolsista de produtividade da Universidade Federal de Lavras, Membro do Comitê Assessor do Conselho Nacional de Desenvolvimento Científico e Tecnológico. Autor de dezenas de artigos científicos e livros. 


\section{PALOMA CARVALHO DINIZ}

Técnica em Meio Ambiente pelo Centro Tecnológico de Lavras. Graduanda em Engenharia Florestal na Universidade Federal de Lavras (UFLA). Atualmente, é bolsista de Iniciação Científica (PIBIC/CNPq) no Laboratório de Silvicultura do Departamento de Ciências Florestais da UFLA.

\section{PATRÍCIA FREIRE CHAGAS}

Possui graduação em Engenharia Civil pela Universidade Federal do Ceará (1997), mestrado em Engenharia Civil (Recursos Hídricos) pela Universidade Federal do Ceará (2000) e doutorado em Engenharia Civil (Recursos Hídricos) pela Universidade Federal do Ceará (2005). Engenheira Civil da Companhia de Águas e Esgotos do RN. Tem experiência na área de Engenharia Civil, com ênfase em Engenharia Ambiental, atuando principalmente nos seguintes temas: Gestão de Recursos Hídricos, Gestão Ambiental, Gestão costeira, saneamento, Saneamento público, modelagem matemática, análise de risco, monitoramento ambiental, e qualidade de água em rios.

\section{PATRÍCIA MICHELE RIBEIRO}

Licencianda em Química pelo Instituto Federal de Goiás - Câmpus Itumbiara, bolsista do Programa Institucional de Bolsas de Iniciação à Docência (PIBID) na mesma instituição. Tem interesse nas áreas de Sustentabilidade, Ensino de Química e Laboratório. Estagiária na Companhia de Saneamento de Goiás (SANEAGO S.A.), realizando análises de bacteriologia e físico-química em água bruta, reservatórios e poços.

\section{PEDRO HENRIQUE DE FREITAS DELIBERTO FERREIRA}

Graduando em Engenharia Agronômica pela Universidade do Estado de Minas Gerais UEMG. Bolsista de Pesquisa pelo PAPq (2018).

\section{PEDRO HENRIQUE PEREIRA E MOREIRA}

Graduando em Bacharelado em Engenharia Elétrica pelo Instituto Federal de Goiás - Câmpus Itumbiara. É Auxiliar de Biblioteca da mesma instituição (Instituto Federal de Educação, Ciência e Tecnologia de Goiás - Câmpus Itumbiara) desde 2016.

\section{RAFAELLA GOUVEIA MENDES}

Graduanda em Agronomia, Universidade do Estado de Minas Gerais (UEMG), Unidade Ituiutaba (2018). Setor de Meio Ambiente BP Biofuels Brasil (2018). Pesquisadora em produção de mudas nativas, reflorestamento, recuperação de áreas degradadas e repovoamento de ictiofauna em recursos hídricos (PAEx UEMG, 2017; FAPEMIG, 2016; CNPq, 2015). Técnica em Agroindústria pelo Instituto Federal de Ciência e Tecnologia do Triângulo Mineiro (2014).

\section{REGINALDO BRITO DA COSTA}

Possui graduação em Engenharia Florestal pela Universidade Federal de Mato Grosso (1980), mestrado em Ciências Florestais pela Escola Superior de Agricultura Luiz de Queiroz (1988) e doutorado em Ciências Florestais pela Universidade Federal do Paraná (1999). Atualmente é professor titular da Universidade Católica Dom Bosco.Tem experiência na área de Genética, com ênfase em Genética Quantitativa, atuando principalmente nos seguintes temas: desenvolvimento local, melhoramento genético, ganho genético, parâmetros genéticos. Orientou 26 monografias de conclusão de curso, 15 pesquisas de Iniciação Científica, 31 orientações de mestrado, 2 teseS de doutorado concluída, 5 em andamento e 1 supervisão de pós-doutorado com foco em genética quantitativa e molecular. É revisor dos 
periódicos científicos: Bragantia, Crop Breeding and Applied Biotechonology, Genetics and Molecular Biology, Plos One, IForest, African Journal of Agricultura Research. Pesquisa Agropecuária Brasileira, Ciência Rural, Scientia Forestalis, Ciência Florestal, Interações, Multitemas. Líder do Grupo de Pesquisa cadastrado no DGP/CNPq \&quot;Desenvolvimento, meio-ambiente e sustentabilidade\&quot; , envolvendo pesquisadores nacionais. No grupo de pesquisa destaca-se, entre outros, o tema \&quot;Caracterização, variabilidade e diversidade genética em populações arbóreas com finalidades madeiráveis e não madeiráveis. Membro titular do Conselho Municipal de Desenvolvimento Rural Sustentável (CMDRS), Campo Grande, MS. Membro titular da Comissão Executiva Local da SBPC 2019.

\section{RICARDO LUIS LOURO BERBARA}

Possui graduação em Agronomia pela Universidade Federal Rural do Rio de Janeiro (UFRRJ1983), MSc Ciências do Solo pela UFRRJ (1989) e PhD em Biologia do Solo - University of Dundee, Escócia (1995). Participa, como coordenador, de projetos junto à Faperj, CNPq, CAPES e é pesquisador junto às Redes CARBIOMA, SISBIOTA e REPENSA. É professor Titular da UFRRJ e participa dos cursos de PG em Ciência do Solo e Biotecnologia, ambos da UFRRJ. Professor convidado junto a Escuela de Graduados da Facultad de Agronomia da Universidad de Buenos Aires (UBA) desde 2004.Foi Coordenador do Programa de PósGraduação em Fitossanidade e Biotecnologia Vegetal Aplicada (2015-) e atual Reitor da UFRRJ. Tem experiência na área de Agronomia, com ênfase em Microbiologia e Bioquímica do Solo, atuando principalmente nos seguintes temas: ecologia e manejo do solo, micorriza e substâncias húmicas.

\section{RILDO VIEIRA DE ARAÚJO}

Possui Graduação em Agrimensura pelo Centro Federal de Ensino Tecnológico de Goiás (2003), Graduação em Matemática (2007), Especialista em Educação Matemática, Mestre em Ambiente e Desenvolvimento pelo Centro Universitário Univates (2014). Atualmente é professor de Agrimensura do Instituto Federal de Educação, Ciência e Tecnologia de Mato Grosso -Campus Barra do Garças. Tem conhecimento na área de Geomática, com ênfase em Tecnologia em Agrimensura, atuando principalmente nos seguintes temas: Agrimensura, Saneamento Ambiental, Geometria plana e Espacial, Ensino e Aprendizagem, Topografia, Meio Ambiente, Estatística, Cadastro Técnico Multifinalitário, plano diretor, área de preservação permanente, regularização fundiária, planejamento urbano. Doutorando em Ciências Ambientais e Sustentabilidade Agropecuária pela UCDB de Campo Grande-MS.

\section{ROBERTA BORGES DE MEDEIROS FALCÃO}

Graduada em Serviço Social pela UFPE (1985), especialista em Ciências Social pela UFRN (1994), especialista em Gestão Ambiental pela UFRN (2001), mestre em Serviço Social pela UFRN (2005). Atua como assistente social na Companhia de Águas e Esgotos do Rio Grande do Norte (CAERN) realizando trabalhos de educação ambiental, ministrando curso de sensibilização em recursos hídricos, palestras e elaborando projetos.

\section{RONALD DE OLIVEIRA RODRIGUES JUNIOR}

Graduando em Engenharia de Agronegócios pela Universidade Federal Fluminense (UFF). Foi bolsista de iniciação científica na área de pesquisa do efeito fungicida de óleos essenciais em grãos armazenados. Foi monitor na disciplina de Biologia. Professore de inglês. Possui ensino-médio-segundo-grau pelo Anglo Sorocaba.

\section{RONALDO ALBERTO POLLO}

Mestre e Doutor em Agronomia-Energia na Agricultura pela FCA/UNESP/Botucatu-SP (2013; 2017). Especialista em Gestão Ambiental e Desenvolvimento Sustentável pela UNINTER /Fatec Internacional (2010); Graduação em Geografia-UNIFAC/Botucatu/SP (1997). Atua na 
Área de Topografia e Sensoriamento Remoto do Departamento de Engenharia Rural da FCA/UNESP/Botucatu-SP e realiza pesquisas nos seguintes temas: Sensoriamento Remoto aplicado em estudos ambientais e na gestão e manejo de bacias hidrográficas, planejamento do uso da terra, Sistemas de Informações Geográficas (SIG), Topografia e Sistema de Posicionamento Global (GPS). Pesquisador do Grupo de Estudos e Pesquisas Agrárias Georreferenciadas - GEPAG na FCA/UNESP/Botucatu-SP, cadastrado pelo CNPq.

\section{ROSENVALDO DA SILVA ARAUJO}

Graduando em Engenharia Agronômica pela Universidade do Estado de Minas Gerais (UEMG), unidade Ituiutaba. Técnico em Agroindústria pelo Instituto Federal de Ciência e Tecnologia do Triângulo Mineiro (IFTM), campus Ituiutaba / MG. Áreas de atuação: ciências agrárias - Agronomia e ciência e tecnologia dos alimentos.

\section{ROSIANE GONÇALVES DE LIMA SANTANA}

Possui graduação em Biblioteconomia pela Universidade Federal de Goiás (1999). Especialização em Biblioteconomia pela Faculdades Integradas Jacarepaguá (2011). Atualmente é Bibliotecária - Instituto Federal de Goiás - Câmpus Itumbiara - GO. Tem experiência na área de Educação, com ênfase em Informática na Educação e Administração em Centro de Documentação.

\section{SABRINNA AIRES GARCIA}

Graduanda em Engenharia de Agronegócios pela Universidade Federal Fluminense (UFF). Bolsista de Iniciação Científica pela Fundação Carlos Chagas Filho de Amparo à Pesquisa do Estado do Rio de Janeiro (FAPERJ) desde maio de 2017, na área de pesquisa do efeito fungicida de óleos essenciais em grãos armazenados, realizada no Laboratório de Biotecnologia e Pós Colheita da UFF. Compõe a Comissão de Prevenção de Acidentes e Meio Ambiente (COPAMA) da Escola de Engenharia Industrial Metalúrgica de Volta Redonda (EEIMVR). Voluntária no projeto de extensão Integrando Alegria da UFF.

\section{SÉRGIO CAMPOS}

Engenheiro Agrônomo pela FCA/UNESP/Botucatu-SP (1977), Mestre em Agronomia pela FCA/UNESP/Botucatu-SP (1986), Doutor em Agronomia pela FCA/UNESP/Botucatu-SP (1993). Atualmente é Professor Titular do Departamento de Engenharia Rural da FCA/UNESP/Botucatu-SP. Tem experiência na área de Agronomia, com ênfase em Sensoriamento Remoto, atuando principalmente nos seguintes temas: sistema de informação geográfica, sensoriamento remoto, uso da terra, geoprocessamento e classes de declive. É pesquisador responsável pelo Grupo de Estudos e Pesquisas em Geotecnologias, Geoprocessamento e Topografia (GEPEGEO) do Departamento de Engenharia Rural da FCA/UNESP.

\section{SÉRGIO RICARDO SILVA MAGALHÃES}

Graduado em Matemática, Matemática Computacional, Pedagogia, Administração, com pós-graduação lato sensu em Fundamentos da Matemática, Matemática e Estatística, Design Instrucional para EaD virtual, Especialização em Matemática, Docência Universitária, tendo pós-graduação estricto sensu em Mestrado em Estatística e Experimentação Agropecuária e Doutorado em Engenharia Biomédica com pós-doutorado em Educação. Possui experiência na Docência, Coordenação de Cursos, Educação a Distância e na área de Probabilidade e Estatística, atuando principalmente nos seguintes temas: estatística, simulação, análise de regressão e correlação. 


\section{SILVÂNIA QUEIROZ E SILVA}

Doutora em Ciências do Ambiente e Sustentabilidade na Amazônia pela Universidade Federal do Amazonas - UFAM (2016). Possui mestrado em Serviço Social e Sustentabilidade na Amazônia pela UFAM (2011),pós graduação em Gestão em Saúde pela Fundação Oswaldo Cruz do Rio de Janeiro - FIOCRUZ (2011) e graduação em Serviço Social pela UFAM (2008). Atualmente é analista judiciário I - Serviço Social - Tribunal de Justiça do Estado do Amazonas e docente em cursos de pós graduação lato sensu como professora convidada. Tem experiência na área de Serviço Social, com ênfase em sustentabilidade socioambiental na Amazônia, atuando principalmente nos seguintes temas: políticas públicas de sustentabilidade, conflitos socioambientais, territórios amazônicos, direitos sociais e ampliação de direitos de indivíduos e famílias.

\section{TEREZINHA CORRÊA LINDINO}

Doutora em Educação pela Universidade Estadual Paulista Júlio de Mesquita Filho. Docente adjunta na Universidade Estadual do Oeste do Paraná (Unioeste, Mal. Cândido Rondon). Vice-líder do Grupo de Estudo e Pesquisa em Ciências Ambientais (GEPECIA). Docente permanente no Programa de Pós-Graduação Stricto Senso em Ciências Ambientais (Unioeste, Toledo).

\section{THAIS PONHÊS DOS SANTOS}

Gestora ambiental pela Universidade Federal de Rondônia.

\section{TYFANNE VERÔNICA LEÃO GARCIA}

Possui graduação em Engenharia Ambiental pela Universidade Federal do Amazonas. Mestranda em Desenvolvimento Regional e Meio Ambiente pela Fundação Universidade Federal de Rondônia.

\section{WESLEY DE PAULO MORAIS}

Estudante do Curso de Gestão Ambiental, da Universidade Federal de Rondônia. Tem experiência na área de Ciências Ambientais, com ênfase em Gestor Ambiental e Técnico em Agronegócio. 


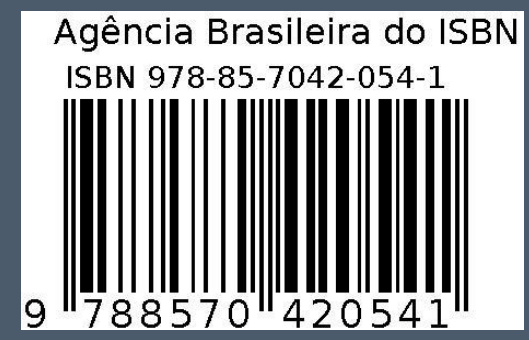

